
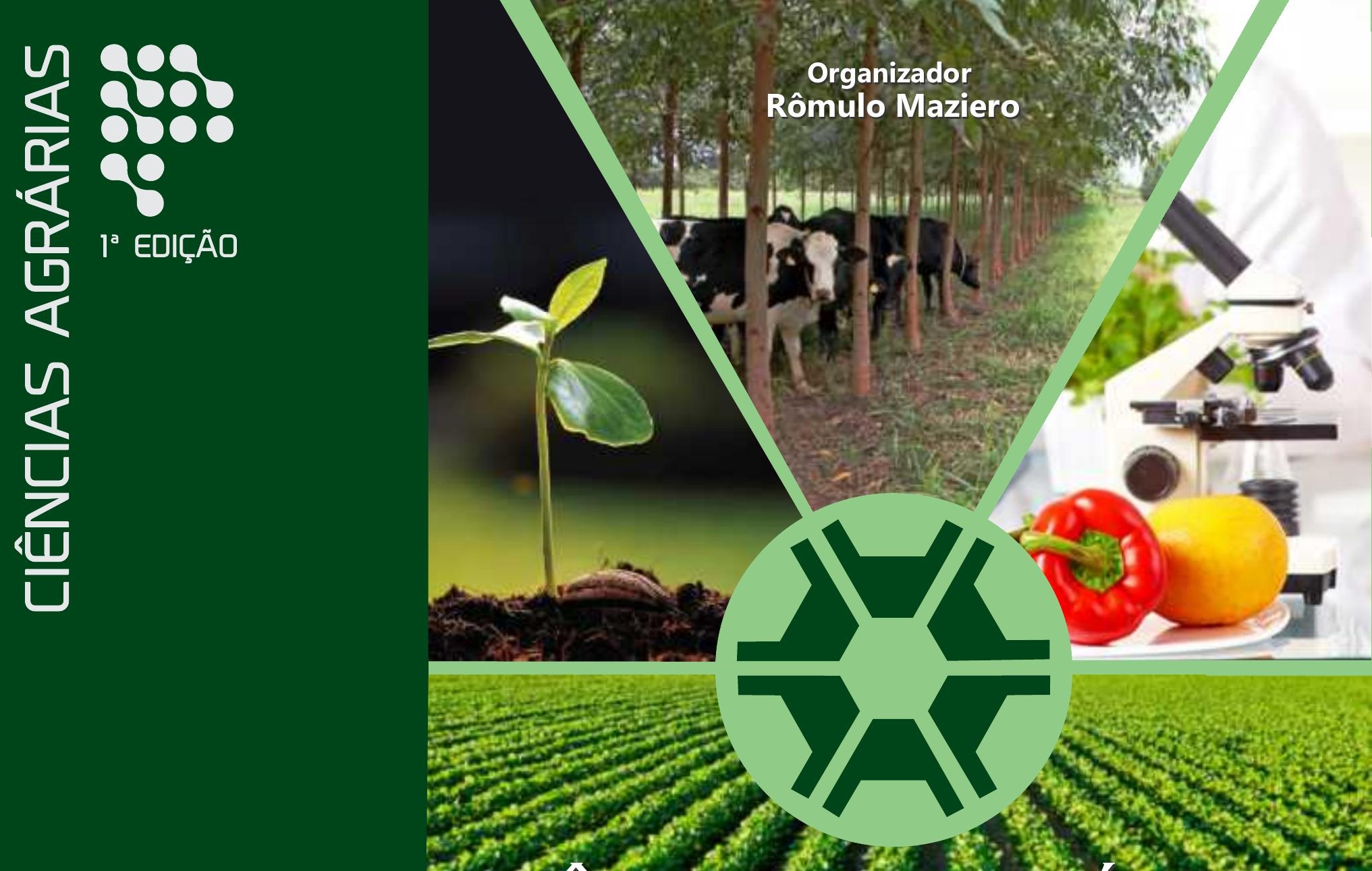

GIENASAGRARAS 1.5.

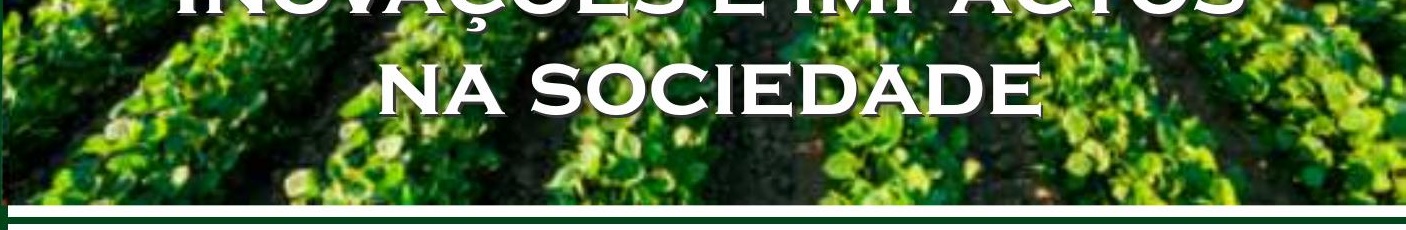
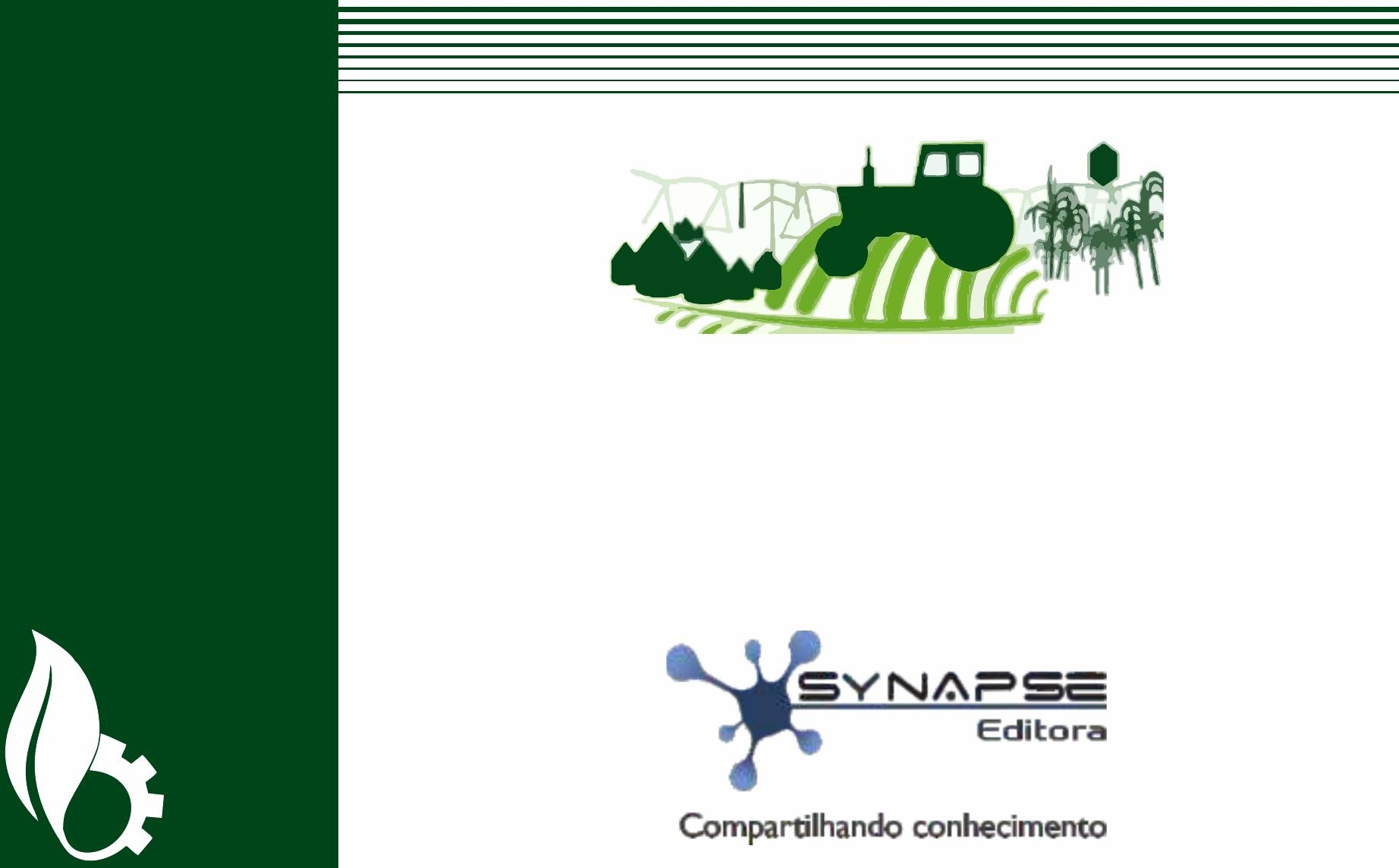

Compartilhando conhecimento 

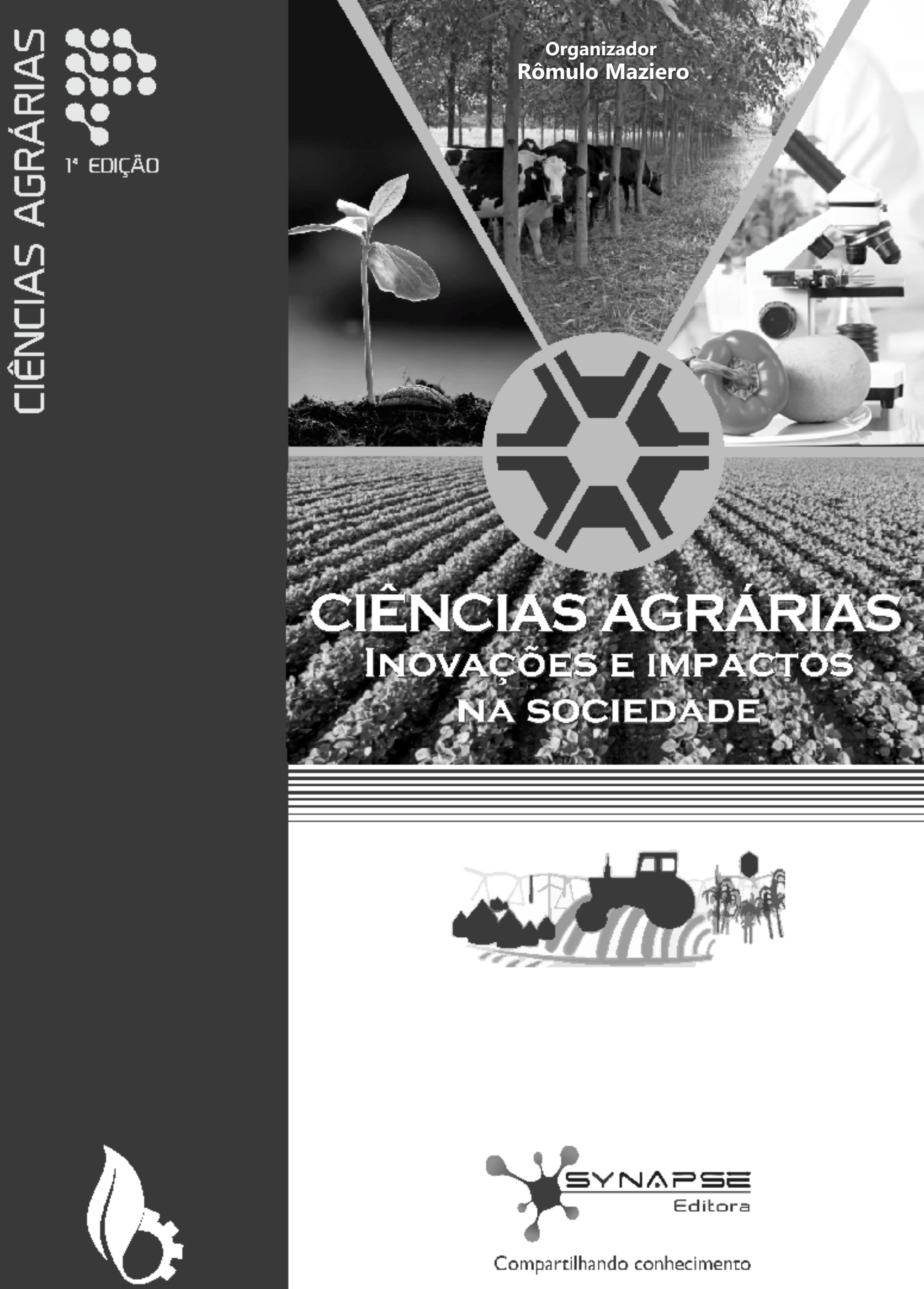

Compartilhando conhecimento 
Editor Chefe

Msc Washington Moreira Cavalcanti

\section{Organizador}

Rômulo Maziero

\section{Conselho Editorial}

Msc Lais Brito Cangussu

Msc Rômulo Maziero

Msc Jorge dos Santos Mariano

Dr Jean Canestri

Msc Elias Rocha Gonçalves Júnior

Msc Daniela Aparecida de Faria

Projeto Gráfico e Diagramação Departamento de arte Synapse Editora

Edição de Arte

Maria Aparecida Fernandes

Revisão

Os Autores
2021 by Synapse Editora

Copyright (C) Synapse Editora

Copyright do Texto (c) 2021 Os autores

Copyright da Edição (c) 2021 Synapse Editora

Direitos para esta edição cedidos à

Synapse Editora pelos autores.

Todo o texto bem como seus elementos, metodologia, dados apurados e a correção são de inteira responsabilidade dos autores. Estes textos não representam de forma alusiva ou efetiva a posição oficial da Synapse Editora.

A Synapse Editora não se responsabiliza por eventuais mudanças ocorridas nos endereços convencionais ou eletrônicos citados nesta obra.

Os livros editados pela Synapse Editora, por serem de acesso livre, Open Access, é autorizado o download da obra, bem como o seu compartilhamento, respeitando que sejam referenciados os créditos autorais. Não é permitido que a obra seja alterada de nenhuma forma ou usada para fins comerciais.

O Conselho Editorial e pareceristas convidados analisaram previamente todos os manuscritos que foram submetidos à avaliação pelos autores, tendo sido aprovados para a publicação.

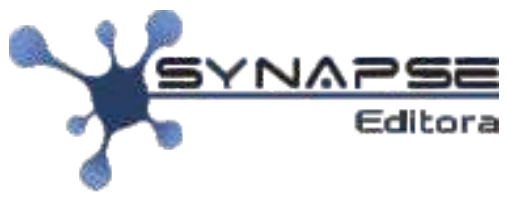

Compartilhando conhecimento

2021 


\section{CIÊNCIAS AGRÁRIAS INOVAÇÕES E IMPACTOS NA SOCIEDADE}

M476c Maziero, Rômulo

Ciências Agrárias inovações e impactos na sociedade Organizador: Rômulo Maziero

Belo Horizonte, MG: Synapse Editora, 2021, 150 p.

Formato: PDF

Modo de acesso: World Wide Web

Inclui bibliografia

ISBN: 978-65-88890-12-7

DOI: doi.org/10.36599/editpa-2021_caiis

1. Ciências Agrárias, 2. Produção Agrária, 3. Inovação,

4. Sociedade, 6. Agronomia.

I. Ciências Agrárias inovações e impactos na sociedade

SYNAPSE EDITORA

Belo Horizonte - Minas Gerais

CNPJ: $40.688 .274 / 0001-30$

Tel: + 5531 98264-1586

www.editorasynapse.org

editorasynapse@gmail.com

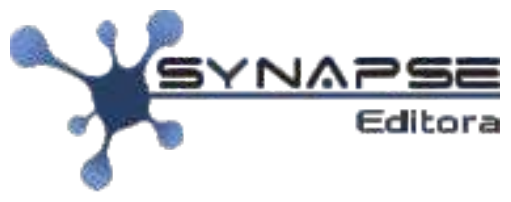

Compartilhando conhecimento

2021 


\section{Apresentação}

O livro Ciências Agrárias: Inovações e Impactos na Sociedade reúne uma diversidade de conteúdos atuais relevantes entre os campos da Agronomia, Engenharia Florestal e Ciências de Alimentos. A busca por novas tecnologias na agricultura, a preservação dos recursos naturais e os alimentos funcionais são temas de enorme interesse à comunidade científica e que refletem diretamente na vida da população. Assim, foram agrupadas informações sobre tais assuntos sem o pretexto de exauri-los, ampliando potencialmente a visão nessas áreas.

O desenvolvimento sustentável - social, econômico e ambiental - perpassa nas Ciências Agrárias e está atrelado ao estudo sistemático de distintas disciplinas. Neste livro, caro leitor, qualitativamente e quantitativamente páginas que abordam os resíduos sólidos orgânicos, compostagem, efeitos da exposição a agrotóxicos, uso de probióticos em embutidos fermentados, prospecção tecnológica, patente, saneamento básico em comunidade rural (estudo de caso), parâmetros fitossociológicos de três famílias botânicas, cultivo de soja no Brasil (uma pesquisa bibliográfica), entre outros, são examinados e discutidos por especialistas, enriquecendo ainda mais a literatura em Ciências Agrárias.

Uma excelente leitura e que esta obra possa complementar as suas bases de fichamento, além de trazer novas perspectivas para futuros trabalhos.

PROF. RÔMULO MAZIERO

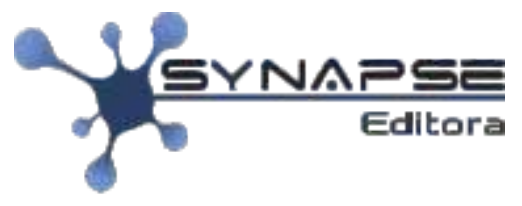

Compartilhando conhecimento

2021 


\title{
CIÊNCIAS AGRÁRIAS INOVAÇÕES E IMPACTOS NA SOCIEDADE
}

\section{Sumário}

CAPÍTULO 1

DORMÊNCIA EM BRACHIARIA PODE SER QUEBRADA COM REFRIGERAÇÃO A $4{ }^{\circ} \mathrm{C}$ E EMBEBIÇÃO EM ÁGUA, DISPENSANDO NITRATO

Renato Fernando Menegazzo

Adré Werlang Menegazzo

João Paulo Francisco

Ana Daniela Lopes

DOI doi.org/10.36599/editpa-2021_caiis-001

CAPÍTULO 2

MONITORAMENTO DE UM SISTEMA DE COMPOSTAGEM DE RESÍDUOS SÓLIDOS ORGÂNICOS NO INSTITUTO FEDERAL DE PERNAMBUCO - CAMPUS RECIFE

\author{
Eduardo Antonio Maia Lins \\ Walter Santiago da Silva \\ Camilla Borges Lopes da Silva \\ Julia Ximenes Botelho de Melo \\ DOI doi.org/10.36599/editpa-2021_caiis-002
}

\section{CAPÍTULO 3}

EFEITOS DA EXPOSIÇÃO A AGROTÓXICOS INIBIDORES DA ACETILCOLINESTERASE:

ALTERAÇÕES FISIOPATOLÓGICAS SISTÊMICAS

Murilo de Jesus Porto

Jaciara Pinheiro de Souza

Cinara Rejane Viana Oliveira

Emile Ivana Fernandes Santos Costa

Luciano Vasconcellos Pacheco

DOI doi.org/10.36599/editpa-2021_caiis-003

\section{CAPÍTULO 4}

MICRORGANISMOS PROBIÓTICOS EM SALAMES: POTENCIAL DE USO

José Eduardo de Matos Paz

Keliane da Silva Maia

João Vitor Fonseca Feitoza

Maria Erica da Silva Oliveira

Francisca Kelia Duarte Dias

DOI doi.org/10.36599/editpa-2021_caiis-004

\section{CAPÍTULO 5}

PROSPECÇÃO TECNOLÓGICA:

MAPEAMENTO DAS TECNOLOGIAS APLICADAS AO BENEFICIAMENTO E DERIVADOS DO CACAU

Fárlei Cosme Gomes dos Santos

Ricardo de Araújo Kalid

DOI doi.org/10.36599/editpa-2021_caiis-005

CAPÍTULO 6 .

SANEAMENTO BÁSICO EM PEQUENAS COMUNIDADES:

UM ESTUDO NA COMUNIDADE RURAL DO RIO DE PEIXE, ITABIRA - MINAS GERAIS.

Fabrine Stephane Fonseca Gregóri

DOI doi.org/10.36599/editpa-2021_caiis-006 


\section{CIÊNCIAS AGRÁRIAS INOVAÇÕES E IMPACTOS NA SOCIEDADE}

\section{Sumário}

CAPÍTULO 7

FITOSSOCIOLOGIA DE TRÊS FAMÍLIAS BOTÂNICAS DE UM

FRAGMENTO FLORESTAL DO MUNICÍPIO DE ALTA FLORESTA, MATO GROSSO

Liliane Barboza Bispo

Marcos Leandro Garcia

Muriel da Silva Folli Pereira

Luciano Farinha Watzlawick

DOI doi.org/10.36599/editpa-2021_caiis-007

\section{CAPÍTULO 8}

ASPECTOS RELACIONADOS À PRODUÇÃO DE SOJA NO BRASIL - UMA REVISÃO DA LITERATURA

Juliana Amaral Vinhote

Gabriel Coradine

Éder Bruno Rebelo da Silva

Welligton Conceição da Silva

Gilbson Santos Soares

DOI doi.org/10.36599/editpa-2021_caiis-008

\section{CAPÍTULO 9}

ASPECTOS LIGADOS À UTILIZAÇÃO E DESCARTE

DE EMBALAGENS VAZIAS DE AGROQUÍMICOS: REVISÃO DE LITERATURA

Éder Bruno Rebelo da Silva

Welligton Conceição da Silva

Eudilene Dalet Vitor de Sousa

Juliana Amaral Vinhote

Maria Roseane Pereira dos Santos

Gilbson Santos Soares

DOI doi.org/10.36599/editpa-2021_caiis-009

\section{CAPÍTULO 10}

PERFIL DOS TRABALHADORES FLORESTAIS E CONDIÇÕES ERGONÔMICAS DO

TRABALHO EM ATIVIDADES DE PRODUÇÃO DE EUCALIPTO

Rômulo Maziero

Elizabeth Neire da Silva Oliveira de Paula

Filipe de Moraes

DOI doi.org/10.36599/editpa-2021_caiis-010 


\section{DORMÊNCIA EM BRACHIARIA PODE SER QUEBRADA COM REFRIGERAÇÃO A $4^{\circ} \mathrm{C}$ E EMBEBIÇÃO EM ÁGUA, DISPENSANDO NITRATO ${ }^{1}$}

\author{
Renato Fernando Menegazzo \\ Instituto Federal de Educação, Ciência e Tecnologia de Rondônia - IFRO \\ renato.menegazzo@ifro.edu.br \\ André Werlang Menegazzo \\ Universidade Federal de Campina Grande - UFCG \\ werlangandre30@gmail.com
}

\author{
João Paulo Francisco \\ Universidade Estadual de Maringá - UEM \\ jpfrancisco2@uem.br \\ Ana Daniela Lopes \\ Universidade Paranaense - UNIPAR \\ anadanielalopes@prof.unipar.br
}

\section{RESUMO}

As Regras para Análise de Sementes (RAS) recomendam uma escarificação com ácido sulfúrico e umedecimento do substrato com nitrato de potássio a 0,2\% para a quebra de dormência de Brachiaria e sua germinação. Este trabalho teve como objetivo avaliar o emprego de metodologia alternativa aos tratamentos recomendados pela RAS por resfriamento das sementes a $4^{\circ} \mathrm{C}$ e imersão em água destilada à temperatura ambiente e ao nitrato de sódio $0,2 \%$, por duas horas, para a quebra de dormência e germinação de B. decumbens Stapf cv. Basilisk e B. brizantha (Hochst. Ex. A. Rich.) Stapf cv. Marandu e cv. Piatã. Para tanto, foi estruturado Delineamento Inteiramente Casualizado $3 \times 2 \times 2$, em gerbox, para comparar os percentuais de germinação de sementes mantidas em temperatura ambiente e embebidas em $\mathrm{H}_{2} \mathrm{O}$ e em
$\mathrm{H}_{2} \mathrm{O}+\mathrm{NaNO}_{3}$ com sementes refrigeradas e embebidas em $\mathrm{H}_{2} \mathrm{O}$ e em $\mathrm{H}_{2} \mathrm{O}+\mathrm{NaNO}_{3}$. Também foi estruturado DIC em rolo, para, além do PG (\%), avaliar comprimento da parte aérea $(\mathrm{cm})$ e de raiz $(\mathrm{cm})$ e massa fresca total (g). Foram, ainda, realizados testes de tetrazólio e índice de velocidade de germinação. Os resultados foram submetidos ao teste de Tukey ( $p$ $0,05)$. A porcentagem de germinação avaliada aos 14 dias foi afetada pelas cultivares e temperatura, sendo que as sementes refrigeradas a $4^{\circ} \mathrm{C}$ superaram as mantidas em temperatura ambiente (aumento de 220\%). Não houve diferença significativa para o fator de embebição em $\mathrm{H}_{2} \mathrm{O}$ ou $\mathrm{H}_{2} \mathrm{O}+\mathrm{NaNO}_{3}$.

\section{Palavras-chave:}

Sementes; Metodologia alternativa; Basilisk; Marandu; Piatã.

\section{ABSTRACT}

The Seed Analysis Rules (RAS) recommend scarification with sulfuric acid and wetting of the substrate with $0.2 \%$ potassium nitrate to break the dormancy of Brachiaria and its germination. This study aimed to evaluate the use of an alternative methodology to the treatments recommended by the RAS by cooling the seeds to $4^{\circ} \mathrm{C}$ and immersion in distilled water at room temperature and in $0.2 \%$ sodium nitrate for two hours to break the seed. dormancy and germination of $B$. decumbens Stapf CV. Basilisk and B. brizantha (Hochst. Ex. A. Rich.) Stapf cv. Marandu and cv. Piata. For this purpose, a completely randomized design $3 \times 2 \times 2$, in gerbox, was structured to compare the germination percentages of seeds kept at room temperature and soaked in $\mathrm{H}_{2} \mathrm{O}$ and in $\mathrm{H}_{2} \mathrm{O}+\mathrm{NaNO}_{3}$ with refrigerated seeds soaked in $\mathrm{H}_{2} \mathrm{O}$ and in $\mathrm{H}_{2} \mathrm{O}+\mathrm{NaNO}_{3}$. It was also structured DIC in roll, to, in addition to PG (\%), evaluate the length of the aerial part $(\mathrm{cm})$ and root $(\mathrm{cm})$ and total fresh mass (g). Tetrazolium and germination speed index tests were also performed. The results were submitted to the Tukey test (p-0.05). The germination percentage evaluated at 14 days was affected by cultivars and temperature, and seeds refrigerated at $4^{\circ} \mathrm{C}$ exceeded those kept at room temperature (increase of 22\%). There was no significant difference for the imbibition factor in $\mathrm{H}_{2} \mathrm{O}$ or $\mathrm{H}_{2} \mathrm{O}+\mathrm{NaNO}_{3}$.

\section{Keywords:}

Academic self-efficacy; Physics Teaching; Albert Bandura.

1 "Este texto é a versão completa do publicado em 2020. Doi: 10.33448/rsd-v9i12.11329." 


\section{INTRODUÇÃO}

A capacidade de germinação de uma espécie define a proporção de suas sementes vivas, dentro de uma amostra, com rapidez e praticidade, e pode ser utilizada para indicar a qualidade de lotes de sementes (Pariz et al., 2010). Esta qualidade é conceituada por parâmetros genéticos, físicos, fisiológicos e sanitários e é estabelecida pelo exame de uma amostra, denominado de análise de sementes (Lopes e Nascimento, 2009; Krzyzanowski et al. 2018). Mas a verificação desta qualidade depende, fundamentalmente, da análise de germinação, especificada nas Regras para Análises de Sementes (RAS), em conformidade com a International Seed Testing Association (Brasil, 2009).

Conceitualmente, germinação de sementes em teste de laboratório é a emergência e desenvolvimento das estruturas essenciais do embrião, com demonstração de sua aptidão para produzir uma planta normal sob condições favoráveis de campo (Brasil, 2009). A RAS disponibiliza métodos padrões de uso obrigatório em laboratórios, objetivando o cumprimento de legislação sobre o assunto. Os testes de germinação visam determinar o potencial máximo de germinação de um lote e seus resultados permitem comparar a qualidade das sementes entre diferentes lotes, além de estimar o valor das mesmas para o plantio. Eles podem ser realizados tanto em laboratório como em campo, mas o laboratorial tem a vantagem de possibilitar repetibilidade (Lopes e Nascimento, 2009).

Testes com sementes de forrageiras do gênero Brachiaria (Trin.) Griseb. têm sido realizados, por exemplo, para verificação de vigor e sanidade (Alexandre, 2016), qualidade fisiológica com variação nas características de pureza (Batista, Nunes e Nóbrega, 2016) e avaliação de viabilidade pelo teste tetrazólio (Dias e Alves, 2008). Isto porque Brachiaria é o gênero de forrageira mais importante dos trópicos, desempenhando grande papel na produção animal no Brasil, além de viabilizar a pecuária em solos fracos e ácidos (Araújo, Deminicis e Campos, 2008). Além disso, apresenta um valor adicional decorrente desta produção, indiretamente mensurado quando convertido em proteína e produtos animais de alto valor agregado, como carne, leite, couro e peles (Valle, Jank e Resende, 2009) e pode ser utilizada nas fases de criação, recria e engorda da pecuária brasileira (Zimmer et al. 2012).

Contudo, é fato que as gramíneas do gênero Brachiaria apresentam baixa porcentagem de germinação devido ao fenômeno da dormência nas sementes, classificada como natural ou primária (Benech-Arnold et al. 2000). Silva, Landgraf e Machado (2013) apontam que as causas mais comuns deste fenômeno são a imaturidade fisiológica do embrião e a impermeabilidade do envoltório à água e, algumas vezes, ao oxigênio. Para superação de dormência, a RAS recomenda escarificação com ácido sulfúrico $\left(\mathrm{H}_{2} \mathrm{SO}_{4}\right)$ concentrado por máximo de 15 min seguido de lavagem com água corrente, $\mathrm{e}$ umedecimento do substrato (duas folhas de papel germitest autoclavadas) com uma solução a 0,2\% de nitrato de potássio $\left(\mathrm{KNO}_{3}\right)$, na proporção de 2,5 vezes a massa do substrato seco (Brasil, 2009).

O emprego de ácido sulfúrico para a quebra de dormência proporciona resultados superiores e estatisticamente diferentes quando comparados a tratamentos sem a escarificação. Silva, et al. (2014), por exemplo, compararam tratamentos com sementes escarificadas + nitrato de potássio e sementes somente umedecidas com $\mathrm{KNO}_{3}$ (sem a escarificação ácida) e o resultado da germinação foi 
de $81,2 \% \pm 16,09$ contra $64,5 \% \pm 3,39$, respectivamente. Em tratamentos com o uso isolado do ácido, Carvalho, Aguiar e Sousa (2015) verificaram índices de germinação de 54,7\% (sementes escarificadas com $\mathrm{H}_{2} \mathrm{SO}_{4}$ ) contra 42,5\% (sem escarificação), respectivamente. Apesar disso, o emprego de ácido sulfúrico traz consequências: riscos operacionais a trabalhadores, poluição do ambiente e possivelmente danos qualitativos às sementes (Lacerda et al., 2010).

O nitrato de potássio é recomendado para a superação de dormência, possivelmente porque muitas vezes não se faz uma clara distinção entre os termos dormência e germinação. Mas isto é necessário, visto que dormência não é simplesmente uma ausência de germinação e sim uma modalidade de desenvolvimento. Esta diferença desafia os pesquisadores a estabelecerem critérios para distinguir os dois processos, ou seja, estabelecer um limite entre o fim da dormência e o começo da germinação (Cardoso, 2009). Entretanto, o autor reconhece que em termos práticos, a maioria dos pesquisadores considera que a germinação visível (critério botânico) continua sendo a indicação mais simples da quebra da dormência, embora tal critério seja uma evidência a posteriori.

Além das considerações apontadas por Cardoso (2009), o nitrato de potássio também é recomendado para a superação de dormência provavelmente porque reagiria com substâncias fixadoras de oxigênio no complexo película-pericarpo (Carvalho e Nakagawa, 2012). Outra razão seria o fato de sofrer redução para nitrito e estimular as vias pentose fosfato e do ácido chiquímico, por meio da eritroese-4-fosfato, importantes para a síntese de compostos como ácidos nucleicos, fenólicos e aminoácidos essenciais, como triptofano, fenilalanina e tirosina (Cardoso et al., 2015). No entanto, no Brasil, a aquisição de nitrato de potássio PA, para qualquer finalidade, depende de autorização do Ministério da Defesa, o que resulta em dificuldades na sua aquisição. Além disso, Bonome et al. (2006) relataram que este sal de baixo peso molecular pode penetrar nos tecidos das sementes e causar fitotoxidez.

De modo geral, as sementes têm dormência imposta pela impermeabilidade do tegumento (Cardoso, 2004) e ainda não foram definidas as condições ideais para o teste de germinação. Por isso, há espaço para o aprimoramento dos métodos e mesmo da própria RAS, para a inclusão de alternativas inovadoras. Trabalhos neste sentido são importantes para a definição de procedimentos mais indicados para a realização do teste de germinação de Brachiaria e obtenção da maior germinação no menor tempo, para facilitar e promover a utilização desse teste pelas empresas e laboratórios de análise de sementes (Gaspar-Oliveira et al., 2008).

Uma alternativa para quebrar a dormência da semente é a refrigeração (Souza et al. 2016), seguida por imersão das sementes em água, resultando em germinação com sucesso igual à alcançada através da utilização de $\mathrm{KNO}_{3}$ (média de 90\%) (Silva et al. 2012). Diante disto, o presente trabalho objetivou avaliar a viabilidade da submissão de sementes de Brachiaria decumbens Stapf cv. Basilisk e Brachiaria brizantha (Hochst. ex. A. Rich.) Stapf cv. Marandu e cv. Piatã a refrigeração a $4^{\circ} \mathrm{C}$ e à embebição com $\mathrm{H}_{2} \mathrm{O}$ e $\mathrm{H}_{2} \mathrm{O}+\mathrm{NaNO}_{3}$ para sua quebra de dormência e germinação, visando o eventual estabelecimento de nova condição para o teste de germinação. 


\section{METODOLOGIA}

O trabalho foi desenvolvido no Laboratório de Biotecnologia de Produtos Vegetais e Microbiologia, do Campus Sede, da Universidade Paranaense - UNIPAR, no município de Umuarama, PR. Foram utilizadas sementes comerciais de $B$. decumbens cv. Basilisk e $B$. brizantha cvs. Piatã e Marandu, sem tratamento fúngico, fornecidas pelo Departamento Técnico de Sementes da Empresa Sementes Fachioli / Grupo Fachioli, Santo Anastácio, São Paulo, Brasil, que as mantinha em armazém convencional, sem controle de temperatura e de umidade (temperatura mínima de $25^{\circ} \mathrm{C}$ e máxima de $30^{\circ} \mathrm{C}$, com Umidade Relativa (UR) anual de $60 \%$ ).

Na universidade, as sementes foram armazenadas em frascos hermeticamente fechados e protegidos da luz. Metade das sementes ficou acondicionada em local a temperatura ambiente (de $25 \pm 2^{\circ} \mathrm{C}$ ) e a outra metade foi acondicionada sob refrigeração a $4^{\circ} \mathrm{C}$. Para a realização do experimento, foram utilizadas sementes separadas manualmente, com auxílio de pinça, para eliminação de material inerte e de palhas, obtendo-se amostras constituídas por sementes fisicamente puras (Brasil, 2009).

\section{Delineamento Inteiramente Casualizado - DIC}

O experimento foi instalado em Delineamento Inteiramente Casualizado (DIC), com um fatorial $3 \times 2 \times$ 2: (A) sementes das três cultivares de Brachiaria; (B) embebição com $\mathrm{H}_{2} \mathrm{O}$ destilada e embebição com $\mathrm{H}_{2} \mathrm{O}$ +nitrato de sódio $\left(\mathrm{NaNO}_{3}\right)$ 0,2\% e (C) sementes armazenadas à temperatura ambiente média de $25^{\circ} \mathrm{C}$ e sementes armazenadas sob refrigeração a $4^{\circ} \mathrm{C}$, com quatro repetições, totalizando 48 unidades experimentais. A metodologia adotada foi adaptada de Silva, Landgraf, Machado (2013).

\section{Testes de germinação}

Testes de germinação foram realizados para obtenção da porcentagem de germinação (PG) e do índice de velocidade de germinação (IVG).

PG (\%) foi calculado de acordo com a Equação 1:

$$
\mathrm{PG}(\%)=\frac{N}{A} \times 100
$$

sendo N o número de sementes germinadas e A o número total de sementes por replicação.

A germinação foi considerada como tendo ocorrido quando qualquer raiz emergida atingiu pelo menos $2 \mathrm{~mm}$ de comprimento (Brasil, 2009). O índice de velocidade de germinação foi calculado de acordo com a Equação 2, descrita por Maguirre (1962):

$$
I V G=\frac{G 1}{N 1}+\frac{G 2}{N 2}+\cdots+\frac{G n}{N n}
$$


sendo $\mathbf{G}$ é o número de sementes germinadas por dia e $\boldsymbol{N}$ o número total de dias, contados do terceiro ao o $12^{\circ}$ dia após a semeadura, ou seja, até o dia em que não germinou mais nenhuma semente.

\section{Teste de Tetrazólio}

Para o teste de tetrazólio (cloreto 2,3,5 trifenil tetrazólio), quatro repetições de 50 sementes cada, resfriadas a $4^{\circ} \mathrm{C}$, foram pré-condicionadas por imersão em água destilada por 6 horas à temperatura ambiente. Em seguida, as sementes foram cortadas longitudinalmente ao embrião e três quartos do endosperma, foram colocadas em vidros plásticos e imersas em solução de tetrazólio $0,1 \%(\mathrm{pH} 6,5)$ (Custódio et al. 2012) e mantidas por $18 \mathrm{~h}$ no escuro em temperatura ambiente. Após esse período, os embriões foram lavados em água corrente e avaliados pela observação da presença (sementes viáveis) ou ausência (sementes não viáveis) de um composto vermelho na superfície do corte, com auxílio de estereomicroscópio (Brasil 2009). Os resultados do teste de tetrazólio foram expressos como porcentagem de sementes viáveis.

\section{Em gerbox}

Para o teste de germinação, sementes de três cultivares, previamente embebidas em $\mathrm{H}_{2} \mathrm{O}$ e em $\mathrm{H}_{2} \mathrm{O}+$ $\mathrm{NaNO}_{3}$ 0,2\%, separadamente, por duas horas, em placas de Petri, foram colocadas em caixas de acrílico tipo gerbox, previamente desinfetadas com água sanitária e álcool 70\%. Em cada gerbox foram colocadas 25 sementes cujo espaçamento entre uma e outra obedeceu ao recomendado na RAS. O substrato consistiu em duas folhas de papel germitest autoclavado, umedecido com água destilada na proporção de 2,5x a massa do substrato seco (Brasil 2009). As unidades experimentais foram armazenadas em sacos de polietileno transparentes e mantidas em incubadora de Demanda Bioquímica de Oxigênio (BOD), regulada para 10h luz / 14h escuro, a uma temperatura de $30 \pm 2^{\circ} \mathrm{Ce} 20$ $\pm 2^{\circ} \mathrm{C}$, respectivamente, por 14 dias, segundo Gaspar-Oliveira et al. (2008), com adaptações.

\section{Em rolo}

Um segundo teste, utilizando um rolo de papel germitest como substrato, foi realizado para comparar o efeito da embebição em $\mathrm{H}_{2} \mathrm{O}$ e em $\mathrm{H}_{2} \mathrm{O}+\mathrm{NaNO}_{3}$ 0,2\% sobre a germinação das sementes mantidas a temperatura de $4^{\circ} \mathrm{C}$. O experimento se deu em delineamento inteiramente casualizado (DIC) em esquema fatorial $3 \times 2$ (cultivares $X$ sementes a $4^{\circ} \mathrm{C}$ embebidas em $\mathrm{H}_{2} \mathrm{O}$ e em $\mathrm{H}_{2} \mathrm{O}+\mathrm{NaNO}_{3}$ a $0,2 \%$ ), com quatro repetições e 20 sementes por rolo. Os rolos foram armazenados verticalmente em sacos plásticos transparentes de polietileno e mantidos em câmara BOD programada para as mesmas condições utilizadas para o teste gerbox. Após 14 dias, além do percentual de germinação, foram avaliados o comprimento da parte aérea $(\mathrm{cm})$, o comprimento da raiz $(\mathrm{cm})$ e a massa fresca total (parte aérea + raiz) (g) das mudas. O comprimento da parte aérea e da raiz foi medido com auxílio de paquímetro universal digital. A massa fresca foi obtida por meio de pesagem em balança analítica. 


\section{Análise de dados}

Os dados foram submetidos ao teste de normalidade de Shapiro-Wilk e teste de homocedasticidade de Bartlett. Após a confirmação da parametricidade, foram avaliados pelo teste " $F$ ", a $5 \%$ de significância. Quando significativa pelo teste " $F$ ", a significância estatística das médias foi calculada pelo teste de Tukey $(a=0,05)$. Os testes de tetrazólio também foram avaliados pelo teste post-hoc de Tukey $(a=0,05)$ e submetidos à análise de correlação linear simples com os dados do teste de germinação, por meio do programa Action for Excel (Equipe Estatcamp 2014). As demais análises foram realizadas com o programa estatístico R, versão 2.2.1 (R. Development Core Team, 2013).

\section{RESULTADOS}

\section{Índice de Velocidade de Germinação - IVG e Tetrazólio}

O índice de velocidade de germinação (IVG) e o teste de tetrazólio revelaram que B. brizantha cv. Piatã apresentou o maior IVG $(20,59)$ com diferença significativa de $B$. brizantha $\mathrm{cv}$. Marandu $(17,86)$ e $B$. decumbens $\mathrm{cv}$. Basilisk (12,68), que também diferiram significativamente ( $\mathrm{Fdf}=59,5980, p=0,0000$ ) (Tabela 1).

Os dados do teste de tetrazólio evidenciam que 95\% dos embriões de Piatã eram viáveis, seguidos de 91\% de Marandu e $88 \%$ de Basilisk, com diferenças não significativas $(P \geq 0,05)$ entre as cultivares. Também mostraram que o teste apresentou correlação linear com a germinação para Piatã e Marandu, com coeficientes de 0,9827 e 0,9486, respectivamente (Figura 1). Em relação ao Basilisk, a correlação $(r=0,32026)$ é compatível com a diferença entre a porcentagem de germinação e a porcentagem de embriões viáveis observada neste estudo, explicando porque a equação quadrática é a que melhor demonstra esse comportamento.

Tabela 1. Análise do Índice de Velocidade de Germinação (IVG) e teste de tetrazólio realizado com B. brizantha cvs. Piatã e Marandu e B. decumbens cv. Basilisk, com o IVG obtido a partir de sementes resfriadas a $4^{\circ} \mathrm{C}$ e embebidas em $\mathrm{H}_{2} \mathrm{O}$ e em $\mathrm{H}_{2} \mathrm{O}+\mathrm{NaNO}_{3}$ a $0,2 \%$ por $2 \mathrm{~h}$, e a porcentagem de embriões viáveis obtida a partir do teste de tetrazólio feito apenas com sementes resfriadas a $4^{\circ} \mathrm{C}$ e embebidas em $\mathrm{H}_{2} \mathrm{O}$.

\begin{tabular}{lcc}
\hline Cultivar & IVG (\%) & Teste de tetrazólio (\%) \\
\hline Piatã & $20,59 \pm 1,21 \mathrm{a}$ & $95,00 \pm 1,49 \mathrm{a}$ \\
Marandu & $17,86 \pm 1,67 \mathrm{~b}$ & $91,00 \pm 1,55 \mathrm{a}$ \\
Basilisk & $12,68 \pm 1,21 \mathrm{c}$ & $88,00 \pm 8,03 \mathrm{a}$ \\
\hline CV $(\%)$ & 8,64 & 3,84 \\
\hline
\end{tabular}

Médias seguidas de letras iguais, na coluna, não diferem pelo teste de Tukey no nível de significância de 0,05. CV = Coeficiente de Variação. 


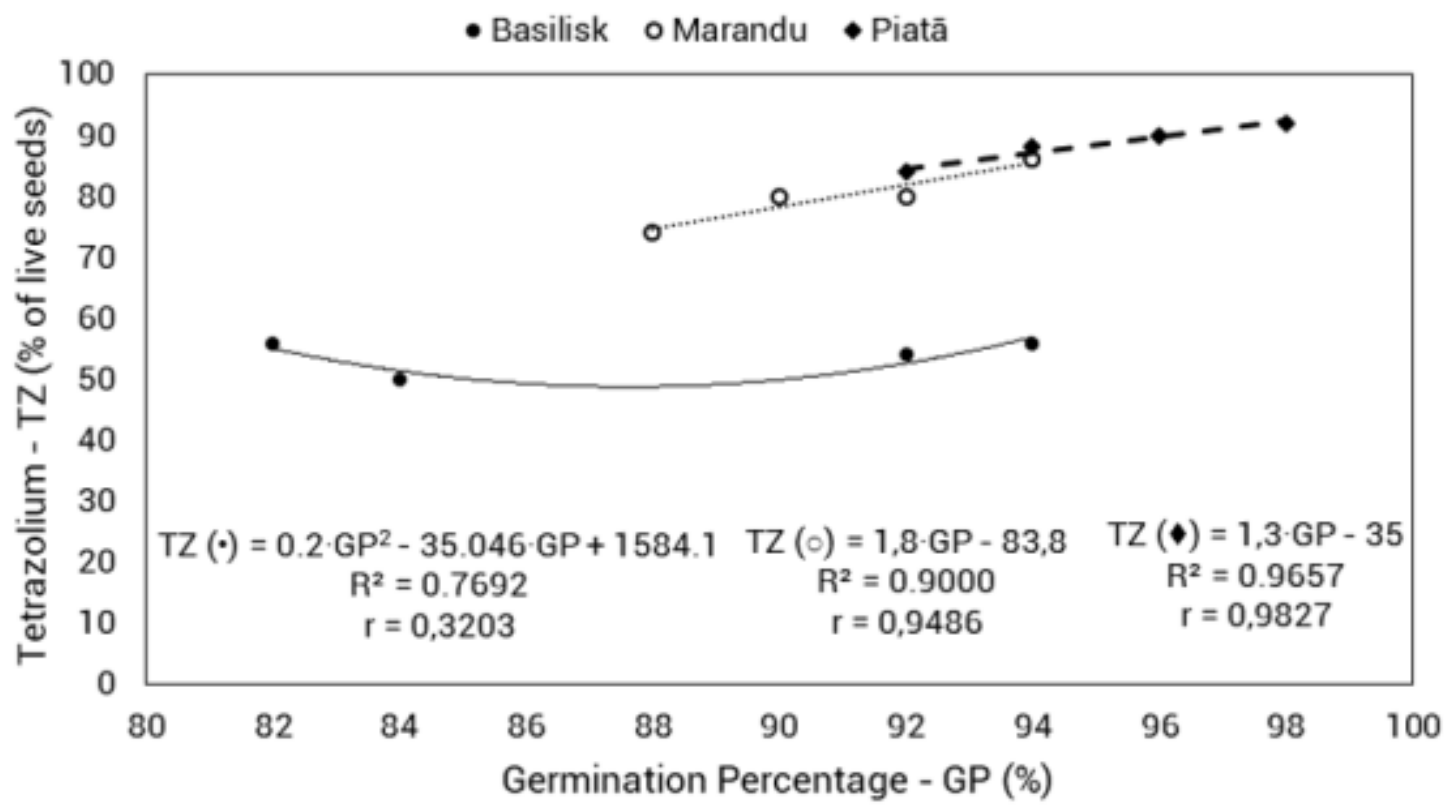

Figura 1: Correlação entre o resultado do teste de Tetrazólio e a porcentagem de germinação (PG) média das cultivares Basilisk, Marandu e Piatã submetidas aos tratamentos de resfriamento a $4^{\circ} \mathrm{C}$ e embebição de $\mathrm{H}_{2} \mathrm{O}$ e em $\mathrm{H}_{2} \mathrm{O}+\mathrm{NaNO}_{3}$ a $0,2 \%$.

\section{Em Gerbox}

A porcentagem de germinação, aos sete dias (Tabela 2), diferiu entre as cultivares ( $F d f=12,20$, $p=0,0001$, temperatura ( $F d f=85,57, p=0,0000)$ e interação entre esses fatores $(F d f=4,0801$, $p=0,0253)$. Não foi verificada diferença em embebição ( $F d f=0,0442, p=0,8347$ ) e interação entre cultivares $x$ embebição $x$ temperatura ( $F d f=0,1851, p=0,8318)$, cultivar $x$ embebição ( $F d f=0,0193$, $p=0,9809$ ) e embebição $x$ temperatura ( $F d f=0,0110, p=0,9169)$.

Aos sete dias, o desdobramento da interação das cultivares dentro das temperaturas mostrou que as cultivares não diferiram entre si a $25^{\circ} \mathrm{C}$, mas diferiram quando mantidas sob refrigeração a $4^{\circ} \mathrm{C}$, sendo que Marandu e Piatã não diferiram entre si, mas diferiram de Basilisk, que apresentou a menor porcentagem de germinação (Tabela 2). Marandu e Piatã apresentaram germinação 80 e $105 \%$ maior que Basilisk, respectivamente. Ainda, na primeira avaliação, a quebra de temperatura para cada cultivar indicou um aumento na porcentagem de germinação para todas as cultivares quando submetidas à refrigeração a $4^{\circ} \mathrm{C}$. Esse aumento foi de $191 \%$ para a cultivar Marandu, $214 \%$ para Piatã e 162\% para Basilisk. 
Tabela 2: Comparação das médias de porcentagem de germinação ( \pm desvios padrão) de sementes de $B$. brizantha cvs. Piatã e Marandu e $B$. decumbens cv. Basilisk mantidas a $25^{\circ} \mathrm{C}$ e submetidas ao resfriamento a $4^{\circ} \mathrm{C}$ e germinação (\%) das sementes das três cultivares mantidas a $25^{\circ} \mathrm{C}$ e resfriadas a $4^{\circ} \mathrm{C}$ e embebidas em $\mathrm{H}_{2} \mathrm{O}$ e em $\mathrm{H}_{2} \mathrm{O}+\mathrm{NaNO}_{3}$ $0,2 \%$, sete dias após a instalação do ensaio.

\begin{tabular}{lcc}
\hline \multirow{2}{*}{ Cultivar } & \multicolumn{2}{c}{ Germinação $(\%)$ aos 7 dias } \\
\cline { 2 - 3 } & $25^{\circ} \mathrm{C}$ & $4^{\circ} \mathrm{C}$ \\
\hline Piatã & $18,00 \pm 15,71 \mathrm{aB}$ & $56,50 \pm 5,83 \mathrm{aA}$ \\
Marandu & $17,00 \pm 13,48 \mathrm{aB}$ & $49,50 \pm 6,74 \mathrm{aA}$ \\
Basilisk & $10,50 \pm 9,55 \mathrm{aB}$ & $27,50 \pm 5,42 \mathrm{bA}$ \\
\hline
\end{tabular}

$\mathrm{CV}(\%)=36,82$

Médias com letras minúsculas iguais na mesma coluna e letras maiúsculas na mesma linha não diferem pelo teste de Tukey no nível de significância de 0,05. CV = Coeficiente de Variação.

A porcentagem de germinação avaliada aos 14 dias (Tabela 3) foi afetada pelas cultivares ( $F d f=8,9062, p=0,0007$ ) e temperatura ( $F d f=135,0519, p=0,0000)$. Não houve diferença significativa para o fator de embebição ( $F d f=0,0519, p=0,821)$, nem para as interações cultivar $x$ temperatura $x$ embebição ( $F d f=0,0187, p=0,9814)$, cultivares $x$ temperatura ( $F d f=3,1197, p=0,0563)$, cultivares $x$ embebição ( $F d f=0,0303, p=0,9702$ ) e temperaturas $x$ embebição ( $F d f=0,0231, p=0,8801)$.

A germinação das cultivares Marandu e Piatã superaram Basilisk em 49 e 59\% respectivamente. Semelhantemente ao observado aos sete dias, a porcentagem de germinação das sementes refrigeradas a $4^{\circ} \mathrm{C}$ superou as mantidas em temperatura ambiente. Esse aumento foi, na média, de aproximadamente $220 \%$. Por cultivar, o aumento foi de 202\% para Marandu, 247\% para Piatã e 209\% para Basilisk.

Tabela 3. Porcentagem de germinação das cvs. Piatã, Marandu e Basilisk sob efeito dos principais fatores (Fator A - cultivares e fator B: temperatura) aos 14 dias após a instalação do experimento.

\begin{tabular}{ll}
\hline Cultivar & Germinação (\%) \\
\hline Piatã & $57,00 \pm 22,52 \mathrm{a}$ \\
Marandu & $53,25 \pm 19,59 \mathrm{a}$ \\
Basilisk & $35,75 \pm 15,41 \mathrm{~b}$ \\
\hline & \\
\hline Temperatura & Germinação (\%) \\
\hline 25으 & $23,17 \pm 18,98 \mathrm{~b}$ \\
4으 & $74,17 \pm 15,65 \mathrm{a}$ \\
\hline
\end{tabular}

$\mathrm{CV}(\%)=31,24$

Médias com letras minúsculas iguais na mesma coluna não diferem pelo teste de Tukey no nível de significância de 0,05 . CV = Coeficiente de Variação. 


\section{Em Rolo}

De acordo com a Tabela 3, em comprimento da parte aérea (CPA) e massa fresca (MF), Piatã e Marandu apresentaram os maiores valores, respectivamente. Especificamente em relação a CPA, essas duas cultivares apresentaram diferenças não-significativas $(P \geq 0,05)$ nas médias dos dois tratamentos, mas diferiram de Basilisk. Para MF, Marandu apresentou o maior valor $(0,66 \mathrm{~g})$, diferindo estatisticamente de Piatã e Basilisk. Para o comprimento da raiz, a interação cultivares ( $F d f=10,0676, p=0,00116)$ e embebição ( $F d f=5,8068, p=0,0269)$ foram significativas. Piatã e Marandu não diferiram entre si, apresentando os menores valores para comprimento de raiz, 5,66 e 5,70 cm, respectivamente, mas diferiram do Basilisk, com comprimento de $6,98 \mathrm{~cm}$. A imersão em $\mathrm{H}_{2} \mathrm{O}+\mathrm{NaNO}_{3}$ também influenciou o comprimento da raiz das plântulas, pois as plântulas originadas de sementes embebidas em $\mathrm{NaNO}_{3}$ excederam em $11 \%$ o comprimento radicular daquelas embebidas em água.

Em relação à germinação, a cultivar que apresentou maior percentual foi Piatã (85\%), seguida de Marandu, com 77,5\%, e Basilisk, com 63,75\%, no tratamento com $\mathrm{NaNO}_{3}$, e respectivamente $73,75 \%$, $70 \%$ e 55\%, no tratamento com água destilada. Porém, estatisticamente, o efeito do tratamento nas cultivares só foi significativo $(P \leq 0,05)$ para Piatã e Marandu em relação ao Basilisk, conforme observado na comparação das médias na coluna de ambos os tratamentos da Tabela 3.

Ainda em relação ao efeito do tratamento sobre as cultivares, foram evidenciadas interações significativas $(P \leq 0,05)$ para comprimento de parte aérea e massa fresca em ambos os tratamentos. Nestes casos, Piatã e Marandu, respectivamente, tiveram as melhores respostas. Especificamente em relação ao comprimento de parte aérea, essas duas cultivares apresentaram diferenças não significativas $(P \geq 0,05)$ nas médias de ambos os tratamentos. Considerando comprimento de raiz, Basilisk apresentou a maior média com diferença significativa quando comparado a Piatã e Marandu no tratamento com $\mathrm{NaNO}_{3}$.

Tabela 4. Análise do comprimento da parte aérea (CPA), comprimento da raiz (CR), massa fresca (MF) e porcentagem de germinação (PG) de B. decumbens cv. Basilisk e B. brizantha cvs. Piatã e Marandu resfriadas a $4^{\circ} \mathrm{C}$ e submetidas ao teste de germinação em rolo após embebição em $\mathrm{H}_{2} \mathrm{O}$ e nitrato de sódio $\left(\mathrm{NaNO}_{3}\right)$ a $0,2 \%$.

\begin{tabular}{|c|c|c|}
\hline \multirow{2}{*}{ Cultivar } & \multicolumn{2}{|c|}{ Tratamentos } \\
\hline & $\mathrm{H}_{2} \mathrm{O}$ & $\mathrm{NaNO}_{3}$ \\
\hline -----. & Comprimento de parte aérea $(\mathrm{cm})$ & ----------------.. \\
\hline Piatã & $6,16 \pm 0,34 \mathrm{aA}$ & $6,53 \pm 0,48 \mathrm{aA}$ \\
\hline Marandu & $5,75 \pm 0,29$ aA & $6,05 \pm 0,48 \mathrm{aA}$ \\
\hline Basilisk & $4,49 \pm 0,55 \mathrm{bA}$ & $4,79 \pm 0,32 \mathrm{bA}$ \\
\hline $\mathrm{CV}(\%)=7,32$ & Média $=5,61 \pm 0,41$ & \\
\hline & Comprimento de raiz (cm) & --------------------. \\
\hline Piatã & $5,56 \pm 0,27 a A$ & $5,76 \pm 0,46 \mathrm{bA}$ \\
\hline Marandu & $5,43 \pm 0,45 a A$ & $5,97 \pm 0,91 \mathrm{bA}$ \\
\hline Basilisk & $6,36 \pm 0,89 \mathrm{aB}$ & $7,60 \pm 0,76$ aA \\
\hline CV $(\%)=10,26$ & Média $=6,09 \pm 0,63$ & \\
\hline
\end{tabular}




\begin{tabular}{|c|c|c|}
\hline & Massa fresca (g) & $\ldots$ \\
\hline Piatã & $0,57 \pm 0,017 \mathrm{bA}$ & $0,58 \pm 0,011 \mathrm{bA}$ \\
\hline Marandu & $0,67 \pm 0,018 \mathrm{aA}$ & $0,65 \pm 0,008$ aA \\
\hline Basilisk & $0,36 \pm 0,040 \mathrm{cA}$ & $0,33 \pm 0,022 \mathrm{cA}$ \\
\hline \multirow[t]{2}{*}{$\mathrm{CV}(\%)=3,67$} & Média $=0,54 \pm 0,02$ & \\
\hline & Germinação (\%), 14 dias após instalação do experimento & $-\cdots$ \\
\hline Piatã & $73,75 \pm 8,54 \mathrm{aA}$ & $85,00 \pm 5,77 \mathrm{aA}$ \\
\hline Marandu & $70,00 \pm 12,91 \mathrm{aA}$ & $77,50 \pm 6,45 \mathrm{aA}$ \\
\hline Basilisk & $55,00 \pm 12,25 \mathrm{bA}$ & $63,75 \pm 11,09 \mathrm{bA}$ \\
\hline$C V(\%)=13,97$ & Média $=70,83 \pm 9,89$ & \\
\hline
\end{tabular}

Médias com letras minúsculas iguais na mesma coluna e letras maiúsculas na mesma linha não diferem pelo teste de Tukey no nível de significância de 0,05. CV = Coeficiente de Variação.

\section{DISCUSSÃO}

Os testes de IVG e Tetrazólio evidenciam a qualidade das sementes empregadas nestes trabalhos. Mas esta qualidade não garante por si mesma a germinação, porque esta depende de mecanismos que podem estar limitados ao tegumento duro e impermeável de suas sementes e de outros fatores, como a ação de fungos (Silva et al., 2014). Estas características geram a chamada dormência cuja natureza, intensidade e persistência não estão suficientemente elucidadas, mas são responsáveis pela irregularidade e baixo estande em campos de produção (Vela et al., 2018).

A embebição é o tratamento recomendado pela RAS para romper a dormência e pode ser feita antes ou depois do início do teste de germinação, porque sementes com tegumento duro podem germinar mais rapidamente após embebição em água (Brasil, 2009). No entanto, as percentagens de germinação reduzidas das sementes em temperatura ambiente obtidas neste estudo indicam que a embebição por si só foi insuficiente para estimular a germinação.

A RAS indica que o período de embebição varie de 24 a 48 horas. Vela et al. (2018) seguiram esta recomendação, em experimento com $B$. brizantha cvs. Xaraés e Marandu. Os resultados foram numericamente parecidos aos obtidos neste experimento, aos sete dias, com Marandu: PG (\%) de 53,5 e 50 , respectivamente.

Sobre $B$. decumbens Basilisk, trabalhos científicos especificamente sobre teste de germinação, para avaliação de quebra de dormência, são escassos na literatura especializada. Mas avaliações conduzidas com gramíneas africanas cultivadas no Brasil revelam que a porcentagem de germinação desta espécie, assim como de Andropogon gayanus, é normalmente inferior à de espécies como Melinis minutiflora (Carmona e Martins, 2010). Mas Carmona e Martins (2010) apontaram que o percentual de germinação de $B$. decumbens varia de $29 \%$ a $85 \%$. Trata-se, portanto, de uma larga faixa de PG (\%) dentre a qual os percentuais obtidos neste experimento com tal espécie cv. Basilisk (tratamento refrigeração, aos 14 dias) se inclui. 


\section{Dormência e germinação}

São considerados responsáveis pela dormência de um embrião, fatores como a restrição física e/ou mecânica, provocada pelo tegumento e/ou endosperma, assim como a ação exercida por inibidores de crescimento (a exemplo de compostos fenólicos) localizados no endosperma, na testa ou no pericarpo (Cardoso, 2009). O papel do nitrato na superação de dormência de sementes de diversas espécies tem sido, há tempos, relatado na literatura especializada. Toole et al. (1956), por exemplo, apontaram os nitratos como um dos principais agentes desta superação.

Mas realmente é o nitrato que atua na quebra da dormência, ou o nitrato tem atuação na germinação, especificamente nas rotas bioquímicas da pentose fosfato e do ácido chiquímico, ou ele é dispensável tanto para a superação da dormência como para a germinação? Ora, como a Brachiaria apresenta dormência causada por imaturidade fisiológica do embrião (Marcos Filho, 1986), é plausível inferir que sua atuação estaria restrita à germinação.

Por outro lado, autores como Santos et al. (2011) não encontraram efeito significativo do nitrato sobre percentual de germinação. Em experimento semelhante ao do presente trabalho, com sementes de B. brizantha cv. Piatã, escarificadas segundo a RAS e umedecidas com água destilada e nitrato de potássio, os autores obtiveram percentuais de 42,5 e 44,17 de germinação das sementes umedecidas com $\mathrm{KNO}_{3}$ e $\mathrm{H}_{2} \mathrm{O}$, respectivamente, na contagem ao 70 dia após a instalação, e de 56,5 e 59,33, respectivamente, obtidos no 14 dia. Em ambas as contagens, não houve diferença estatística significativa entre as médias.

Santos et al. (2011) concluíram que nenhuma das soluções utilizadas interferiu na porcentagem de germinação e/ou emergência das sementes do cultivar Piatã. Já Novembre, Chamma e Gomes (2006), avaliando a germinação de sementes de $B$. brizantha, obtiveram valores superiores a $70 \%$ quando utilizaram água destilada. Pode ser inferido desses resultados que a germinação decorre da embebição, não da quebra de dormência por ação do nitrato, que, ao entrar em contato com o envoltório da semente, teria o papel de promover seu amolecimento para facilitar trocas gasosas (Frank e Nabinger, 1996). Mas como esta ação ainda é bastante discutida (Lula et al., 2000), o presente trabalho reforça a hipótese de que a utilização deste sal pode ser dispensada.

Não há na literatura especializada trabalho com metodologia semelhante a esta, no que se refere à combinação de tratamentos frio $x$ embebição em $\mathrm{H}_{2} \mathrm{O}$ e $\mathrm{H}_{2} \mathrm{O}+\mathrm{NaNO}_{3}$. O uso do $\mathrm{NaNO}_{3}$ como estimulador da germinação de sementes foi demonstrado por Adkins, Simpson e Naylor (1984), em experimento com Avena fatua (linha AN51) L., com as sementes mantidas em temperatura ambiente, sem terem sido submetidas a embebição em $\mathrm{H}_{2} \mathrm{O}$, ou seja, sem sofrer o efeito do frio em seus tegumentos para desencadear o processo de germinação.

A única variável que sofreu o efeito da embebição de $\mathrm{NaNO}_{3}$ foi o comprimento da raiz, que ultrapassou o tamanho das raízes das mudas embebidas em água. Uma variável associada ao crescimento radicular é a presença de células mitóticas. Gajbhiye (2013) encontrou um número mais significativo dessas células nas raízes de Vigna radiata quando embebidas em água e uma redução desta quantidade na concentração de $0,1 \%$ e ausência de células mitóticas na concentração de $\mathrm{NaNO}_{3}$ 0,9\%. No entanto, para este tratamento, o autor relatou a presença de células alongadas, o 
que sugere que um possível alongamento celular, promovido pelo nitrato, pode ter ocasionado o maior comprimento de raiz encontrado neste trabalho.

Também não há evidências de que o $\mathrm{KNO}_{3}$ não poderia ser substituído por $\mathrm{NaNO}_{3}$, se efetivamente fosse necessário para a quebra de dormência e/ou germinação. Os nitratos são íons poliatômicos que apresentam carga pequena, -1 , e raio iônico de 165 pm, o que Ihes conferem uma baixa entalpia de hidratação $\left(\Delta \mathrm{hidH}^{\circ}=-295 \mathrm{~kJ} \mathrm{~mol}^{-1}\right)$ e entropia relativamente elevada em água $\left(\mathrm{S}^{\circ}=146,7 \mathrm{~J} \mathrm{~K}^{-1} \mathrm{~mol}^{-1}\right)$. Tanto o de potássio como o de sódio - que apresentam dados termodinâmicos e de solubilidade, respectivamente, de 138 e $98 \mathrm{r}$ cátion / pm, -361 e -344 $\Delta \mathrm{hidH}^{\circ} / \mathrm{kJ} \mathrm{mol}^{-1}$ e 101.2 e $59 \mathrm{~S} / \mathrm{J} \mathrm{K}^{-1} \mathrm{~mol}^{-1}$ (cátion hidratado) - se dissociam em água porque a variação de entropia resultante da solvatação do ânion, associada à entalpia de solvatação do sal, normalmente, é suficiente para compensar o aumento na energia de rede e diminuição de entropia na solvatação de cátions com relação carga/raio elevada (Silva, Martins e Andrade, 2004).

Todo nitrato é solúvel em água (Silva, Martins e Andrade, 2004), pelo processo de solvatação, formando, no caso do nitrato de potássio, nitrato e potássio em solução, conforme pode ser observado na equação de dissociação: $\mathrm{KNO}_{3}(\mathrm{~s}) \underset{\mathrm{H}_{2} \mathrm{O}}{\longrightarrow} \mathrm{K}+(\mathrm{aq})+\mathrm{NO}_{3}$ - (aq) (Nery, Liegel e Fernandez, 2007). Assim, no caso de o nitrato ser de sódio, o $\mathrm{Na}$ se dissocia de $\mathrm{NO}_{3}$ e tanto o cátion quanto o ânion ficam combinados com a molécula do solvente. Isto porque o processo de solvatação é justamente o fenômeno que ocorre quando um composto iônico ou polar se dissolve em uma substância polar, sem formar uma nova substância, ou seja, o processo de inserção de um soluto em um dado solvente, na qual uma partícula do soluto (átomo ou molécula) é transferida para uma posição fixa na solução, mantendo-se constantes, temperatura, pressão, e composição do solvente (Weissermel e Arpe, 1997).

Quanto à água, diferentemente do nitrato, sua ação no processo de germinação está consagrada na literatura especializada. Ela é considerada o principal agente estimulador e controlador dos processos de embebição e germinação, por proporcionar amolecimento do tegumento, acréscimo no volume do embrião e dos tecidos de reserva, aumento nos estímulos à digestão, à translocação e à assimilação dos nutrientes, com consequente crescimento do eixo embrionário (Villela, 1998). A água também estimula a síntese de giberelina (GA), que favorece a produção de enzimas hidrolíticas responsáveis por quebrar reservas do endosperma durante a germinação, enfraquecendo os tecidos circunvizinhos que cobrem o embrião, facilitando a protusão da radícula (Guimarães, Dias e Loureiro, 2008).

Uma das ações da água no processo de germinação de sementes é a ativação da enzima $\alpha$-galactosidase. A enzima catalisa, por exemplo, a hidrólise de galactomanas da parede celular a manose e a galactose, absorvidas para o crescimento do embrião e, posteriormente, usadas como fonte de carbono para o fornecimento de energia a vários processos metabólicos (Góes e Ribeiro, 2002). Esta é, conforme as autoras, uma característica para promoção de crescimento vegetal, fato confirmado em estudo com Pisum sativum, com a participação da $\alpha$-galactosidase no processo de crescimento da planta. A reação se dá por meio de uma molécula aceptora $\left(\mathrm{R}^{\prime} \mathrm{OH}\right)$ presente em D-galactose localizada na parede celular, para a hidrólise deste polissacarídeo. 


\section{Temperatura}

A ação da temperatura baixa para a quebra de dormência foi demonstrada por Souza et al. (2016), em experimento estruturado para avaliar a qualidade fisiológica de lotes de sementes de B. brizantha cv. Piatã. $O$ teste de frio foi realizado com a utilização de 100 sementes umedecidas com $\mathrm{KNO}_{3}$ 0,2\% dispostas em rolo com papel germitest, em quatro repetições, com temperatura de $20^{\circ} \mathrm{C}$ por $16 \mathrm{~h}$ no escuro e $35^{\circ} \mathrm{C}$ por $8 \mathrm{~h}$ de iluminação, em câmara de germinação. A análise de variância dos resultados revelou significância para interação lotes de sementes x superação de dormência e o maior PG foi obtido ao 21을 dia após a instalação do ensaio, com média de 73,5\%.

Em 1701, Isaac Newton publicou anonimamente o artigo "Scala graduum caloris", descrevendo método para medir temperaturas de até $1000^{\circ} \mathrm{C}$, inalcançável para os termômetros da época. Seu método estava baseado no que denominamos hoje de lei do resfriamento (esfriamento) de Newton, segundo a qual a taxa de diminuição da temperatura de um corpo é proporcional à diferença de temperaturas entre o corpo e o ambiente (French, 1993). Além disso, todos os corpos da natureza estão sujeitos a sofrer variação em suas dimensões lineares em função da temperatura, aumentando (dilatação térmica) ou diminuindo de tamanho (contração térmica). Exemplo bem prático (e didático) disto é o da argila. Durante processo de calcinação, ela pode sofrer uma série de transformações físicas e químicas, entre as quais estão a dilatação e contração térmicas (Hartke, 2007).

Outro fenômeno, que causa modificações nas propriedades mecânicas dos materiais, é o encruamento, ou seja, um trabalho a frio que provoca um aumento constante das tensões limites de escoamento e resistência à tração e uma queda acentuada da ductilidade (Longo e Reed-Hill, 1973/1974; Garcia, Spim e Santos, 2012). Quando a temperatura é aumentada, os efeitos do encruamento podem ser diminuídos até o retorno às suas propriedades originais, mas com algum dano. Isto porque, quando a tensão limite de escoamento se torna muito próxima da tensão limite de resistência, associada à baixa ductilidade, o material passa a apresentar um estado em que a continuidade da deformação o leve à ruptura (Longo e Reed-Hill, 1973/1974), a exemplo do que pode ter acontecido com os tegumentos das sementes de $B$. decumbens cv. Basilisk e B. brizantha cvs. Piatã e Marandu.

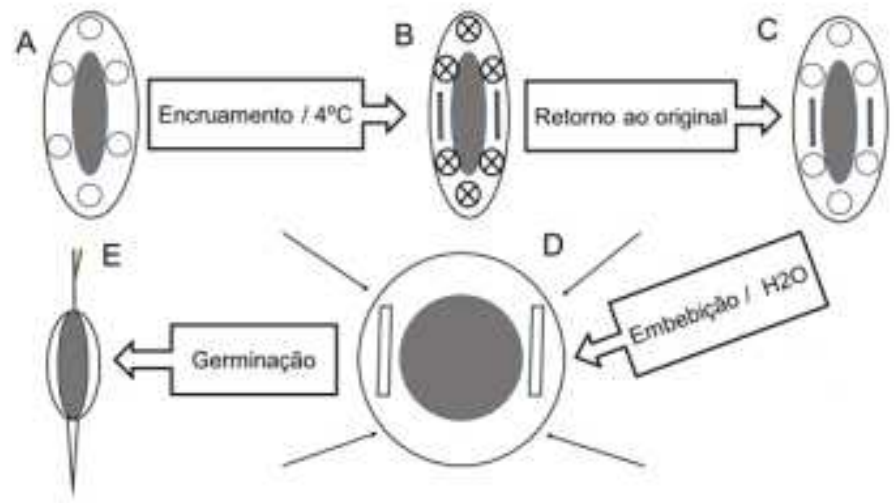

Figura 2. Desenho esquemático representando o hipotético processo de quebra de dormência por encruamento e desencadeamento da germinação por embebição. (A) Semente de Brachiaria a temperatura ambiente. (B) Após uma semana sob refrigeração a $4^{\circ} \mathrm{C}$, tegumento sofre encruamento, com aumento constante das tensões limites de 
escoamento e resistência à tração, assim como uma queda acentuada da ductilidade, incluindo transformações plásticas antes de seu rompimento. (C) Novamente a temperatura ambiente, o tegumento da semente retoma as propriedades originais, mas com fissuras, trincas e dormência quebrada. (D) Água adentra à semente pelas trincas, embebendo-as e desencadeando o processo de germinação. (E) Semente de Brachiaria germina.

Por isso, com base nas características mecânicas dos tegumentos, na lei de resfriamento de Newton e nos conceitos de contração térmica e encruamento de materiais, é possível estabelecer a hipótese de que ao ser submetido a uma temperatura de $4^{\circ} \mathrm{C}$, o tegumento das sementes de Brachiaria sofreu encruamento, mas à temperatura ambiente, retomou suas propriedades originais com fissuras e trincas que possibilitaram a entrada de água, levando à quebra da dormência e desencadeando o processo de germinação, tal como apresentado na Figura 2.

\section{CONCLUSÃO}

A germinação de sementes submetidas ao resfriamento a $4^{\circ} \mathrm{C}$ foi superior aos tratamentos a temperatura ambiente, com melhor resposta apresentada por Piatã, independentemente de terem sido ou não tratadas com nitrato. A eficácia do emprego de nitrato para fins de germinação, portanto, se mostrou dispensável. Em decorrência disto, formulou-se a hipótese de que a quebra da dormência das sementes se deu por encruamento, com rupturas no material que compõe o tegumento, permitindo a embebição e, consequentemente, a superação da imaturidade fisiológica do embrião. Assim, a germinação começou a ocorrer a partir da absorção da água, pela reativação do metabolismo responsável pelo crescimento do eixo embrionário.

\section{Agradecimentos}

Os autores agradecem à Universidade Paranaense (UNIPAR) pelo apoio financeiro à pesquisa, à Coordenação de Aperfeiçoamento de Pessoal de Nível Superior (Capes), ao Conselho Nacional de Desenvolvimento Científico e Tecnológico (CNPq), à Fundação Araucária e ao Instituto Federal de Educação, Ciência e Tecnologia de Rondônia (IFRO) pelo apoio à capacitação e pesquisa. 


\section{REFERÊNCIAS}

ADKINS, S. W.; SIMPSON, G. M.; NAYLOR, J. M. The physiological basis of seed dormancy in Avena fatua IV. Alternative respiration and nitrogenous compounds. Physiologia Plantarum, v. 60, n. 2, p. 234-238, 1984.

ALEXANDRE, P. F. R. de M. Testes de vigor e sanidade de sementes de Brachiaria brizantha cv. Marandú e Xaraés. 70f. 2016. Tese (Doutorado em Agronomia / Produção Vegetal) - Universidade Estadual Paulista "Júlio de Mesquita (UNESP), Jabuticabal, 2016.

ARAÚJO, S. A. C; DEMINICIS, B. B.; CAMPOS, P. R. S. S. Melhoramento genético de plantas forrageiras tropicais no Brasil. Archivos de zootecnia, v. 57 (R), p. 61-76, 2008.

BATISTA, V. T.; NUNES, J. V. D.; NÓBREGA, L. H. P. Qualidade fisiológica de sementes de Brachiaria brizantha cv. Marandu com variação nas caracteristicas de pureza. Revista de Agricultura, v. 91, n.1, p. 92-100, 2016.

BENECH-ARNOLD, R. L.; SÁNCHEZ, R. A.; FORCELLA, F.; KRUK, B. C.; GHERSA, C. M. Controle ambiental de dormência em bancos de sementes de plantas daninhas no solo. Field Crops Research, v. 67, p. 105-122, 2000.

BONOME, L. T. da S.; GUIMARÃES, R. M.; OLIVEIRA, J. A.; ANDRADE, V. de C.; CABRAL, P. de S. Efeito do condicionamento osmótico em sementes de Brachiaria brizantha cv. Marandu. Ciência e Agrotecnologia, v. 30, n. 3, p. 422-428, 2006.

BRASIL. Ministério da Agricultura, Pecuária e Abastecimento. Regras para Análise de Sementes. Brasília: Mapa/ACS, 2009, 399p.

CARDOSO, V. J. M. Germinação. In: KERBAUY, G. B. Fisiologia vegetal. São Paulo: Guanabara Koogan, 2004. p.386-408.

CARDOSO, J. V. M. Conceito e classificação da dormência em sementes. Oecologia Brasiliensis, v. 13, n. 4, p. 619631, 2009. Doi:10.4257/oeco.2009.1304.06.

CARDOSO, E. D.; SÁ, M. E.; HAGA, K. I.; BINOTTI, F. F. S.; COSTA, E. Qualidade fisiológica e composição química de sementes de Brachiaria brizantha em função do condicionamento osmótico. Revista de Agricultura Neotropical, v. 2, n. 2, p.42-48, 2015.

CARMONA, R.; MARTINS, C. R. Dormência e armazenabilidade de sementes de capim-gordura. Revista Brasileira de Sementes, v. 32, n. 4, p. 71-79, 2010.

CARVALHO, N. M.; NAKAGAWA, J. Sementes: ciência, tecnologia e produção. 5 ed. Jaboticabal: Funep, 2012, 590p.

CARVALHO, F. J.; AGUIAR, L. M. de A.; SOUSA, L. A. de. Uso do ácido sulfúrico e nitrato de potássio no teste de germinação de Brachiaria brizantha cv. Marandu. AGRARIAN ACADEMY, Centro Científico Conhecer, v. 2, n. 4, p. 82-89, 2015. Doi: 10.18677/Agrarian_Academy_020.

CUSTÓDIO, C. C.; DAMASCENO, R. L.; MACHADO NETO, N. B. Imagens digitalizadas na interpretação do teste de tetrazólio em sementes de Brachiaria brizantha. Revista Brasileira de Sementes, v. 34, n. 2, p.334-341, 2012.

DIAS, M. C. L. de L.; ALVES, S. J. Avaliação da viabilidade de sementes de Brachiaria brizantha (Hochst. ex A. Rich) Stapf pelo teste de tetrazólio. Revista Brasileira de Sementes, v. 30, n. 3, p.145-151, 2008.

EQUIPE ESTATCAMP. Estatcamp - Consultoria em estatística e qualidade. Software Action. São Carlos - SP, 2014. $<$ http://www.portalaction.combr/>. 
FRANK, L.B.; NABINGER, C. Avaliação da germinação de seis acessos de Paspalum notatum Flügge, nativos do Rio Grande do Sul. Revista Brasileira de Sementes, v.18, n.1, p.102-107, 1996. Doi: 10.17801/01013122/rbs.v18n1p102-107.

FRENCH, A. P. Issac Newton's thermometry. The Physics Teacher, v. 31, n. 4, p. 208-211, 1993. Doi:10.1119/1.2343725.

GAJBHIYE, N. D.Toxic effect of sodium nitrate on germinating seeds of Vigna radiate. International Journal of Biotechnology and Bioengineering, v. 7, n. 10, p. 1002-1006, 2013.

GARCIA, A.; SPIM, J. A.; SANTOS, C. A. dos. Ensaios dos materiais. 2. ed. Rio de Janeiro: LTC - Livros Técnicos e Científicos Editora Ltda, 2012. 378p.

GASPAR-OLIVEIRA, C. M.; MARTINS, C. C.; NAKAGAWA, J.; CAVARIANI, C. Duração do teste de germinação de Brachiaria brizantha cv. marandu (Hochst. ex A. Rich.) Stapf. Revista Brasileira de Sementes, v. 30, n. 3, p. 30-38, 2008. Doi: 10.1590/S0101-31222008000300005.

GUIMARÃES, M. de A.; DIAS, D. C. F. dos S.; LOUREIRO, M. E. Hidratação de sementes. Revista Trópica - Ciências Agrárias e Biológicas, v. 2, n. 1, p. 32-39, 2008.

GÓES, S. P; RIBEIRO, M. L. L. $\alpha$-galactosidase: aspectos gerais e sua aplicação em produtos a base de soja. Semina: Ciências Agrárias, Londrina, v. 23, n. 1, p. 111-119, 2002.

HARTKE, R. F. Modelagem e simulação térmica de um forno rotativo para a produção de agregado de argila calcinada. 122f. 2007. Dissertação (Mestrado em Engenharia) - Universidade Federal de Santa Catarina, Florianópolis, 2007.

KRZYZANOWSKI, F. C.; FRANÇA-NETO, J. B.; HENNING, A. A. A alta qualidade da semente de soja: fator importante para a produção da cultura. Londrina, PR: Embrapa Soja, 2018 (Circular Técnica, 136).

LACERDA, M. J. L.; CABRAL, J. S. R.; SALES, J. F.; FREITAS, K. R.; FONTES, A. J. Superação da dormência de sementes de Brachiaria brizantha cv. "Marandu". Semina: Ciências Agrárias, v. 31, n. 4, p. 823-828, 2010. Doi: 10.5433/1679-0359.2010v31n4p823.

LONGO, W. P; REED-HILL, R. E. Alguns aspectos do encruamento dos metais. Revista do Círculo de Engenharia Militar, v. 69, p. 1-8, 1973.

LONGO, W. P; REED-HILL, R. E. Alguns aspectos do encruamento dos metais. Revista do Círculo de Engenharia Militar, v. 70, p. 22-30,1973.

LONGO, W. P; REED-HILL, R. E. Alguns aspectos do encruamento dos metais. Revista do Círculo de Engenharia Militar, v. 71, p. 43-49, 1974.

LOPES, A. C. A.; NASCIMENTO, W. M. Análise de sementes de hortaliças. Brasília, DF: Embrapa Hortaliças, 2009 (Circular Técnica, 83), 9p.

LULA, A. de A.; AlvarengA, A. A. de; AlMEIDA, L. P. de; AlVES, J. D.; MAgAlhãES, M. M. Estudos de agentes químicos na quebra da dormência de sementes de Paspalum paniculatum L. Revista Ciência Agrotecnica, v.24, n.2, p.358-366, abr./jun., 2000.

MAGUIRRE, J. D. Speed of germination-aid in selection and evaluation for seedling emergence and vigor. Crop Science, v.2, n.1, p.176-177, 1962.

MARCOS FILHO, J. Germinação de sementes. In: SEMANA DE ATUALIZAÇÃO EM PRODUÇÃO DE SEMENTES, 1986, Piracicaba, SP. Anais... Campinas: Fundação Cargill, 1986, p.11-39. 
NERY, A. L.; LIEGEL, R. M.; FERNANDEZ, C. Um olhar crítico sobre o uso de algoritmos no ensino de Química no ensino médio: a compreensão das transformações e representações das equações químicas. Revista Electrónica de Enseñanza de las Ciencias, v. 6, n. 3, p. 587-600, 2007.

NOVEMBRE, A. D. L. C.; CHAMMA, H. M. C. P.; GOMES, R. B. R. Viabilidade das sementes de braquiária pelo teste de tetrazólio. Revista Brasileira de Sementes, v. 28, n. 2, p. 147-151, 2006. Doi: 10.1590/S0101-31222006000200020.

PARIZ, C. M.; FERREIRA, R. L.; DE SÁ, M. E.; ANDREOTTI, M.; CHIODEROLI, C. A.; RIBEIRO, A. P. Qualidade fisiológica de sementes de Brachiaria e avaliação da produtividade de massa seca em diferentes sistemas de integração lavoura-pecuária sob irrigação. Pesquisa Agropecuária Tropical, v. 40, n. 3, p. 330-340, 2010. Doi.org/10.5216/pat.v40i3.6590.

R DEVELOPMENT CORE TEAM. R: A language and environment for statistical computing. Viena: R Foundation for Statistical Computing, 2013.

SANTOS, L. D. C. dos; BENETT, C. G. S.; SILVA, K. S.; SILVA, L. V. da. Germinação de diferentes tipos de sementes de Brachiaria brizantha cv. BRS Piatã. Bioscience Journal, v. 27, n. 3, p. 420-426, 2011.

SILVA, L. A.; MARTINS, C. R.; ANDRADE, J. B. de. Por que todos os nitratos são solúveis? Química Nova, v. 27, n. 6, p. 1016-1020, 2004.

SILVA, A. B.; LANDGRAF, P. R. C.; MACHADO, G. W. O. Brachiaria seeds germination under different concentration of gibberellin. Semina: Ciencias Agrarias, v. 34, n. 2, p. 657-662, 2013. Doi:10.5433/1679-0359.2013v34n2p657.

SILVA, K. S.; MACHADO, S. L. O.; MENEZES, N. L.; URBAN, L. J. K.; ALVES, M. V. P. Adequação da metodologia do teste de tetrazólio para sementes de Hymenachne amplexicaulis. Semina: Ciências Agrárias, v. 33, n. 5, p. 1819-1824, 2012.

SILVA, A. L. M. S.; TORRES, F. E.; GARCIA, L. L. P.; MATTOS, E. M.; TEODORO, P. E. Tratamentos para quebra de dormência em Brachiaria brizantha. Revista de Ciências Agrárias, v. 37, n. 5, p. 37-41, 2014.

SILVA, A. L. M. de S.; TORRES, F. E.; GARCIA, L. L. P.; MATTOS, E. M.; TEODORO, P. E. Tratamentos para quebra de dormência em Brachiaria brizantha. Revista de Ciências Agrárias, v. 37, n. 1, p. 37-41, 2014.

SOUZA, V. Q.; FOLLMANN, D. N.; TROMBETTA, C. G.; ZIMMER, P. D.; NARDINO, M.; CARVALHO, I. R. Testes de vigor associado à superação de dormência em Brachiaria brizantha cv. BRS Piatã. Global Science and Technology, v. 9, n. 2, p. 13-24, 2016.

TOOLE, E. H.; HENDRICKS, S. B.; BORTHWICK, H. A.; TOOLE, V. K. Physiology of Seed Germination. Annual Review of Plant Physiology, v. 7, n. 1, p. 299-324, 1956. Doi:10.1146/annurev.pp.07.060156.001503.

VALLE, C. B.; JANK, L.; RESENDE, R. M. S. O melhoramento de forrageiras tropicais no Brasil. Revista Ceres, v. 56, n. 4, p. 460-472, 2009.

VELA, R. S.; MOTERLE, L. M.; SANTOS, R. F.; CHICHANOSKI, C.; BRACCINI, A. L. Quebra de dormência em sementes de Brachiaria brizantha (Hochst. ex A. Rich.) Stapf. Revista de Ciências Agrárias, v. 41, n. 2, p. 327-335, 2018. Doi: 10.19084/RCA17267.

VILLELA, F. A. Water relations in seed biology. Scientia Agricola, v. 55 (Número Especial), p. 98-101, 1998. Doi: 10.1590/S0103-90161998000500018.

WEISSERMEL, K.; ARPE, H.-J. Industrial organic chemistry. 3. completely rev. ed. Weinheim, DE: VCH A Wiley company, 1997.480p.

ZIMMER, A. H.; MACEDO, M. C. M.; KICHEL, A. N.; ALMEIDA, R. G. Degradação, recuperação e renovação de pastagens. Brasília, DF: Embrapa Gado de Corte, 2012 (Documentos 189). 


\section{MONITORAMENTO DE UM SISTEMA DE COMPOSTAGEM DE RESÍDUOS SÓLIDOS ORGÂNICOS NO INSTITUTO FEDERAL DE PERNAMBUCO - CAMPUS RECIFE}

\author{
Eduardo Antonio Maia Lins \\ Instituto Federal de Pernambuco - IFPE - Campus Recife \\ eduardomaialins@gmail.com \\ Walter Santiago da Silva \\ Instituto Federal de Pernambuco - IFPE - Campus Recife
}

\author{
Camilla Borges Lopes da Silva \\ Instituto Federal de Pernambuco - IFPE - Campus Recife \\ Julia Ximenes Botelho de Melo \\ Instituto Federal de Pernambuco - IFPE - Campus Recife
}

\begin{abstract}
RESUMO
O Instituto Federal de Pernambuco (IFPE) - Campus Recife implantou a Política Ambiental em vista adequar-se à Política Nacional de Resíduos Sólidos. Porém, os resíduos sólidos orgânicos ainda são encaminhados para aterros sanitários através de uma empresa privada que coleta resíduos considerando que a instituição é uma grande geradora. $\mathrm{O}$ objetivo deste trabalho foi realizar um monitoramento em um sistema de compostagem implantado através de um projeto de pesquisa utilizando-se restos de alimentos, podas e aparas de grama e serrapilheira. Assim, implantou-se um projeto piloto de compostagem utilizando baldes plásticos de $70 \mathrm{~L}$ como as leiras de compostagem e preenchendo-os da seguinte maneira: a composteira 1, preenchida com $30 \%$, em volume, de serrapilheira e outros $70 \%$ de poda; a composteira 2 , composta de $30 \%$ de poda e os $70 \%$ de volume
\end{abstract}

restantes, com serrapilheira, além da adição de fungos em cupinzeiros coletados na mata localizada na própria instituição; a composteira 3, foi preenchida com $50 \%$, em volume, de poda e $50 \%$ de serrapilheira. As análises compreenderam atributos físico-químicos de $\mathrm{pH}$, temperatura e umidade. Após um período de quatro meses de análise, pôde-se observar que o produto obtido dos materiais das três leiras tornou-se um produto homogêneo e humificado. $\mathrm{O}$ projeto, mesmo que incipiente e operacionalizado por pouco capital humano e financeiro, veio a apresentar um potencial de produção e utilização do produto em serviços agrícolas de forma comercial ou interna na própria instituição de ensino.

\section{Palavras-chave:}

Orgânico; Tratamento; Uso; Composto.

\begin{abstract}
The Federal Institute of Pernambuco (IFPE) - Campus Recife implemented the Environmental Policy in order to adapt to the National Solid Waste Policy. However, organic solid waste is still sent to landfills through a private company that collects waste considering that the institution is a great generator. The objective of this work was to carry out a monitoring in a composting system implemented through a research project using food waste, pruning and grass clippings and litter. Thus, a pilot composting project was implemented using $70 \mathrm{~L}$ plastic buckets as compost windrows and filling them as follows: compost bin 1, filled with $30 \%$ by volume of litter and another $70 \%$ of pruning; composter 2, composed of 30\% pruning and the remaining $70 \%$ of volume, with litter, in addition to the addition of fungi in termite mounds collected in the forest located in the
\end{abstract}

institution itself; compost bin 3 was filled with $50 \%$ by volume of pruning and 50\% of litter. The analyzes comprised physicochemical attributes of $\mathrm{pH}$, temperature and humidity. After a period of four months of analysis, it could be observed that the product obtained from the materials of the three windrows became a homogeneous and humified product. The project, even if incipient and operated by little human and financial capital, came to present a potential for production and use of the product in agricultural services in a commercial or internal manner at the educational institution itself.

\section{Keywords:}

Organic; Treatment; Use; Compound. 


\section{INTRODUÇÃO}

A ineficácia das políticas públicas ambientais pode trazer inúmeras consequências negativas. Os resíduos sólidos, por exemplo, quando gerenciados e dispostos incorretamente, continuam causando relevantes impactos ambientais negativos como degradação e poluição do solo, comprometimento dos corpos d'água e mananciais, obstrução dos sistemas de drenagem, intensificação de enchentes, degradação da paisagem urbana, ocupação de vias e logradouros públicos, proliferação de moscas, baratas, ratos e outros vetores de importância sanitária nos centros urbanos (KARPINSK et al., 2009; LU \& TAM, 2013). A fração orgânica dos resíduos não deve ser destinada ao aterro, mas valorizada por meio de tratamento biológico, sendo a compostagem como uma das alternativas mais promissoras para um país essencialmente agrícola, como é o caso do Brasil, se destacando por permitir a reciclagem das moléculas orgânicas que têm função nutricional e por diminuir o potencial poluidor e contaminante dos resíduos (DOMíNGUEZ e GÓMEZ, 2010; GUIDONI, 2013).

A Política Nacional de Resíduos Sólidos (Lei 12.305/2010) previu, no art. 36, inciso V, a necessidade de implantação, pelos titulares dos serviços, "de sistemas de compostagem para resíduos sólidos orgânicos e articulação com os agentes econômicos e sociais formas de utilização do composto produzido". Desta forma, entende-se que a promoção da compostagem da fração orgânica dos resíduos, assim como a implantação da coleta seletiva e da disposição final ambientalmente adequada dos rejeitos, faz parte do rol de obrigações dos municípios, empresas e instituições inseridas pela Lei $12.305 / 2010$, onde estes são tratados de forma econômica e eficaz por meio da degradação biológica da matéria orgânica, ao ser reduzida em volume e estabilizar (DE AQUINO et al. 2005). De acordo com Mora et al. (2015), a compostagem é uma técnica usada para obter uma estabilização da matéria orgânica, atribuindo melhores condições para o seu uso. O processo de compostagem consiste em utilizar matérias-primas com uma relação carbono/nitrogênio $(\mathrm{C} / \mathrm{N})$ favorável ao metabolismo dos microrganismos decompositores, facilitando a decomposição dessa matéria prima por meio do controle das condições ambientais (VALENTE et al., 2009; ASSIS et al., 2011).

O IFPE - Campus Recife comporta, nos três turnos, mais de 6 mil alunos em 78 cursos de diversas modalidades: técnico integrado, proeja, subsequente, tecnológico, licenciatura, bacharelado e pósgraduação; além de cerca de 500 servidores. Mesmo sendo um local onde milhares de pessoas transitam, a instituição, em termos de compostagem é considerada como de pequena-média escala, de tal maneira que o material utilizado para a implantação e monitoramento dos sistemas de compostagem não requerem grandes investimentos humanos e financeiros, o que é passível de ser financiado e operacionalizado por alguns indivíduos (PEREIRA et al., 2012).

Segundo a instrução normativa no 10, de 12 de novembro de 2012, que estabelece as regras para elaboração dos planos de gestão de logística sustentável da lei no 7.746/12, todos os campi de ensino do Instituto Federal de Pernambuco (IFPE) devem elaborar, individualmente, um plano de ação em prol da gestão mais sustentável da instituição. Dentro desse contexto, surgiu a implantação de uma Política Ambiental para o IFPE (Resolução 41 de 29 de dezembro de 2017) baseada na NBR ISO 14001/2004 e nas políticas ambientais ora existentes, como por exemplo a Política nacional do Meio 
ambiente de 1981 (LINS et al., 2018). A implantação da política ambiental baseou-se: na natureza, na escala, no porte, e nos impactos ambientais negativos da organização. Dentro das metas dessa política institucional implementada encontra-se o Plano de Gerenciamento de Resíduos Sólidos, sob a ótica da Política Nacional de Resíduos Sólidos - PNRS (BRASIL, 2010).

Desta forma, o objetivo deste trabalho foi realizar um monitoramento em um sistema de compostagem implantado através de um projeto de pesquisa utilizando-se restos de alimentos, podas e aparas de grama e serrapilheira. Para isso, foram definidos como objetivos específicos: a implantação do projeto piloto de compostagem; realização do preenchimento das composteiras com resíduos orgânicos do IFPE-Campus Recife; análise dos atributos de umidade, temperatura e pH e estimativa, como base na regulação nacional, da utilização do produto para uso agrícola.

\section{METODOLOGIA}

No presente estudo em questão, a separação dos resíduos sólidos orgânicos oriundos das lixeiras dos blocos foi realizada em ação conjunta com os pesquisadores do projeto, em parceria com funcionários da equipe de limpeza da instituição. Após a separação na quantidade pré-determinada para os três reservatórios, os resíduos foram homogeneizados aos resíduos de podas e grama provenientes do Campus.

A implantação do projeto piloto foi baseada em três baldes plásticos de $70 \mathrm{~L}$ contendo tampa e que foram perfurados (cerca de $3 \mathrm{~mm}$ para passagem de ar), tornando o modelo de compostagem aeróbia. Para preenchimento dos baldes (composteiras), foram coletados materiais orgânicos oriundos do próprio Instituto, lançadas nas proporções indicadas para cada balde.

A composteira 1 foi preenchida com 50\%, em volume, de serragem e outros $50 \%$ de poda. A composteira 2, em volume, foi preenchida com $33 \%$ de serragem, $33 \%$ de poda e $34 \%$ de fungos. Já a composteira 3 foi preenchida na proporção, em volume, de $70 \%$ de poda e $30 \%$ de serragem. De acordo com Mariagno et al., (2017), o uso da serragem, ao mesmo tempo em que permite absorver umidade da massa de resíduos orgânicos, apresenta características que poderiam evitar a compactação dessa massa, melhorando a aeração da mesma e com isso favorecendo o processo. Ressalta-se que ela é encontrada em abundância nos armazéns e nas madeireiras das proximidades da instituição. As serragens foram obtidas sem custo numa madeireira da região, e ainda representou uma opção de destino adequado para tais resíduos.

Para captação dos dados referentes aos atributos de umidade, temperatura e pH em cada composteira foi utilizado um equipamento eletrônico que permitiu aos pesquisadores rápida verificação dos dados, analisados diariamente. Também foi imprescindível a supervisão da relação carbono:nitrogênio (C:N) dos produtos iniciais, pois trata-se de um indicador de como ocorrerá o processamento e maturação do composto em um produto humificado e se é passível ou não de ser utilizado na agricultura em larga escala e até mesmo em pequenas hortas de jardins residenciais.

Disponibilizou-se um tempo até que a atividade biológica (microrganismos, bactérias e fungos) 
crescesse em quantidade e iniciasse o processo de bioestabilização do composto. Nesse período, no que tange aos reservatórios sob o processo de compostagem, esperava-se inclusão de microrganismos termofílicos e um acentuado aumento de temperatura (40으 $\mathrm{C}$ 60으. $\mathrm{C}$ ). Além disso, a sanitização de organismos patogênicos. Após essa fase, ocorre a maturação do composto ao passar pelo processo de humificação, que torna o material bruto dos resíduos, estando novamente disponível para utilização agrícola o qual dar-se o nome de húmus. "Esse processo deve ser cuidadosamente observado", afirma Herbets et al. (2005, p. 43), onde a aplicação de composto imaturo no solo leva à inviabilidade na utilização do nitrogênio do meio (relação carbono/nitrogênio elevada) e/ou produção excessiva de amônia, que por muitas vezes passa a ser tóxica para as plantas (relação carbono/nitrogênio baixa). De acordo com Valente et al. (2009), o conjunto de fatores condicionantes para o bom desenvolvimento da compostagem deve ser baseado por uma série de parâmetros, porém, cada tipo de material a ser compostado exige uma combinação ótima de umidade, aeração, relação $\mathrm{C} / \mathrm{N}, \mathrm{pH}$, granulometria e altura de leira.

\section{RESULTADOS E DISCUSSÃO}

Observa-se na Figura 1 que as taxas de temperatura das leiras de compostagem ao longo de todo período da pesquisa apresentam grande variação: picos baixos e altos, porém com temperaturas insuficientes para uma adequada digestão onde as temperaturas devem variar de 40 a 60 C (De AQUINO, 2005; PAIVA et al., 2010). De acordo com Hecke et al., (2013), a temperatura média da leira de compostagem variou entre $37,3^{\circ} \mathrm{C}$ no início do processo, alcançando a temperatura de no máximo $67,6^{\circ} \mathrm{C}$ durante a fase termofílica e retornando ao valor inicial de $37^{\circ} \mathrm{C}$ no final do processo. Temperaturas máximas de 60 ${ }^{\circ} \mathrm{C}$ durante esta fase de compostagem também foram observadas por Silva et al. (2009) com utilizando estercos suínos. O aumento da temperatura durante o processo de compostagem é consequência do metabolismo de decomposição microbiana podendo ser considerado um parâmetro de eficiência do processo de degradação, desde que a temperatura seja controlada.

De um modo geral se observou que as taxas de temperatura não foram tão elevadas, podendo sugerir uma degradação mais lenta. A este fato, sugere-se que em decorrência dos furos nos baldes, a passagem constante de ventos, não permitiu o aumento da temperatura.

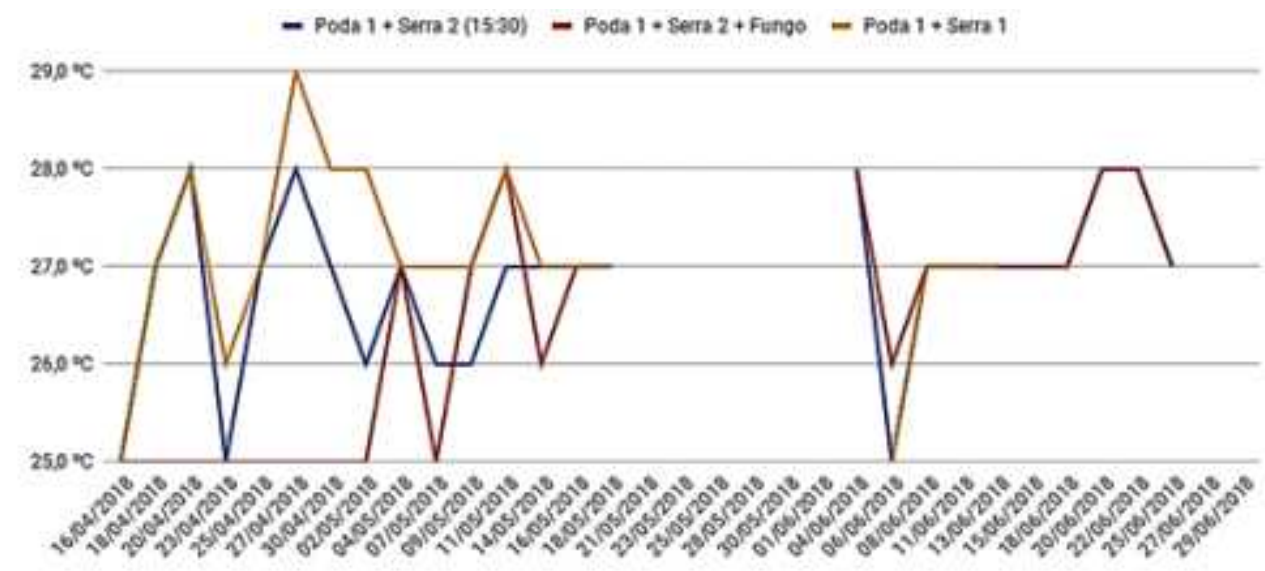

Figura 1 - Gráfico da Temperatura nas Composteiras 1, 2 e 3. 
Os níveis de pH (Figura 2) encontrados na leira de compostagem com adição do fungo manteve-se na faixa de 7 até 8,5 , diferentemente das que não possuíam a adição. Os valores do $\mathrm{pH}$ aumentaram (alcalinidade) com o decorrer do processo atingindo o valor máximo de 8,37 e retornando a pH 7,5 no estágio de maturação do composto. Resultados semelhantes foram encontrados em trabalhos de Kalamdhad \& Kazmi (2009) e Yang et al. (2008). De um modo geral, ao longo do período de análise, os níveis foram consoantes com o que se esperava, finalizando em um valor que se encontra de acordo com a legislação vigente (BRASIL, 2009) e adequado para utilização posterior na agricultura residencial ou institucional. Não houve, assim como na temperatura, alterações substanciais ao longo do tempo.

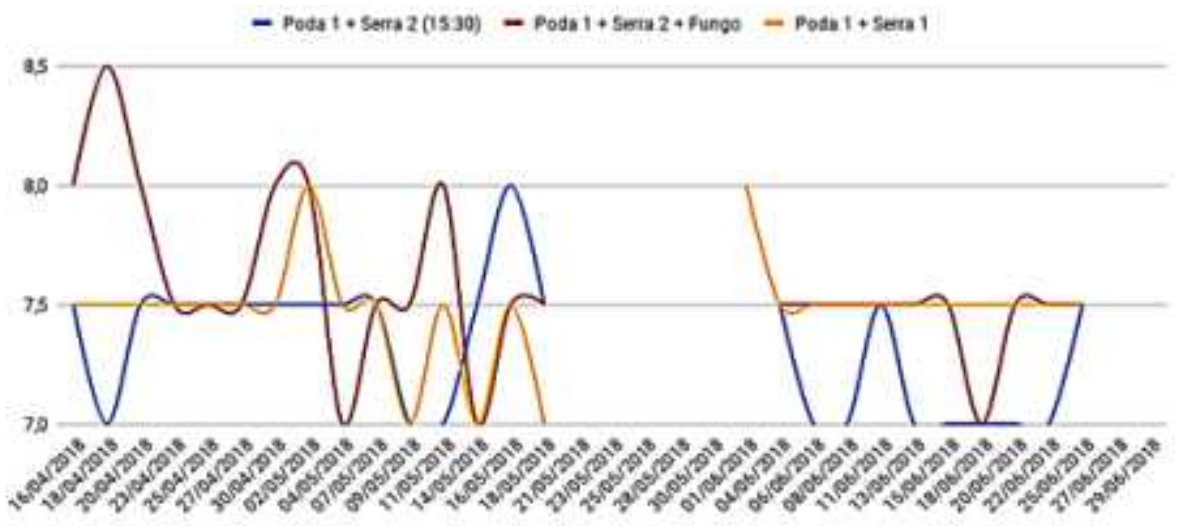

Figura 2 - Gráfico do pH nas Composteiras.

O terceiro atributo analisado, por meio de equipamento eletrônico, foi o de umidade das leiras. Este é um fato correlato à temperatura e que se apresenta de vital importância para análise de como procedeu o processo. Ressalta-se que, como afirmado na metodologia, o local de guarda dos reservatórios era fechado, sendo assim não suscetível às mudanças naturais de sol e chuva.

A umidade das leiras se manteve, na maior parte do tempo, variando nos níveis de DRY, DRY+e NOR (seco, muito seco e normal, respectivamente), como pode ser observado nas Figuras 3 a 5 . De um modo geral, baixa a umidade no interior pode estar associado a uma baixa assimilação dos microrganismos quanto aos nutrientes. Faz-se necessário o acompanhamento diário e o lançamento cuidadoso de água ou outro material orgânico úmido, em quantidade e proporção adequada ao balanço final da umidade desejada. Para Pereira Neto (2007), se a umidade estiver elevada basta adicionar materiais que ajudem a absorver o excesso de umidade, onde ao final do processo estes materiais poderão ser reaproveitados em novas leiras na forma de inóculo.

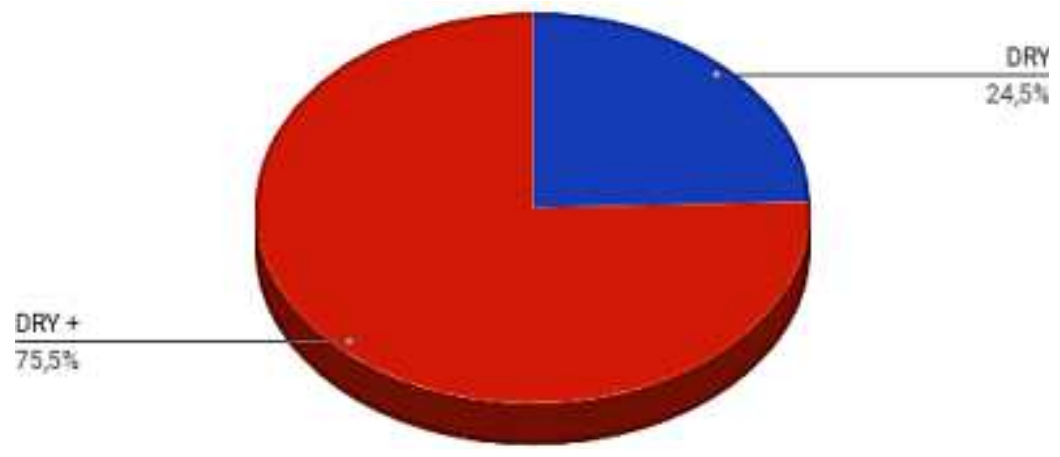

Figura 3 - Gráfico da Umidade na Composteira 1. 


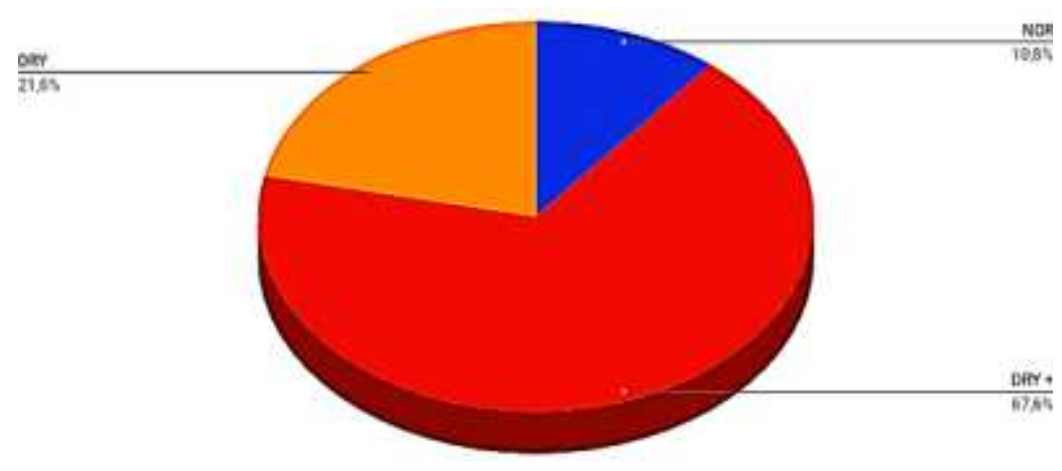

Figura 4 - Gráfico da Umidade na Composteira 2.

Segundo Nunes (2009), a umidade no interior da leira deve ser mantida em torno de $60 \%$ uma vez que os microrganismos apenas conseguem assimilar nutrientes através das suas paredes celulares quando estes se encontram na forma dissolvida. Ainda segundo o autor, a umidade é um parâmetro fundamental não só no processo de compostagem, mas também na qualidade do produto. A umidade, quando em excesso, é capaz de dificultar a circulação do ar dentro do composto. A diminuição excessiva da umidade, ocasiona a redução da atividade microbiológica. Segundo Cooper et al. (2010), os limites ideais para a umidade do composto, nos quais os microrganismos decompositores são capazes de desenvolver suas funções, são acima de $40 \%$ e abaixo de $60 \%$. Segundo Kiehl (1985), o processo de humificação da matéria orgânica é diretamente proporcional a sua capacidade de retenção de água, ou seja, quanto mais humificado o composto mais umidade este pode reter.

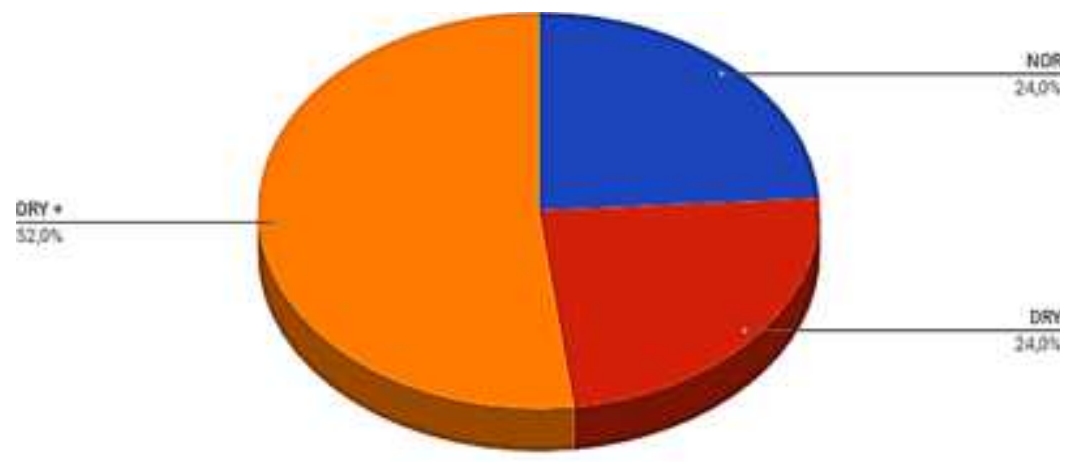

Figura 5 - Gráfico da Umidade na Composteira 3.

A legislação brasileira vigente (BRASIL, 2009), que dá base regulatória acerca das especificações de compostos e biofertilizantes, classifica estes em quatro categorias ( $A, B, C$ e D), tomando como base a origem dos resíduos. Os produtos classificados na categoria " $A$ " apresentam as seguintes características: matéria-prima de origem vegetal ou de processamento da agroindústria, não empregando no processo metais pesados tóxicos, elementos ou compostos orgânicos sintéticos potencialmente tóxicos, resultando em produto de utilização segura na agricultura. Sendo assim, o produto obtido das três leiras (Figura 6), classifica-se, em tese, em um composto de classe A, devido à sua origem, não levando em conta uma análise mais profunda em termos de qualidade, visto que seria um processo para além deste projeto de pesquisa 


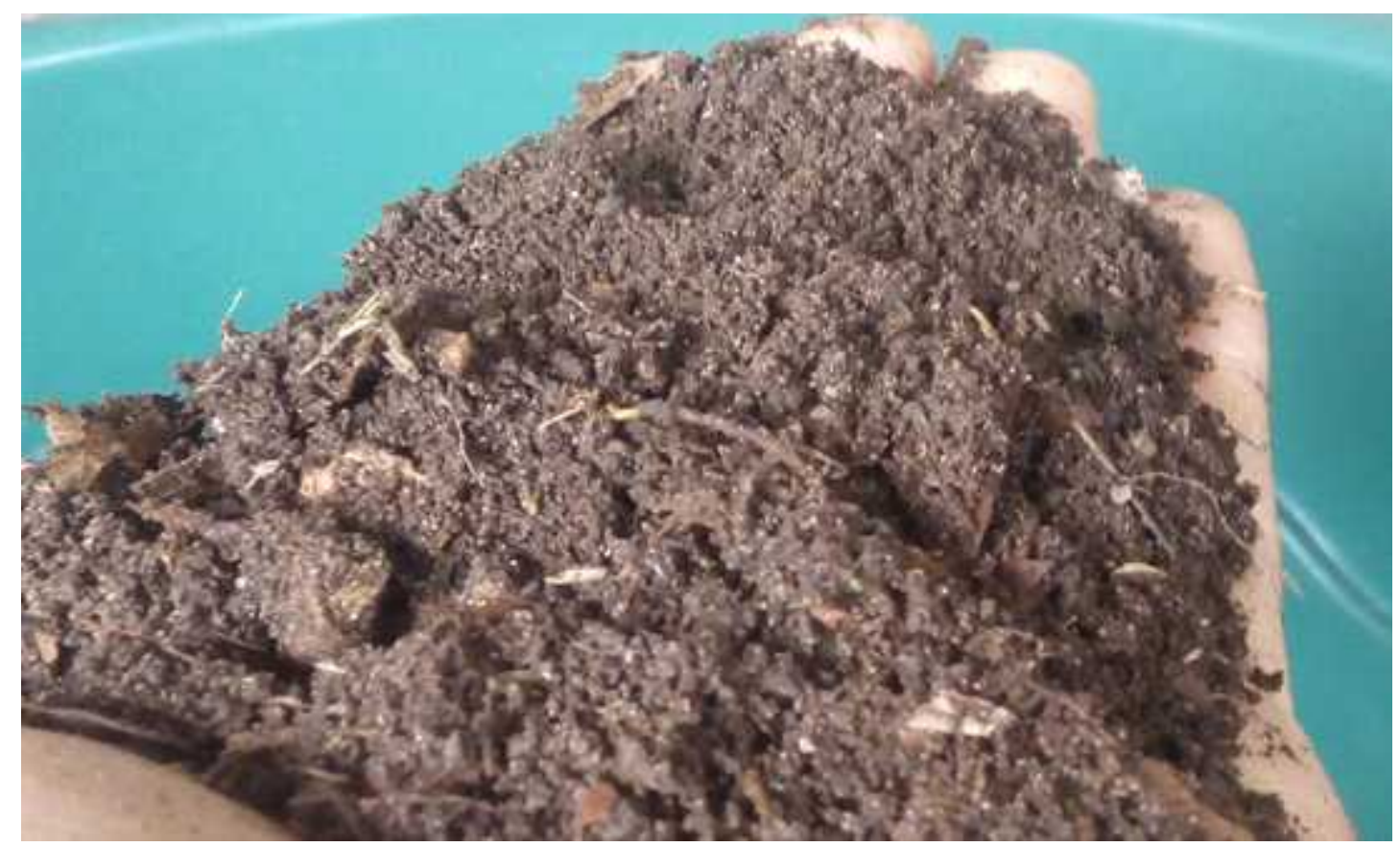

Figura 6 - Produto de uma das leiras de compostagem. Fonte: Os autores.

Em virtude de todos os resíduos que foram utilizados serem provenientes da própria instituição de ensino, observou-se no processo de compostagem uma alternativa simples e que não onera de forma financeira, em contraponto ao método atualmente utilizado por parte das instituições, de dispor, por meio de uma empresa terceirizada, esses resíduos em um aterro sanitário. As aparas de grama e serrapilheira são amplamente disponíveis, em vista de sua retirada semanal, independente das estações do ano - visto que na região Nordeste as amplitudes térmicas não são tão grandes - além de o regime de chuva e sol ser mais uniforme quando comparado às regiões Sul e Sudeste do Brasil (NIMER, 1971), o que propicia o rápido crescimento vegetal na instituição. Observa-se assim, com este projeto de pesquisa, um nascimento de caminho alternativo que busca colocar o IFPE em conformidade com o que preconiza a política ambiental, de tornar-se uma instituição de referência nacional em formação profissional que promove educação, ciência e tecnologia de forma sustentável.

Para que o progresso sustentável tome corpo e sua filosofia seja aplicada de forma prática em níveis globais ou locais, faz-se necessário ter a educação como aliada. Ela está situada na discussão e difusão dos conhecimentos, valores essenciais, princípios e suas técnicas, sejam elas na agricultura ou no momento de consumir. Para isso, com o advento da pedagogia ambiental, que amplia o círculo de aprendizado do indivíduo, com a adição de perspectivas “(...) na forja do pensamento do não pensado, do proceder, do que ainda não é, no horizonte de uma transcendência para a autoridade e diferença, na transição para a sustentabilidade e justiça" (LEFF, 2000). 


\section{CONCLUSÕES}

Os resultados obtidos das leiras de compostagem apresentaram homogeneidade e um produto humificado. As partículas de maior granulometria, provenientes da adição de serrapilheira foram as que demonstraram maior potencial de decomposição e se tornaram poucos visíveis após os três meses de compostagem;

O produto obtido das três leiras, classifica-se, em tese, em um composto de classe $A$, devido à sua origem, não levando em consideração uma análise mais profunda em termos de qualidade;

Priorizando a utilização de materiais naturalmente disponíveis para a construção dos espaços para o reaproveitamento dos resíduos sólidos orgânicos, sugere-se elaboração de leiras a serem confeccionadas com bambus e escoras de madeira para a sustentação vertical destes, de tal maneira que a implantação do projeto fosse realizada de maneira sustentável;

Para a implantação final deste de reaproveitamento de resíduos sólidos orgânicos, torna-se importante a participação dos educadores na tomada do projeto. Este, além de sua atividade funcional, deverá também proporcionar aos discentes e docentes a sua contribuição no meio de forma que o projeto não se resuma às atividades preconizadas de reaproveitamento, mas que também venha a fazer parte dos currículos de ensino compatíveis com a temática de ensino, podendo ser palco de: aulas, workshops, palestras, oficinas etc.

Em virtude de todos os resíduos que foram utilizados serem provenientes da própria instituição de ensino, observou-se no processo de compostagem uma alternativa simples e que não onera de forma financeira, em contraponto ao método atualmente utilizado por parte das instituições, de dispor, por meio de uma empresa terceirizada, esses resíduos em um aterro sanitário. 


\section{REFERÊNCIAS}

ASSIS, A. M. D.; UNEMOTO, L. K.; YAMAMOTO, L. Y.; LONE, A. B.; SOUZA, G. R. B. D.; FARIA, R. T. D.; ROBERTO, S. R.; TAKAHASHI, L. S. A. Cultivo de orquídea em substratos à base de casca de café. Bragantia, Campinas, v. 70, n. 3, p. 544-549, 2011. DOI: http://dx.doi.org/10.1590/S0006-87052011000300009

BRASIL. Ministério da Agricultura, Pecuária e Abastecimento. Instrução Normativa no 25, de 23 de julho de 2009. Aprova as Normas sobre as especificações e as garantias, as tolerâncias, o registro, a embalagem e a rotulagem dos fertilizantes orgânicos simples, mistos, compostos, organominerais e biofertilizantes destinados à agricultura. Diário Oficial [da] República Federativa do Brasil, Brasília, DF, 28 jul. 2009. Seção 1, p.20.

DARWIN, Charles. The formation of vegetable mould, through the action of worms, with observations on their habits. D. Appleton, 1892.

DE AQUINO, A. M.; OLIVEIRA, A. M.; LOUREIRO, D. C.; Integrando compostagem e vermicompostagem na reciclagem de resíduos orgânicos domésticos. Embrapa Agrobiologia-Circular Técnica (INFOTECA-E), 2005.

DOMÍNGUEZ, J.; GÓMEZ-BRANDÓN, M. Ciclos de vida de lãs lombrices de tierra aptas para El vermicompostaje. Acta Zoológica Mexicana, Cidade do México, n. 2, p. 309 -320, 2010.

DORES-SILVA, P. R.; LANDGRAF, M. D.; REZENDE, M. O.; Processo de estabilização de resíduos orgânicos: vermicompostagem versus compostagem. Revista Química Nova, São Paulo, v. 36, n. 5, p. 640-645, 2013.

FOUTO, A. R. F. O papel das universidades rumo ao desenvolvimento sustentável: das relações internacionais às práticas locais. Dissertação. (Mestrado em Gestão e Políticas Ambientais Relações Internacionais do Ambiente), 2002.

GUIDONI, L. L. C. et al. Compostagem domiciliar: implantação e avaliação do processo. Tecnológica, Santa Cruz do Sul, v. 17, n. 1, p. 44-51, 2013.

HECK, K., et al. Temperatura de degradação de resíduos em processo de compostagem e qualidade microbiológica do composto final. Rev. bras. eng. agríc. ambient., Campina Grande, v. 17, n. 1, p. 54-59, Jan. 2013.

HERBETS, R. A.; Compostagem de resíduos sólidos orgânicos: aspectos biotecnológicos. Revista Saúde e Ambiente, v. 6, n. 1, 2005.

Kalamdhad, A. S.; Kazmi, A. A. Rotary drum composting of different organic waste mixtures. Waste Management \& Research, v.27, p.129-137, 2009.

KARPINSK, L. A. et al. Gestão diferenciada de resíduos da construção civil: uma abordagem ambiental. Porto Alegre: Edipucrs, 2009. Disponível em: <http://www.pucrs.br/orgaos/edipucrs/>. Acesso em: out. 2015.

KIEHL, E. J. (1985). Fertilizantes Orgânicos. Editora Agronômica Ceres, 492p.: il. Piracicaba.

LU, W.; TAM, V. W. Y. Construction waste management pol-icies and their effectiveness in Hong Kong: A longitudinal review. Renewable and Sustainable Energy Reviews, 23, 214-223, 2013. doi: 10.1016/j.rser.2013.03.007

MALHEIROS, R., CAMPOS, A. C., OLIVEIRA, D.G., SOUZA, H.A. Utilização de resíduos orgânicos por meio da compostagem como metodologia de ensino de Gestão e Educação Ambiental. Anais V Congresso Brasileiro de Gestão Ambiental. Belo Horizonte: IBEAS, 2014. 
MORA, M. M; DE ASSIS, A. M.; YAMAMOTO, L. Y.; PIVETTA, K. F. L.; DE FARIA, R. T. Resíduos agrícolas e argila expandida no cultivo de orquídea Oncidium baueri Lindl. Semina: Ciências Agrárias, Londrina, v. 36, n. 1, p. 39-46, 2015. DOI: https://dx.doi.org/10.5433/1679-0359.2015v36n1p39.

NIMER, E. Climatologia da Região Sul do Brasil: Introdução à Climatologia Dinâmica - Subsídios à Geografia Regional do Brasil, Periódicos IBGE, p. 3-64, 1971. Disponível: https://biblioteca.ibge.gov.br/ visualizacao/periodicos/115/rbg_1971_v33_n4.pdf. Acesso: 30 de maio de 2020.

NUNES, M. U. C. (2009). Compostagem de Resíduos para Produção de Adubo Orgânico na Pequena Propriedade. EMBRAPA, Circular Técnica 59. Aracaju-SE.

PEREIRA NETO, J. T. (2007). Manual de compostagem: processo de baixo custo. Ed. UFV, 81 p., il, $21 \mathrm{~cm}$. Viçosa MG.18. TAUCHEN, J.; BRANDLI, L. L. A gestão ambiental em instituições de ensino superior: modelo para implantação em campus universitário. Revista Gestão \& Produção, v. 13, n. 3, p. 503-515, 2006.

VALENTE, B. S.; XAVIER, E. G.; MORSELLI, T. B. G. A.; JAHNKE, D. S.; CABRERA, B. S. B. Jr.; CABRERA, B. R.; MORAES, P. O.; LOPES, D. C. N. Fatores que afetam o desenvolvimento da compostagem de resíduos orgânicos, Arch. Zootec. 58 (R): 59-85. 2009.

YANG, Y.; ZHANG, X.; YANG, Z.; XI, B.; LIU, H. Turnover and loss of nitrogenous compounds during composting of food wastes. Frontiers of Environmental Science \& Engineering in China, v.2, p.251-256, 2008. 
EFEITOS DA EXPOSIÇÃO A AGROTÓXICOS INIBIDORES DA ACETILCOLINESTERASE: ALTERAÇÕES FISIOPATOLÓGICAS SISTÊMICAS

Murilo de Jesus Porto

Universidade do Estado da Bahia

Jaciara Pinheiro de Souza

Universidade do Estado da Bahia
Cinara Rejane Viana Oliveira

Universidade do Estado da Bahia

Emile Ivana Fernandes Santos Costa

Universidade do Estado da Bahia

Luciano Vasconcellos Pacheco

Universidade do Estado da Bahia

\section{RESUMO}

Agrotóxicos são substâncias envolvidas na produção, armazenamento ou melhoramento de produtos agrícolas, e sua principal finalidade é alterar a composição da flora ou da fauna, com o intuito de preservá-las da ação de agentes externos que possam prejudicar o seu desenvolvimento. Porém, os grandes impactos ambientais, como contaminação dos solos e das águas, e por consequência a intoxicação da população, têm gerado várias discussões acerca de soluções em termos do uso adequado dos agrotóxicos. Dessarte, uma forma eficaz para monitorar o quadro de intoxicação decorrente desses compostos, é acompanhar a atividade das enzimas acetilcolinesterase (AChE) e butilcolinesterase (BChE). Elas são enzimas responsáveis pelo processo de degradação do neurotransmissor acetilcolina (ACh) presente nas sinapses colinérgicas, sendo que a exposição a agrotóxicos, quando atinge os neurônios, desencadeia inúmeras disfunções fisiológicas, ligada, principalmente, à diminuição da AChE . Assim, ao longo deste capítulo, buscou-se abordar os efeitos da exposição a agrotóxicos inibidores da acetilcolinesterase nos principais sistemas do corpo humano.

\section{Palavras-chave:}

Agrotóxicos; Acetilcolinesterase; Contaminação dos solos.

\begin{abstract}
Pesticides are substances involved in the production, storage or improvement of agricultural products, and their main purpose is to change the composition of the flora or fauna, with the aim of preserving them from the action of external agents that could harm their development. However, the great environmental impacts, such as contamination of soil and water, and consequently the intoxication of the population, have generated several discussions about solutions in terms of the proper use of pesticides. Thus, an effective way to monitor the intoxication picture resulting from these compounds is to monitor the activity of the enzymes acetylcholinesterase (AChE) and butylcholinesterase (BChE). They are enzymes responsible for the
\end{abstract}

degradation process of the neurotransmitter acetylcholine (ACh) present in cholinergic synapses, and exposure to pesticides, when it reaches neurons, triggers numerous physiological dysfunctions, mainly linked to the decrease in AChE. Thus, throughout this chapter, we sought to address the effects of exposure to pesticides that inhibit acetylcholinesterase in the main systems of the human body.

\section{Keywords:}

Pesticides; Acetylcholinesterase; Soil contamination. 


\section{INTRODUÇÃO}

Na natureza, o crescimento populacional, aliado ao avanço tecnológico, ocasionou o aumento na concentração de poluentes ambientais de diferentes classes químicas que têm a capacidade de alterar a homeostase do organismo vivo (CORREIA; FONTOURA, 2015; LANDRIGAN; FULLER, 2015; DIAMANTI-KANDARAKIS et al., 2009; FRYE et al., 2012). Dentre os poluentes ambientais, destacam-se os agrotóxicos como a classe química que provoca maior número de intoxicações (MS/SINITOX/Fiocruz, 2018).

Neste sentido, vale ressaltar que o Brasil está nas primeiras posições do ranking mundial de consumo de agrotóxicos na produção agrícola. Esta realidade é muito preocupante, pois gera grandes impactos ambientais, como contaminação de solos e águas, e por consequência intoxicação da população, em especial dos trabalhadores diretamente ligados à agricultura (CARNEIRO et al., 2015). Porém, o que obscurece esses dados seriam as subnotificações ocorridas no país. Segundo o Ministério da Saúde (MS), na medida em que um evento de intoxicação por agrotóxico é registrado, estima-se que outros 50 eventos ocorridos não foram registrados nos sistemas de informação (DE JESUS; BELTRÃO; DE ASSIS, 2012).

Os problemas de saúde associados à intoxicação pelos agrotóxicos podem ser os mais diversos, desde uma simples cefaleia, náuseas, até mesmo o desencadeamento de doenças respiratórias (como a asma), alterações em hormônios sexuais (androgênios masculinos e estrogênios femininos), distúrbios mentais (como a ansiedade e a depressão), quadro cancerígeno (linfoma não-Hodgkin, tumor cerebral), além de provocar abortos e malformações congênitas fetais (LOPES; ALBUQUERQUE, 2018).

Uma forma eficaz para monitorar os quadros de intoxicação ocupacional pelo uso de agrotóxicos, é acompanhar a atividade das enzimas acetilcolinesterase (AChE) e butilcolinesterase (BChE), já que pesticidas pertencentes aos grupos químicos dos organofosforados e dos carbamatos possuem como mecanismo de ação inibir suas atividades (OLIVEIRA et al., 2001).

A acetilcolinesterase ( $A C h E)$ e butilcolinesterase (BChE) são enzimas responsáveis pelo processo de degradação do neurotransmissor acetilcolina (ACh) presente nas sinapses colinérgicas. A AChE age no processo de comunicação entre os neurônios, tanto a nível de Sistema Nervoso Central (SNC) quanto de Sistema Nervoso Periférico (SNP); enquanto a BChE possuem ligação direta com o SNP (BERNE; LEVY, 2018; HALL; GUYTON, 2017).

A exposição a agrotóxicos, quando atinge os neurônios, desencadeia inúmeras disfunções fisiológicas, ligada, principalmente, a diminuição da atividade enzimática da acetilcolinesterase. Dessarte, este capítulo abordará os efeitos da exposição a agrotóxicos inibidores da acetilcolinesterase nos principais sistemas do corpo humano. 


\section{FISIOLOGIA DAACETILCOLINESTERASE}

A acetilcolinesterase (AChE) é uma enzima encarregada pelo processo de degradação da acetilcolina (Ach), neurotransmissor que se encontra nas fendas sinápticas colinérgicas, responsável pela interligação entre os distintos neurônios do Sistema Nervoso Central (SNC) e do Sistema Nervoso Periférico (SNP) (COLOVIC et al., 2011; BERNE; LEVY, 2018; ARAUJO; SANTOS; GONSALVES, 2016).

O sistema nervoso central é constituído por distintos processos anatômicos e fisiológicos formado por diversos tipos de neurônios, estes por sua vez funcionam à base de impulsos elétricos e químicos. Os impulsos elétricos são denominados de sinapse que é passado de um neurônio para outro até chegar ao alvo e se obter a resposta. Enquanto os impulsos químicos são denominados de neurotransmissores ou substância transmissora no qual promove uma excitação, inibição ou ainda modificação de algo a nível celular (HALL; GUYTON, 2017).

Desta forma, a ação enzimática da AChE se responsabiliza em capturar o neurotransmissor acetilcolina onde apresenta em excesso na fenda sináptica, permitindo o processo de equilíbrio em sua ação. Contudo, a ACh gera estímulos em receptores específicos: nicotínicos e muscarínicos, que por sua vez realizam o seu potencial de ação nas células pós-sináptica e pré-sinápticas (BERNE; LEVY, 2018; HALL; GUYTON, 2017).

A acetilcolina age nas junções musculares esqueléticas induzindo a contração do músculo, e também na sinapse entre o nervo vago e as fibras cardíacas gerando uma resposta inibitória, além disso, controla a atenção, o aprendizado e a memória. Esse neurotransmissor é sintetizado dispondo da acetilcoezima A associada ao grupo colina, no qual é inserido em vesículas citoplasmáticas. Desta forma, ocorrerá à sua liberação na fenda sináptica quando houver um estímulo, fazendo com que ele se ligue aos receptores do neurônio seguinte para fornecer a resposta referente ao estímulo específico (HALL; GUYTON, 2017).

Há vários receptores que recebem a acetilcolina, denominados de receptores colinérgicos. Até o presente momento, a ciência aponta a presença de dois tipos específicos desses receptores: ionotrópicos e metabotrópicos. Os receptores colinérgicos ionotrópicos são ligantes agonista da nicotina, dessa forma, em algumas literaturas, também são denominados de receptores nicotínicos, estando presentes em gânglios autonômicos e junções neuromusculares. Enquanto os metabotrópicos ou receptores muscarínicos (ligantes agonistas da muscarina) estão presentes, principalmente, no coração, no músculo liso e nas glândulas exócrinas (FIELDS et al., 2017).

Os receptores nicotínicos são caracterizados por quatro unidades $\alpha, \beta, \gamma$ e $\delta$. Já os receptores muscarínicos estão interligados ao processo de neuromodulação e ocasionam uma resposta na proteína $\mathrm{G}$, e ainda o mesmo possui cinco tipos de subunidades representado por M1, M2, M3, M4 e M5, havendo a ação em regiões moleculares e funcionais (SANABRIA-CASTRO et al., 2017; BERNE; LEVY, 2018 e ALTENHOFEN et al., 2017). 
Para Oliveira-Silva (2001) e Oliveira-Silva, Alves e Rosa, (2003), a atividade da acetilcolina na corrente sanguínea é proveniente da ação de duas diferentes enzimas, uma contida na membrana dos eritrócitosa $\mathrm{AChE}$ e outra sérica a butirilcolinesterase (BChE). As enzimas colinesterásicas apresentam distintas diferenças na cinética, estrutural e gênese. Vale ressaltar que a acetilcolinesterase é sintetizada durante o processo de hematopoese, enquanto a butirilcolinesterase (BChE) é originada no tecido hepático e exportada consecutivamente para o sangue. Ambas apresentam meias-vidas distintas, AchE com aproximadamente 90 dias e BChE (atua em vários órgãos, essencialmente em tecido hepático, no plasma, tecido pancreático e no intestino delgado) por 7 dias (ANWAR, 1997; OLIVEIRA-SILVIO; ALVES, ROSA, 2003; CÂMARA et al., 2012).

Vale ressaltar que os altos níveis de acetilcolina disponíveis aos receptores provocarão várias reações sistêmicas e, posteriormente, efeitos crônicos. Abaixo segue um quadro apresentando características sistêmicas do envenenamento por inseticida organofosforado (OP) (VALE; LOTTI, 2015).

Quadro 1 - Características sistêmicas do envenenamento por inseticida organofosforado.

\begin{tabular}{|l|l|}
\hline \multicolumn{1}{|c|}{ AÇÃO/LOCAL } & \multicolumn{1}{|c|}{ EFEITOS CRÔNICOS } \\
\hline Sistema nervoso central & $\begin{array}{l}\text { Tosse, dispnéia, broncorréia, broncoconstrição, } \\
\text { edema pulmonar e cianose. }\end{array}$ \\
\hline $\begin{array}{l}\text { Muscarínico (receptores M1, } \\
\text { M2, M3, M4, M5) }\end{array}$ & $\begin{array}{l}\text { Rinite, rinorreia, aumento da salivação, } \\
\text { lacrimação, sudorese incontinência urinária e } \\
\text { fecal, náusea, vômito, cólicas abdominais, } \\
\text { diarreia, tenesmo, bradicardia, hipotensão,visão } \\
\text { turva e miose. }\end{array}$ \\
\hline $\begin{array}{l}\text { Nicotínico } \\
\text { (Subunidades } \alpha, \beta, \gamma \text { e } \delta)\end{array}$ & $\begin{array}{l}\text { Fasciculação muscular, incluindo fraqueza } \\
\text { muscular do diafragma, taquicardia, palidez, } \\
\text { midríase e hiperglicemia. }\end{array}$ \\
\hline
\end{tabular}

Fonte: VALE; LOTTI, (2015, p.151) - adaptado pelos autores, 2021.

Dentre os principais pesticidas associados à intoxicação no ser humano, têm-se os organofosforadose os carbamatos, ambos inibidores diretos das enzimas, pela ligação direta do princípio ativo na AChE, impedindo a hidrólise da ACh. A inibição das verdadeiras colinesterases pelos pesticidas anteriormente citados desencadeiam a ação tóxica nos seres humanos (SILVA, 2015; KATZUNG, 2014; BRUNTON; GOODMAN; GILMAN, 2012).

Os organofosforados ligam-se às AChE de maneira irreversível, formando um complexo de grande estabilidade química, os carbamatos por sua vez inibem a AChE de maneira reversível (BRUNTON; GOODMAN; GILMAN, 2012).

A inativação da enzima converge na elevação dos níveis de acetilcolina culminando na síndrome colinérgica aguda com consequente hiperestimulação dos receptores nicotínicos e muscarínicos. Assim, uma intoxicação por inibidores da acetilcolinesterase caracteriza-se por sintomas nicotínicos, muscarínicos e do sistema nervoso central (SILVA, 2015). 


\section{EFEITOS DOS AGROTÓXICOS NOS RINS DECORRENTES DE ALTERAÇÕES NA ACETILCOLINESTERASE}

Considerando todas as consequências que os pesticidas podem causar no organismo humano, existem poucos estudos que abordam sobre os seus efeitos nos rins (FUENTE-DELGADO et al., 2018).

Entre as diferentes classes de agrotóxicos, os inibidores irreversíveis da acetilcolinesterase são os que mais requerem atenção, pois quando são utilizados de forma sistêmica e exagerada podem interferir na transmissão do sinal neuromuscular sendo que, essas alterações podem ramificar para todo o organismo humano (GEORGIADIS et al., 2018).

Os organofosforados entre os diferentes tipos de pesticidas são os mais abordados em literatura por causarem danos renais. Os organofosforados foram criados em 1850 e desde então são utilizados em vários campos da ciência, sendo que, devido ao seu uso de forma indiscriminada são relatadas várias consequências nos seres humanos (GEORGIADIS et al., 2018).

Apesar da nefrotoxicidade ainda não ser reconhecida como uma consequência clínica de envenenamento por anticolinesterase, estudos realizados já correlacionam insuficiência renal aguda, necrose e rabdomiólise após alta dose de exposição a organofosforados (PEIRIS-JOHN et al., 2006; LANEROLLE et al., 2000; BETROSIAN et al., 1995).

Os mecanismos para o surgimento de lesão renal após exposição aos organofosforados ainda não estão bem estabelecidos, algumas hipóteses tentam explicar através de diferentes mecanismos essa possibilidade (GEORGIADIS et al., 2018). Entre os mecanismos sugeridos, acredita-se que os níveis de pseudocolinesterase no túbulo contorcido distal renal podem acarretar em estresse oxidativo (MAMOULAKIS et al., 2017; TSAROUHAS et al., 2018). Outra hipótese sugere que a elevada concentração de organofosforados intratubular pode ocasionar rabdomiólise e hipovolemia devido à desidratação (AGOSTINI; BIANCHIN, 2003). Já outra hipótese explica que a circulação renal e a excreção de eletrólitos são prejudicadas quando se tem alta concentração de organofosforados, uma vez que foram sugeridas que a circulação renal e excreção são parcialmente controladas pelo mecanismo colinérgico (WEDIN, 1992).

O diagnóstico rápido e correto da lesão renal aguda (LRA) é de extrema importância para a vida do paciente, uma vez que acarreta em alta morbidade em especial nos pacientes críticos. A LRA pode ser diagnosticado com facilidade de forma errônea, pois principalmente em casos de manifestações maciças de toxicidade os outros órgãos podem ofuscar a LRA já que a mesma é silenciosa, porém pode ser mortal (GEORGIADIS et al., 2018).

Estudos que abordam os danos histopatológicos causados pelos organosfosforados são mais esclarecedores que os estudos sobre a fisiopatologia. Entre as alterações ocasionadas em ratos tratados com organofosforados, é possível observar: glomérulos encolhidos, espaço

urinário alargado, infiltração de células inflamatórias do tecido intersticial, núcleos picnóticos, vacuolização citoplasmática dos túbulos renais, material hialino no lúmen de alguns túbulos, dilatação e congestão 
de sangue vasos, degeneração do citoplasma dos túbulos renais, deposição de moldes epiteliais no lúmen de alguns túbulos e ruptura da cápsula de Bowman (ZIDAN, 2015).

Atualmente, faz-se associações com os possíveis efeitos que podem ser causados pela exposição a diferentes tipos de organofosforados. Como por exemplo: o clorpirifos é associado por produzir vários efeitos, além da nefropatia colinérgica e retardada (GEORGIADIS et al., 2018). Já o tetraclorvinfos e o paration são correlacionados como "possivelmente carcinogênicos", enquanto o malathion e o diazinon como "provavelmente carcinogênicos" para humanos (GUYTON et al., 2015). Contudo, por mais que existam essas associações sobre os possíveis efeitos causados por diferentes organofosforados, são necessários estudos que realmente estabeleçam quais são os efeitos de cada pesticida, uma vez que uma associação errônea pode induzir a diagnósticos errados.

Alguns estudos contradizem os efeitos representativos associados a diferentes tipos de organofosforados. A Análise realizada por Tsitsimpikou e colaboradores em 2013 na Nova Zelândia, realizado com dez coelhas brancas, demonstrou que diazinon e o propoxur induziram inflamação focal e fibrose no fígado e rins, ambos ocasionaram um dano oxidativo ao DNA estatisticamente significativo no fígado e nos rins e um aumento subsequente na atividade da telomerase nesses tecidos, possivelmente como um mecanismo de neutralização.

Outro estudo realizado por Fuente-Delgado e colaboradores (2018), examinou a influência de baixas doses de metil paration (MP) na estrutura e função do rim de ratos Wistar machos. Após a administração de $0,56 \mathrm{mgkg}^{-1}$ por via oral a cada três dias por 8 semanas, verificou-se a que houve danos estruturais e funcionais aos túbulos proximais dos rins dos animais estudados, bem como regulou negativamente a expressão de mRNA de TNF- $\alpha$ e BAX. Com a análise de densitometria foi possível observar uma diminuição significativa nos níveis de expressão de TNF- $\alpha$ e BAX mRNA na 2ำ 4ㅇs semanas após o tratamento com MP. Portanto, como conclusão, esse estudo aponta que baixas doses de MP produziram danos estruturais e funcionais aos túbulos proximais do rim de rato macho.

Em suma, apesar de todos os danos que os pesticidas podem causar à saúde humana, ainda existe pouco conhecimento sobre essa questão. Sendo assim, novos estudos devem ser realizados para expansão do conhecimento, pois somente através de pesquisas é possível garantir informações verídicas sobre os pesticidas, além de entender as consequências prejudiciais e propor formas adequadas de proteção.

\section{EFEITOS NO TRATO GASTROINTESTINAL DA INTOXICAÇÃO POR INIBIDORES DA ACETILCOLINESTERASE}

O sistema nervoso entérico (SNE), por vezes, considerado como uma terceira subdivisão do sistema nervoso autonômico (SNA), compreende um conjunto grande e organizado de neurônios localizados na parede do trato gastrointestinal (TGI), desde o esôfago até o colo distal. O SNE engloba tanto o plexo mioentérico quanto o plexo de Meissner (submucoso) (KATZUNG, 2014; BRUNTON; GOODMAN; GILMAN, 2012). 
A ACh é um dos neurotransmissores envolvidos nas sinalizações do SNA e atua como neurotransmissor primário do músculo liso e células secretoras, principalmente, nos receptores muscarínicos M3 do TGI, e configura-se como o principal neurotransmissor ganglionar do SNE. Após a liberação da ACh na fenda sináptica, ocorre a ligação a um receptor de acetilcolina com consequente ativação do mesmo. Entretanto, as fendas sinápticas são ricas em uma enzima chamada acetilcolinesterase (AChE) que promove uma rápida de gradação da Ach liberada e propicia que o neurônio colinérgico retorne ao estágio de repouso (KATZUNG, 2014; BRUNTON; GOODMAN; GILMAN,2012).

Existem diferentes cenários de intoxicação com diferentes respostas fisiológicas de maneira que o início e a gravidade dos efeitos dependem de vários fatores, incluindo agente, via de administração, formulação, quantidade e duração da exposição (KING; AARON, 2015). Associado a isso, tanto os organofosforados quanto os carbamatos possuem características lipofílicas e consequentemente apresentam facilidade em ultrapassar as membranas do trato gastrointestinal (KLEIN et al., 2018).

Referente à exposição, na intoxicação aguda, a absorção pode ser tanto cutânea, como respiratória ou digestiva. São descritos alguns sintomas no trato gastrointestinal, desde as formas mais leves de intoxicação até as formas mais graves associados à hiperestimulação dos receptores muscarínicos, tais como cólicas, vômito, diarreia, tenesmo e incontinência fecal são recorrentes. As glândulas salivares também são afetadas evidenciando quadro de sialorréia (PARANÁ, 2018).

A diarreia, relativamente comum nos quadros de intoxicação aguda, pode culminar em gastroenterite aguda, o que pode ser utilizado como um dos principais diagnósticos diferenciais, especialmente quando se trata de intoxicação em vários indivíduos e quando a anamnese não deixa a exposição totalmente clara (SILVA, 2015). Em relação às intoxicações crônicas, as quais podem resultar de uma exposição a níveis baixos de pesticidas por maiores períodos de tempo, podendo ser causada por resíduos nos alimentos e no ambiente, os sintomas no TGI tornam-se menos específicos por serem evidenciados apenas nas exacerbações, sendo eles também: náuseas, vômitos, diarreia e dores abdominais. A diminuição dos níveis de atividade da colinesterase, menor que 50\%, ocorre concomitantemente com o início da sintomatologia aguda, podendo também ser observada em uma intoxicação crônica, mesmo sem sintomas agudos manifestos (KING; AARON, 2015). O estudo de Klein et al., (2018), dispondo de 27 trabalhadores rurais, com tempo médio de exposição aos inibidores da AChE de 10,7 anos e apresentando redução significativa da colinesterase plasmática sem relatar sintomas de intoxicação no TGI, ilustra bem a dificuldade de monitorizar os sintomas no TGI em pacientes sob exposição crônica.

$\mathrm{Na}$ intoxicação subaguda ocorre à exposição prolongada a uma dose elevada, como o que acontece nos fabricantes e manuseadores dos pesticidas e as características sintomatológicas são incertas apresentando variação individual, de modo que podem se manifestar após horas ou dias da exposição (BARBOSA et al., 2020; PARANÁ, 2018; SILVA, 2015).

Como citado anteriormente, um indicador valioso da relação entre a exposição aos pesticidas é a determinação da colinesterase eritrocitária ou a plasmática, até mesmo na ausência de sintomas, devendo ser empregada para trabalhadores rurais que lidam com pesticidas (KLEIN et al., 2018). 
De maneira que, a colinesterase eritrocitária apresenta, na maioria dos casos, correlação com a gravidade do quadro clínico (SILVA, 2015). Além da dosagem das colinesterases (AChE e BChE), a monitorização de indivíduos intoxicados por organofosforados deve englobar exames laboratoriais que envolvem a dosagem de enzimas hepáticas Aspartato Transferase (AST), Alanina Transferase (ALT), Fosfatase Alcalina (FAL) e Gama Glutamil Transferase (GT); a dosagem com essa determinação pode-se estabelecer o tipo de intoxicação aguda ou crônica, de acordo com a variação da meia vida de cada enzima (MARQUES; CAIXETA, 2016).

Em um estudo, dispondo de modelo murino, foi observado que ocorreu elevação estatisticamente significativa das transaminases hepáticas (AST e ALT) após exposição por 21 dias às doses de 50 e 100 $\mathrm{mg} / \mathrm{kg}$, do organofosforado, Malation $500 \mathrm{EC}^{\circledR}$ (MLT) (TORIANI et al., 2017). Associado a isso, outro estudo aponta que após tratamento de ratos machos e fêmeas com MLT por 7, 14 e 21 dias, com aplicação diária de dose de $250 \mathrm{mg} \mathrm{kg}^{-1}$, ocorreu dano hepático associado com esteatose, necrose e infiltração leucocitária (INOUYEA et al., 2014).

O trabalho de Tomaz, Mariotto e Ferrante (2017) relata a importância da também determinação das enzimas pancreáticas amilase e lipase, em animais domésticos intoxicados com aldicarb, um carbamato, em razão do risco de pancreatite aguda que foi relatada previamente em humanos intoxicados, que pode ocorrer devido aumento da pressão intraductal e da secreção exócrina pancreática, causados pela estimulação colinérgica.

O estudo de Sanchez-Hernandez; Ríos e Attademo (2018) dispondo de modelo animal Lumbricus terrestris (minhoca), observou que a utilização organofosforado clorpirifós ( $5 \mathrm{mg} \mathrm{kg}^{-1}$ de solo úmido) além de ter sido capaz de inibir atividade tanto da acetilcolinesterase quanto da butirilcolinesterase nos tecidos gastrointestinais deprimiu significativamente a atividade das enzimas carboxilesterase e lipase no tecido gastrointestinal dos animais estudados (42-67\% de inibição da carboxilesterase e 15\% de inibição da lipase).

Relatos prévios em humanos citam que a intoxicação por inibidores da acetilcolinesterase pode levar à hiperglicemia transitória até 05 vezes superior aos valores normais, sendo contra-indicado o uso de Insulina, além de pancreatite com elevação da amilase sanguínea em valores três ou mais vezes superiores aos normais. Portanto, afetando diretamente um órgão importante tanto para o funcionamento do TGI quanto para o metabolismo do indivíduo (KING; AARON, 2015; CALDAS, 2000).

A descontaminação gastrointestinal após a ingestão de organofosforados ou carbamato possui benefício desconhecido. Como citado anteriormente, o vômito é comum e a remoção posterior por aspiração gástrica ou lavagem provavelmente não traz benefícios adicionais. Associado a isso, a descontaminação mecânica nas intoxicações por organofosforados pode causar aspiração pulmonar e pneumonite. Ademais, a utilização de carvão ativado pode ser empregada para limitar a absorção do agente (KING; AARON, 2015).

Por fim, pensando em todos os sistemas fisiológicos afetados pela intoxicação, a estratégia terapêutica padrão para exposição aguda aos organofosforados inclui o uso de atropina (anticolinérgico), oximas (reativadores de AChE), benzodiazepínicos (anticonvulsivantes) e o monitoramento contínuo do paciente ao longo do tratamento (CAVALCANTI et al., 2016). 


\section{EFEITOS NO SISTEMA ENDÓCRINO DA INTOXICAÇÃO POR INIBIDORES DA ACETILCOLINESTERASE}

O organismo humano é composto por vários sistemas que integram entre si para manutenção da vida. Mantidos em constante homeostase, permitem a funcionalidade normal do corpo humano. Dentre os vários sistemas, o nervoso e o endócrino destacam- se pela capacidade de integrarem-se, por meio da associação entre neurônios, neurotransmissores, receptores e hormônios, para coordenar e controlar a atividade celular de todo organismo. Sendo que essa condição de equilíbrio funcional das células pode ser desestabilizada na medida em que agentes físicos, químicos e biológicos são incorporados ao nosso organismo (MOLINA, 2014; GUYTON, 2008; RHOADES et al., 2005; SHERWOOD, 2011).

A exposição a agrotóxicos, quando atinge os neurônios, desencadeia inúmeras disfunções fisiológicas, ligada, principalmente, a diminuição da atividade enzimática da acetilcolinesterase. Como mencionado ao longo desse capítulo, a exposição aos agrotóxicos interfere na catalisação do excesso da acetilcolina nas fendas sinápticas nervosas, proporcionando maior disponibilização desse neurotransmissor aos receptores das células pós-sináptica que, através do processo de endocitose, terá uma estimulação ou inibição da função que desempenha (NERILO et al., 2014).

Vários são os efeitos crônicos provocados pelos diversos tipos de agrotóxicos no organismo humano (VALE; LOTTI, 2015). Porém o que chama a atenção é como a estimulação e/ou inibição dos receptores (nicotínicos e muscarínicos) desencadeiam disfunções no sistema endrócrino. Partindo do pressuposto que os receptores muscarínicos são os responsáveis pelo funcionamento das glândulas endócrinas, o excesso de acetilcolina no sítio desses receptores será determinante para promover a desregulação endócrina.

Neste sentido, ressalta-se que alguns agrotóxicos inibem a AChE que encontram-se nas sinapses nervosas entre um neurônio pré-sináptico e pós- sináptico, consequentemente o acúmulo de acetilcolina ocasionará estímulos excitatórios e inibitórios dos receptores colinérgicos, desencadeando desregulação nas células (MUDAWAL et al., 2015; CROSBY et al., 2015; JING LIU; CAREY POPE, 2015). O fato de ocorrer desregulação em células específicas como as que sintetizam hormônios, geralmente, faz com que qualquer órgão, desde que possuam receptores hormonais, possa ser afetado (DIAMANTI- KANDARAKIS et al., 2009; FRYE et al., 2012).

Os hormônios são produzidos por glândulas que são estruturas formadas por tecido glandular especializado em produção e secreção de substâncias. A maior parte dos hormônios é produzida por glândulas denominadas de endócrinas (liberam substâncias na corrente sanguínea) (MOLINA, 2014). Os agrotóxicos, quando atingem receptores das glândulas endócrinas, perturbam a homeostase dos hormônios, e são denominados de disruptores ou desreguladores endócrinos (DE) (BIRKETT; LESTER, 2003; EPA, 1997; WARNER et al., 2019).

Segundo a Environmental Protection Agency (EPA) (1997) os DE são considerados composto ou substâncias que interferem em vários processos do tecido glandular (produção, secreção, transporte, ligação ou eliminação dos hormônios), a partir disso, alteram inúmeras funções do organismo. 
Vale ressaltar que eles podem mimetizar hormônios, desempenhar a função de agonista e antagonista nos sítios de receptores hormonais, aumentar a síntese e secreção de hormônios, promover a estimulação da formação de mais receptores hormonais e alterar a estrutura dos hormônios (BIRKETT; LESTER, 2003; WARNER et al., 2019).

Vários estudos sugerem diversas alterações desencadeadas pelos agrotóxicos no sistema endócrino, principalmente a nível reprodutivo. Pesquisa realizada por Aguilar-Garduno e seus colaboradores (2012) em uma floricultura, comparou amostras de sangue dos trabalhadores expostos a agrotóxicos (organosfosforados) em dois períodos distintos: estação chuvosa (maior uso de pesticidas) e estação seca (menor uso de pesticidas). Um total de 136 trabalhadores forneceram amostras biológicas durante a estação chuvosa e o mesmo processo e repetiu com 84 deles na estação seca. Todos os níveis séricos de hormônios sexuais estudados (FSH; prolactina; estradiol; testosterona) apresentaram diferenças significativas entre os dois períodos agrícolas, com exceção do LH. Os níveis de FSH, prolactina e estradiol foram maiores enquanto os de testosterona foram menores no período chuvoso em comparação com a estação seca. Em conclusão, os resultados deste estudo sugerem que os agrotóxicos podem ter um impacto na função endócrina devido ao seu potencial de modificar o perfil hormonal masculino.

Segundo Boas e seus colaboradores (2006), apesar da grande parcela de evidências de estudos voltar-se para o sistema reprodutivo, também há suspeita de que a exposição a agrotóxico prejudique a homeostase da tireoide. Em estudo realizado por Piccoli (2015), é sugerido que a exposição crônica de trabalhadores rurais a agrotóxicos pode interferir na função do sistema tireoideo.

Dessa maneira, as alterações desencadeadas pelos agrotóxicos ao sistema nervoso e ao endócrino são inúmeras e inter-relacionadas. E o fato de compreender os diversos mecanismos fisiopatológicos existentes entre neurônios, neurotransmissores, hormônios e receptores, promoverá maiores descobertas dos inúmeros efeitos dos agrotóxicos no organismo humano. 


\section{REFERÊNCIAS}

AGOSTINI, M; BIANCHIN, A. Acute renal failure from organophospate poisoning: a case of success with haemofiltration. Human \& experimental toxicology, v. 22, n. 3, 2003.

AGUILAR-GARDUÑO, C.; LACASAÑA, M.; BLANCO-MUÑOZ, J.; RODRÍGUEZ-BARRANCO, M.; HERNÁNDEZ, A. F.; BASSOL, S.; GONZÁLEZ-ALZAGA, B.; CEBRIÁN.; M. E. Changes in male hormone profile after occupational organophosphate exposure. A longitudinal study. Toxicology. 2013 May 10;307:55-65. Epub 2012 Nov 12.

ALTENHOFEN. S.; NABINGER, D. D.; WIPRICH, M. T.; BRANDÃO PEREIRA, T. C.; BOGO, M. R.; BONAN, C. D. Tebuconazole Alters Morphological, Behavioral and Neurochemical Parametersin Larvae and Adult Zebrafish (DanioRerio). Chemosphere, 2017; 180:483-490.

ANWAR, W. A. Biomarkers of human exposure to pesticides. Environmental Health Perspectives, 105(4): 801-806, 1997.

ARAUJO, C. R. M.; SANTOS, V. L. A.; GONSALVES, A. A. Acetilcolinesterase-AChE:Uma Enzima de Interesse Farmacológico. Rev.VirtualQuim.,2016,8(6),1818-1834.

BARBOSA, R. S.; SOUZA, J. P.; ALMEIDA, D. J.; SANTOS, J. B.; PAIVA, W. S.; PORTO, M. J. As possíveis consequências da exposição a agrotóxicos: uma revisão sistemática The. Research, Society and Development, v. 9, n. 11, p. 1689-1699, 2020.

BERNE,R.M.; LEVY, M. N. Fisiologia. Editores: Bruce M. Koeppen, Bruce A. Stanton.; tradução Soraya Imon de Oliveira ...[et al.]. - 7. ed. - Rio de Janeiro: Elsevier, 2018.

BETROSIAN, A.; BALLA, M.; KAFIRI, G.; KOFINAS, G.; MAKRI, R.; KAKOURI, A. Multiple systems organ failure from organophosphate poisoning. Journal of Toxicology: Clinical Toxicology, v. 33, n. 3, p. 257-260, 1995.

BOAS, M; FELDT-RASMUSSEN, U;. SKAKKEBAEK, N. E.; MAIN, K. M. Environmental chemicals and thyroid function. Eur J Endocrinol. 2006 May;154(5):599-611.

BRASIL. Leino 6.455 de 25 de Janeirode 1993. Dispõe sobre o controle da produção, da comercialização, do uso, do consumo, do transporte e armazenamento de agrotóxicos, seus componentes e afins no território do Estado da Bahia e dá outras providências. Governo do Estado da Bahia. 1993.

BRASIL. Leino 7802, de 11 de julho de 1989. Dispõe sobre a pesquisa, a experimentação, a produção, a embalagem e rotulagem, o transporte, o armazenamento, a comercialização, a propaganda comercial, a utilização, a importação, a exportação, o destino final dos resíduos e embalagens, o registro, a classificação, o controle, a inspeção e a fiscalização de agrotóxicos, seus componentes e afins, e dá outras providências. Diário Oficial da União. 1989.

BRUNTON, L. L; GOODMAN.; GILMAN: As Bases Farmacológicas da Terapêutica. 12aㅡ ed. Rio de Janeiro: McGrawHill, p. 127-214, 2012.

BERTRAM G.; KATZUNG, S. B.; MASTERS, A. J.; TREVOR. farmacologia básica \& clínica - 12a ED. 2014.

BOLETIM EPIDEMIOLÓGICO. Casos notificados de intoxicações exógenas relacionados ao glifosato no Brasil, no período de 2007 a 2016. Secretaria de Vigilância em Saúde | Ministério da Saúde Volume 49, Nov. 
2018. Disponivel em: <http://portalarquivos2.saude.gov.br/images/pdf/2018/dezembro/04/BE-2018-31Glifosato.pdf>. Acesso em 10 agos. 2019.

BRUNTON, L. L. GOODMAN \& GILMAN: As Bases Farmacológicas da Terapêutica. 12ª ed. Rio de Janeiro: McGrawHill, p. 127-214, 2012.

CÂMARA,S.A.V.; SILVA,I.S.; PONTES, E. R. J. C.; BARBOSA, A. M. J. Exposição a agrotóxicos: determinação dos valores de referência para colinesterase plasmática e eritrocitária. Brasília Med, v.2, n.49, p.163-169, 2012.

CALDAS L. Q. A. Intoxicações exógenas agudas por carbamatos, organofosforados, compostos bipiridílicos e piretróides. Centro de controle de intoxicações Hospital Universitário Antônio Pedro. Universidade Federal Fluminense. 2000.

CARNEIRO, F. F., RIGOTTO, R. M., AUGUSTO, L. G. da S., Friedrich, K., Búrigo, A. C. Dossiê ABRASCO: uma lerta sobre os impactos dos agrotóxicos na saúde. Rio de Janeiro, EPSJV; São Paulo, Expressão Popular, 624 p.,2015.

COLOVIC, M.; KRSTIC, D.; USCUMLIC, G.; VASIC, V. Single and simultaneous exposure of acetylcholinesterase to diazinon, chlorpyrifos and their photodegradation products. Pesticide Biochemistry and Physiology, 100, 2011.

CORREIA, C. C.; FONTOURA, M. A influência da exposição ambiental a disruptores endócrinos no crescimento e desenvolvimento de crianças e adolescentes. Revista Portuguesa de Endocrinologia, Diabetes e Metabolismo, $\mathrm{v}$. 10, n. 2, p. 1-7, 2015.

CAVALCANTI, L. P. A. N. et al. Organophosphorous poisoning: Treatment and analytical methodologies applied in evaluation of reactivation and inhibition of acetylcholinesterase. Revista Virtual de Quimica, v. 8, n. 3, p. 739-766, 2016.

DIAMANTI-KANDARAKIS, E.; BOURGUIGNON, J. P.; GIUDICE, L. C.; HAUSER, R.; PRINS, G. S.; SOTO, A. M.; ZOELLER, R. T.; GORE, A. T. Endocrine-disrupting chemicals: An Endocrine Society scientific statement. Endocrine Reviews, v. 30, n. 4, p. 293-342, 2009.

DE JESUS, H. S.; BELTRÃO, H. B. M.; DE ASSIS, B. M. Avaliação do sistema de vigilância das intoxicações exógenas no âmbito da saúde do trabalhador no Brasil entre 2007 e 2009. Cad. Saúde Colet., n. 4, v. 20, p. 515-24, 2012.

FUENTES-DELGADO, Victor Hugo et al. Danos renais induzidos pelo pesticida metil paration em ratos Wistar machos. Jornal de Toxicologia e Saúde Ambiental, Parte A , v. 81, n. 6, pág. 130-141, 2018.

FRYE, C.; BO, E.; CALAMANDREI, G.; CALZÀ, L.; DESSì-FULGHERI, F.; FERNÁNDEZ, M.; FUSANI, L.; KAH, O.; KAJTA, M.; LE PAGE, Y.; PATISAUL, H. B.; VENEROSI, A.; WOJTOWICZ, A. K.; PANZICA, G. C. Endocrine disrupters: A review of some sources, effects, and mechanisms of actions on behaviour and neuroendocrine systems. Journal of Neuroendocrinology, v. 24, n. 1, p. 144-159, 2012.

FIELDS, R. D.; DUTTA, D. J.; BELGRAD, J.; ROBNETT, M. Cholinergic Signaling in Myelination. Review Article. Volume 65, No. 5; 65:687-698, 2017.

GEORGIADIS, G. et al. Problemas de nefrotoxicidade dos organofosforados. Toxicologia, v. 406, p. 129$136,2018$.

GUYTON, K. Z.; LOOMIS, D.; GROSSE, Y.;EL GHISSASSI, F.; BENBRAHIM-TALLAA, F.; GUHA, N.; SCOCCIANTI, C.; MATTOCK , H.; STRAIF, K. Carcinogenicidade de tetraclorvinfos, paration, malathion, diazinon e glifosato.Lancet Oncol. Lancet Oncol. 2015 May;16(5):490-1.

GUYTON, A.C. Fisiologia humana. 6a ed. Rio de Janeiro: Editora Guanabara Koogan, 2008. 
HALL, J. E.; GUYTON, A. C. Tratado de fisiologia médica. 13.ed. Rio de Janeiro: Elsevier, 2017.

INOUYEA, L. A. S.; FERNANDEZA, L. M.; CARNEIROA, L. F. S.; GERMANOA, J. J.; CRISCI, A. R. Avaliação morfológica do fígado e do pulmão pós intoxicação por organofosforado em ratos wistar. Uniciências, v.18, n.2, p.103-109, 2014.

KING, A. M.; AARON, C. K. Organophosphate and Carbamate Poisoning. Emergency Medicine Clinics of North America, v. 33, n. 1, p. 133-151, 2015.

KLEIN, B. et al. Análise do impacto do uso de organofosforados e carbamatos em trabalhadores rurais de um município da região noroeste do estado do Rio Grande do Sul. Acta toxicológica argentina, v. 26, n. 3, p. 104-112, 2018.

LANDRIGAN, P. J.; FULLER, R. Global health and environmental pollution. International Journal of Public Health, v. 60, n. 7, p. 761-762, 2015.

LANEROLLE, R. D. et al. Demographic characteristics of end stage renal disease in Sri Lanka. 2000.

LOPES, C. V. A; ALBUQUERQUE, G. S. C. Agrotóxicos e seus impactos na saúde humana e ambiental: uma revisão sistemática. Saúde em debate, v. 42, p. 518-534,2018.

MAMOULAKIS, C et al. Contrast-induced nephropathy: basic concepts, pathophysiological implications and prevention strategies. Pharmacology \& therapeutics, v. 180, p. 99-112, 2017.

PARANÁ. Secretária de Estado da Saúde. Manual de intoxicação por agrotóxicos. Material técnico intoxicações agudas por agrotóxicos atendimento inicial do paciente intoxicado. Paraná, 2018.

MARQUES, P. V.; CAIXETA, B. T. a Importância Da Avaliação Das Dosagens Das Colinesterases Em Casos De Intoxicações Por Organofosforados. Psicologia e Saúde em Debate, v. 2, n. 1, p. 1-17, 2016.

MOLINA, P. Fisiologia Endócrina. 4 a edição. AMGH EDITORA LTDA: 2014- pag. 02-50.

NERILO, S. B.; MARTINS, F. A.; NERILO, L. B.; SALVADEGO, V. E. C.; ENDO, R. Y.; ROCHA, G. H. O.; MOSSINI, S. A. G.; JANEIRO, V.; NISHIYANA, P.; MACHINSKI JUNIOR, M. Pesticide use and cholinesterase inhibition in small-scale agricultural workers in southern Brazil. Braz. J. Pharm. Sci., v. 50, n. 4, 2014.

OLIVEIRA-SILVA, Jefferson José et al. Influência de fatores socioeconômicos na contaminação por agrotóxicos, Brasil. Revista de Saúde Pública, v. 35, p. 130-135, 2001.

OLIVEIRA-SILVA, S.; ALVES, R.; ROSA, H. C. D. Avaliação da exposição humana a agrotóxicos. Agrotóxicos, saúde e ambiente [online]. Rio de Janeiro: Editora FIOCRUZ, p. 121-136, 2003.

PEIRIS-JOHN, Roshini et al. Exposure to acetylcholinesterase-inhibiting pesticides and chronic renal failure. 2006.

PICCOLI, C. Exposição a agrotóxicos, função tireoidiana e alterações hematológicas: estudo em agricultores e familiares moradores da área rural do município de Farroupilha - RS. / Camila Piccoli. -- 2015.

RIBEIRO, A. C. C.; MELLA, E. A. C. Intoxicação Ocupacional por Organofosforados- A Importância da dosagem de colinesterase. Iniciação Científica CESUMAR. v.9, n.2, p.125-134, 2007.

RHOADES, A. R.; TANNER, A. G. Fisiologia médica. 2a ed. Rio de Janeiro: Editora Guanabara Koogan, 2005.

SANCHEZ-HERNANDEZ, J. C.; RÍOS, J. M.; ATTADEMO, A. M. Response of digestive enzymes and esterases of ecotoxicological concern in earthworms exposed to chlorpyrifos-treated soils. Ecotoxicology. Sep;27(7):890899, 2018. 
SHERWOOD, L. Human physiology: from cells to systems. 7ạ ed. Publishing company North American, 2011.

SANABRIA-CASTRO, A.; ALVARADO-ECHEVERRÍAI.; MONGE-BONILLA, C. Molecular Pathogenesis of Alzheimer's Disease: An Update. Ann Neurosci. 2017 May;24(1):46-54.

SILVA, S.M.S. Intoxicações por inibidores da Acetilcolinesterase: etiologia, diagnóstico e tratamento. Dissertação (mestrado integrado em medicina) - Trabalho final do 60 ano médico com vista à atribuição do grau de mestre no âmbito do ciclo de estudos de mestrado integrado em medicina- Faculdade de Medicina da Universidade de Coimbra, p.47. 2015.

TSAROUHAS, K et al. Oxidative stress and kidney injury in trans-radial catheterization. Biomedical reports, v. $8, \mathrm{n}$. 5, p. 417-425, 2018.

TSITSIMPIKOU, C et al. Histopathological lesions, oxidative stress and genotoxic effects in liver and kidneys following long term exposure of rabbits to diazinon and propoxur. Toxicology, v. 307, p. 109-114, 2013.

TOMAZ, D. F.; MARIOTTO, Í.; FERRANTE, M. Intoxicação De Cães E Gatos Por Aldicarb - Revisão De Literatura. Anais do II Simpósio em Produção Sustentável e Saúde Animal, p. 95-100, 2017.

TORIANI, S. S.; OLIVEIRA, T. M. N.; L PEREIRA, E. M.; FERRAZZA, M. H. H . A influência do organofosforado Malation $500 \mathrm{EC}^{\circledR}$ na função hepática, renal e tireoidiana de ratas. Rev. Bras. Cir. Cabeça Pescoço, v. 46, n. 2, p. 52-56, 2017.

US. EPA. Special Report on Environmental Endocrine Disruption: An Effects Assessment and Analisys, U.S. Environmental Protection Agency, Report No. EPA/630/R-96/012, Washington D. C, 1997.

VALE, A.; LOTTI, M. Organophosphorus and carbamate insecticide poisoning. Handb Clin Neurol. 2015;131:149-68.

WARNER, G. R.; MOURIKES, V. E.; NEFF, A. M.; BREHM, E.; FALHAS, J. A. Mecanismos de ação de agroquímicos agindo como desreguladores endócrinos, Molecular e Celular Endocrinologia (2020). Reportagem.

WEDIN, G. P. Nefrotoxicidade de anticolinesterases. In: Clinical and Experimental Toxicology of Organophosphates and Carbamates. Butterworth- Heinemann Oxford, 1992. p. 195-202.

ZIDAN, N. El-H. A. Hepato-and nephrotoxicity in male albino rats exposed to malathionand spinosa dinstored wheat grains. Acta Biologica Hungarica, v.66, n.2, p. 133-148, 2015. 


\section{MICRORGANISMOS PROBIÓTICOS EM SALAMES: POTENCIAL DE USO}

José Eduardo de Matos Paz

Instituto Federal do Rio Grande do Norte - Campus Currais Novos

Keliane da Silva Maia

Instituto Federal do Rio Grande do Norte - Campus Apodi

João Vitor Fonseca Feitoza

Instituto Federal do Rio Grande do Norte - Campus Apodi

\author{
Maria Erica da Silva Oliveira \\ Instituto Federal do Rio Grande do Norte - Campus Apodi \\ Francisca Kelia Duarte Dias \\ Instituto Federal do Rio Grande do Norte - Campus Apodi
}

\section{RESUMO}

A criação de estratégias que visem à agregação de valor à carne tem marcado o desenvolvimento do setor. Os apelos negativos sobre a saúde têm alavancado o investimento pelas comunidades industrial e científica na busca de tornar os produtos processados mais saudáveis. Nesse contexto, encontra-se o consumo de probióticos, muito presente na dieta da população, por promover saúde e bemestar. Com isso, buscou-se reunir informações de cunho científico sobre o uso de probióticos na produção de salames, contribuindo para o acesso à informação da área. É recente, porém crescente, o uso

desses probióticos em produtos cárneos, especialmente embutidos fermentados. Verificou-se que o uso de probióticos em salames é promissor e que os estudos desenvolvidos contribuem para o crescimento da área.

\section{Palavras-chave:}

Alimento funcional; Salame; Probióticos.

\begin{abstract}
The creation of strategies aimed at adding value to meat has marked the development of the sector. The negative health appeals have leveraged investment by the industrial and scientific communities in the quest to make processed products healthier. In this context, there is the consumption of probiotics, present in the population's diet, as it promotes health and well-being. With this, we sought to gather scientific information on the use of probiotics in the production of salami, contributing to access to information in the area. It is recent, but growing, the use of these probiotics in meat products, especially fermented sausages. It was found
\end{abstract}

that the use of probiotics in salami is promising and that the studies developed contribute to the growth of the area.

\section{Keywords:}

Functional food; Salami; Probiotics. 


\section{INTRODUÇÃO}

É crescente a preocupação dos consumidores em adquirir produtos com foco na saudabilidade, impulsionando a indústria da carne a desenvolver produtos que vão além do efeito nutricional inerente, ou seja, promovem saúde e bem-estar.

Alimentos que aliam ação nutricional e benefícios à saúde são designados funcionais. Dentre os alimentos funcionais, destacam-se os probióticos, definidos como microrganismos vivos que quando ingeridos em quantidades suficientes conferem benefícios a saúde do hospedeiro (BRASIL, 2002). Sua ação é decorrente da presença de componentes biologicamente ativos naturalmente presentes ou adicionados em substituição total ou parcial de substâncias indesejáveis à composição do produto (FERREIRA, 2012; MISRA; PANDEY; MISHRA, 2021). São largamente difundidos em produtos lácteos, produtos à base de cereais, sucos de frutas e alimentos destinados ao público infantil, (DE VUYST et al., 2008), porém sua aplicação em produtos cárneos ainda é escassa.

Contudo, a ingestão de probióticos, de acordo com a Agência Nacional de Vigilância Sanitária (ANVISA), deve ser indicada por meio de estudos que comprovem a quantidade mínima viável do microrganismo para exercer a propriedade funcional no final do prazo de validade do produto e nas condições de uso, armazenamento e distribuição (BRASIL, 2019).

Em função disso, existe uma estimativa de que o mercado de alimentos funcionais saltará dos US\$ 46,17 bilhões de 2017 para aproximadamente US\$ 69,29 bilhões em 2023, o que representa um crescimento médio anual de $7 \%$, indicando a oportunidade para o desenvolvimento de produtos nesse nicho de mercado (LIU; COOK; ROUX, 2020).

Devido ao interesse por alimentos funcionais, estudos têm sido realizados para avaliar a viabilidade de bactérias probióticas em produtos cárneos (BIS-SOUZA et al., 2019; PAVLI et al., 2020). A inserção de probióticos em embutidos é vista como uma oportunidade de melhorar sua "imagem" frente às necessidades e objetivos nutricionais dos consumidores (JIMÉNEZ-COLMENERO, 2007; MISRA; PANDEY; MISHRA, 2021).

O consumo de probióticos possibilita a ocorrência de diversos efeitos benéficos a saúde humana, como: equilíbrio da microbiota intestinal, diminuição da constipação e facilitação da digestão, alívio dos sintomas da má absorção à lactose, melhora da resposta imune, menores quadros de diarreia, menor índice de câncer de cólon e redução do nível de colesterol sanguíneo, desta forma, esses alimentos atendem uma demanda da população, que é manter uma dieta mais saudável, o que leva os consumidores a escolher um produto alimentar com propriedades bioativas (DÍAZ, FERNÁNDEZ-RUIZ, CÁMARA, 2020; BIS-SOUZA; PENNA; DA SILVA BARRETTO, 2020). Embora os embutidos cárneos apresentem ambiente desafiador para a sobrevivência de estirpes de probióticos, os salames mostram-se promissores no uso desses microrganismos, pois são fabricados com carne crua fermentada por bactérias lácteas e consumidos sem prévio aquecimento, facilitando a manutenção e viabilidade dos microrganismos probióticos (PAVLI et al, 2020). 
Desta forma, o uso de cepas probióticas no processamento de produtos cárneos fermentados ganhou espaço por causa dos inúmeros benefícios oferecidos ao consumidor pela ingestão desses microrganismos (BIS-SOUZA et al., 2019).

O salame, assim como todo embutido cárneo, é considerado um alimento que proporciona reduzidos benefícios à saúde, devido ao elevado teor de gordura, aditivos e especiarias. Logo, a adição de probióticos a esses alimentos pode proporcionar benefícios à saúde de quem o ingerir, contribuindo para o aumento do consumo desses produtos por aqueles preocupados em manter e/ou melhorar a saúde (MACEDO et al., 2008).

Diante do exposto, o objetivo do presente trabalho foi reunir informações das tendências atuais no uso de probióticos para produção de salames, contribuindo para o conhecimento dos avanços científicos nessa área.

\section{METODOLOGIA}

Esta pesquisa refere-se a um estudo de revisão bibliográfica sobre o tema salames probióticos. As fontes de informações utilizadas foram as plataformas do Periódicos Capes (CAPES), SienceDirect ${ }^{\circledR}$, Scielo ${ }^{\circledR}$, Google Acadêmico, além de endereços eletrônicos independentes, institucionais e governamentais, ligados à regulamentação da produção de alimentos funcionais. Foram selecionados, preferencialmente, artigos científicos de pesquisa e revisão nos idiomas português e inglês. Os descritores utilizados, nas respectivas línguas foram: alimentos funcionais, probióticos, embutidos cárneos, salame e salames probióticos.

\section{RESULTADOS}

\subsection{PRODUTOS CÁRNEOS}

Produtos cárneos são aqueles preparados, total ou parcialmente, com carnes, miúdos ou gorduras, adicionados ou não de ingredientes de origem vegetal, como condimentos, especiarias e aditivos. A adição desses ingredientes melhora o perfil sensorial dos produtos e, quando associados a tratamentos físicos e térmicos, promovem modificações físicas, químicas e microbiológicas capazes de aumentar a vida útil, além de agregar valor (ORDOÑEZ et al., 2005).

Dentre os produtos cárneos existentes no mercado, os embutidos merecem destaque, por estarem incluídos nos hábitos alimentares da grande maioria dos consumidores brasileiros, variando em qualidade, preço e perfil sensorial (RAMUNDO; COUTO; LANZILLOTTI, 2005; PÉREZ-BURILLO et al., 2020). 
Hoje, no entanto, a elaboração de embutidos é considerada uma ciência sofisticada e não mais uma arte como no princípio. Tecnologias inovadoras no processamento, nos equipamentos e até na apresentação, preparo e distribuição dos produtos, tornou a indústria cárnea uma área dinâmica e competitiva (BIS-SOUZA et al., 2019; DÍAZ, FERNÁNDEZ-RUIZ, CÁMARA, 2020).

Embutidos como o salame, que são produtos crus, curados e fermentados encaixam-se perfeitamente nessa tendência atual de consumo, por serem práticos, estáveis e vastamente utilizados na culinária (PÉREZ-BURILLO et al., 2020).

\subsection{SALAME}

A palavra salame, do latim salsus, que significa salgado ou conservado pelo sal, deu origem a arte de elaborar embutidos, conservando a carne fresca mediante o uso da salga e a secagem (PRICE; SCHWEIGERT, 1994).

O salame é um produto fermentado, curado, maturado, dessecado, defumado ou não, embutido em envoltórios naturais ou artificiais, elaborado a partir da mistura de carne suína ou suína e bovina, adicionados de gordura animal, açúcares, sal, nitrito e/ou nitrato, ascorbato e condimentos, e podem ser classificados como produto cárneo seco ou semi-seco e não emulsionado (FAO, 1985).

De acordo com a Instrução Normativa n²2/2000 do Ministério da Agricultura e do Abastecimento (MAPA), os salames podem receber nove denominações considerando as particularidades de cada um, sendo assim nomeados: Salame Tipo Alemão, Salame Tipo Calabrês, Salame Tipo Friolano, Salame Tipo Hamburguês, Salame Tipo Italiano, Salame Tipo Milano, Salame Tipo Napolitano, Salaminho e Pepperoni (BRASIL, 2000).

Dentre os fatores que diferenciam esses produtos encontram-se a origem da carne (espécie animal), calibre e natureza do envoltório, moagem da carne e toucinho, ingredientes, condimentos, período de maturação e se o produto é defumado ou não (CACCIOPPOLI et al., 2006), desenvolvimento ou não de bolor na superfície externa, condições de tempo e temperatura aplicados na fermentação e quantidade de açúcar empregada (TERRA, 2005; BRASIL, 2000).

Internacionalmente, os embutidos fermentados tipo salame podem ainda ser classificados em dois grandes grupos de acordo com a tecnologia de fabricação e o pH final do produto. Os salames elaborados com carne bovina e suína, submetidos a fermentação curta com rápida queda de pH, são tradicionais do norte europeu e compõem o primeiro grupo. Já os produtos com uso apenas de carne suína e fermentação longa com pH superior a 5,0, com adição de especiarias, que conferem sabor e aroma diferenciados, são típicos do sul da Europa e compõem o segundo grupo (TALON; LEROY; LEBERT, 2007).

No Brasil a produção de salame se enquadra no segundo grupo, pois são elaborados produtos predominantemente a partir de carne suína, maturados por aproximadamente 30 dias, apresentando flavor suave e pH em torno de 5,4 (MACEDO, 2005; TERRA, 2006). Sua fabricação envolve, essencialmente, duas etapas: a etapa inicial, caracterizada pela mistura da matéria-prima com os 
demais ingredientes, embutimento e fermentação, resultando na acidificação e desenvolvimento de características sensoriais, e a etapa final, marcada pela perda de 30 a $40 \%$ do seu peso inicial resultante da desidratação gradual do embutido, contribuindo para a estabilidade microbiológica e qualidade sensorial do alimento (TERRA, 2003).

A desvantagem desse produto, no entanto, está atrelada ao seu elevado teor de gordura e de sódio, presença de nitrito residual e de compostos potencialmente tóxicos, como as aminas bioativas (COLORETTI et al., 2008). O consumo elevado destes compostos pode ser associado a ocorrência de diversos problemas de saúde e são indesejáveis para os consumidores que buscam ter uma alimentação mais saudável (MARTíNEZ; NIETO; ROS, 2014).

Entretanto, o salame é consumido em todo o mundo, o que motivou a busca pela melhoria na qualidade deste produto nos últimos anos, utilizando como estratégia a modificação de produtos de carne mediante a formulação, com a adição de ingredientes funcionais, modificação da composição da carne por meio da alimentação dos animais ou por inovações nas condições de processamento e/ou armazenamento (PÉREZ-BURILLO et al., 2020).

\subsection{ALIMENTOS FUNCIONAIS}

Em 1989 surgiu no Japão o conceito de "alimentos funcionais" em decorrência da preocupação do governo com os gastos elevados na saúde pública, ocasionadas pelo aumento de doenças crônicas que atingiram a população. A partir desta preocupação, houve maior incentivo ao desenvolvimento de alimentos que ofertam junto à nutrição básica a promoção de saúde e bem-estar do indivíduo (ARAI, 2002). Para ser considerado funcional, o alimento deve oferecer benefícios a uma ou mais funções no organismo com o intuito de melhorar as condições de saúde do indivíduo ou diminuir o risco de doenças. Estes alimentos estimulam os consumidores a associarem nutrição e saúde (OLIVEIRA, 2007).

No Brasil, o termo alimento funcional é definido pela Agência Nacional de Vigilância Sanitária (ANVISA) por meio da biblioteca Virtual em Saúde (BVS), como "Alimentos ou ingredientes que produzem efeitos benéficos à saúde, além de suas funções nutricionais básicas" (BRASIL, 2009).

Esses alimentos contêm componentes biologicamente ativos que, quando ingeridos em quantidades normais, são capazes de produzir benefícios ao organismo do indivíduo, como a redução nos riscos de doenças crônicas, promovendo saúde e bem-estar, além de seu efeito nutricional inerente. Alimentos que apresentem composição nutricional balanceada também podem ser considerados funcionais, pois oferecem benefícios à saúde de quem o consumir (FERREIRA, 2012). Esses alimentos são classificados em diferentes grupos: fito estrógenos, ácidos fenólicos, tióis, carotenoides, proteínas de soja, probióticos, prebióticos e são vistos como agentes de saúde e bem-estar, estando associados à redução do risco de doenças crônico-degenerativas e não transmissíveis (HAULY et al., 2005). 


\subsection{PROBIÓTICOS}

A palavra probiótico é derivada do latim e grego e significa "pró-vida" ou para vida, existindo várias definições que o conceitue (KARKOW; FAINTUCH, 2007). A definição mais aceita internacionalmente define os probióticos como sendo "microrganismos vivos, que administrados em quantidades adequadas conferem benefícios à saúde do hospedeiro" (FAO/OMS, 2002).

De acordo com Isolauri et al. (2000), os probióticos são suplementos alimentares vivos com benefícios ao seu receptor, por equilibrar a flora microbiana intestinal. Para De Vrese (2001), o conceito para probiótico inclui produtos com quantidades adequadas de microrganismos viáveis capazes de modificar a flora microbiana de um hospedeiro causando melhoria na saúde.

Contudo, os probióticos para uso em alimentos devem, além de sobreviver à passagem pelo trato digestivo, apresentar capacidade de proliferar-se no intestino (OLIVEIRA, 2007). Dentre as cepas utilizadas como probióticos, as principais são as pertencentes aos gêneros Lactobacillus e Bifidobacterium (BIS-SOUZA; PENNA; DA SILVA BARRETTO, 2020; PAVLI et al., 2020).

Estudos realizados em humanos, com a administração de Lactobacilos e Bifidobactérias, por cerca de um ano, nas doses $10^{6}-10^{9}$ UFC/dia, não demonstraram efeitos adversos (BATISTA; OLIVEIRA, 2002; MISRA, PANDEY, MISHRA, 2021).

Para Oliveira et al. (2007), as doses de probióticos ainda não foram bem estabelecidas, mas podem variar com a espécie e cepas utilizadas, e seus benefícios estão ligados à quantidade de microrganismos viáveis consumidos. Atualmente, a indicação de consumo diária de microrganismos viáveis é de no mínimo $10^{8}$ a $10^{9}$ UFC/dia (BRASIL, 2017).

De acordo com Saad (2006), a garantia de benefícios à saúde se dá pela ingestão diária de probióticos com populações acima de $10^{6}$ a $10^{7} \mathrm{UFC} / \mathrm{g}$ ou ml de bioproduto administrados por um tempo mínimo de 15 dias. BIS-SOUZA et al. (2019), também relatam que a ingestão de $10^{6}$ a $10^{7}$ UFC/g de probióticos é suficiente para que se promova os benefícios à saúde.

Os benefícios da ingestão dos probióticos são fundamentados na ciência de que os microrganismos intestinais podem proteger os indivíduos contra infecções e que o desequilíbrio dessa microbiota pode aumentar a suscetibilidade às doenças infecciosas. Os efeitos dos microrganismos variam com a linhagem (cepa) e podem agir tanto no equilíbrio da flora microbiana intestinal como no sistema imunológico. Logo, a população bacteriana intestinal em condições normais representa uma forte barreira frente aos microrganismos patogênicos e oportunistas (KARKOW; FAINTUCH, 2007; LARAYER, 2005).

Quanto aos mecanismos de ação dos probióticos, destaca-se a "exclusão competitiva", em que os probióticos competem por nutrientes e espaço físico e impedem a colonização da mucosa por microrganismos potencialmente patogênicos, por meio da produção de compostos antimicrobianos como bacteriocinas, ácidos graxos de cadeia curta, peróxido de hidrogênio, ácido lático e estímulo ao sistema imune (GUARNIER; MALAGELADA, 2003; AMORES et al.,2004).

Em suma, as bactérias probióticas para uso industrial devem ser adequadas a cada tipo de alimento, proporcionando boa viabilidade, eficácia terapêutica, além de permanecer em um número elevado 
durante a vida de prateleira do produto, garantindo a ingestão de números viáveis de microrganismos agindo de forma benéfica ao organismo humano (STANTON et al., 2005).

\subsection{USO DE CULTURAS PROBIÓTICAS NA PRODUÇÃO DE SALAME}

Para que o uso de microrganismos probióticos como culturas iniciadoras na elaboração de salames seja viável, os probióticos devem ser resistentes ao ambiente hostil do embutido e serem capazes de se desenvolverem, produzir ácidos orgânicos, sobreviverem as etapas de secagem e maturação, apresentando elevadas quantidades de microrganismos viáveis no produto final (ERKKIL̈̈; PETÄJÄ, 2000).

O produto final deve apresentar ainda características tecnológicas e sensoriais similares aos salames tradicionais, mantendo a aceitação de mercado (DE VUYST; FALONE; LEROY, 2008). Essa microbiota pode, ainda, exibir outras características igualmente apreciáveis ao processamento, como a capacidade de inativar patógenos e produzir compostos antimicrobianos. O poder de produzir aminas bioativas também é relevante na seleção das culturas iniciadoras probióticas, visto que esses compostos em embutidos fermentados estão atrelados a algumas espécies de Lactobacillus spp. (PIRCHER; FRIEDRICH; PAULSEN, 2007).

Substituir as culturas iniciadoras tradicionais, total ou parcialmente, por microrganismos probióticos pode contribuir para a estabilidade microbiológica do produto final e proporcionar melhorias nas características sensoriais, tecnológicas e nutricionais, oferecendo benefícios à saúde e tornando-se uma opção atrativa para a indústria alimentícia (MUTHUKUMARASAMY; HOLLEY, 2007).

Os microrganismos probióticos são tradicionalmente utilizados no processamento de produtos lácteos como iogurtes, leites fermentados e sobremesas lácteas. Apesar de não ser aplicados comumente em produtos cárneos, o uso de probióticos na indústria cárnea se mostra promissora, em especial nos produtos embutidos fermentados, como o salame, que são produzidos e consumidos sem tratamento térmico (AMMOR; MAYO, 2007; BIS-SOUZA et al., 2019; MISRA; PANDEY; MISHRA, 2021).

A aplicação de probióticos em embutidos cárneos fermentados requer que eles sobrevivam na presença de sais de cura, pH ácido, a baixa atividade de água e a ação letal da bile (DE VUYST et al., 2008). Deve-se considerar também, alguns fatores como a adequação da cultura ao tipo do produto, a funcionalidade no intestino delgado ou grosso à espera da espécie, a produção de ácido láctico em quantidade suficiente, não ocasionar mudanças sensoriais significativas, no flavor e textura tradicionais do produto, a viabilidade de microrganismos viáveis que, deve ser de $10^{6} \mathrm{UFC} / \mathrm{g}$ para Lactobacillus e $10^{7}$ UFC/g para Bifidobacterium (LÜCKE, 2000).

Além de prolongar a vida útil e melhorar a consistência dos produtos cárneos fermentados, culturas starter probióticas devem ser de fácil cultivo em escala industrial e sobreviverem aos processos de congelamento e liofilização, bem como atribuir qualidade ao produto final (ERKKILÄ et al., 2001).

Nos produtos cárneos fermentados, a matriz alimentar protege as bactérias lácticas encapsulando-as com carne e gordura. Esses componentes não digeridos nas primeiras porções do trato gastrintestinal podem atuar como fonte de energia para a sobrevivência e proliferação das bactérias no trato 
intestinal (MARTíNEZ; NIETO; ROS, 2014). Esses alimentos apresentam condições favoráveis para o transporte de microrganismos probióticos em função da proteção lipídica em células bacterianas durante a passagem pelo trato gastrointestinal (PAVLI et al., 2020).

Macedo, Pflanzer e Gomes (2011) afirmam que é possível acrescentar culturas probióticas aos embutidos, total ou parcialmente à cultura starter durante a mistura da massa. Outros estudos demonstram a viabilidade do uso de lactobacilos probióticos como agente conservante em produtos cárneos fermentados, como os desenvolvidos por Arihara et al. (1998), que estudaram o uso Lactobacillus gasseri para aumentar a segurança microbiológica de embutidos fermentados. Cepas de Lactobacillus rhamnosus também foram usadas para a fermentação de produtos cárneos, como fizeram Sameshima et al. (1998) por Erkkilä e Petäjä (2000) e Pavli et al. (2020) que utilizaram o Lactobacillus plantarum em embutidos fermentados a seco.

O uso parcial de cultura potencialmente probiótica também foi pesquisado por Andersen (1998), que provou a viabilidade de fermentar um produto cárneo com uma mistura da cultura starter tradicional Bactoferm T-SPX (Chr Hansen) e uma cultura probiótica em potencial sendo ela Lactobacillus casei LC01 ou Bifidobacterium lactis Bb-12. O mesmo foi realizado por Macedo et al. (2008) que também utilizaram cultura comercial Bactoferm T-SPX e como culturas probióticas testaram as espécies Lactobacillus casei, Lactobacillus paracasei ssp. paracasei e Lactobacillus casei ssp. rhamnosus e concluíram que é viável sua utilização como culturas probióticas em produtos cárneos curados.

Relatos feitos por Erkkilä et al. (2001) também confirmam o potencial probiótico das cepas de Lactobacillus gasseri, Lactobacillus rhamnosus, Lactobacillus paracasei subsp. paracasei, Lactobacillus casei e Bifidobacterium lactis utilizadas para a fermentação de salame. Já os estudos de Muthukumarasamy e Holey (2007) demostraram que a utilização de Lactobacillus reuteri ATCC55730 e Bifidibacterium longum ATCC15708 como culturas starter tem efeito antimicrobiana frente a Escherichia coli 0157:H7 durante a produção de salame. Em outro estudo, realizado por Sameshima et al. (1998) cepas probióticas de Lactobacillus paracasei subsp. paracasei e a cultura comercial de Lactobacillus sakei inibiram a proliferação do Staphylococcus aureus e a produção da enterotoxina

Já para as pesquisas de Callewaert, Hugas, De Vuyst (2000), os resultados indicam que as cepas probióticas de Lactobacillus casei e Enterococcus faecium podem inibir a multiplicação de Listeria monocytogenes em salames por meio da produção de bacteriocinas. Outros microrganismos como Lactobacilus reuteri, Lactobacillus acidophilus, Lactobacillus paracasei e Bifidobacterium lactis também apresentam atividade antimicrobiana, pois foram eficazes na inibição da multiplicação de Listeria monocytogenes, Escherichia coli e Salmonella spp. (PIDCOCK; HEARD; HENRIKSON, 2002; ROSS; MORGAN; HILL, 2002).

Kim et al. (2014) avaliaram a qualidade dos salames produzidos com culturas de partida funcionais (Lactobacillus plantarum 115 e 167, e Pediococcus damnosus L12) e diferentes níveis de gordura, para determinar o estado ótimo para a fabricação destes produtos, concluindo que esses dois microrganismos trouxeram benefícios quanto à redução do tempo de secagem e diminuição do teor de colesterol. 
Quanto às características sensoriais, Arief et al. (2016) utilizaram bactérias ácido-lácticas de Lactobacillus plantarum IIA-2C12 e Lactobacillus acidophilus IIA-2B4 e estirpes isoladas do gado de corte, que têm mostrado potencial para ser utilizadas como culturas probióticas, indicando que, embora o conteúdo em nutrientes não fosse afetado pelos probióticos, o pH, a textura, e a cor variava entre as salsichas.

Em relação a preservação do microrganismo, Knapik et al. (2017) desenvolveram um salame tipo italiano utilizando Lactobacillus paracasei paracasei microencapsulado em sistema cálcio-alginato para proteger o microrganismo no meio mantendo as cepas ativas no intestino. Laranjo, Potes e Elias (2019) afirmam que as culturas de partida podem aumentar a segurança dos produtos de carne fermentada por meio de uma rápida acidificação do meio ou devido à produção de substâncias antimicrobianas, tais como as bacteriocinas. Além disso, culturas de partida podem ajudar a normalizar as propriedades do produto e a encurtar os tempos de maturação.

Estudos utilizando combinação de microrganismos também foram realizados. Najjari et al. (2020) avaliaram o efeito das estirpes de Lactobacillus sakei isoladas de diferentes origens, sobre as qualidades de salames fermentados a seco fabricados com diferentes combinações de culturas iniciais de Lactobacillus sakei e Staphylococcus xylosus maturadas utilizando as mesmas matériasprimas e condições, durante 45 dias. As bactérias de ácido láctico foram dominantes durante o processamento. Após a realização de análise sensorial, os autores observaram que os salames produzidos com Lactobacillus sakei e Staphylococcus xylosus tinham um odor, sabor e textura mais desejáveis quando comparado ao salame de cultura tradicional.

Vale ressaltar que, a redução de microrganismos nocivos à saúde no trato intestinal é um dos principais benefícios da utilização de probióticos. Nesse contexto, Liu et al. (2021) estudaram os probióticos Lactobacillus delbrueckii N102, Latilactobacillus sakei H1-5, Debaryomyces hansenii Y4-1 e Wickerhamomyces anomalus Y12-3. Os autores verificaram que ambos os Lactobacillus delbrueckii $\mathrm{N} 102$ e Lactobacillus sakei $\mathrm{H} 1-5$ crescem bem e podem reduzir rapidamente o valor do $\mathrm{pH}$ do alimento e ao mesmo tempo reduziram significativamente o número de Enterobacter putrefaciens, de modo a garantir a segurança do alimento. Em comparação com bactérias ácido-lácticas, as leveduras apresentaram maior potencial para contribuir na formação de sabor agradável e inibição eficaz da oxidação lipídica.

\section{CONCLUSÃO}

O uso de culturas probióticas em embutidos fermentados e sua ação benéfica ao organismo é promissor, sendo necessário estabelecer, apenas, o número de células viáveis capazes de resistir ao processamento, ao trato gastrointestinal, a vida útil do alimento e ainda ser capaz de proporcionar benefícios a saúde de quem ingere, sem, no entanto, alterar as características sensoriais e tecnológicas inerentes aos produtos tradicionais. Os estudos desenvolvidos e em desenvolvimento, possibilitam e impulsionam a expansão do mercado de salames funcionais. 


\section{REFERÊNCIAS}

AMMOR, M.; MAYO, B. Selection criteria for lactic acid bacteria to be used as functional starter cultures in dry sausage production: An update. Meat Science, v. 76, n. 1, p. 138-146, 2007.

AMORES, R.; CALVO, A.; MAESTRE, J. R.; MARTÍNEZ-HERNÁNDEZ, D. Probióticos. Revista Espanola de Quimioterapia, v. 17, n. 2, p. 131-139, 2004.

ANDERSEN, L. Fermented dry sausages produced with the admixture of probiotic cultures. In: International Commitment of Meat Science and Technology, 44, 1998, Barcelona. Anais... Barcelona: Institut de Recerca i Tecnologia Agroalimentaries, 1998. p. 826-827.

ARAI, S. Global view on functional foods: Asian perspectives. British Journal of Nutrition, Cambridge, v. 88, n. S2, p. S139-S143, 2002.

ARIEF, I. I.; AFIYAH, D. N.; WULANDARI, Z.; BUDIMAN, C. Physicochemical Properties, Fatty Acid Profiles, and Sensory Characteristics of Fermented Beef Sausage by Probiotics Lactobacillus plantarum IIA-2C12 or Lactobacillus acidophilus IIA-2B4. Journal of Food Science. v. 81, n. 11, p. 2761-2769, 2016.

ARIHARA, K; OTA, H.; ITOH, M.; KONDO, Y.; SAMESHIMA, T.; YAMANAKA, H. Lactobacillus acidophilus group lactic acid bacteria applied to meat fermentation. Journal of Food Science, v. 63, 1998.

BATISTA, S.M.M.; OLIVEIRA, L.T. A atuação dos probióticos na resposta imunológica. Nutrição em Pauta, n. 57, 2002.

BIS-SOUZA, C. V., BARBA, F. J., LORENZO, J. M., PENNA, A. L. B., \& BARRETTO, A. C. S. New strategies for the development of innovative fermented meat products: A review regarding the incorporation of probiotics and dietary fibers. Food Reviews International, v. 35, p. 467-484, 2019.

BIS-SOUZA, C. V., PENNA, A. L. B., DA SILVA BARRETTO, A.C. Applicability of potentially probiotic Lactobacillus casei in low-fat Italian type salami with added ructooligosaccharides: in vitro screening and technological evaluation. Meat Science, v. 168, 108186, 2020.

BRASIL. BVS - BIBLIOTECA VIRTUAL EM SAÚDE. Dicas em Saúde: Alimentos Funcionais. 2009. Disponível em <https://bvsms.saude.gov.br/bvs/dicas/220_alimentos_funcionais.html>. Acesso em: 28/02/2021.

BRASIL. Ministério da Agricultura, Pecuária e do Abastecimento. Secretaria de Defesa Agropecuária. Instrução Normativa no. 22 de 31 de julho de 2000. Regulamentos Técnicos de Identidade de Qualidade de Salames. Diário Oficial da União, Brasília, 03 de agosto de 2000. p. 15-28.

BRASIL. Agencia Nacional de Vigilância Sanitária (ANVISA). Alegações de propriedade funcional aprovadas: lista de alegações de propriedade funcional aprovadas. 2019. Disponível em: <https://www.gov.br/agricultura/ptbr/assuntos/inspecao/produtos-vegetal/legislacao-1/biblioteca-de-normas-vinhos-e-bebidas/alegacoes-depropriedade-funcional-aprovadas_anvisa.pdf $>$. Acesso em:27/02/2021.

BRASIL. Agencia Nacional de Vigilância Sanitária (ANVISA). Probióticos: Construção da Lista de Linhagens Probióticas. 2017. Disponível em: <http://antigo.anvisa.gov.br/documents/3845226/0/An\%C3\%A1lise+ das+Linhagens+de+Probi\%C3\%B3ticos__23042018.pdf/6e37da13-2151-4330-85b0-0f449dbb0e95>. Acesso em:28/02/2021. 
BRASIL. Ministério da Saúde. Agência Nacional de Vigilância Sanitária. Resolução RDC no 2, de 07 de janeiro de 2002. Aprova o Regulamento Técnico de Substâncias Bioativas e Probióticos Isolados com Alegação de Propriedades Funcional e ou de Saúde. Diário Oficial da União, Brasília, 09 jan. 2002.

CALLEWAERT, R.; HUGAS, M.; DE VUYST, L. Competitiveness and bacteriocin production of Enterococci in the production of Spanish-style dry fermented sausages. International Journal of Food Microbiology, v. 57, p. 33-42, 2000.

CACCIOPPOLI, J.; CUSTÓDIO, F.B.; VIEIRA, S.M.; COELHO, J.V.; GLÓRIA M.B.A. Aminas bioativas e características físicoquímicas de salames tipo italiano. Arquivo Brasileiro de Medicina Veterinária eZootecnia, v. 58, p. 648-657, 2006.

COLORETTI, F., CHIAVARI, C., ARMAFORTE, E., CARRI, S., CASTAGNETTI, G.B. Combined use of starter cultures and preservatives to control production of biogenic amines and improve sensorial profile in low-acid salami. Journal of Agricultural and Food Chemistry, v. 56, p. 11238-11244, 2008.

DE VUYST, L.; FALONE, G.; LEROY, F. Probiotic in fermented sausage. Meat Science, v. 80, p. 75-78, 2008.

DE VReSE, M.; STEgelmanN, A.; RICHTER, B.; FEnSELAU, S.; LAUE, C.; SCHREZENMEIR, J. Probiotic compensation for lactose insufficiency. American Journal of Clinical Nutrition, v. 73, n. 2, p. 421-429, 2001.

DÍAZ, L. D., FERNÁNDEZ-RUIZ, V., CÁMARA, M., An international regulatory review of food health-related claims in functional food products labeling, Journal of Functional Foods, v. 68, 2020.

ERKKILÄ, S.; PETÄJÄ, E. Screening of commercial meat starter cultures at low pH and in the presence of bile salts for potential probiotic use. Meat Science, v. 55, p. 297-300, 2000.

ERKKILÄ, S; SUIHKO, M. L.; EEROLA, S.; PETÄJÄ, E.; MATTILA-SANDHOLM, T. Dry sausage fermented by Lactobacillus rhamnosus strains. International Journal of Food Microbiology, v. 64, p. 205-210, 2001.

FERREIRA, C. L. de L. F. Prebióticos e probióticos: atualização e prospecção. Rio de Janeiro: Rubio, p. 226, 2012.

FAO - FOOD AND AGRICULTURE ORGANIZATION OF THE UNITED NATIONS, WORLD HEALTH ORGANIZATION. Small-scale sausage production. 1981. Disponível em: <http://www.fao.org/3/x6556e/X6556E05.htm>, Acesso em: 27/02/2021.

FOA/OMS - FOOD AND AGRICULTURE ORGANIZATION OF THE UNITED NATIONS, WORLD HEALTH ORGANIZATION. Evaluation of health and nutritional properties of probiotics in food including powder milk with live lactic acid bacteria. Córdoba, 2002.

GUARNIER, F.; MALAGELADA, J.R. Gut flora in health and disease. The Lancet, v. 360, p. 512-519, 2003.

HAULY, M. C. O. Suplementação de iogurte de soja com fruto oligossacarídeos: características probióticas e aceitabilidade. Revista de Nutrição, Campinas, v. 18, n. 5, p. 613-622, set./out. 2005.

ISOLAURI, E.; ARVOLA, T.; SUTAS, Y.; MOILANEN, E.; SALMINEN, S. Probiotics in the management of atopic eczema. Clinical \& Experimental Allergy, v. 30, n.11, p. 1604-10, 2000.

JIMÉNEZ-COLMENERO, F. Healthier lipid formulation approaches in meat based functional foods. Technological options for replacement of meat fats by non-meat fats. Trends Food Science Technology, v.18, n.11, p.567-578, 2007.

KARKOW, F.J; FAINTUCH, J. Probióticos: perspectivas médicas. Revista da AMRIGS, v. 51, n. 1, p. 38-48, 2007.

KIM, Y. J.; PARK, S. Y.; LEE, H. C.; YOO, S. S.; OH, S. J.; KIM, H. S.; CHIN, K. B. Evaluation of Fermented Sausages Manufactured with Reduced-fat and Functional Starter Cultures on Physicochemical, Functional and Flavor Characteristics. Korean Journal for Food Science of Animal Resources, v. 34, n.3, p. 346-354, 2014. 
KNAPIK, A.; TEICHRIEB, M.; NESELLO, M.; LOPES, W.; MATTANNA, P. Desenvolvimento De Salame Probiótico Fermentado Com Microcápsulas Contendo Lactobacillus paracasei paracasei. Revista Eletrônica Biociências, Biotecnologia e Saúde, n. 18, p. 82-88, maio-ago 2017.

LARANJO, M.; POTES, M. E.; ELIAS, M. Role of Starter Cultures on the Safety of Fermented Meat Products. Frontiers in Microbiology, v. 10, p. 1-11, abr 2019.

LARAYER, A. Introdução ao tema probióticos: estágio atual das pesquisas no Brasil. In Fibras, Prebióticos e Probióticos. ILSI Brasil: São Paulo, 2005.

LIU, J., COOK, B., ROUX, S. The challenges in commercialisation of Probiotic API manufacturing. Microbiology Australia, v. 41, n. 2, p.82-85, maio 2020.

LIU, Y.; WAN, Z.; YOHANNES, K. W; YU, Q.; YANG, Z.; LI, H.; LIU, J.; WANG, J. Functional Characteristics of Lactobacillus and Yeast Single Starter Cultures in the Ripening Process of Dry Fermented Sausage. Frontiers in Microbiology, v. 11, p. 1-15, 2021.

LÜCKE, F. K. Utilization of microbes to process and preserve meat. Meat Science, v. 56, p. 105-115, 2000.

MACEDO, E.F.R.; PFLANZER, S.B.; GOMES, C.L. Probióticos e Prebióticos em alimentos. Produtos Cárneos Probióticos. 1 ed. São Paulo: Varela, p. 669, 2011.

MACEDO, R.E.F.; PFLANZER Jr, S.B.; TERRA, N.N.; FREITAS, R.J.S. Desenvolvimento de embutido fermentado por Lactobacilos probióticos: características de qualidade. Ciência e Tecnologia de Alimentos, v. 28, 2008.

MACEDO, R.E.F. Utilização de culturas lácticas probióticas no processamento de produto cárneo. 210f. (Tese de Doutorado) em Universidade Federal do Paraná, Paraná, 2005.

MARTÍNEZ, J., NIETO, G., ROS, G. Total antioxidant capacity of meat and meat products consumed in a reference 'Spanish standard diet'. International Journal of Food Science \& Technology, v. 49, n. 12, p. 2610-2618, 2014.

MISRA, S.; PANDEY, P; MISHRA, H. N. Novel approaches for co-encapsulation of probiotic bacteria with bioactive compounds, their health benefits and functional food product development: A review. Trends in Food Science \& Technology, v. 109, p. 340-351, mar 2021.

MUTHUKUMARASAMY, P.; HOLLEY, R.A. Survival of Escherichia coli 0157:H7 in dry fermented sausages containing microencapsulated probiotic lactic acid bacteria. Food Microbiology, v.24, p.82-88, 2007.

NAJJARI, A.; BOUMAIZA, M.; JABALLAH, S.; BOUDABOUS, A.; OUZARI, H. Application of isolated Lactobacillus sakei and Staphylococcus xylosus strains as a probiotic starter culture during the industrial manufacture of Tunisian dry-fermented sausages. Food Science Nutrition, v. 8, p. 4172-4184, 2020.

OLIVEIRA, M.N. Probióticos: seus benefícios a saúde humana. Nutrição em Pauta, v. 15, n.87, 2007.

ORDÓÑEZ, J.A.P.; RODRIGUEZ, M.I.C.; ALVAREZ, L.F.; SANZ, M.L.G.; MINGUILLÓN, G.D.G.F.; PERALEZ, L.H. Tecnologia de Alimentos: alimentos de Origem Animal. Porto Alegre: Artmed, p. 279, 2005.

PÉREZ-BURILLO, S., PASTORIZA, S., GIRONÉS, A., AVELLANEDA, A., PILAR FRANCINO, M., \& RUFIÁN-HENARES, J. A. Potential probiotic salami with dietary fiber modulates metabolism and gut microbiota in a human intervention study. Journal of Functional Foods, v. 66, 2020.

PAVLI, F. G., ARGYRI, A. A., CHORIANOPOUlOS, N. G., NYCHAS, G. E., TASSOU, C. C., Effect of Lactobacillus plantarum $\mathrm{L} 125$ strain with probiotic potential on physicochemical, microbiological and sensorial characteristics of dry-fermented sausages, LWT, v. 118, 108810, 2020. 
PIDCOCK, K.; HEARD, G.M; HENRIKSON, A. Application of nontraditional meat starter cultures in production of Hungarian salami. International Journal of Food Microbiology, v. 76, p. 75-81, 2002.

PRICE, J.F.; SCHWEIGERT, B.S. Ciência de la carne y de los productos cárnicos. 2ed. Zaragoza: Acribia, 1994.

PIRCHER, A.; FRIEDRICH, B.; PAULSEN, P. Formation of cadaverine, histamine, putrescine and tyramine by bacteria isolated from meat, fermented sausages and cheeses. Europen Food and Research Technology, v. 226, p. 225-231, 2007.

ROSS, R.P.; MORGAN, S.; HILL, C. Preservation and fermentation: past, present and future. International Journal of Food Microbiology, v. 70, p. 3-16, 2002.

RAMUNDO, A.; COUTO, S. M.; LANZILLOTTI, H. S. Elaboração e análise sensorial de linguiças caseiras. Higiene Alimentar, São Paulo, v.19, n. 128, 2005.

SAMESHIMA, T.; MAGOME, C.; TAKESHITA, K.; ARIHARA, K.; ITOH, M.; KONDO,Y. Effect of intestinal Lactobacillus starter cultures on the behaviour of Staphylococcus aureus in fermented sausage. International Journal of Food Microbiology, v. 41, p. 1-7, 1998.

SAAD, S.M.I. Probióticos e prebióticos: o estado da arte. Revista Brasileira de Ciências Farmacêuticas, v. 42, n. 1, p. 1-16, 2006.

STANTON, C.; ROSS, R. P.; FITZGERALD, G. F.; VAN SINDEREN, D. Fermented functional foods based on probiotics and their biogenic metabolites. Current Opinion in Biotechnology. v. 16, p. 196-203, 2005.

TALON, R.; LEROY, S.; LEBERT, I. Microbial ecosystems of traditional fermented meat products: the importance of indigenous starter. Meat Science, v. 77, p. 55-62, 2007.

TERRA, N. N. Apontamentos de tecnologia de carnes. São Leopoldo: UNISINOS, 2003.

TERRA, N. N. Apontamentos de Tecnologia de Carnes. São Leopoldo: UNISINOS, 2005.

TERRA, N.N. Fermentação cárnea: princípios e inovações. Atualidades em Ciência e Tecnologia dos Alimentos. São Paulo: Varela, 2006. 


\section{PROSPECÇÃO TECNOLÓGICA: \\ MAPEAMENTO DAS TECNOLOGIAS APLICADAS AO BENEFICIAMENTO E DERIVADOS DO CACAU}

Fárlei Cosme Gomes dos Santos

Universidade Estadual de Santa Cruz - UESC

\author{
Ricardo de Araújo Kalid \\ Universidade Federal do Sul da Bahia - UFSB
}

\begin{abstract}
RESUMO
A cacauicultura teve e tem papel importante na construção social, econômica e ambiental do Território Litoral Sul da Bahia. Diante da importância do cacau na construção social, econômica e ambiental do TLS, estudar as tecnologias relacionadas ao cacau pode estimular discussões acerca das estratégias para o desenvolvimento de políticas públicas destinadas ao fomento de inovação para Região. O mapeamento da produção científica e tecnológica é uma ferramenta relevante para o levantamento das competências e evolução da ciência e tecnologia. Assim, este capítulo tem por objetivo elaborar um mapeamento tecnológico aplicado ao beneficiamento e derivados do cacau, a partir de um estudo prospectivo em banco de patentes, a fim de identificar: (i) os principais depositantes de patentes; (ii) o perfil do depositante; (iii) a quantidade de registros de depósitos de patentes em cada país; e a (iv) distribuição por temas. A pesquisa consistiu no monitoramento tecnológico em fontes de informações tecnológicas acessíveis em base de patentes. O estudo utilizou duas bases de dados: a) Instituto Nacional de Propriedade Industrial; b) software ORBIT ${ }^{\circledR}$. A estratégia de busca combinou os campos: palavras-chave, isoladamente ou agrupadas por conectores booleanos. A área de busca
\end{abstract}

não foi delimitada, pois desejou-se saber as patentes existentes em todos os países que têm sistema de propriedade industrial. O mapeamento apontou tendência de rotas tecnológicas relacionadas ao processo de fermentação e secagem de cacau, que, por sua vez está associado ao processo de qualidade das amêndoas. Esse indicativo pode possibilitar e agregar valor a esse produto, para exploração de novos nichos de mercado e geração de receitas. Por fim, as contribuições tecnológicas desse estudo na cadeia de valor do conhecimento sobre cacau, tornam-se relevantes para embasar tomada de decisão na construção do planejamento estratégico para o cacau; para pensar políticas públicas para fomento a inovação com a participação dos atores sociais (produtores, empreendedores do setor); e para construção de uma agenda que atenda demandas regionais e discuta o processo de transferência dessas tecnologias, além de desenvolver a capacidade de absorção dessas tecnologias pelos produtores de cacau.

\section{Palavras-chave:}

Prospecção Tecnológica; Patente; Mapeamento Tecnológico; Cacau.

\begin{abstract}
Cocoa cultivation had and has an important role in the social, economic and environmental construction of the Southern Coastal Territory of Bahia. Given the importance of cocoa in the social, economic and environmental construction of the TLS, studying technologies related to cocoa can stimulate discussions about strategies for the development of public policies aimed at fostering innovation for the Region. The mapping of scientific and technological production is a relevant tool for surveying the skills and evolution of science and technology. Thus, this chapter aims to develop a technological mapping applied to the processing and derivatives of cocoa, based on a prospective study in a patent bank, in order to identify: (i) the main patent applicants; (ii) the depositor's profile; (iii) the number of patent filings registered in each country; and (iv) distribution by themes. The research consisted of technological monitoring in sources of technological information accessible on the basis of patents. The study used two databases: a) National Institute of Industrial Property; b) $\mathrm{ORBIT}^{\circledR}$ software. The search strategy combined the fields: keywords, alone or grouped by Boolean
\end{abstract}

connectors. The search area was not defined, since it was desired to know the patents existing in all countries that have an industrial property system. The mapping showed a trend in technological routes related to the cocoa fermentation and drying process, which, in turn, is associated with the almond quality process. This indicator can enable and add value to this product, to explore new market niches and generate revenue. Finally, the technological contributions of this study in the value chain of knowledge about cocoa, become relevant to support decision-making in the construction of the strategic planning for cocoa; to think about public policies to foster innovation with the participation of social actors (producers, entrepreneurs in the sector); and to build an agenda that meets regional demands and discusses the process of transferring these technologies, in addition to developing the capacity for the absorption of these technologies by cocoa producers.

\section{Keywords:}

Technological Prospecting; Patent; Technological Mapping; Cocoa. 


\section{INTRODUÇÃO}

O Brasil foi por muitos anos um dos maiores produtores de amêndoa de cacau no mundo, e, durante a primeira década do século XX, chegou a ocupar a posição de maior produtor mundial (CEPLAC, 1982) ${ }^{1}$. O Território Litoral Sul da Bahia - (TLS) têm sua vocação agrícola baseada na cacauicultura, o que o faz um dos principais produtores de cacau do país. No passado, o cacau foi protagonista na construção social e econômica, sendo considerado como principal gerador de receita e emprego nos municípios que compõem este território. Diante da importância do cacau na construção social, econômica e ambiental do TLS, estudar as tecnologias relacionadas ao cacau pode estimular discussões acerca das estratégias para o desenvolvimento de políticas públicas destinadas ao fomento de inovação para Região.

O mapeamento da produção científica e tecnológica é uma ferramenta relevante para o levantamento das competências e evolução da ciência e tecnologia. Os avanços tecnológicos e a modernização dos sistemas de informação, Big Data e sistemas de busca, possibilitaram a criação de uma variedade de dados disponíveis como periódicos indexados, artigos científicos, e-book, teses dentre outros tipos, além de informações tecnológicas, como é o caso das patentes. O monitoramento da produção tecnológica em base de patentes torna-se relevante, pois possibilita mensurar o grau de desenvolvimento em determinada área de conhecimento, identificar possíveis rotas tecnológicas, desdobramentos pesquisas futuras e a inter-relação entre os players (COELHO, 2003; BORSCHIVER et al, 2016; SANTOS \& KALID, 2020).

Neste entendimento, este capítulo tem por objetivo, elaborar um mapeamento tecnológico aplicado ao beneficiamento e derivados do cacau, a partir de um estudo prospectivo em banco de patentes, a fim de identificar: (i) os principais depositantes de patentes; (ii) o perfil do depositante; (iii) a quantidade de registros de depósitos de patentes em cada país; e a (iv) distribuição por temas. A pesquisa consistiu no monitoramento tecnológico em fontes de informações tecnológicas acessíveis em base de patentes.

\section{DESENVOLVIMENTO E PRODUÇÃO DE CACAU NO TERRITÓRIO LITORAL SUL DA BAHIA}

A cacauicultura teve e tem papel importante na construção social, econômica e ambiental do Território Litoral Sul da Bahia. Na década de 1930, o cacau já era considerado como o principal produto da base econômica e de exportação da Região Sul da Bahia (COSTA, 2012) e respondia por uma fatia substancial das receitas de todo o Estado (MIRA, 2014). No referido território parte do plantio do cacau é feito sob a sombra de árvores nativas da Mata Atlântica, através do sistema agroflorestal-SAF,

1 o Território Litoral Sul da Bahia (TLS) foi criado a partir do projeto de lei 12.638 de 10 de janeiro de 2013, é composto por 26 municípios, o que corresponde a 2,6\% do território estadual (BAHIA, 2013). 
conhecido como cacau Cabruca ou cacau cabrocado, que associa o cultivo do cacau à Mata Atlântica, sendo um sistema diferente dos modelos tradicionais da agricultura. Desse modo, pode-se dizer que essa forma de produção é um exemplo de sustentabilidade ambiental (SANTOS et al., 2020).

Por volta de 1989, com o aparecimento e a propagação da doença conhecida como vassoura-de-bruxa, houve uma redução significativa da produção de amêndoas de cacau, com fortes impactos na estrutura agrária e na dinâmica econômica das cidades que compõe o referido Território (COSTA, 2012). Outro acontecimento relevante está relacionado ao longo período de estiagem 93/97, o que provocou, uma devastação das fazendas de cacau (NASCIMENTO, 1994), associado à forte depressão de preços que ocorreu nas exportações de cacau (COSTA, 2012; NOIA, 2011; FONTES, 2013; ESTIVAL, 2013).

Por exemplo, as exportações de cacau e derivados nos anos de 1990 correspondiam por 20,71\% do total do Estado, no período de 10 anos foi reduzido para 5,11 \% no ano 2000 (CEPLAC, 2009). Com referência a esse cenário, em 1990, o Brasil produzia 384 mil toneladas de amêndoas secas de cacau, em 1999, reduziu para o patamar de 123 mil toneladas, ou seja, ocorreu uma perda de $68 \%$ do que era produzido. No mesmo período, o Estado da Bahia que respondia por 356 mil toneladas, viu a sua produção diminuir para 99 mil toneladas (CEPLAC, 2009). O que fez eclodir uma desestruturação econômica de segmentos da sociedade notadamente os grandes cacauicultores, tendo como plano de fundo o retrocesso da lavoura cacaueira, acontecimento que representou um forte ponto de inflexão (MIRA, 2015).

Além dos fatores supracitados, pesquisadores/as indicaram outros motivos como responsáveis pelo descompasso da economia e do processo de declínio na produção de cacau; alguns indícios estão associados, dentre outros: à queda nos preços em função do aumento significativo da oferta de outros países e baixo investimento em tecnologia, (GONÇALVES et al., 2010). Nesse entendimento, com discute (COSTA, 2016) as crises da cacauicultura sempre convergem para a questão dos preços e o baixo aporte tecnológico utilizado na lavoura.

Apesar de ser predominante nos estudos sobre o cacau na região Sul, a tese de que a crise foi instaurada pela vassoura de bruxa, autores como Mira (2014) e Santos (2019) não concordam com a denominada "crise do cacau", uma vez que o Índice de Desenvolvimento Humano - (IDH), das cidades que fazem parte do Território Litoral Sul da Bahia apresentaram melhoras nos desempenhos do IDH, nos períodos censitários de 1991, 2000 e 2010. Por exemplo, cidades como Barro Preto, que o IDH era de 0,226 em 1991 alcançou o valor de 0,662 em 2010; Mascote de 0,208 para 0,581 em 2010; e Maraú, com 0,224 avançando para 0,593 em 2010 (SANTOS, 2019). É importante sublinhar que, se por outro lado, a queda na produção de cacau trouxe o descompasso econômico para os grandes latifundiários, por outro, insurgiram e consolidaram outros vetores econômicos, tais como: polo industrial e serviços que preencheram a lacuna deixada por este produto (MIRA, 2015).

O cacau que em seu processo de beneficiamento possui métodos e práticas singulares, é um produto primário que tem como finalidade mais conhecida o chocolate, mas seus derivados são utilizados em vários outros produtos (CEPLAC, 2009). O interesse pelo cultivo do cacau está no aproveitamento das amêndoas de cacau para produção de derivados como: manteiga de cacau, nibs, licor de cacau e pó de cacau; produto que servem de base para indústria de cosméticos, chocolates e doces (ALVES, 2002). 0 
processo tradicional que envolve as etapas de beneficiamento da amêndoa de cacau consiste em: colheita do fruto, operações de quebra ou abertura dos frutos, retirada do mel de cacau, fermentação, secagem e armazenamento das amêndoas (CRUZ, 2012; MARTINS, et al., 2012; FERREIRA et al., 2013). As etapas posteriores continuam na indústria (EFRAIM et al., 2010).

As tecnologias aplicadas a colheita e pós-colheita (beneficiamento) do cacau influenciam na qualidade final das amêndoas, consequentemente, dos seus derivados (CIDELL; ALBERTS, 2006; PIMENTEL, 2007). As inovações tecnológicas relacionadas a qualidade das amêndoas de cacau estão associados aos processos de pós-colheita (beneficiamento), principalmente nas etapas de fermentação e a secagem, que é de fundamental importância para a qualidade dos produtos derivados do cacau, sendo que nenhum outro processamento posterior é capaz de corrigir falhas nesta etapa (CRUZ, 2012).

Desde 2010, a Bahia entrou na rota do cacau de qualidade, com premiação em evento internacional em 2010 e 2011. O reflexo dessa conquista fomentou outros desdobramentos como por exemplo, o processo de Indicação Geográfica - IG, de procedência Sul da Bahia iniciado em 2014 e concedido em 2018. Tal desdobramento possibilita valorizar o cacau do Sul da Bahia com o selo de indicação de procedência, consequentemente abertura de novos mercados para Região (ACSB, 2018; UESC, 2017; CIC, 2017). Outro resultado relevante, foi implantação do Centro de Inovação do Cacau - CIC, sendo esse centro um elo estratégico para a Região, com aporte tecnológico para atender demandas relacionadas à qualidade do cacau e do chocolate.

\subsection{PROSPECÇÃO TECNOLÓGICA}

Os estudos de prospecção tecnológica ganharam maior impulso em meados dos anos 50 nos Estados Unidos (TEIXEIRA, 2013). No Brasil, tais estudos tiveram avanço mais tardio, a partir da década de 90. As discussões que abordam essa temática são relevantes para os estudos de tendências (TEIXEIRA, 2013). Esses estudos baseiam-se no pressuposto de ser possível identificar novas tecnologias a partir da análise dos padrões de pedidos de patentes em determinadas áreas do conhecimento (COELHO, 2010).

Nesse entendimento, a prospecção tecnológica é um processo que se ocupa da análise sistemática da tecnologia e suas relações com a ciência, economia e sociedade, com o objetivo de identificar áreas estratégicas de pesquisas e as tecnologias emergentes que tenham propensão de gerar valor econômico e social (SECTES/CEDEPLAR, 2009).

As informações tecnológicas extraídas dos documentos de patentes são importantes indicadores das atividades relacionadas a Pesquisa, Desenvolvimento e Inovação (PD\&l) e aos avanços tecnológicos na área da ciência e tecnologia. A prospecção tecnológica por meio de patentes consiste em coletar, analisar e validar as informações coletadas em base de dados, pois através dessas informações sistematizadas é possível verificar lacunas existentes, e as rotas tecnológicas em relação ao mercado (KUPFER; TIGRE, 2004).

Os trabalhos de prospecção tecnológica têm se tornado relevantes por contribuir para análise de informações, estabelecendo métricas e eficiência dos sistemas de inovação (SANTOS et al., 2010). 
Através desta ferramenta é possível identificar informações sobre tecnologias emergentes, o estágio de maturidade da tecnologia em questão e como ela se insere na sociedade (QUINTELLA et al., 2011), apontando para oportunidades de licenciamento, novas parcerias, monitoramento das atividades de PD\&l e melhor foco para alocação dos investimentos (BORSCHIVER et al, 2016).

A prospecção tecnológica envolve o mapeamento e a evolução de conhecimentos científicos e tecnológicos. O mapeamento tecnológico elaborado através dessas informações contidas em bancos de dados de patentes, permite conhecer o estado atual de uma tecnologia, e onde há maior concentração tecnológica nessa área (SPEZIALLI e SINISTERRA, 2015). Vale ressaltar que a patente tem prazo de vigência de 20 anos, após esse período de privilégio, o invento cai em domínio público, o que pode derivar em novas apropriações do conhecimento tecnológico, com investimentos menores dos que os praticados na patente original, além de estar disponível para uso, o que pode proporcionar subsídios para futuros projetos científicos (CANONGIA et al., 2002).

As bases de patentes podem ser utilizadas para: prospecção tecnológica; identificação de novas tecnologias aplicadas em determinadas áreas de desenvolvimento; mapeamento de tecnologias e percepção de tendências, entre outros fins (JAGHER, 2013). Desse modo, a busca em base de dados tecnológicos é um importante instrumento para apoio a pesquisas e podem ser utilizados para as mais diversas atividades acadêmicas e empresariais.

\section{METODOLOGIA}

A metodologia utilizada no presente estudo é composta por três etapas bem definidas, para identificação e análise das informações como mostra a Figura 1, o fluxograma da pesquisa, a seguir, apresenta uma síntese destas etapas. Nesta pesquisa, foram investigados artigos científicos e patentes relacionadas às tecnologias aplicadas a qualidade do cacau.

Nesta pesquisa, foram investigadas patentes relacionadas às tecnologias aplicadas ao beneficiamento e derivados do cacau. Como pesquisa exploratória, este estudo processou-se mediante o levantamento em fontes bibliográficas, busca em base dados, tratamento e análise das informações tecnológicas acessíveis em base de patentes. Para elaboração do mapeamento tecnológico, foi realizado estudo preliminar acerca do tema, com buscas em sites, revistas especializadas, da mídia especializada, sites das empresas do setor, relacionado ao assunto com cacau (etapa pré-prospectiva).

Foram utilizadas duas bases para busca de dados, essa tomada de decisão pode ser justificada pelas seguintes razões: a) O Instituto Nacional de Propriedade Industrial - (INPI) é órgão responsável por analisar os pedidos de patentes depositados no Brasil, ou seja, limita-se apenas a documentos de patentes depositadas no Brasil; b) o software ORBIT ${ }^{\circledR}$ foi utilizado, visto que a sua abrangência é maior. O ORBIT ${ }^{\circledR}$ permite acesso à base de dados FamPat, que cobre publicações de patentes, em todos os segmentos tecnológicos, como por exemplo a base do (EPO - European Patent Office); (WIPO - World Intellectual Property Organization). Além dessa ferramenta possuir funções analítica, o que propicia 
buscas mais refinadas, o software possui também display que exibe partes integrantes do pedido de patente como: resumos, descrição, reivindicações, inventores, titulares e classificações de patentes (QUESTEL,2018).

Figura 1 - Metodologia para a elaboração do mapeamento tecnológico

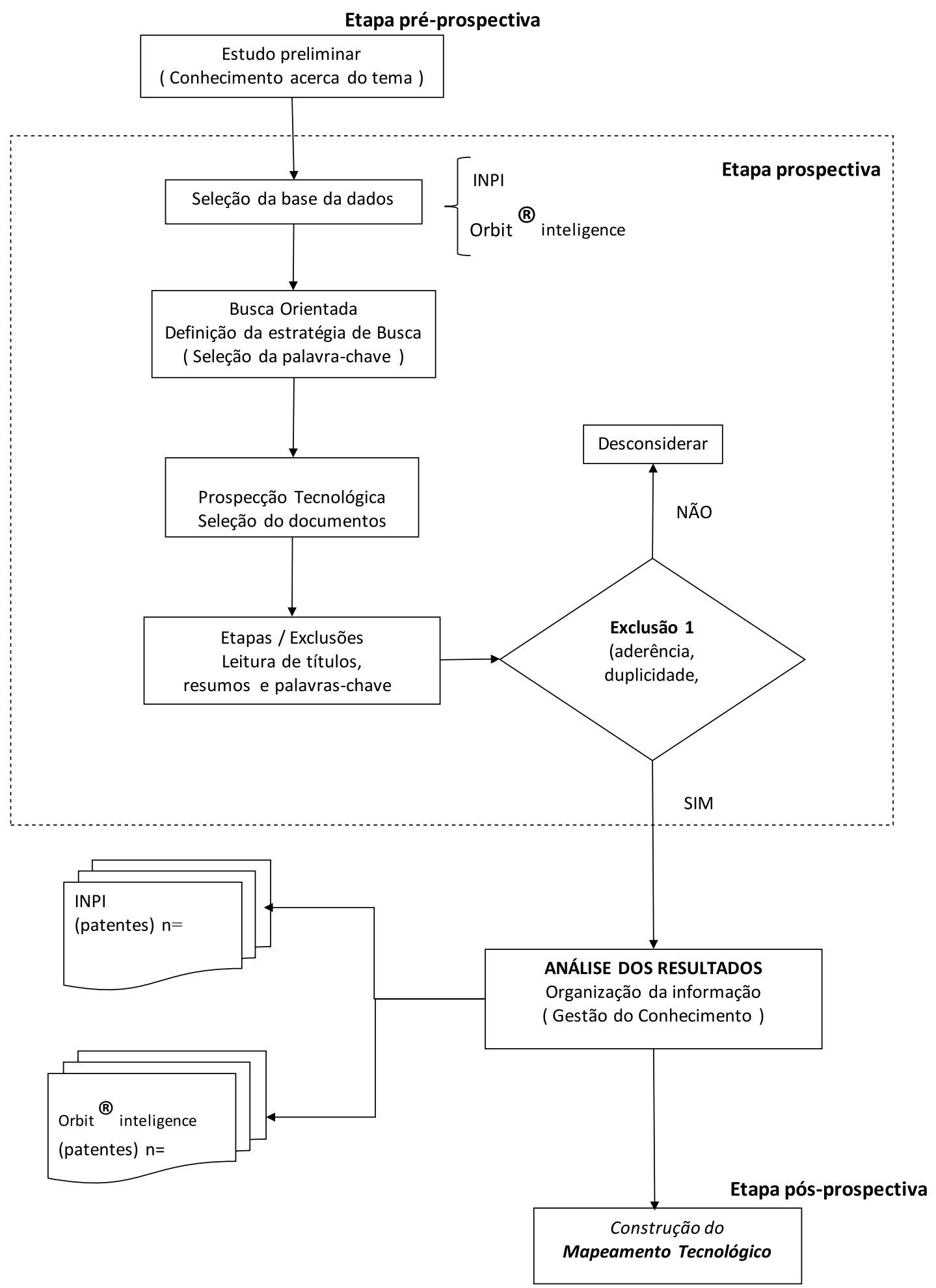

Fonte: Elaborado pelo autor 
Na etapa prospectiva, foram encontradas informações de uso cuja leitura permitiu identificação das palavras-chave adequadas para validar a estratégia e permitiu ainda um aprofundamento da real necessidade da tecnologia a ser desenvolvida. A seleção e análise destes documentos foram baseadas nas informações descritas nos documentos de patentes, tendo uma abordagem quantitativa e exploratória.

A pesquisa consistiu na realização do monitoramento tecnológico em fontes de informações tecnológicas acessíveis em base de patentes. O objeto desse estudo tem como cerne os ativos de propriedade intelectual patentes acerca do cacau, a estratégia de busca nas bases citadas combinou os campos: palavras-chave, isoladamente ou agrupadas por conectores booleanos. A área de busca não foi delimitada, pois desejou-se saber as patentes existentes em todos os países que têm sistema de propriedade industrial. A busca patentária foi atualizada até março de 2019.

\section{RESULTADOS E DISCUSSÕES}

\subsection{Resultados na base de dados do INPI}

Esta prospecção tecnológica encontrou 146 documentos na base de dados do Instituto Nacional de Propriedade Industrial - INPI, considerados como relevantes para a pesquisa. Utilizando a estratégia de busca citada na metodologia, após análise e leitura do resumo, foi possível identificar e retirar os dados em duplicidade, e que não tinha aderência a pesquisa, ou não foram localizados, restando 108 documentos.

Em relação aos códigos da Classificação Internacional de Patentes - IPC mais referenciados nos documentos de patente, foram encontrados com maior incidência os códigos: A23G 1/00, que tratam de "Cacau; Produtos de cacau, por exemplo: chocolate; seus substitutos (equipamento de cozinha para preparação de cacau, por exemplo, aparelhos para fazer bebidas A47J 31/00)"; A23G 1/02 tratamento preparatório, por exemplo: fermentação de cacau (máquina para torrar cacau A23N 12/00); Observa-se que as patentes estão relacionadas a produtos de cacau e substituto, equipamentos e máquinas para fermentação e secagem, e aparelhos para trituração, as demais subclasses não possuem relação direta com tema.

Na tabela 1, é demonstrado, que houve um crescimento no número de depósito de patentes que tratam de tecnologias relacionadas à fermentação de cacau, com 10 depósitos; processo de secagem com 5 depósitos; e equipamento secador de cacau, 6 depósitos. Os processos citados são primordiais para manter os níveis dos teores de compostos polifenóis do cacau, bem como para qualidade do produto, consequentemente agregação de valor e abertura de novos mercados. A qualidade do cacau é uma combinação entre o efeito do genótipo e do local do tratamento pós-colheita, manejo eficiente; e do controle rigoroso de cada etapa do beneficiamento (FERREIRA, 2017). A qualidade dos chocolates está relacionada diretamente com a qualidade das amêndoas. 
TABELA 1 - Número de patentes por combinação de palavras-chave e base

\begin{tabular}{l|c|c}
\hline \multirow{2}{*}{\multicolumn{1}{c|}{ Palavras-chave }} & \multicolumn{2}{c}{ Bases / número de documento } \\
\cline { 2 - 3 } & INPI & ORBIT \\
\hline Cacau & 146 & $\mathbf{1 6 5}$ \\
\hline Cacau AND Chocolate / Achocolatado & 12 & 25 \\
\hline Cacau AND Conchagem & 1 & 1 \\
\hline Cacau AND Contaminates & 2 & 2 \\
\hline Cacau AND Descascador & 2 & 3 \\
\hline Cacau AND Despolpador & 3 & 2 \\
\hline Cacau AND Equipamento/Quebra & 7 & 3 \\
\hline Cacau AND Fermentação & 10 & 9 \\
\hline Cacau AND Manteiga de cacau & 9 & 15 \\
\hline Cacau AND Massa & 7 & 12 \\
\hline Cacau AND Medicamento & 3 & 1 \\
\hline Cacau AND Mel & 3 & 2 \\
\hline Cacau AND Moagem & 6 & 22 \\
\hline Cacau AND Nibs & 3 & 2 \\
\hline Cacau AND Pó de Cacau & 7 & 5 \\
\hline Cacau AND Polifenóis & 11 & 2 \\
\hline Cacau AND Qualidade & 4 & 4 \\
\hline Cacau AND Refinador & 1 & 8 \\
\hline Cacau AND Refrigerante & 1 & 1 \\
\hline Cacau AND Secador & 6 & 6 \\
\hline Cacau AND Secagem & 5 & 7 \\
\hline Cacau AND Temperar & 3 & 28 \\
\hline Cacau AND Torrefação & 108 & 2 \\
\hline Exclusão 1 (aderência, duplicidade, não localizados) & & 2 \\
\hline TOTAL & 38 \\
\hline
\end{tabular}

Fonte: Elaborado pelo autor

Dessa forma, inicialmente, foi analisada a distribuição dos pedidos de depósitos por estado brasileiro, como mostra a Figura 4.1, nota-se que São Paulo e a Bahia são os estados brasileiros com a maior quantidade de depósito de patentes relacionadas às tecnologias de beneficiamento e derivados do cacau. Se considerarmos as patentes depositadas em parceria com São Paulo e Rio de Janeiro, o estado da Bahia ultrapassa São Paulo, totalizando 17 depósitos.

Este fato pode ser justificado pelo fato da Bahia, além de ser o maior produtor do país, em 2017 produziu 88,6 mil toneladas do fruto, seguido do estado do Pará que produziu cerca de 57 mil (IBGE, 2017). O Estado de Bahia possui também os principais dos centros de pesquisa sobre cacau como por exemplo: Ceplac; Centro Mars de Ciência do Cacau; Universidade Estadual de Santa Cruz - UESC e Instituto Federal de Educação, Ciência e Tecnologia Baiano - IFbaiano, a ainda concentra o cluster do setor industrial de moagem de cacau. 
Em 2011, 96\% do processamento de cacau foi concentrado em apenas quatro indústrias: Cargill, ADM Olam, Barry Callebaut e Delfi Cacau, todas com plantas industriais no Sul da Bahia. Em 2012, a Barry Callebaut adquiriu a Delfi Cacau, com essa aquisição, o market share da Barry Callebaut consolidou-se como a maior processadora instalada no Brasil, com $42 \%$ do total do processamento, seguida pela Cargill, com 32\%, ADM Olam, com 23\%, e Indeca, com 4\%. (MERCADO DO CACAU, 2013).

Figura 4.1 - Quantidade de pedido de depósito de patentes, por Estado - INPI.

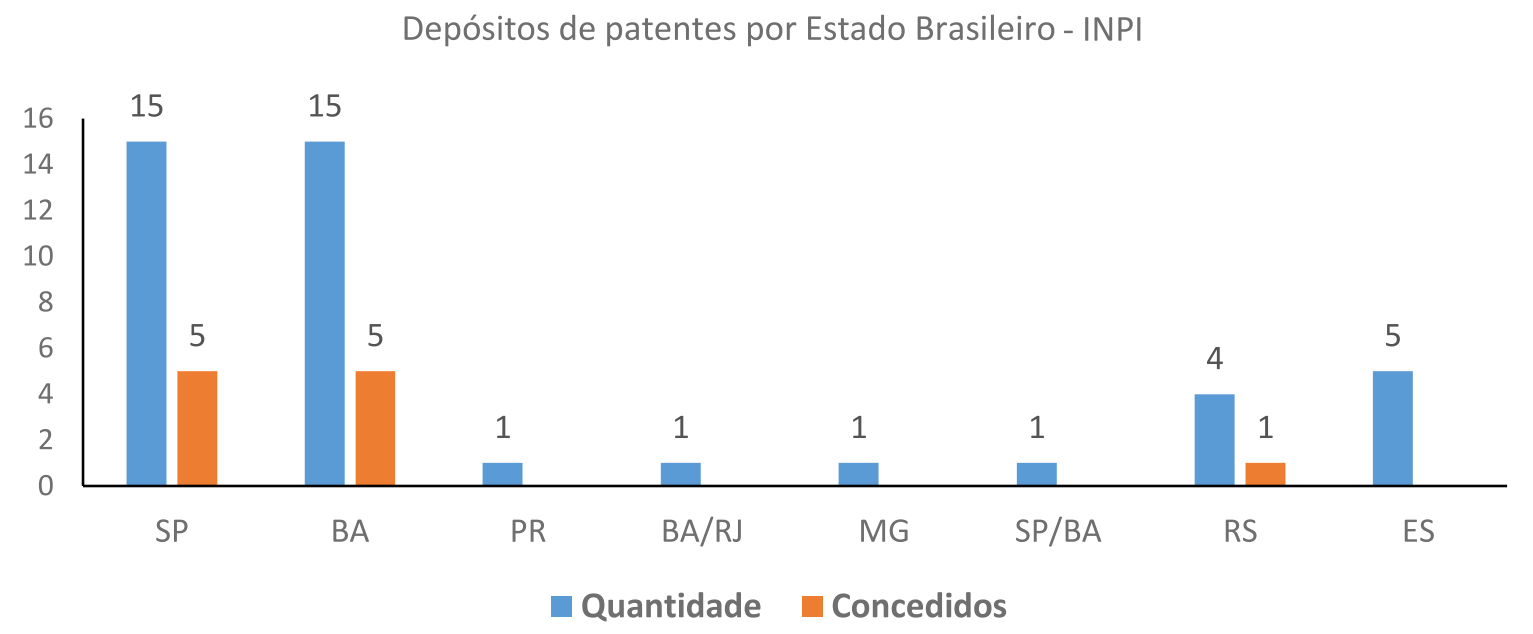

Fonte: Elaborado pelo autor

A Figura 4.1 evidencia que o estado de São Paulo concentra o maior número de indústria de chocolates, a exemplo das Kraft Foods com unidades em Bauru (SP) e Piracicaba (SP); Arcor com unidade em Bragança Paulista (SP); a Hershey's com unidade em São Roque (SP) e outras como Nestlé, Mars, além da Universidade Estadual de Campinas - UNICAMP que desenvolve pesquisas sobre cacau.

Em relação à concessão da carta patente, analisando as datas de concessão, observa-se que as patentes concedidas ao Estado na Bahia encontram-se expiradas, pois todas possuem mais de 20 anos, ou seja, caiu em domínio público. Vale ressaltar, que o prazo de vigência da patente é de 15 anos para de modelo de utilidade - MU e 20 anos para patentes de invenção - PI, contados a partir da data do depósito (INPI, 2018). Essas patentes foram depositadas por inventores independentes, com aplicação na área de equipamento para fermentação, secagem e despolpadora.

Ainda na análise das patentes concedidas, verifica-se que São Paulo concentra uma quantidade relevante de empresa e instituições que desenvolvem tecnologias relacionadas ao cacau. A JAF inox, indústria de máquinas de chocolates S.A (BR/SP), é detentora de 2 patentes na área de equipamentos industriais; bem como a Pinhal Ind. máquinas agric. S.A (BR/SP) possui 1 patente na área de equipamentos industriais; já a Universidade Estadual de Campinas - UNICAMP (BR/SP) possui uma patente relacionada ao um "Novo processo de fermentação de sementes de cacau utilizando inibidores químicos e enzimáticos, visando minimizar a perda de compostos fenólicos, em especial da 
classe dos flavonóides, e consequentemente, da obtenção de matérias-primas como massa de cacau (liquor), cacau em pó e produtos de chocolate com elevados teores de compostos fenólicos sem prejudicar em níveis perceptíveis seu sabor característico"; e uma patente de inventor independente na área de equipamento para secagem de cacau, que encontra-se expirada.

Como pode ser visto na Figura 4.1, o Estado de São Paulo além de concentrar a maior quantidade de indústrias de chocolates e doces, têm um número considerável de patentes conforme visto no gráfico. Isso pode ser justificado devido as competências tecnológicas na área industrial e de equipamentos.

$\mathrm{Na}$ análise do perfil dos depositantes no Brasil, os resultados mostram que $75 \%$ da propriedade intelectual relacionada aos pedidos de patentes sobre tecnologias aplicadas ao beneficiamento e derivados do cacau são de empresas, seguido dos inventores independentes com $21 \%$ com mostra a Figura 4.2. Entre os depositantes, é possível identificar o percentual de patentes que foram depositadas pela academia.

Figura 4.2 - Perfil dos depositantes - INPI

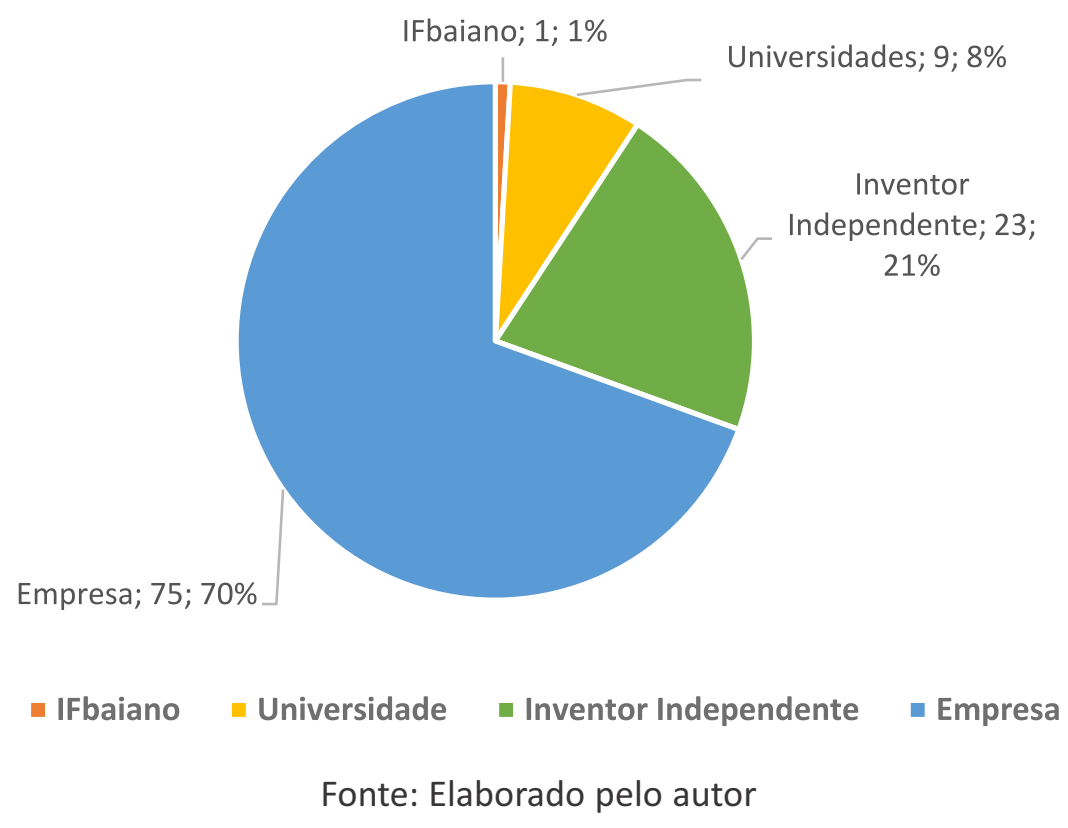

Analisando ainda a Figura 4.2, no perfil dos depositantes, verifica-se que $8 \%$ são de universidades (academia) com 9 pedidos e 1\% é do IFbaiano com 1 depósito. Apesar do percentual relevante de depósitos por inventor independente, ainda são poucas as concessões de carta patente para esse perfil.

A Figura 4.3 apresenta os seguintes depositantes de patentes: Universidades, Empresas e Inventores independentes. A MARS, Cargill e a JAF Inox são empresas com maior quantidade de depósitos de patentes que tratam desse tema. A MARS possui 8 depósitos, dentre essas, 2 patentes já concedidas, seguido da Cargill com 6 depósitos e a JAF inox indústria de máquinas de chocolates S.A (BR/SP) é 
detentora de 5 depósitos de patentes na área de equipamento industriais para cacau, dentre essas, 2 patentes já concedidas, intituladas: "refinador de produtos de cacau", com processo PI 0902425-5, com data do depósito 30/07/09 e concedida em 30/01/18; e a "temperadeira de adição", depositada 09/10/09 e concedida em 24/07/18, com número PI 0903968-6, tendo como inventor Adriano Sartori Pedroso. Nota-se que o processo de pedido dessas patentes concedidas demorou em média 9 anos até a concessão.

Figura 4.3 - Principais depositantes e a quantidade de patentes depositadas e concedidas - INPI.

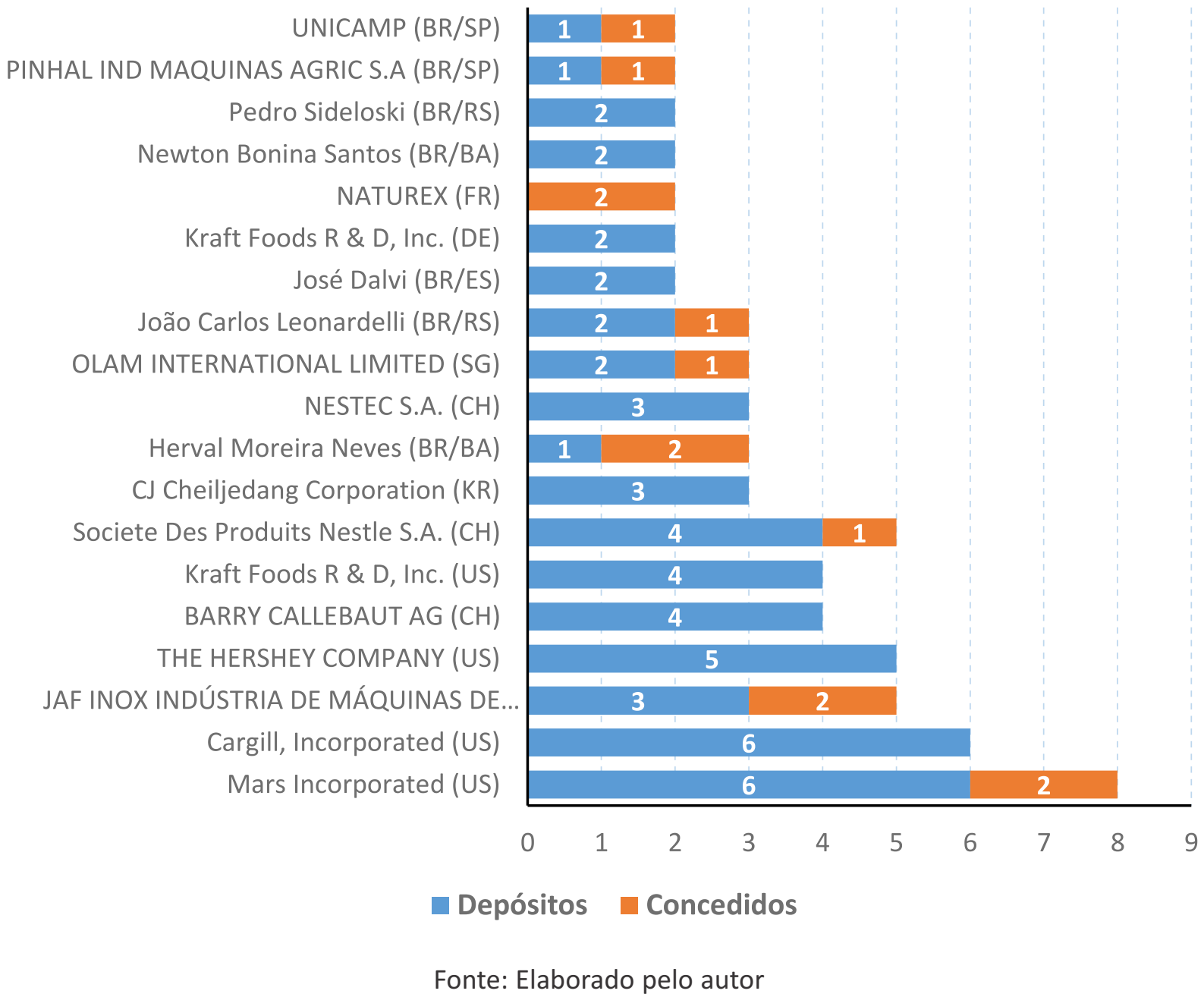

Pode-se observar, que o inventor independente Herval Moreira Neves (BR/BA) possui 3 depósitos de patentes, sendo 2 patentes já concedidas, na área de fermentação e secagem de cacau PI 7805778-7; a primeira intitulada "conjunto para fermentação de cacau", depositada em 24/08/1978 e concedidas em 25/10/1983; e a outra patente, PI 8005762-4, intitulada de "conjunto tubular para secagem continua de cacau, café ou outros produtos agrícolas", depositada em 29/08/1980 e concedidas em $26 / 10 / 1985$. Analisando o período de concessão dessas patentes, percebe-se que essas encontramse expiradas, ou seja, em domínio público. 
A Figura 4.4, apresenta a análise da evolução histórica dos depósitos de patentes. O gráfico mostra que em 1997 houve um aumento considerável na quantidade de depósitos de patentes de cacau no Brasil. Percebe-se então, que a quantidade de pedidos de patentes no Brasil nos últimos anos vem oscilando. É possível observar um crescimento linear na quantidade de depósitos de patentes entre 2001 e 2006, tendo uma queda no ano seguinte. Vale ressaltar que todos os pedidos de patentes possuem o chamado período de sigilo, que geralmente tem duração de até 18 meses, contados após a data de depósito ou data de prioridade mais antiga (data do primeiro depósito no país de origem).

Figura 4.4 - Evolução anual de depósito de patentes de tecnologias aplicadas ao cacau e seus derivados no Brasil - INPI.

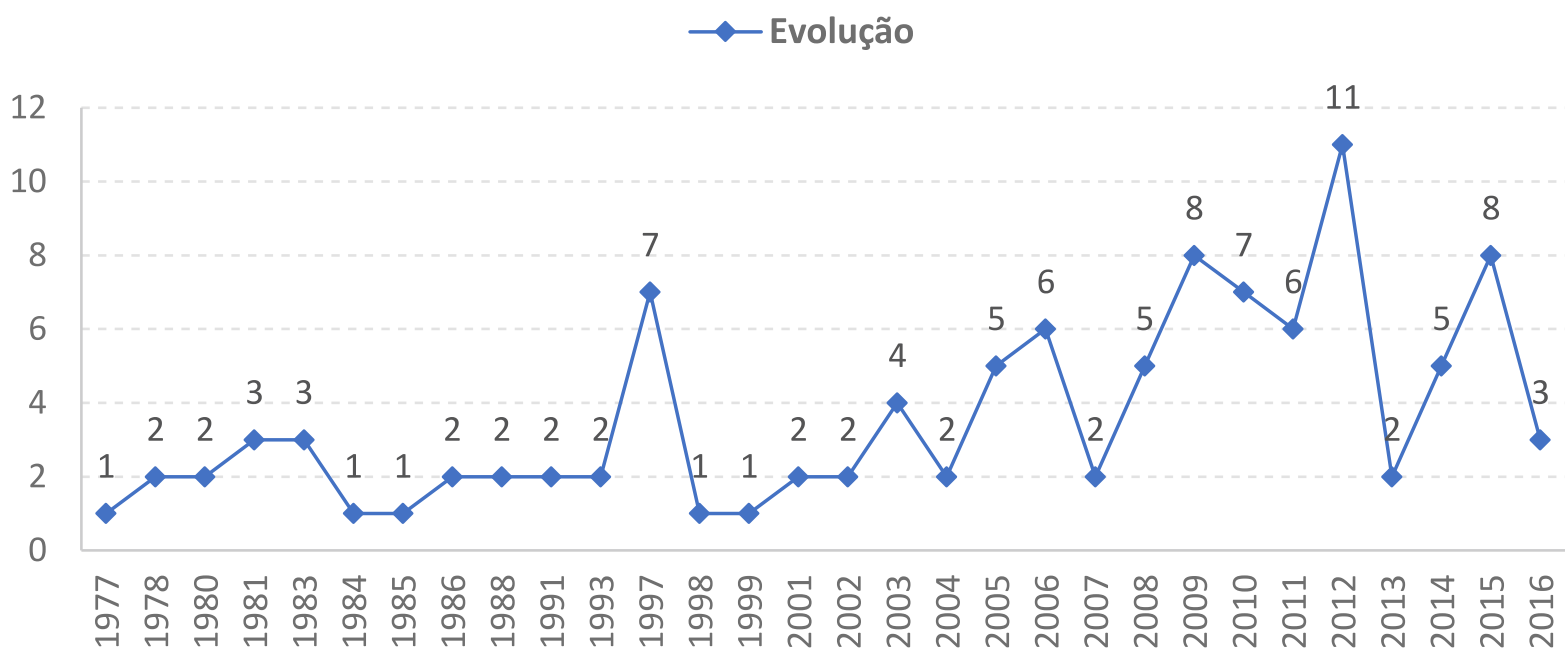

Ano

Fonte: Elaborado pelo autor

Em 2009 houve crescimento em comparação ao ano anterior com 8 depósitos, isso pode ser justificado pelo cenário que o Brasil vem mostrando nos últimos anos, com um grande potencial para a produção de cacau de qualidade. No ano de 2010, o Sul da Bahia foi incluído no mapa internacional de cacau fino, e, para fortalecer ainda mais este cenário, o mercado de chocolate redescobriu o Sul da Bahia como a região produtora de amêndoas de excelência, isto pode ser constatado em importantes concursos internacionais de qualidade das amêndoas de cacau (FERREIRA, 2017).

Para reforçar essa tese que atesta a qualidade do cacau produzido no Sul da Bahia, recentemente no ano de 2018, o TLS foi concedido o selo de Indicação Geográfica - IG ${ }^{2}$, de procedência Sul da Bahia pelo Instituto Nacional de Propriedade Industrial INPI, que reconhece no modo de fazer da região e

\footnotetext{
2 A Indicação Geográfica é um meio de valorizar e proteger juridicamente uma região reconhecida por produzir um produto singular, especial, que possui um "saber fazer" local característico e uma qualidade diferenciada (Lei $n^{\circ}$ 9279/96 - LPI, artigos 177 a 179).
} 
imprime a qualidade do produto, e que está relacionado aos aspectos socioeconômico, culturais e ambientais um mecanismo de diferenciação no mercado o que permite alcançar um novo posicionamento no mercado de cacau e chocolate (DANTAS et al., 2019; FERREIRA, 2017; SANTOS e KALID, 2020). Outro resultado importante foi implantação do Centro de Inovação do Cacau - CIC, sendo um elo estratégico para atender demandas relacionadas à qualidade do cacau e do chocolate (UESC, 2017; CIC, 2017). Ainda fazendo referência ao esse cenário, em 2011 foram 6 depósitos, no ano seguinte 11 depósitos, e em 2013 houve uma queda acentuada, oscilando no ano seguinte.

\subsection{Resultados na base de dados ORBIT ${ }^{\circledR}$}

$\mathrm{Na}$ busca utilizando a base de dados $\mathrm{ORBIT}^{\circledR}$, foram encontrados 165 documentos de patentes relacionados à palavra-chave cacau. A Figura 4.5 apresenta os principais países que realizam PD\&l sobre a tecnologias aplicada ao beneficiamento e derivados do cacau.

Figura 4.5 - Quantidade de depósito de patente por país de origem na base do ORBIT ${ }^{\circledR}$.

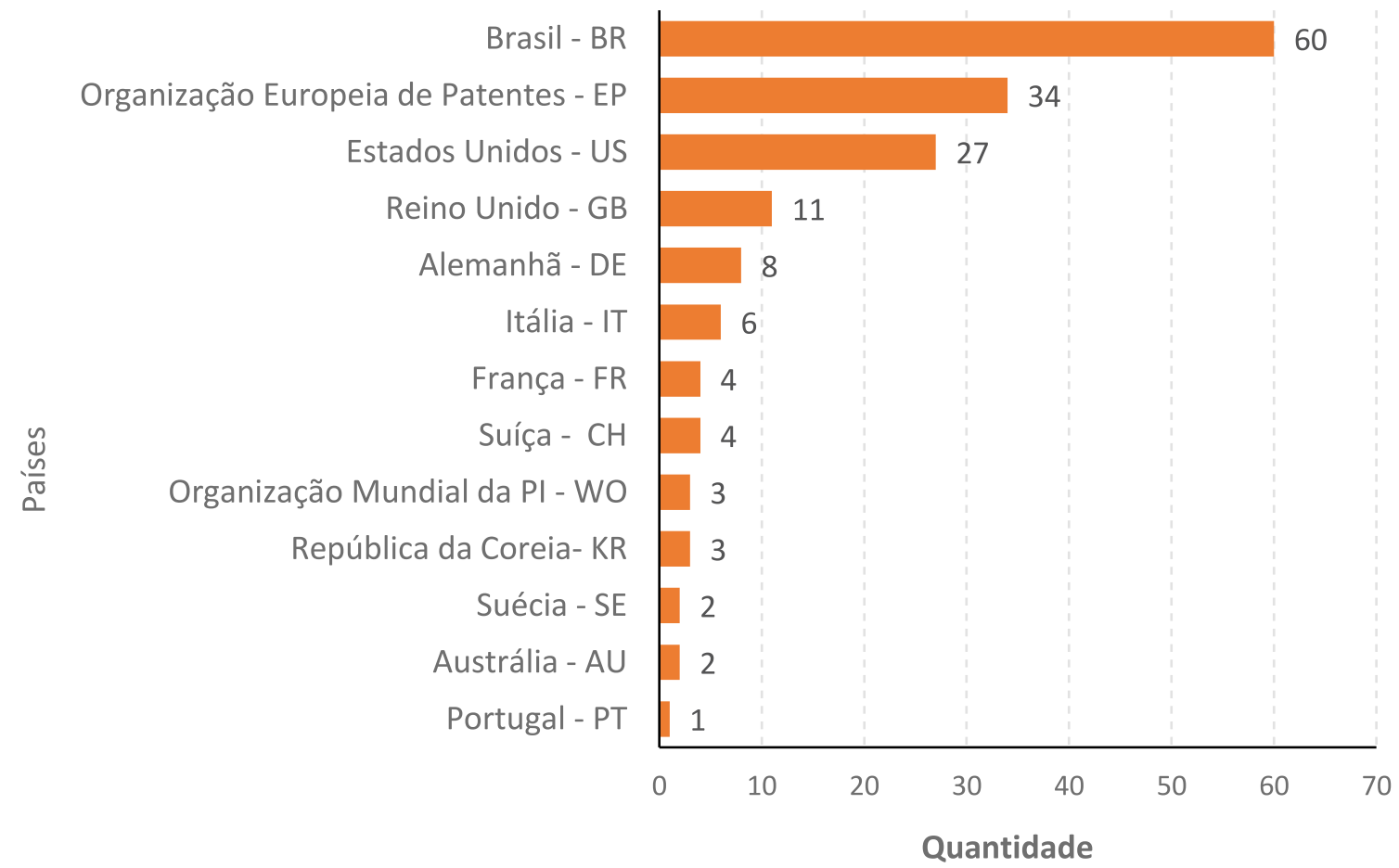

Fonte: Elaborado pelo autor

A pesquisa aponta que o Brasil possui a maior quantidade de depósito de patentes por países de prioridade, com 60 depósitos, o que representa (36,4\%), seguido da Organização Europeia de Patentes - EP, com depósitos internacionais via Tratado de Cooperação de Patentes (Patent Cooperation Treaty-PCT), com 34 famílias de patentes (20,6\%) depositadas prioritariamente em seu 
país, seguido dos Estados Unidos - US com 27 (16,4\%). Ainda, entre os 10 principais países aparecem Reino Unido, com 11 famílias de patentes prioritárias (6,7\%) e Alemanha, com 08 (4,8\%).

A Figura 4.6 apresenta as principais empresas depositantes que atuam no Brasil com posicionamento estratégico de proteção da propriedade industrial. A maioria das empresas atuam no setor de alimentos e equipamentos industriais. Na análise dos players, verifica-se que Mars e Nestle são detentoras da maior quantidade de depósitos de patentes, ambas com 11 pedidos, seguido da Cargill e Kraft Foods com 9 pedidos cada, a maior parte das patentes estão relacionadas ao processamento (moagem) e do segmento alimentício (engenharia de alimentos).

Figura 4.6 - Principais empresas depositantes na base do ORBIT ${ }^{\circledR}$.

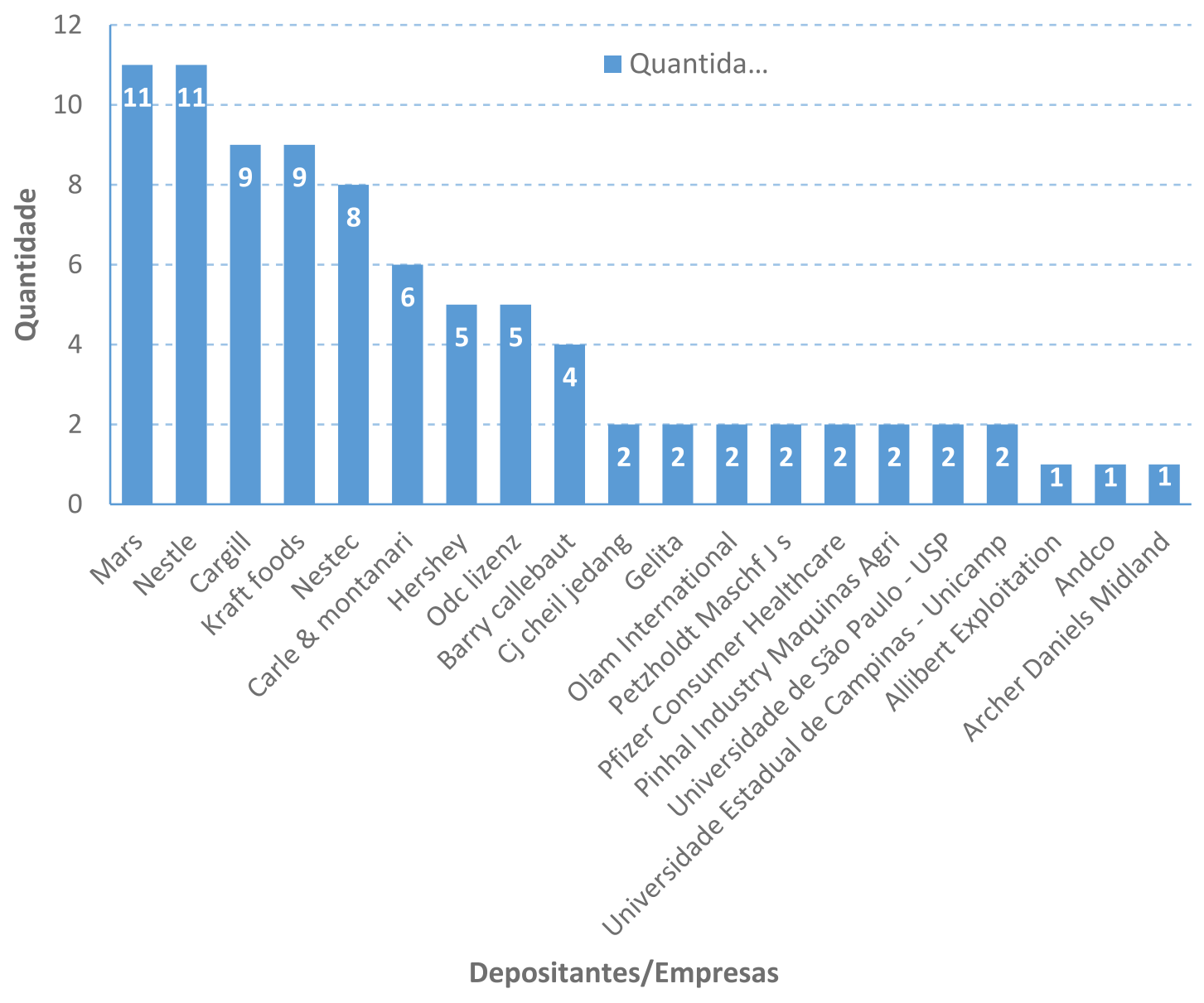

Fonte: Elaborado pelo autor

Na Figura 4.7, é apresentado o status legal das patentes, observa-se que a Mars e Nestle possuir a maior quantidade de depósito de patente que tratam desse tema. Entretanto, ao analisar o status de concessão da carta patente, as empresas Kraft Foods e Cargill são os players como maior quantidade de pedidos concedidos. 
Figura 4.7 - Status legal das patentes na base do ORBIT ${ }^{\circledR}$.

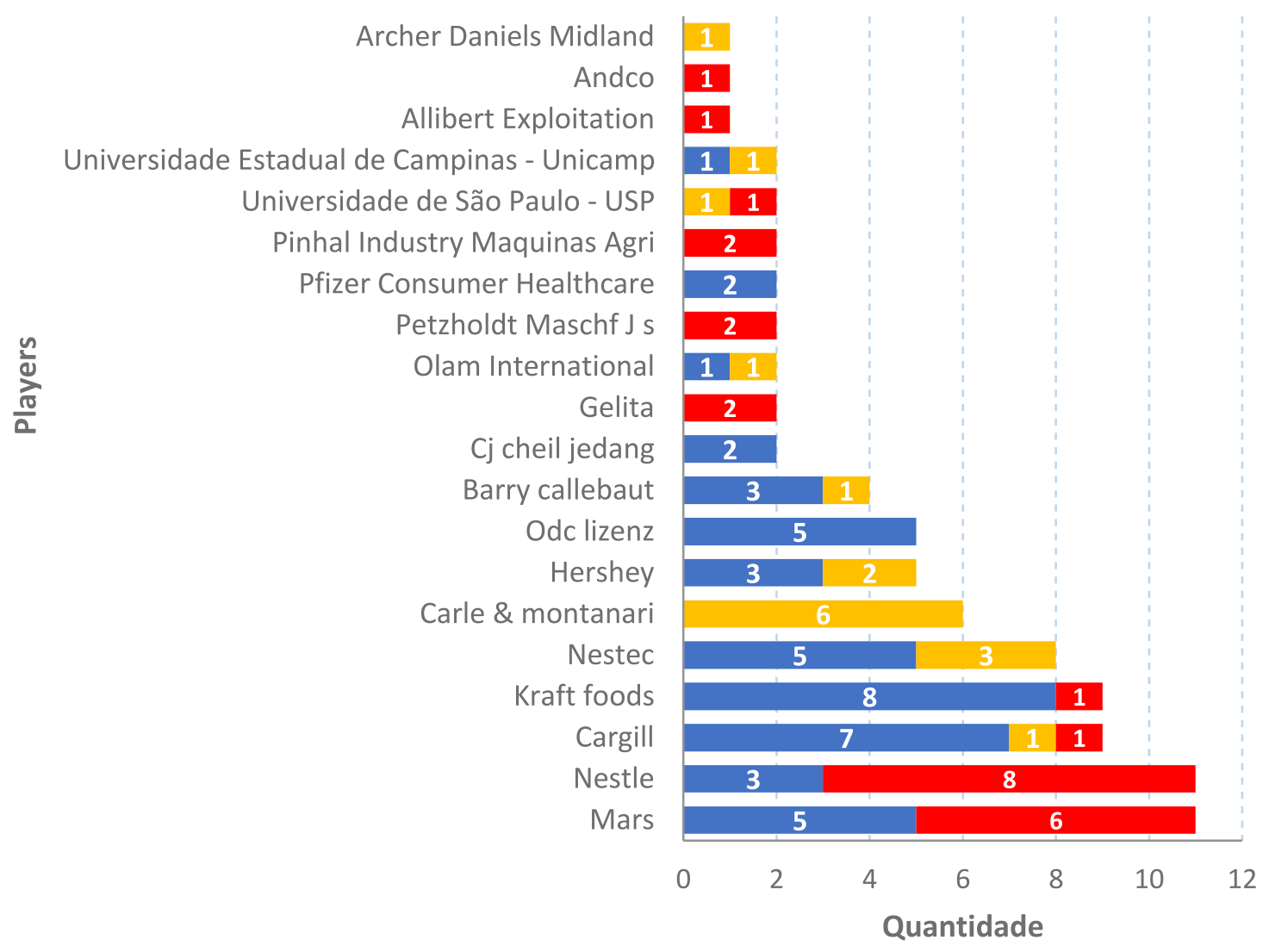

Patentes Concedida $\square$ Patentes Pendente $\quad$ Patentes Expidada

Fonte: Elaborado pelo autor

Nota-se que a Kraft Foods possui 8 patentes concedidas, relacionadas ao processo de "temperar chocolate", "chocolate em pó e polifenóis", como exemplo CA2635073 - "Grãos de cacau com reduzida atividade polifenol oxidase e alto teor de polifenóis"; BRPI0601933 - "Processo para o fabricar uma composição enriquecida com polifenóis a partir da extração da casca de cacau".

Apesar da maior parte das empresas citadas atuarem no setor de alimentos, com foco principal em chocolate, os resultados mostram que tem crescido o desenvolvimento tecnológico relacionados a fármaco, que englobam o mercado de cosméticos e alimentos funcionais, biodinâmicos e produtos com maior concentração de polifenol do cacau, como mostra da Figura 4.8 - A. Esses compostos podem agir como potenciais antioxidantes, que desempenham uma importante função na redução do risco ou retardo do desenvolvimento de doenças cardiovasculares, câncer e outras relacionadas a idade (SARMENTO, 2007). Devido ao tamanho do mapeamento, a figura foi dividida em duas partes, conforme mostra a Figura 4.8-A e 4.8-B 
Figura 4.8-A - Mapeamento das tecnologias aplicadas ao beneficiamento e derivados do cacau

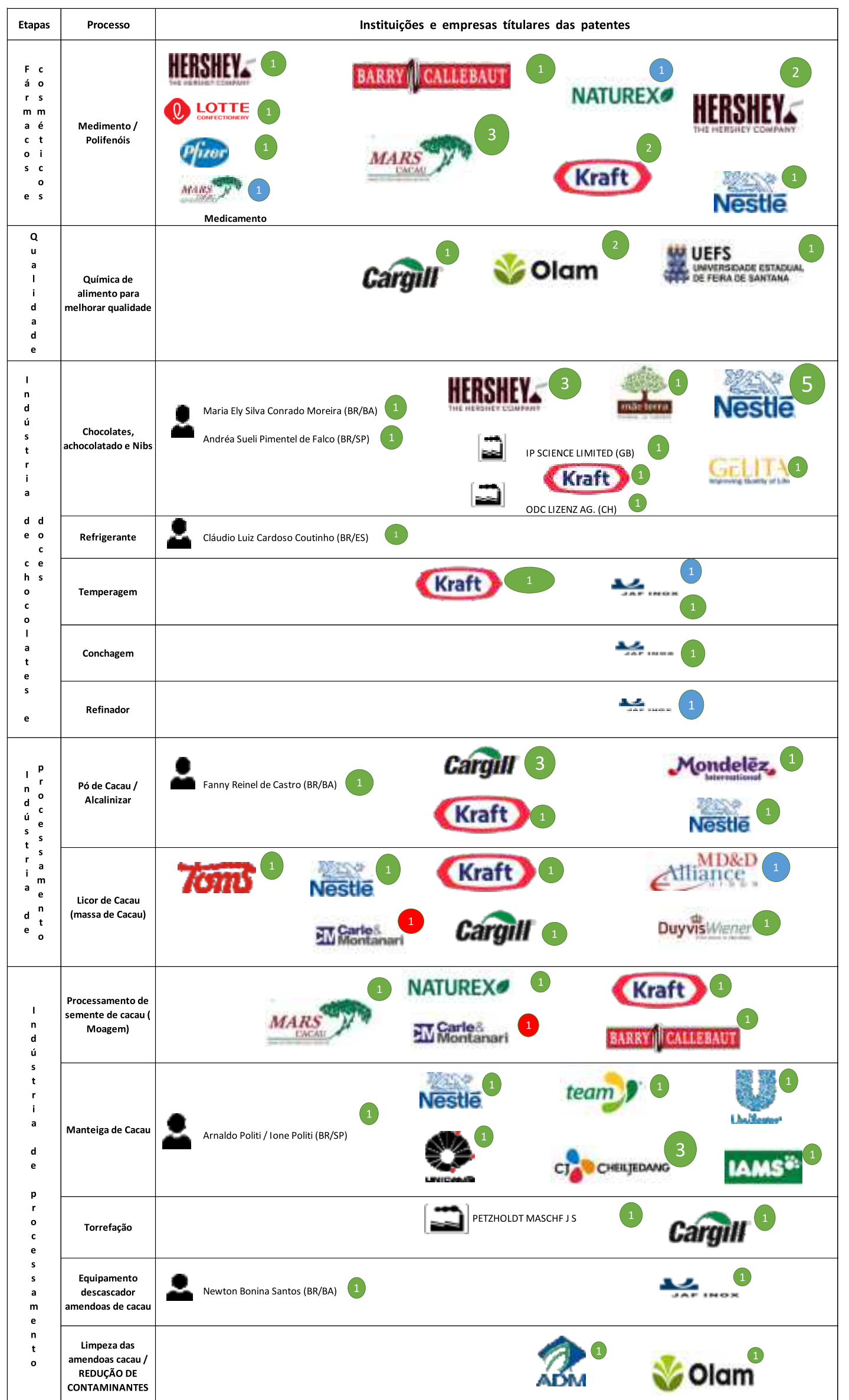




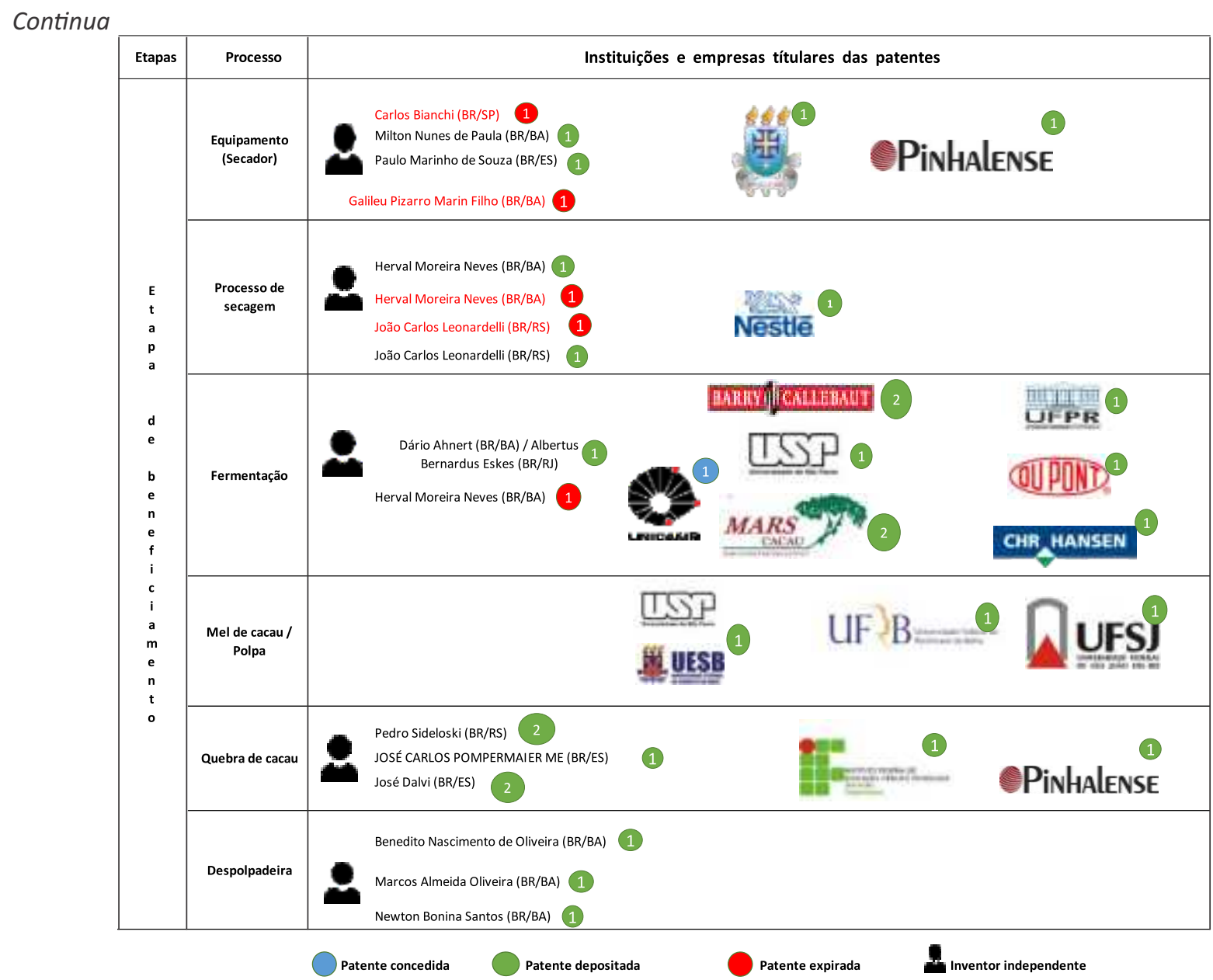

Fonte: Elaborado pelo autor

A pesquisa aponta para rotas tecnológicas em área relacionadas à qualidade do cacau, com tecnologias focadas no processo de fermentação e secagem, uma vez que, essas etapas são importantes para se obter características sensoriais e de sabor ao produto final, o chocolate conforme mostra Figura 4.8-B. As patentes mais recentes que tratam deste tema foram depositadas em 2016 "Método de fermentação de grãos de cacau" - WO2016030465- Dupont Nutricionais; seguindo da MARS que depositou em 2014 patentes que tratam desse tema - "Metodo de processamento de semente não fermentada de frutas, como cacau ou cupuaçu" - W02014130539 e "Microfermentação do cacau" - WO2013025621; outra empresa que tem deposito que trata desse processo é BARRY CALLEBAUT com patente intitulada "Composição microbiana para a fermentação do material de cacau" - WO2011012680

A CHR HANSEN Ind. com unidade de São Paulo, depositou uma patente recente que tratam sobre o tema fermentação intitulada "Melhoria da qualidade e do sabor do cacau usando a cultura de levedura de Pichia kluyveri para a fermentação do cacau" WO2013064678 depositada via tratado de cooperação de patentes - $\mathrm{PCT}^{3}$; uma outra patente que trata também dessa máteria é a dos pesquisadores e inventores Dário Ahnert e Albertus Bernardus Eskes, intitulada "Processo para a

3 O PCT é um tratado multilateral que permite requerer a proteção patentária de uma invenção, simultaneamente, num grande número de países, por intermédio do depósito de um único pedido internacional de patente (INPI, 2018). 
fermentação de grãos de cacau para modificar seu perfil aromático" - BRPI0800944, patente essa que encontra-se em processo de arquivamento no INPI.

Recentemente, foi depositada uma patente pela Universidade Federal do Paraná - UFPR (BR/PR) 01/09/2015, intitulada "processo para obtenção de licores de cacau, chocolates e outros produtos alimentares à base de cacau com superiores propriedades funcionais e sensoriais através da fermentação das sementes de cacau em sucos naturais de frutas com adição de agentes microbianos de fermentação".

Vale mencionar ainda patente relacionada ao processo de qualidade, depositada pela Universidade Estadual de Feira de Santana - UEFS (BR/BA) com aplicação no "processo de aproveitamento de amêndoas de cacau de baixa qualidade para a obtenção de cacau que, após a torrefação, desenvolva um aroma de chocolate significativamente semelhante ao aroma desenvolvido a partir de amêndoas de cacau de alta qualidade". Assim, o mapeamento mostra que tanto a inciativa privada como o setor público (universidades públicas) tem interesse no tema fermentação de cacau.

Como observado na Figura 8-B, o estudo aponta para o crescimento de tecnologias associadas ao processo de fermentação de cacau, isso evidencia tendência para pesquisa com foco em melhoria da qualidade do cacau. Outro dado relevante, diz respeito aos depósitos de patentes que trata de tecnologias relacionadas ao processo de secagem de cacau. Em 2015 foi depositada pela Universidade Estadual de Santa Cruz - UESC (BR/BA) um equipamento intitulado "Secador de Cacau Vertical" BR102015005977-9, do professor, inventor e Pesquisador Jorge Henrique de Oliveira Sales do DCET. Anterior a esse depósito, encontra-se uma patente de modelo de utilidade MU 8500575-4, depositada em 29/03/2005, com o título de "Secador rotativo duplo de eixo horizontal (SDR) para café, cacau, nozes, castanhas e outros produtos granulados", depositada pela empresa Pinhal Ind Máquinas Agric S.A (BR/SP), como certificado de adição de invenção com a patente concedida 11/01/2012.

Ainda na Figura 8-B, complemento da Figura 8-A, aponta que, apesar de encontrar apenas 3 patentes que tratam sobre o mel ou néctar de cacau, esse derivado vem sendo explorado comercialmente por empresas locais, como a Bahia Cacau fábrica de chocolate localizada no município de Ibicaraí-BA, primeira fábrica de chocolate da agricultura familiar no Brasil, que está envazando e congelando o mel de cacau para comercialização na forma in natura sem conservantes. Outra empresa que está produzindo aguardente feito à base de mel de cacau intitulado "Cauchaça" produzido pela fazenda Porto Esperança localizada no Sul da Bahia.

Apesar dessas inovações, o derivado mel de cacau carece de mais pesquisas em termos de tecnologias, pois, foram mapeadas patentes que fazia uso do mel com aditivo para composição de outro produto. Os depósitos de patentes que tratam deste tema são: BR 102013 005053-9 patente intitulada "composições alimentícias de chocolate e de gelado comestível contendo mel de cacau" uma parceria entra a Universidade de São Paulo - USP (BR/SP) e a Universidade Estadual do Sudoeste da Bahia - UESB (BR/BA); a patente BR 102015 013975-6 "Bebida gaseificada funcional" Universidade Federal do Recôncavo da Bahia - UFRB (BR/BA); e a patente BR 102016 025928-2 "Bebida à base de polpa de cacau in natura com adição de probiótico", Universidade Federal de São João Del Rei (BR/MG). 
Vale ressaltar que todas as patentes sobre mel de cacau são do setor público, o que se torna relevante para um processo de transferência dessa tecnologia com o custo menor, que o praticado setor privado. O resultado mostra que o derivado mel de cacau é uma matéria-prima ainda pouco aproveitada pela indústria beneficiadora de alimentos.

\section{CONSIDERAÇÕES FINAIS}

Esse estudo apresentou o panorama atual e as possíveis rotas tecnológicas relacionadas ao beneficiamento e derivados do cacau. O mapeamento apontou tendência de tecnologia aplicada ao processo de fermentação e secagem de cacau, que, por sua vez está associado ao processo de qualidade das amêndoas. Esse indicativo pode possibilitar e agregar valor a esse produto, para exploração novos nichos de mercado e geração de receita.

O mapeamento mostrou ainda que há algumas patentes que encontram-se expiradas, o que pode derivar em novas apropriações do conhecimento tecnológico a um custo menor do que o praticado em uma patente original, além dessa tecnologia está disponível para uso e para futuros projetos científicos.

Os resultados mostraram que as Universidades Brasileiras, como por exemplo a UESC, UNICAMP, UEFS; USP e UESB tem papel relevante na geração de conhecimento científico e tecnológico aplicado ao cacau, com competências tecnológicas que atendem demandas relacionadas as etapas de beneficiamento que são realizados ainda na fazenda; como por exemplo, equipamento para abertura do fruto desenvolvido por pesquisadores do IFbaiano, com objetivo de reduzir os índices de acidentes de trabalho no campo, nesta etapa do processo, uma vezes que nesta etapa utiliza-se de instrumento cortante (facão) para abertura do fruto; processo de fermentação e equipamento para secagem de cacau.

Essas inovações são fundamentais para melhorar o processo de qualidade do cacau, com tecnologias de baixo custo, uma vez que o conhecimento gerado por essas ICTs é financiado por recursos públicos, tornando assim, mais acessível o processo de transferência dessas tecnologias para os produtores de cacau, o que permitirá agregar valor à sua produção.

As discussões estabelecidas neste estudo trazem dados relevantes sobre as competências das ICTs locais, que neste estudo mostrou que essas instituições são um dos principais agentes da geração conhecimento sobre cacau. Fato que revela o papel das universidades no desenvolvimento tecnológico local. Sendo assim, torna-se necessário promover discussões acerca das tecnologias aplicadas ao cacau e a qualidade das amêndoas, como forma de fomentar alternativas que permitam a valorização desse produto e ainda a difusão dessas tecnologias, no sentido de facilitar o acesso a essasinovações.

Dessa maneira, as discussões deste capítulo podem auxiliar numa melhor compreensão do modo como os avanços tecnológicos estão sendo direcionados, e, poderá ainda, apontar possíveis rotas 
tecnológicas, dando subsídios para alocação de recurso e direcionamento de pesquisas, que tenham propensão de gerar valor econômico, social e ambiental para Território Litoral Sul da Bahia.

Com base nessas considerações, as contribuições desse trabalho permitirão gerar valor a cadeia do conhecimento, fomentando outros estudos sobre prospecção tecnológica, patentes e inovações para os produtos do cacau, que poderão ser objeto de pesquisa para trabalhos futuros. Por fim, as contribuições tecnológicas desse estudo na cadeia de valor do conhecimento sobre cacau, tornam-se relevantes para embasar tomada de decisão na construção do planejamento estratégico para o cacau; para pensar políticas públicas para fomento a inovação com a participação dos atores sociais (produtores, empreendedores do setor); e para construção de uma agenda que atenda demandas regionais e discuta o processo de transferência dessas tecnologias, além de desenvolver a capacidade de absorção dessas tecnologias pelos produtores de cacau. 


\section{REFERÊNCIAS}

ALVES, S. A. M.; FILHO, A. B. Epidemiologia da vassoura-de-bruxa (Crinipellis perniciosa (Stahel) Singer) em cacaueiros enxertados em Uruçuca, BA. Escola Superior de Agricultura Luiz de Queiroz, v. Mestrado, p. 53, 2002.

ACSB - Associação Cacau Sul Bahia - Indicação de Procedência Sul da Bahia - IP Sul da Bahia, Disponível em: http://www.cacausulbahia.org/ Acesso em: 02 julhos 2020.

BORSCHIVER, S.; SILVA, A.L.R., 2016. Technology Roadmap - Planejamento Estratégico para alinhar MercadoProduto-Tecnologia. ISBN: 97885719338661 .a Edições - 2016.

BAHIA. Lei n. 12.638 de 10 de janeiro de 2013. Dispõe sobre a atualização dos limites dos Municípios que integram o Território de. Identidade Litoral Sul, 2013. Disponível em: https://www.sei.ba.gov.br/ images/leis/LEI_12.638_10_01_2013.pdf>. Acesso em: 30 março 2019.

BRASIL. Lei de Propriedade Industrial. Disponível em: <http://www.planalto.gov.br/ccivil_03/leis/I9279.htm> Acesso em: 02 março 2021.

CEPLAC - Comissão Executiva do Plano da Lavoura Cacaueira. Nota Técnica (Abril/2009). Disponível em: http://www.seagri.ba.gov.br/not_notatecnica20042009.pdf. - Nota técnica (Abril/2009). Acesso em:26junho 2020.

CEPLAC. Avaliação econômica das atividades desenvolvidas pela Comissão Executiva do Plano da Lavoura Cacaueira no período de 1957 a 1980 (98). 1982. Disponível em: <http://www.ceplac.gov.br/ paginas/publicacoes/paginas/boletim_tecnico/cartilhas/BOLETIM\%20T\%C3\%89C.\%20N\%C2\%BA\%2098.pdf>. Acesso em: 03 de abril. 2021.

COELHO, G.M. Prospeç̧ão tecnológica: metodologias e experiências nacionais e internacionais. Rio de Janeiro: INT/Finep/ANP Projeto CT-Petro, 2003. (Petro Tendências tecnológicas). Disponível em: <http://www.tendencias.int.gov.br/>. Acesso 16 fevereiro 2021.

CIC - Centro de Inovação do Cacau. Disponível em: http://pctsb.org/cic/ Acesso em: 26 junho 2019.

CIDELL, J.L.; ALBERTS, H.C. “Constructing quality: The multinational histories of chocolate". Geoforum, London, v. 37, p. 999-1007, 2006.

CANONGIA, CLÁUDIA; MARIA, DE NAZARÉ F. PEREIRA; ADELAIDE, A. Gestão da informação e monitoramento tecnológico: o mercado dos futuros genéricos. p. 155-166, 2002.

COSTA, F. M. Políticas Públicas e Atores Sociais na Evolução da Cacauicultura Baiana. Tese de Doutorado. (Curso de Doutorado em Ciências Sociais, em Desenvolvimento, Agricultura e Sociedade - Doutorado). Universidade Federal Rural do Rio de Janeiro. Instituto de Ciências Humanas e Sociais. Rio de Janeiro. 2012.

COSTA, F. M. N. S. S. CACAU, Riqueza de Pobres. p. 104, 2016.

CRUZ, J. F. M. Caracterização das sementes de variedades de cacau Theobroma cacao L. resistentes à vassoura de bruxa durante a fermentação e após a secagem. p. 101, 2012.

DANTAS, P. C. C. et al. O Mercado de Chocolate no Sul da Bahia: Estrutura, Produção e Comercialização. v. 53, n. 9, p. 1689-1699, 2019. 
EFRAIM, P. et al. Influência da fermentação e secagem de amêndoas de cacau no teor de compostos fenólicos e na aceitação sensorial. Ciência e Tecnologia de Alimentos, v. 30, p. 142-150, 2010.

ESTIVAL, Katianny Gomes Santana. Construção social do mercado de qualidade do cacau no Brasil. Tese doutorado, Universidade Federal Rural do Rio de Janeiro, Instituto de Ciências Humanas e Sociais - UFFRJ, 2013.

FONTES, M. J. V. Do cacau ao chocolate: trajetória, inovações e perspectivas das pequenas agroindústrias de cacau/chocolate. Tese (Doutorado) Universidade Federal Rural do Rio de Janeiro, Instituto de Ciencias Humanas e Sociais, RJ., p. 1-216, 2013.

FERREIRA, Adriana. C. R. et al. Guia de Beneficiamento de Cacau de Qualidade - Instituto Cabruca. Ilhéus, Bahia: 201352 p.:il

FERREIRA, Adriana C. R. Indicação de Procedência Sul da Bahia - Manual de controle da Qualidade do Cacau Sul da Bahia - Editora: PTCSB, Ilhéus-BA; 2017. ISBN: 978-85-93727-02-3. 1. Qualidade de cacau; 2. Indicação Geográfica; 3. Sul da Bahia.

GONÇALVES, M. F.; CARNEIRO, W. M. A.; SENA, J. V. C. A CADEIA PRODUTIVA DO CACAU NA BAHIA: Uma Análise à Luz da Nova Economia Institucional. IV Encontro Regional Nordeste da Sociedade Brasileira de Economia, Administração e Sociologia Rural - (SOBER NE). Anais...2010

IBGE (Instituto Brasileiro de Geografia e Estatística). Produção Agrícola, 2017. Disponível em: <http:www.ibge.gov.br>. Acesso em: 20 fev. 2020.

INPI - Instituto nacional de propriedade industrial. Guia Prático para Buscas de Patentes. Disponível em:<http://www.inpi.gov.br/menu-servicos/informacao/guia-pratico-para-buscas-de-patentes >Acesso em: 8 abril 2018.

INPI - Instituto nacional de propriedade industrial. Buscas Avançada. Disponível em:<https://gru.inpi.gov.br/ pePI/jsp/patentes/PatenteSearchBasico.jsp>Acesso em: 8 agosto 2018.

IG - Indicação de Procedência Sul da Bahia Disponível em: http://www.cacausulbahia.org/ Acesso em: 5 abril 2021.

JAGHER,T. Busca em Banco de Dados de Patentes. Agência de Inovação / UTFPR. Disponível em: http://www.utfpr.edu.br/medianeira/estrutura/diretorias/direc/downloads/PROCEDIMENTOPARAPESQUISAU MAPATENTE.pdf. (2013) Acesso em: 18 jan. 2019.

KUPFER, D.; TIGRE, P.B. Modelo SENAI de Prospecção: Documento Metodológico. Capítulo 2: Prospecção Tecnológica. In: Organizacion Internacional Del Trabajo CINTERFOR. Papeles de La Oficina Técnica, n.14, Montevideo: OIT/CINTERFOR, 2004.

MIRA, E. C. CONTROVÉRSIAS SOBRE A ECONOMIA DO SUL DA BAHIA: uma análise evolutiva do desenvolvimento humano a partir da crise do cacau nos anos 1980. 2014.

MIRA, E. C. Mudança institucional e reconversão produtiva no sul da Bahia. EDITUS - ILHÉUS-BA, p. $336,2015$.

MERCADO DO CACAU. Barry Callebaut compra a Delfi Cacau Itabuna. Disponível em:http://mercadodocacau.com.br/2013/noticia/20663/barry_callebaut_compra_a_delfi_cacau_itabuna 03 de abril. 2021.

MARTINS, J.M.; MARTINS J. M.; OJ.H. F.; SILVA W. S.; SILVA V. B.; ARRUDA J. A. P; NASCIMENTO J. A. R.; DORTAS L. C.; FREITAS A. J. A.; RAMOS A. R. Melhoria da Qualidade de Cacau. Ilhéus. 2012 CEPLAC/CENEX. 45p. 
NASCIMENTO, Fernando Rios do, coord. 1994. A crise da lavoura cacaueira: sua natureza e soluções (uma análise das possibilidades do cacau). Brasília: IPEA.

NOIA, A. C. A construção do desenvolvimento local no município de Ilhéus-BA: uma análise das alternativas geradas após a crise da monocultura do cacau. Tese (doutorado) - Universidade Federal Rural do Rio de Janeiro, Instituto de Ciências Humanas e Sociais., p. 1-188, 2011.

PIMENTEL, F.A. "Avaliação do Poder Antioxidante do Chocolate Amargo - Um comparativo com o vinho tinto". (Dissertação). Mestrado em Ciência e Tecnologia de Alimentos, ICTA, UFRGS, Porto Alegre, 2007.

QUINTELLA, C. M. et al. Prospecção Tecnológica como uma Ferramenta Aplicada em Ciência e Tecnologia para se Chegar à Inovação. Revista Virtual de Química, v. 3, n. 5, p. 406-415, 2011.

QUESTEL. Orbit Intelligence, 2018. Disponível em: https://www39.orbit.com/?locale=en\&ticket=9e3d35ccf829-401c-a76e-baf08da87a1fAcesso em: 8 abril 2021.

SANTOS, M. M; COELHO, G. et al. Prospecção de tecnologias de futuro: métodos, técnicas e abordagens. Parcerias Estratégicas, v. 9, n. 19, p. 165-188, 2010.

SARMENTO, L. AL. V. Obtenção e separação de polifenóis de sementes de cacau por extração supercrítica associada a membranas. Tese de Doutorado apresentada ao Programa de Pós-graduação em Engenharia Química como requisito final para obtenção do Grau de Doutor em Engenharia Química. p. 105, 2007.

SANTOS, F. C. G. DOS; KALID, R. DE A. Prospecção tecnológica: um estudo das tecnologias aplicada ao beneficiamento e derivados do cacau. Research, Society and Development, v. 21, n. 1, p. 1-9, 2020.

SANTOS, Souza Dayvid. Panorama da socioeconomia solidária do Território Litoral Sul da Bahia. Dissertação de Mestrado Programa de Pós-Graduação em Engenharia Industrial, Escola Politécnica, Universidade Federal da Bahia. 116f. Salvador, 2019.

SANTOS, D. S. et al. Economia Solidária no Sul Da Bahia: Um Olhar Sobre a Política Territorial e no Conteúdo Tecnológico. Research, Society And Development, v. 21, n. 1, p. 1-9, 2020.

TEIXEIRA, L. P. Prospecção Tecnológica: importância, métodos e experiências da Embrapa Cerrados. Embrapa, 2013.

SECTES/CEDEPLAR. Metodologia de Prospecção Tecnológica - Projeto Oportunidades ao Desenvolvimento Socioeconômico e Desafios da Ciência, Tecnologia e da Inovação em Minas Gerais. Belo Horizonte - MG: Disponível em: https://www.infoteca.cnptia.embrapa.br/bitstream/doc/981247/1/doc317.pdf. Acesso em 04 de maio 2020.

SPEZIALLI, M. G.; SINISTERRA, R. D. Busca de informações tecnológicas com base em dados de patentes: estudo de caso dos líquidos iônicos no Brasil. Química Nova, v. 38, p. 1132-1138, 2015. Disponível em: http://www.scielo.br/scielo.php?pid=S0100-40422015000801132\&script=sci_abstract Acesso em 04 de abril 2021.

UESC, Jornal da Universidade Estadual de Santa Cruz, Cacau e chocolate ganham Centro de Inovação Tecnológica, Ano XIX - No 262, P. 12, março 2017 Disponível em: http://www.uesc.br/jornal/2017/jornal_262.pdf Acesso em 04 de abril 2021. 


\section{SANEAMENTO BÁSICO EM PEQUENAS COMUNIDADES: UM ESTUDO NA COMUNIDADE RURAL DO RIO DE PEIXE, ITABIRA - MINAS GERAIS.}

Fabrine Stephane Fonseca Gregório

Fundação Comunitária de Ensino Superior de Itabira - FUNCESI

fabrine.gregorio@hotmail.com

\section{RESUMO}

Este artigo tem por objetivo analisar as condições de acesso aos serviços de saneamento básico em pequenas comunidades. Para tanto, foi realizado um estudo de caso na comunidade rural do Rio de Peixe, localizada no município de Itabira - Minas Gerais. Verificaram-se as condições sanitárias e os hábitos higiênicos dos moradores que residem nessa comunidade, e, posteriormente, foram apontadas as tecnologias mais apropriadas, visando melhorias na qualidade de vida de todos os moradores. Quanto aos resultados obtidos, observou-se a precariedade do acesso aos serviços de saneamento básico na comunidade. Em relação à percepção dos moradores quanto à utilização de tecnologias apropriadas, foram apontadas como viáveis, a nascente, a fossa séptica, a compostagem, a reciclagem e as barraginhas. Tais resultados indicam a ausência de saneamento básico adequado na comunidade rural estudada, e a necessidade de inserir tecnologias apropriadas para reverter esse quadro de déficit.

\section{Palavras-chave:}

Comunidade rural; Saneamento básico; Tecnologias apropriadas.

\section{ABSTRACT}

This article aims to analyze the conditions of access to basic sanitation services in small communities. Therefore, a case study was carried out in the rural community of Rio de Peixe, located in the municipality of Itabira - Minas Gerais. The sanitary conditions and hygienic habits of the residents living in this community were verified, and, later, the most appropriate technologies were identified, aiming at improving the quality of life of all residents. As for the results obtained, the precariousness of access to basic sanitation services in the community was observed. Regarding the residents' perception regarding the use of appropriate technologies, the spring, the septic tank, composting, recycling and dams were identified as viable. These results indicate the absence of adequate basic sanitation in the rural community studied, and the need to introduce appropriate technologies to reverse this deficit picture.

\section{Keywords:}

Rural community; Sanitation; Appropriate technologies. 


\section{INTRODUÇÃO}

Nas áreas rurais brasileiras verificam-se os maiores déficits de acesso aos serviços de saneamento básico. Segundo dados do Instituto Brasileiro de Geografia e Estatística (IBGE), no Brasil, aproximadamente 29,9 milhões de pessoas vivem em áreas rurais, em, aproximadamente, 8,1 milhões de residências (IBGE, 2010). No espaço peridomicílio constata-se a recorrente precariedade de condições de vida dos moradores, decorrente da falta de saneamento básico adequado para as famílias (IBGE, 2010). Esse quadro decorre de limitações técnicas e de recursos sendo também marcante a ausência de políticas públicas de saneamento básico em áreas rurais o que contribui para o elevado déficit de acesso nessas localidades (Teixeira, 2011; Araújo 2011).

Diante dos impactos no meio ambiente, na saúde pública, e na qualidade de vida da população residente nas comunidades rurais decorrentes da falta de saneamento básico adequado, tornase necessária a realização de estudos nessas regiões e o desenvolvimento de tecnologias apropriadas. Segundo Oliveira e Moraes (2005), tecnologia apropriada é uma opção tecnológica que considera a adaptação ao meio, através da consideração da dimensão sócio cultural, como também dos aspectos do meio físico, com o intuito de ter um bom desenvolvimento de acordo com as especificidades de cada região.

Nesse contexto, este artigo busca contribuir para geração de conhecimentos sobre o saneamento básico em áreas rurais. Para fins de formação do arcabouço empírico, foi desenvolvido um estudo na comunidade rural do Rio de Peixe - Itabira - Minas Gerais. Nessa comunidade, foi analisada a questão do acesso aos serviços de saneamento básico dos moradores, bem como se verificou as tecnologias mais aptas para serem implantadas nesses espaços, com o intuito de ampliar o acesso de toda a comunidade em questão.

\section{METODOLOGIA}

A estratégia metodológica utilizada na pesquisa foi a triangulação de métodos qualitativos e quantitativos, dessa forma foi possível quantificar os dados coletados, a partir de variáveis matemáticas, como também interpretar a natureza do problema, por meio de ações vividas por grupos sociais (fontes). Nesse contexto, foi utilizado um estudo descritivo, com pesquisa de campo, de modo a analisar toda a população da comunidade do Rio de Peixe, sendo o critério de amostragem o Censo. Foram também feitas observações e entrevistas abertas na região estudada. 


\section{Condições de acesso aos serviços de saneamento básico na comunidade rural do Rio de Peixe - Itabira Minas Gerais.}

A área de estudo da presente pesquisa é a comunidade rural do Rio de Peixe, localizada no município de Itabira - Minas Gerais. Sendo que a mesma é uma possível fonte de abastecimento de água para o município de Itabira.

Ao se analisar o abastecimento de água na comunidade rural, percebeu-se que a fonte de captação é a nascente, pelo fato dos moradores possuírem as mesmas nas proximidades das suas residências. Por meio da força da gravidade, através da bica, a água chega às residências, e posteriormente a mesma é tratada por meio do filtro caseiro. Entretanto, torna-se indispensável a utilização da desinfecção, que como observado pelo SAAE (2013), tem a finalidade destruir ou inativar os organismos patogênicos, causadores de doenças, com a utilização do desinfetante (geralmente cloro).

Em relação ao esgotamento sanitário, verificou-se uma precariedade quanto a esse item do saneamento básico, sendo que o despejo dos efluentes domésticos é realizado de forma incorreta, com lançamento in natura nos cursos d'água, como ilustrado na FIG.1.

FIGURA 1 - Despejo dos efluentes no curso d'água.

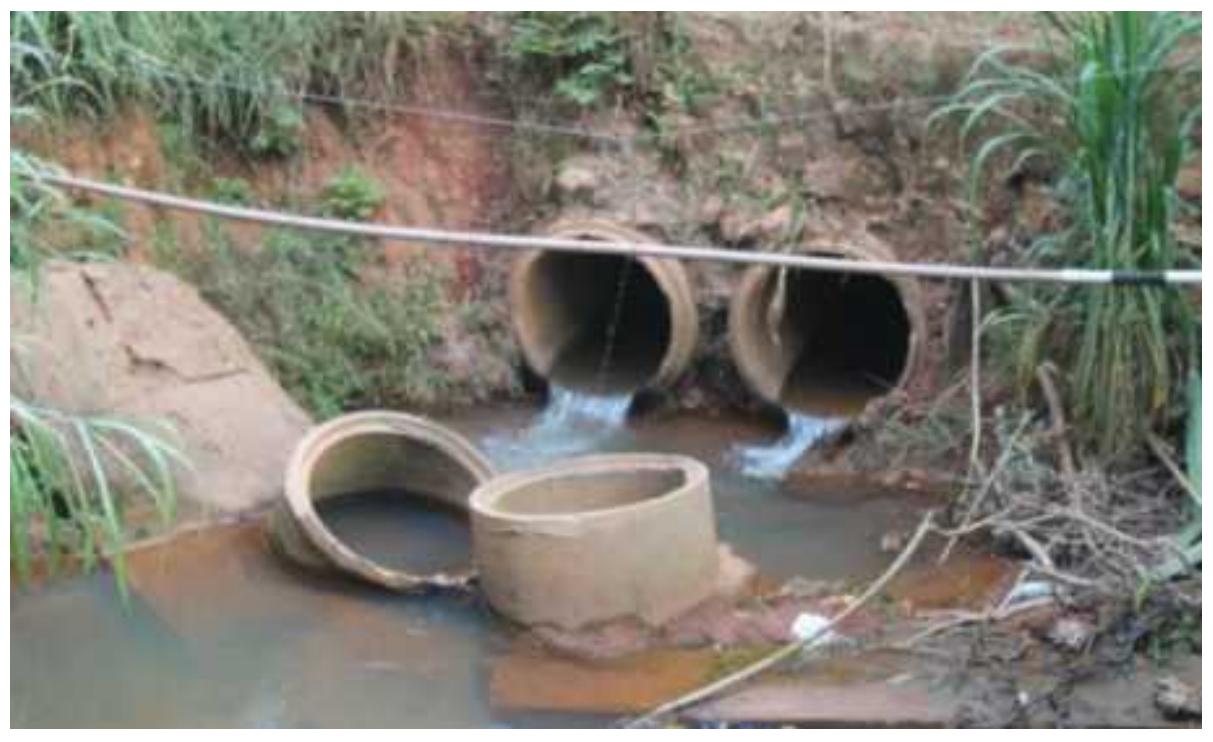

Fonte: Arquivo pessoal da autora, 2013.

Verificou-se que a maioria da população, que atualmente reside na comunidade rural do rio de Peixe, despeja os efluentes no curso D'água, como representado no GRAF.1. Sendo que esse despejo é um fator agravante á saúde pública, levando em consideração, os altos índices de diarreia e mortalidade infantil, causado pelo despejo inadequado pelos moradores. 
GRÁFICO 1 - Destinação dos efluentes domésticos

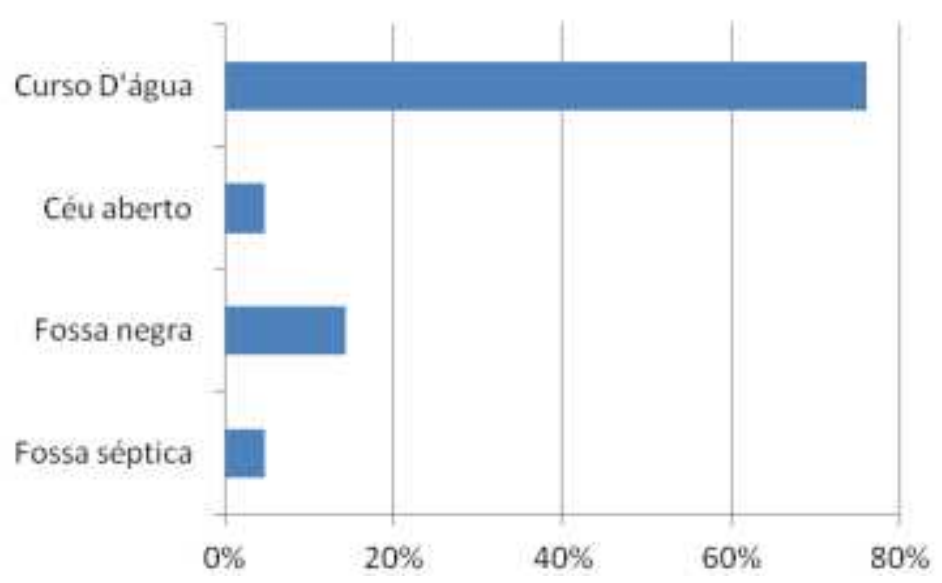

Fonte: Arquivo pessoal da autora, 2013.

Nesse contexto, como ressalta Ferreira (1992), ao se referir à mortalidade infantil, aponta a diarreia como a principal causa de mortes em crianças menores de um ano, fator esse que provoca a desidratação e a posterior morte em um período considerado curto. Dessa forma, torna-se imprescindível a destinação e o tratamento adequado dos efluentes domésticos, uma vez que os mesmos são despejados de forma incorreta.

Em relação à destinação dos resíduos sólidos, verificou-se que os moradores possuem um ponto de coleta na própria comunidade, no entanto é um local que tem se caracterizado como foco de vetores, conforme apresentado na FIG.2.

FIGURA 2 - Ponto de coleta dos resíduos sólidos.

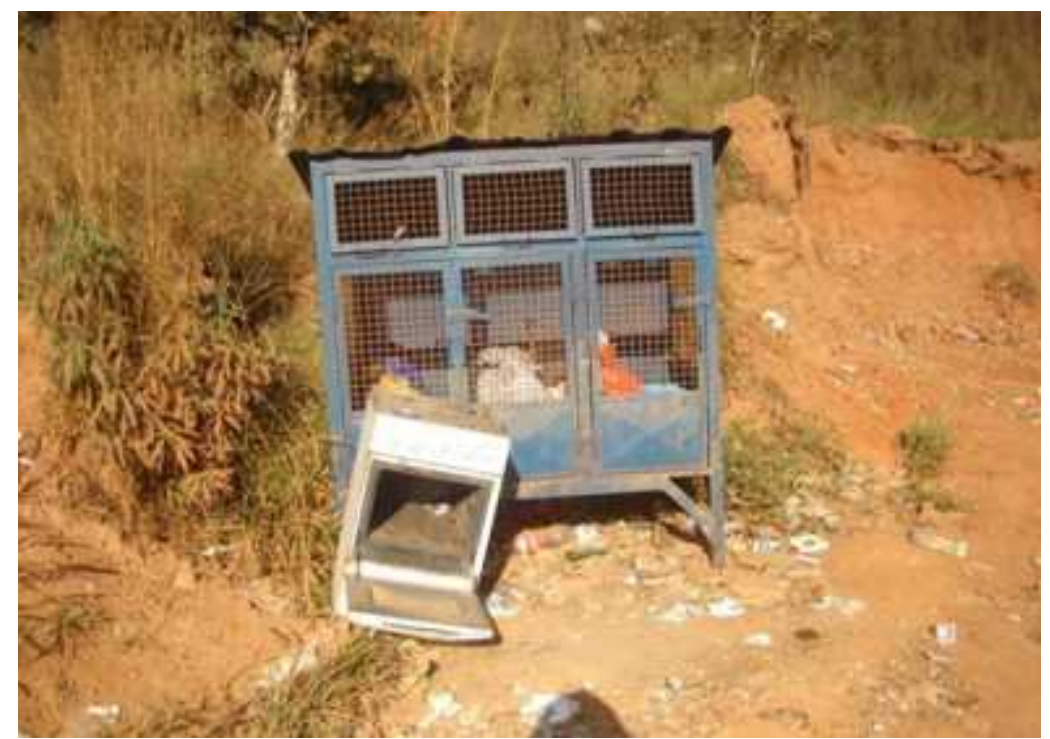

Fonte: Arquivo pessoal da autora, 2013 
Ao se analisar a drenagem na comunidade rural, verificou-se a inexistência desse item do saneamento básico, sendo encontradas poucas formas de sistemas de drenagem no decorrer da pesquisa de campo.

\section{Tecnologias apropriadas apontadas segundo a percepção dos moradores da comunidade rural do Rio de Peixe.}

As tecnologias apropriadas são imprescindíveis para as comunidades rurais, uma vez que proporcionam, com sustentabilidade, melhorias na qualidade de vida dos moradores. Como apontam Chagas et al. (2009), as tecnologias apropriadas não são aquelas que envolvem apenas uma solução. Uma vez que mesmo que as possibilidades estejam claras, sempre devem ser analisadas as demais alternativas. Os mesmos autores ressaltam que a tecnologia apropriada, nem sempre é aquela mais viável economicamente, que demonstra ser mais atual, nem que passa maior segurança e sim aquela que se adéqua a real situação da comunidade a ser atingida.

De acordo com a percepção da população em relação às tecnologias mais apropriadas quanto o acesso aos serviços de saneamento básico na comunidade estudada, verificou- se que, em relação ao abastecimento de água, os moradores apontaram como a mais viável a nascente, pelo fato de possuir a mesma em suas residências, conforme apresentado no GRAF.2.

GRÁFICO 2 - Melhor tecnologia para o abastecimento de água

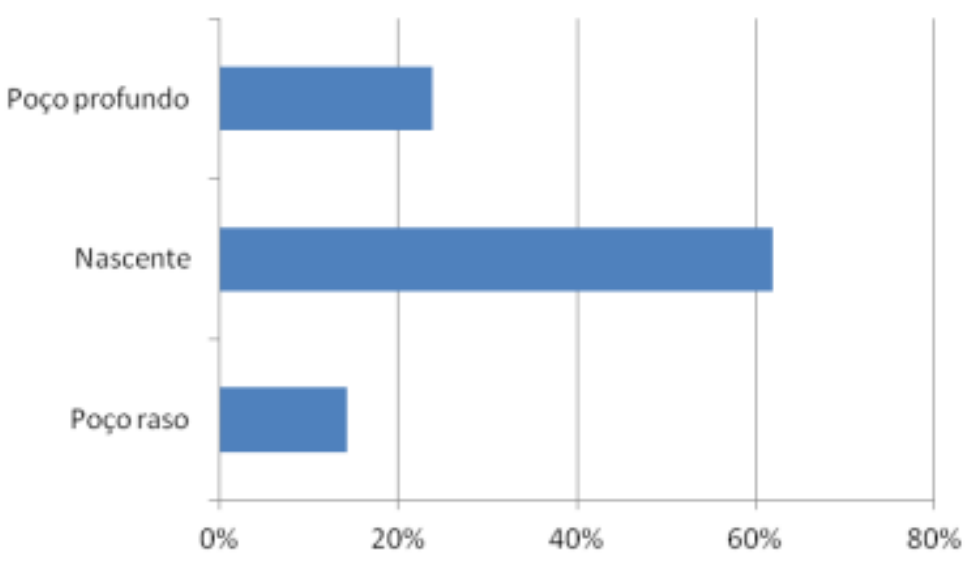

Fonte: Arquivo pessoal da autora, 2013

Ao se analisar a tecnologia mais apropriada para o esgotamento sanitário, os moradores apontaram como a mais adequada, a fossa séptica coletiva, conforme representado no GRAF.3, sendo a mesma de extrema importância para o tratamento correto dos efluentes domésticos, uma vez que essa tecnologia visa melhorias na qualidade de vida de toda a população. 
GRÁFICO 3 - Melhor tecnologia para o esgotamento sanitário

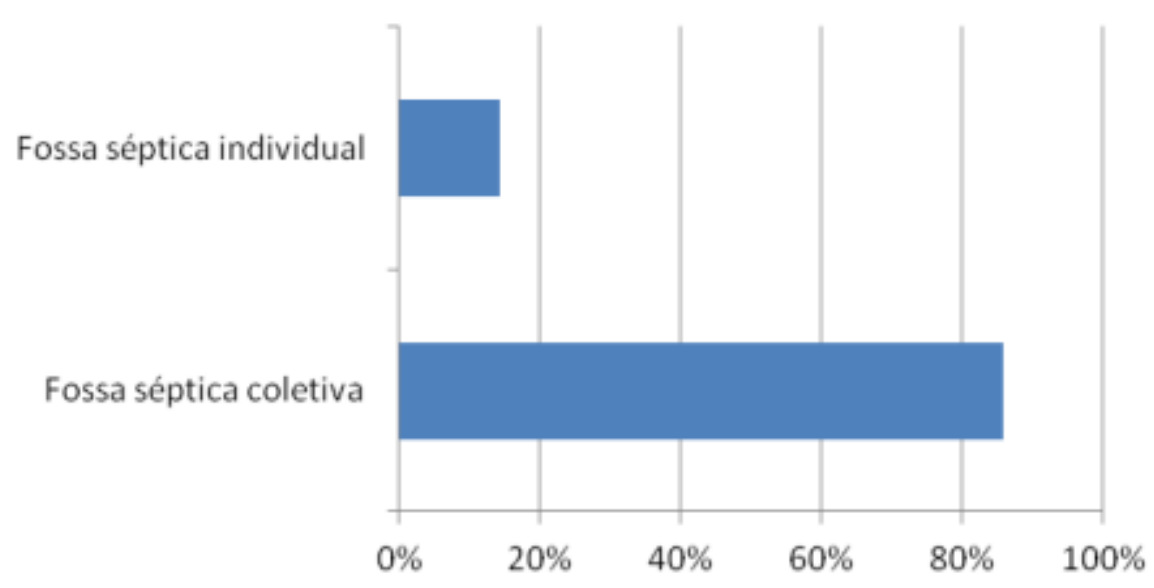

Fonte: Arquivo pessoal da autora, 2013

Essa opção é também sugerida por Crespo (1997) ao apontar que em pequenas comunidades rurais a tecnologia mais apropriada para o tratamento de esgoto é a fossa séptica.

Em relação à destinação dos resíduos sólidos, a tecnologia apontada foi a reciclagem e a compostagem, sendo uma destinação correta na própria residência, uma vez que as comunidades rurais são distantes dos aterros sanitários, o que dificulta o transporte. Ao se analisar a tecnologia mais adequada para a drenagem, a maioria dos moradores apontaram as barraginhas.

\section{CONSIDERAÇÕES FINAIS}

Diante dos conhecimentos adquiridos, cabe ressaltar que, nas comunidades rurais, é imprescindível a realização de estudos específicos, de modo a obter melhorias na qualidade de vida a partir de intervenções que considerem a realidade local.

Pela comunidade rural do Rio de Peixe existem mananciais estratégicos que podem ser uma fonte futura para a captação de água no município de Itabira- MG. Entretanto, ao se analisar a condição de acesso aos serviços de saneamento básico nessa localidade, verificou-se déficit de acesso. Sendo assim, o déficit de saneamento básico é a possível causador de poluição dos mananciais locais. Dessa forma, há a necessidade de adoção de tecnologias apropriadas para reverter esse quadro de déficit.

A utilização de dados quantitativos e qualitativos foi essencial para a realização da pesquisa, de modo a verificar as condições atuais que se encontram as famílias. As fotografias e a vivência em campo foram indispensáveis para verificar a realidade de toda a comunidade, e essencial para a interpretação dos resultados da pesquisa. 


\section{REFERÊNCIAS}

ARAÚJO, G. V. R. et al. Ausência de saneamento básico no semiárido Pernambucano: a percepção de moradores na comunidade de poço da cruz, em Ibimirim-PE.II Congresso Brasileiro de gestão ambiental.2011. Disponível em: http://www.ibeas.org.br/congresso/Trabalhos2011/IX-011.pdf. Acesso em: 10 mai 2013.

CHAGAS, L. R. et al. Saneamento básico integrado as comunidades rurais e populações tradicionais: guia do profissional em treinamento. Nivel 2. Transversal, 2009. 92p. Disponível e m : http://www.unipacvaledoaco.com.br/ArquivosDiversos/saneamento_basico_integrado_a s_comunidades_rurais_e_populacoes_tradicionais.pdf. Acesso em: 26 mai 2013.

CRESPO, P. G. Sistema de esgotos. Belo Horizonte: UFMG, 1997.131p.

FERREIRA, C.E.C. Saneamento e mortalidade infantil. São Paulo, 1992.8p. Disponível em: http://www.seade.gov.br/produtos/spp/v06n04/v06n04_09.pdf. Acesso em: 10 abr 2014.

INSTITUTO BRASILEIRO DE GEOGRAFIA E ESTATISTICA (IBGE/2009).

FUNASA 2010. Disponível em: http://www.funasa.gov.br/site/engenharia-de-saude- publica-2/saneamentorural/ Acesso em: 28 abr 2013.

INSTITUTO BRASILEIRO DE GEOGRAFIA E ESTATISTICA (IBGE). CENSO 2010. Minas Gerais: Itabira. 2010.

OLIVEIRA, M. T. C.; MORAES, L. R. S. A Tecnologia apropriada e o sistema condominial de esgoto sanitário: uma revisão conceitual. 2005. Disponível em: http://www.bvsde.paho.org/bvsacd/abes23/II-256.pdf. Acesso em: 25 mai 2013.

ORGANIZAÇÃO DAS NAÇÕES UNIDAS (ONU). ONUBR: nações unidas do Brasil, 2013. Disponível em: http://www.onu.org.br/onu-dos-7-bilhoes-de-habitantes-do- mundo-6-bi-tem-celulares-mas-25-bi-nao-tembanheiros/. Acesso em: 25 mai 2013.

SERVIÇO AUTÔNOMO DE ÁGUA E ESGOTO (SAAE). Minas gerais: Itabira.

Disponível em:http://www.saaeitabira.com.br/EmpresaCidadã/ETE/tabid/601/Default. aspx. Acesso em:01 fev2013.

VON SPERLING, M. Introdução à qualidade das águas e ao tratamento de esgotos. 3 ed.Belo Horizonte:UFMG,2005.452p.

TEIXEIRA, J. et al. Saneamento rural no Brasil - perspectivas. In: REZENDE, S.C. (org.). Cadernos temáticos. (Vol. 7). In: HELLER, L.; MORAES, L. R. S.; BRITTO, A.

L. N. P.; BORJA, P. C.; REZENDE, S. C. (coord.). Panorama do saneamento básico no Brasil. Brasília: Ministério das Cidades, 2011. 


\section{FITOSSOCIOLOGIA DE TRÊS FAMÍLIAS BOTÂNICAS DE UM FRAGMENTO FLORESTAL DO MUNICÍPIO DE ALTA FLORESTA, MATO GROSSO}

Liliane Barboza Bispo

Universidade do Estado de Mato Grosso - UNEMAT

Campus de Alta Floresta - MT

lilianebarboza@hotmail.com

Marcos Leandro Garcia

Universidade do Estado de Mato Grosso - UNEMAT

Campus de Alta Floresta - MT

ml.marcos@unemat.br

\author{
Muriel da Silva Folli Pereira \\ Universidade do Estado de Mato Grosso - UNEMAT \\ Campus de Alta Floresta - MT \\ muriel.folli@unemat.br \\ Luciano Farinha Watzlawick \\ Universidade Estadual do Centro Oeste - UNICENTRO \\ Campus de Guarapuava - PR \\ farinha@unicentro.br
}

\begin{abstract}
RESUMO
O presente trabalho de pesquisa teve como objetivo analisar a estrutura da vegetação e avaliar a distribuição espacial de três famílias com maior abundânca, por meio dos parâmetros fitossociológicos, assim como avaliar a distribuição diamétrica,com intuito de conhecer sua importância ecológica e aumentar o conhecimento sobre a vegetação presente em uma área, pertencente a CEPLAC (Comissão Executiva da Lavoura Cacaueira), no município de Alta Floresta, Mato Grosso. O estudo foi realizado em 1,0 hectare de um fragmento. Instalou-se nessa aréa 25 subparcelas de $400 \mathrm{~m}^{2}(20 \mathrm{~m} \times 20 \mathrm{~m})$, das quais foram identificados e medidos todos os indivíduos com diâmetro à altura de 1,30 do solo e DAP $5 \mathrm{~cm}$. As análises dos dados foram realizadas no programa Excel for windows. No levantamento florestal foi encontrado um total de 906 indivíduos, classificados em 49 famílias e 193 espécies e aplicados os índices de diversidade de Shannon $\left(\mathrm{H}^{\prime}\right)$, obtendo 4,60 e índice de equabilidade de Pielou (J'), com 0,88 , destacando que a área tem uma grande diversidade
\end{abstract}

florística. Os parâmetros fitossociológicos foram calculados para as três famílias com os maiores números de indivíduos: Moraceae com 140 ind ha- ${ }^{1}$, Violanaceae com 72 ind ha- ${ }^{1}$ e Fabaceae com 69 ind ha- ${ }^{-}$. A espécies Rinoreocarpus ulei obteve a maior densidade relativa $(18,60 \%)$, frequência relativa $(10,22 \%)$, dominância relativa $(11,15 \%)$, IVI $(13,32$ \%) e IVC (14,87 \%) e índice de Payandeh (Pi) 2,02, indicando o agrupamento dessa espécie. A distribuição espacial da maioria das espécies nesse levantamento tem padrão de tendência ao agrupamento, cerca de $54 \%$ dos indivíduos tem diâmetro inferior a 9,99 centímetro, considerando que a área tem muito indivíduos jovens, elevada diversidade florística e pouca dominância ecológica.

\section{Palavras-chave:}

Espécies florestais; Parâmetros fitossociológicos;

Diversidade florística.

\section{ABSTRACT}

The present research work aimed to analyze the structure of the vegetation and to evaluate the spatial distribution of three families with greater abundance, through phytosociological parameters, as well as assessing the diametric distribution, in order to know its ecological importance and increase the knowledge about the vegetation present in an area, belonging CEPLAC (Executive Committee of Lavaca Cacaueira), in the municipality of Alta Floresta, Mato Grosso. The study was carried out on 1.0 hectare of a fragment In this area, 25 subplots of $400 \mathrm{~m}^{2}(20 \mathrm{~m} \times 20 \mathrm{~m})$ were installed in this area, of which all individuals with a diameter at the height of 1.30 and a DBH $5 \mathrm{~cm}$ were identified and measured. Data analysis was performed using the Excel for windows program. The results obtained from the floristic composition showed a total of 906 individuals, classified in 49 families and 193 species and applied the Shannon diversity index $\left(\mathrm{H}^{\prime}\right)$, obtaining 4.60 and

Pielou's equability index $\left(J^{\prime}\right)$, with 0,88 , highlighting that the area has a great floristic diversity. Phytosociological parameters were calculated for the three families with the largest numbers of individuals: Moraceae with 140 ind ha $^{-}{ }^{1}$, Violanaceae with 72 ind ha- ${ }^{1}$ and Fabaceae with 69 ind ha- ${ }^{1}$. The species Rinoreocarpus ulei obtained the highest relative density $(18,60 \%)$, relative frequency $(10.22 \%)$, relative dominance (11,15\%), IVI (13,32\%) and CVI (14,87\%) and 2,02 Payandeh index, indicating the grouping of that species. The spatial distribution of most species in this survey has a pattern of tendency to cluster, about 54\% of individuals have a diameter of less than $9,99 \mathrm{~cm}$, considering that the area has a lot of young individuals, high floristic diversity and little ecological dominance.

\section{Keywords:}

Forest species; Phytosociological parameters;

Floristic diversity. 


\section{INTRODUÇÃO}

O Brasil é o segundo país com a maior área de floresta do mundo, no qual 58 \% do seu território são constituídos de florestas nativas, o equivalente a aproximadamente 485,8 milhões de hectares (SFB, 2016). No entanto a conservação da biodiversidade torna-se fundamental para garantir a permanência de espécies florestais longe da lista de extinção, em função ao aumento das invasões antrópicas nos ecossistemas naturais brasileiros (CHAVES et al., 2013).

A Floresta Amazônica por sua vez é conhecida pela sua vasta diversidade biológica, porém a perda de espécies florestais de importância ecológica, está sendo cada vez mais intensa, com a introdução da pecuária, agricultura, o corte seletivo de espécies florestais e a urbanização (FERREIRA et al., 2005; FEARNSIDE, 2005).

A vegetação nativa Mato-grossense tem sofrido grandes perdas não só da sua flora e fauna, como também para o interesse humano. Essas perdas ocorrem principalmente devido a falta de coletas de dados e principalmente o desmatamento provocado pela ação humana (IVANAUKAS et al., 2004). Dependendo do tipo de pertubações oriundas de atividades antrópicas, as espécies vegetais podem ser afetadas em diferentes vertentes, como por exemplo, ser suprimidas

A vegetação é um aspecto fundamental devido ao seu habitat e função trófica, e também porque auxilia na observação das espécies, que por sua vez podem ser identificadas e classificadas de acordo com a sua dominância no ambiente (NOUKEU et al., 2019).

Dentre os diversos componentes que compõem um ecossitema natural, a vegetação torna-se um bom indicador das condições do meio ambiente e do estado de conservação dos ecossistemas próximos, pois a vegetação responde de forma acelerada às variações ambientais, e sua avaliação permite inferir sobre a conservação dos demais componentes do ambiente natural (DIAS, 2005).

Os estudos sobre a composição florística e a estrutura fitossociológica das comunidades florestais são importantes e se fazem necessários, pois é possível ter uma melhor compreensão da estrutura e da dinâmica destas formações, além de auxíliar no manejo e regeneração das diferentes comunidades vegetais (CHAVES et al., 2013). A fitossociologia é indispensável, para o estudo da vegetação, pois a partir de informações quantitativas, pode-se conhecer as diferentes função das espécies dentro de uma comunidade, assim como a dinâmica de cada uma delas (OLIVEIRA et al., 2008).

Conforme Martins (1989), a fitossociologia pode ser definida como sendo o estudo das relações entre espécies vegetais dentro da comunidade e refere-se ao estudo quantitativo do desenvolvimento da floresta e a estrutura da comunidade tornando-se distinta de um estudo de composição florística. Por 
meio dos levantamentos fitossociológicos é possível estabelecer graus de hierarquização entre as espécies estudadas e avaliar a necessidade de medidas voltadas para a preservação e conservação das unidades florestais (CHAVES et al., 2013).

Nesse sentido, o estudo tem por objetivo analisar a estrutura da vegetação e avaliar os padrões de distribuição espacial de espécies de três famílias com maior abundânca, por meio dos parâmetros fitossociológicos, assim como avaliar a distribuição diamétrica com intuito de conhecer sua importância ecológica na região e aumentar o conhecimento sobre a vegetação presente em uma área de floresta nativa localizado no município de Alta Floresta, Mato Grosso.

\section{METODOLOGIA}

\subsection{CARACTERÍSTICA DAÁREA DE ESTUDO}

tudo foi realizado em uma área de floresta nativa, pertencente à Comissão Executiva do Plano de Lavoura Cacaueira (CEPLAC), localizada próximo ao município de Alta-Floresta-MT, com as coordenadas, $9^{\circ} 53^{\prime} 44.9^{\prime \prime}$ Se 56²17'53.5"W (Figura 1 e 2).

Figura 1 - Mapa de localização de Alta Floresta, Mato Grosso.

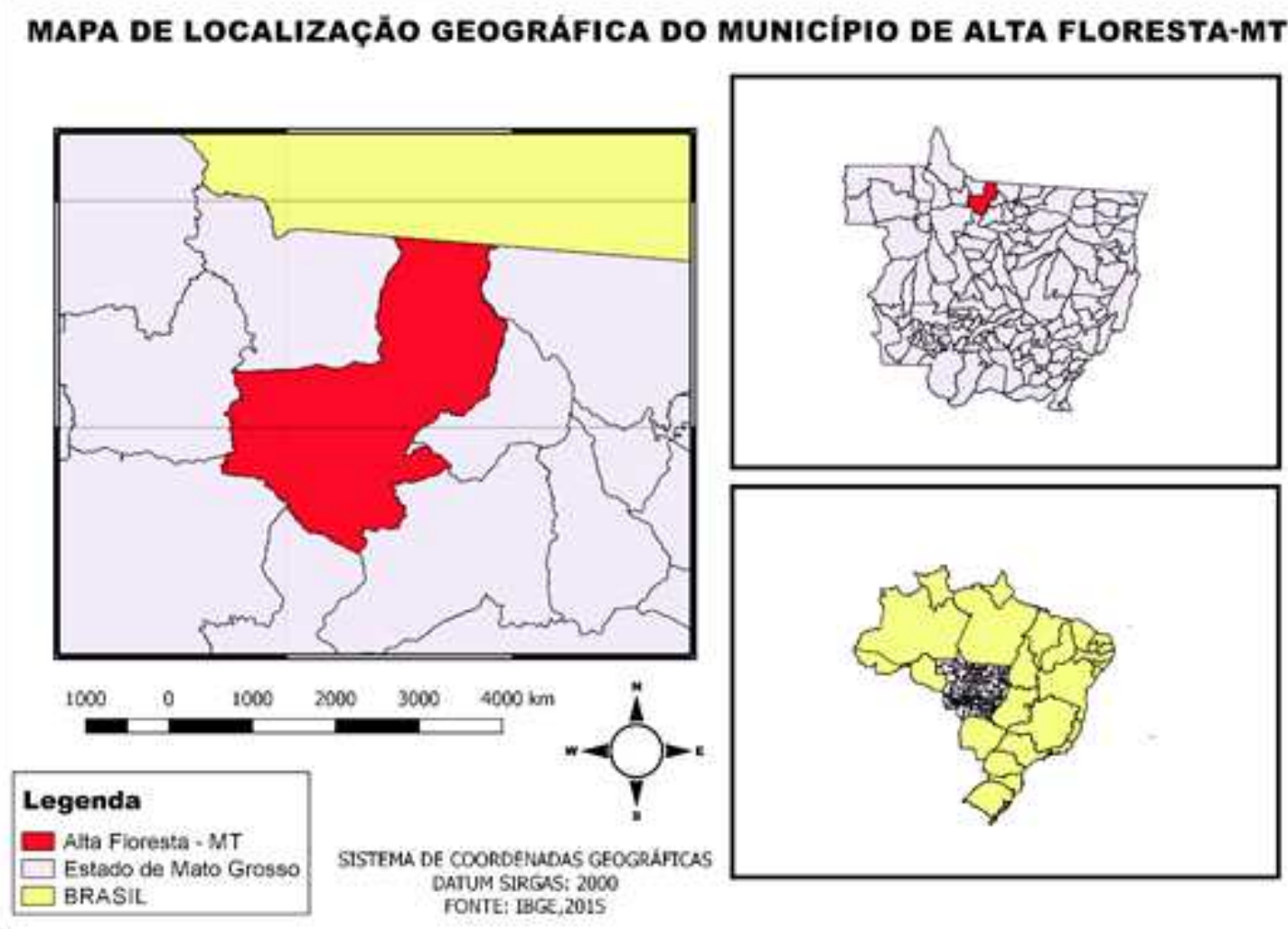

Fonte: autor 
Figura 2 - Localização da parcela onde foi realizado o estudo.

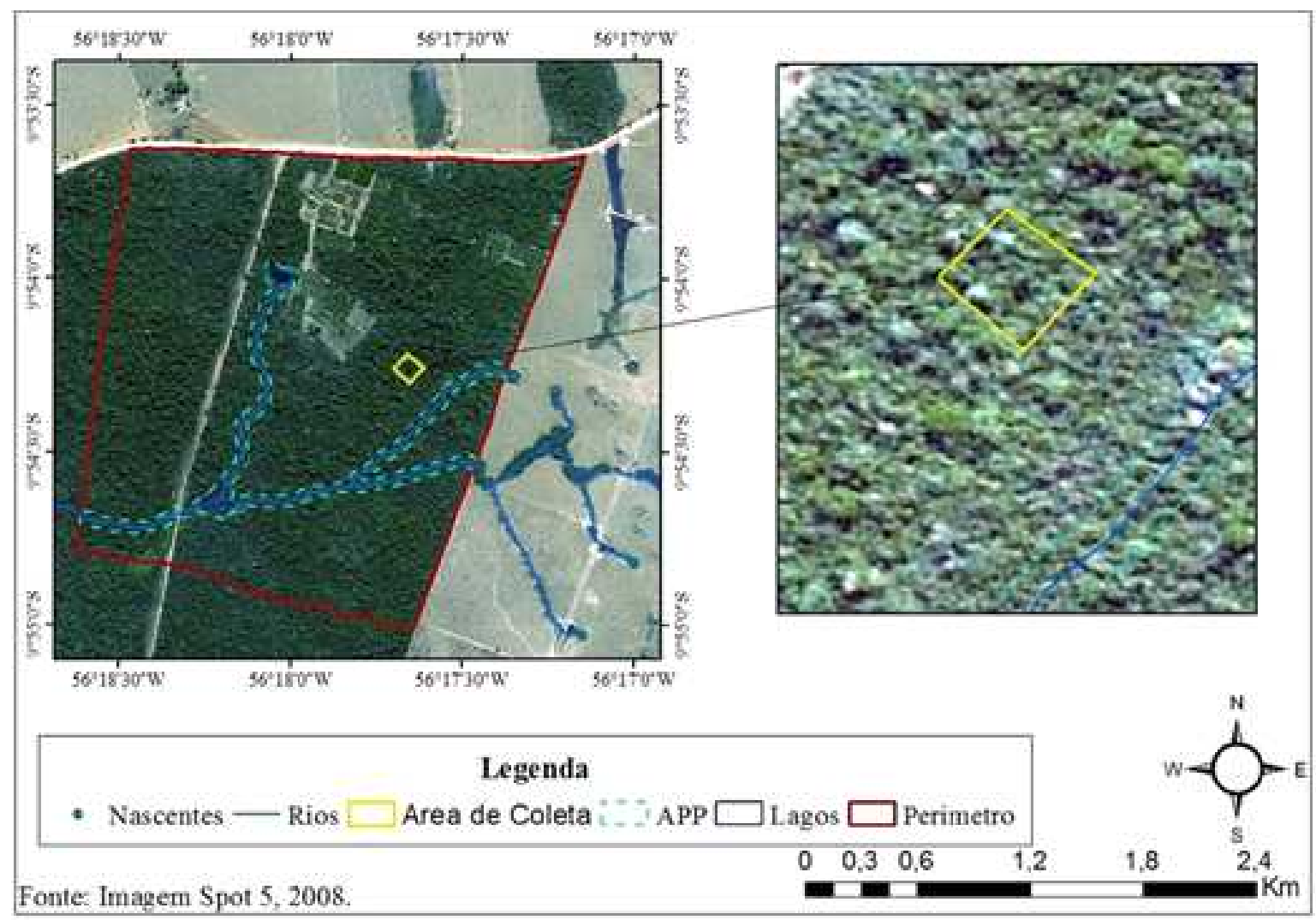

Foto: Oliveira, 2019

A região de Alta Floresta possui clima tropical quente úmido $(\mathrm{Am})$, com temperaturas médias entorno de $23^{\circ} \mathrm{C}$ e $26^{\circ} \mathrm{C}$ durante o ano, com temperaturas diárias de 34 a 37으 (MALHEIROS et al., 2009). A precipitação média histórica é de $3032 \mathrm{~mm}$ anuais (ALVARES et al., 2013). Os solos variam de Argissolo Amarelo e Vermelho-Amarelo, com pouca quantidade o Latossolo e solos hidromórficos (MIRANDA, 2016). Este tipo de solos possuem baixa a média fertilidade, com baixos teores de fósforo e médio teor de potássio, cálcio, magnésio e matéria orgânica (FERREIRA, 2001). A altitude do municipío é de 283 $m$, a vegetação predominante em Alta Floresta é do tipo Floresta Ombrófila Aberta (IBGE, 2012).

A floresta ombrófila é caracteriza pelo clima e pela presença de quatro faciações, onde nessas área ocorre um periodo de quatro meses secos e as faciações são: floresta aberta com palmeiras, floresta aberta com cipó; floresta aberta com sororoca e floresta aberta com bambu (IBGE, 2012). A cobertura vegetal dominante no município é do tipo Floresta Ombrófila aberta com palmeiras e cipós, sendo esse tipo de vegetação caracterizada pela presença de indivíduos arbóreos de grande porte, geralmente espaçadas, ocorrendo agrupamento de palmeiras e as principais espécies de valor econômico são as castanheira (Bertholletia excelsa), mogno (Swietenia macrophylla) e o cedro (Cedrella odorata) (DAS NEVES, 2013). A área de estudo há muitos anos passou por um processo de exploração seletiva com baixa intensidade. 


\subsection{COLETA DE DADOS}

O local onde foi realizado o levantamento florístico e fitossociológico, pertencente a Comissão Executiva do Plano de Lavoura Cacaueira (CEPLAC), possui uma área total de 504,00 hectares, sendo cedido 1,0 hectare para o referido levantamento. Baseado na metodologia da rede RAINFOR descrita por Phillips et al. (2016), foi alocada uma parcela amostral nesse fragmento florestal com área de 100 $\mathrm{m} \times 100 \mathrm{~m}$, equivalente à 1 hectare e instalado 25 subparcelas com tamanho de $20 \mathrm{~m} \times 20 \mathrm{~m}$ cada.

Os limites da linha de base da parcela e de cada subparcela foram demarcados fixando vergalhões de ferro ( $3 / 8$ polegadas) de diâmetro e $(1 \mathrm{~m}$ ) de comprimento e as mesmas foram georreferenciadas em cada base da subparcela. Em cada subparcela foi medido todos os indivíduos vivos em pé do componente arbóreo a 1,30 m de altura acima do solo e diâmetro a altura do peito (DAP $\geq 5 \mathrm{~cm}$ ). Os indivíduos mensurados foram pintados com tinta de emulsão (vermelha) na altura em que foi medida, também foram marcados os indivíduos com plaquetas metálicas colocadas a 1,60 m de altura com numeração de identificação, sequencial, que serviu para associar numeração e a identificação dos indíviduos com os dados anotados na ficha de campo.

O estudo foi realizado no ano de 2020, e o mesmo representado por tabelas e figuras gerados pelo programa Excel for Windows. A determinação dos parâmetros fitossociológicos da aréa foi calculada a partir dos dados do levantamneto florestal, onde a equipe de campo foi formada por auxiliar de campo, identificador botânico e anotador. A metodologia aplicada pela equipe para realizar a coleta de dados foi a método de parcela, onde em cada subparcela foram identificadas as espécies, famílias, número de indivíduos, onde foram realizadas medições diamétricas dos indivíduos com DAP > 5 centímetros e suas respectivas alturas totais.

Utilizando o software Excel versão 2016, foram obtidos os seguintes parâmetros fitossociológicos: densidade, frequência e dominância absolutas e relativas, valor de importância e valor de cobertura e também obtivemos o índice de Shannon-Wiener $\left(\mathrm{H}^{\prime}\right)$ para estimar a diversidade alfa, o índice de Pielou (J') para calcular a equitabilidade e índice de Payandeh para calcular a ditribuição espacial dos indivíduos.

\subsection{LEVANTAMENTO FLORESTAL}

O levantamento florestal para realização do presente estudo foi efetuado com base em estudos de campo. O presente estudo foi dividido em duas etapas para obter as informações, sendo na primeira etapa: instalação das unidades amostrais de Abril à Julho de 2020; segunda etapa: o levantamento florestal propriamente dito de Agosto à Setembro de 2020, abordando.

\subsubsection{Medições das unidades amostrais}

As variáveis medidas para cada árvore das subparcelas foram o DAP (diâmetro à altura do peito), além da identificação das espécies pelo nome vulgar. Cada árvore foi devidamente marcada (tinta) à altura 
do peito $(1,30 \mathrm{~m})$, foram medidas as alturas (total) de todos os indivíduos, para posterior calcúlar as aréas basais e os parâmentros fitossociológicos.

\subsubsection{Diâmetro}

Em cada unidade amostral de $400 \mathrm{~m}^{2}$ foram medidas todas as árvores com diâmetro à altura do peito $(1,30 \mathrm{~m})$ superior a 5 centímetros e marcadas com tinta vermelha. Os diâmetros foram medidos com fita métrica.

\subsubsection{Altura}

Em cada unidade amostral de $400 \mathrm{~m}^{2}$ foram medidas as alturas totais de todas as árvores, com o auxílio do hipsômetro de Blume-Leiss, considerando a altura entre o solo e a parte final da copa

\subsection{ANÁLISE DA COMPOSIÇÃO FLORÍSTICA}

A composição florística foi analisada considerando a ocorrência das espécies arbóreas no fragmento florestal nativa. Para conhecer a diversidade e equabilidade dessas espécies, foram utilizados os índices de Shannon-Weaver $\left(\mathrm{H}^{\prime}\right)$ e de Pielou $\left(\mathrm{J}^{\prime}\right)$ e para saber a distribuição espacial das espécies utilizou-se o índice de Payandeh (Pi). Diante da extensão territorial da Floresta Amazônica os estudos realizados com a finalidade de entender a composição florística geralmente são realizados em nível de família (TERBORGH; ANDRESEN, 1998).

\subsection{1. Índice de diversidade de Shannon-Weaver $\left(H^{\prime}\right)$}

O índice de diversidade de Shannon-Weaver $\left(\mathrm{H}^{\prime}\right)$, está relacionado com a quantidade e riqueza das espécies dentro de uma determinada comunidade vegetal, sendo assim quanto maior o número de espécies ou em proporções semelhantes é posivel observar que os valores de $\mathrm{H}^{\prime}$ é maior, indicando que a aréa apresenta uma grande diversidade florística, porém em comunidades com baixo número de espécie ou com forte dominância de determinada espécie, o índice tendem a assumir valores baixos, variando entre 1,26 a 1,39 (MOTA et al., 2013). O índice de diversidadede de ShannonWiener representa o grau de incerteza que existe em se dizer a qual espécie pertence um indivíduo escolhido ao acaso em uma comunidade contendo " $\mathrm{E}$ " espécies e " $\mathrm{N}$ " indivíduos (LUDWIG e REYNOLDS, 1988). Os valores assumidos pelo índice de Shannon-Wiener situam-se entre 1,5 e 3,5 e só raramente ultrapassam o valor de 4,5 (Magurran, 1988).A expressão que representa o índice de diversidade de Shannon-Weaver $\left(\mathrm{H}^{\prime}\right)$ é:

$$
\mathrm{H}^{\prime}=\sum \mathrm{Pi} * \ln (\mathrm{Pi})
$$


Onde:

$$
\begin{aligned}
& \mathrm{Pi}=\mathrm{ni} / \mathrm{N} \text { em que } \\
& \mathrm{ni}=\text { é o número de indivíduos da espécie, } \\
& \mathrm{N} \text { = é o número total de indivíduos, } \\
& \mathrm{ln}=\text { logaritmo neperiano }
\end{aligned}
$$

\subsection{2 Índice de equabilidade de Pielou (J)}

A Equabilidade de Pielou é derivado do índice de diversidade de Shannon e permite representar a uniformidade da distribuição dos indivíduos entre as espécies existentes (PIELOU, 1966). Este índice de equabilidade de Pielou calcula a proporção da diversidade observada no índice de Shannon pela máxima diversidade esperada (PIELOU, 1975). O índice assume valor igual a 1 (uniformidade máximo), quando as espécies são igualmente abundantes (POLLOCK, 1998) e apresenta uma amplitude de 0 (uniformidade mínima). A expressão que a representa é :

\section{$\mathrm{J}^{\prime}=\mathrm{H}^{\prime} /$ Hmáx}

Onde:

$$
\begin{aligned}
& H^{\prime} \text { = índice de diversidade de Shannon, } \\
& \text { Hmáx = In (S) } \\
& \text { S = número de espécies amostradas }
\end{aligned}
$$

\subsection{DISTRIBUIÇÃO ESPACIAL}

Segundo Lima et al. (2018), os estudos sobre a distribuição espacial são importantes para conhecer a dinâmica ecológica das espécies, uma vez que os padrões de distribuição espacial podem influênciar na ecologia da comunidade e conhecendo a dinâmica das espécies é possivel tornar os recursos naturais das espécie mais sustentável. O comportamento do padrão espacial em diferentes escalas (agrupamento, têndencia ao agrupamento e aleatório), pode contribuir positivamente na elaboração dos planejamentos de inventários florestais e manejo florestal, assim como reduzir impactos ambientais (CONDÉ et al., 2016).

As espécies vegetais possuim necessidades particulares conforme o seu estágio de vida, sendo assim apresentam padrões espaciais específicos em relação as condições ambientais como sombreamento, luminosidade, abertura no dossel da floresta são essenciais para indivíduos na fase juvenil (SOUZA, 
2020). Indivíduos que estão no estágio de vida inicial tendem a ter distribuição espacial agregada (BRUZINGA et al., 2013).

O padrão de distribuição espacial também está relacionado aos diferentes meios de dispersão das sementes, primária ou secundária (CHRISTIANINI, 2004). Neste estudo utilizou-se o índice de agregação de Payandeh (Pi) para avaliar a distribuição dos indivíduos nas subparcelas amostrais.

\subsection{1 Índice de Payandeh (Pi)}

Para calcular a ditribuição espacial dos indivíduos utilizou-se o índice de Agregação de Payandeh, por meio da relação entre a variância do número de árvores por subparcela, e a média do número de árvores (PAYANDEH, 1970). A classificação do padrão de distribuição espacial dos indivíduos obedece a seguinte escala: $\mathrm{Pi}<1$ distribuição aleatória ou não agrupada; $1<\mathrm{Pi}<1,51$ tendência ao agrupamento e $\mathrm{Pi}>1,51$ distribuição agregada ou agrupada (WATZLAWICK et al., 2011).$$
P i=\frac{S i^{2}}{M i}
$$

Onde :

$$
\begin{aligned}
& \mathrm{Pi} \text { = “Índice de Payndeh" para i-ésima espécie; } \\
& \mathrm{Si}^{2} \text { = variância do número de árvores da i-ésima espécie; } \\
& \mathrm{Mi} \text { = média do número de árvores da i-ésima espécie }
\end{aligned}
$$

\subsection{ANÁLISE FITOSSOCIOLÓGICA}

Os parâmetros fitosociológicos utilizados para a análise da estrutura horizontal foram: Densidade relativa (DR), Densidade absoluta (DA), Dominância relativa(DoR), Dominância absoluta (DoA), Frequência relativa (FR), Frequência absoluta (FA), Índice de valor de importância (IVI \%) e Índice de valor de cobertura (IVC\%).

\subsubsection{Densidades}

Densidade absoluta por Área proporcional (DA): representa o número médio de árvores de uma determinada espécie, por unidade de área, A unidade amostral comumente usada para formações florestais é um hectare $\left(10,000 \mathrm{~m}^{2}\right)$, A fórmula é a seguinte: 


\section{$\mathrm{DAi}=\mathrm{ni} \mathrm{U} / \mathrm{A}$}

Onde:

ni = número de indivíduos da espécie por unidade amostral (ha);

$A=$ área total amostrada.

Densidade Relativa (DR): é definida como a porcentagem do número de indivíduos de uma determinada espécie em relação ao total de indivíduos amostrados,

\section{$\mathrm{DRi}=\mathrm{ni} * 100 / \mathrm{N}$}

Onde:

ni= número de indivíduos da espécie i;

$\mathrm{N}=$ número total de indivíduos

\subsubsection{Dominância}

Dominância Absoluta: (DoA): é calculada a partir da somatória da área basal dos indivíduos de cada espécie.

\section{$\mathrm{DoAi}=\mathrm{ABi} U / \mathrm{A} \quad$ Área basal $(g i)=\pi * D A P^{2 / 4}$}

Onde:

ABi $U$ = Área basal total de um determinada espécie por unidade de área;

$A=$ Área em (ha)

Dominância relativa (DoR): representa a relação entre a área basal total de uma espécie e a área basal total de todas as espécies amostradas.

\section{$\mathrm{DoR}=(\mathrm{ABi} / \mathrm{ABT}) \times 100$}


Onde:

$A B i$ = é a área basal de cada indivíduo da espécie;

$A B T$ = é a soma das áreas basais de todas as espécies

\subsubsection{Frequência}

Frequência absoluta (FA) = é a porcentagem de unidades de amostragem com ocorrência da espécie, em relação ao número total de unidades de amostragem.

$$
\mathrm{FAi}=\mathrm{Pi} * 100 / \mathrm{P}
$$

Onde:

$\mathrm{Pi}$ = número de subparcelas ou pontos de amostragem em que a espécie ocorreu;

$\mathrm{P}=$ Número total de subparcelas ou pontos de amostragem.

Frequência relativa (FR): é obtida da relação entre a frequência absoluta de cada espécie e a soma das frequências absolutas de todas as espécies amostradas.

\section{$\mathrm{FRi}=\mathrm{FAi} * 100 / \mathrm{FAZ}$}

Onde:

FAi = frequência absoluta de cada espécie;

FAZ = soma das frequências absolutas de todas as espécies amostradas.

\subsection{4 Índice de valor de importância}

Índice de valor de importância (IVI), representa em que grau a espécie se encontra bem estabelecida na comunidade e resulta em valores relativos já calculados para a densidade, frequência e dominância. Esse índice serve para dar valor a cada espécie presente na aréa e permitir saber a distribuição da espécie e sua importância na floresta (BATISTA et al., 2012).

$$
\mathrm{IVIi}=(\mathrm{DRi}+\mathrm{DoRi}+\mathrm{FRi}) / 3
$$




\subsection{5 Índice de valor de cobertura}

Índice de valor de cobertura (IVC) é a soma dos valores relativos de densidade e dominância de cada espécie, serve para informar a importância ecológica da espécie em termos de distribuição horizontal.

\section{$\mathrm{IVCi}=(\mathrm{DR} i+\mathrm{DoRi}) / 2$}

O valor de cobertura (VC) expressa à quantidade de terreno que está ocupada pelos indivíduos de cada espécie, somando-se as densidades e as dominâncias relativas.

\section{RESULTADOS E DISCUSSÃO}

No levantamento realizados na área, foi encontrado um total de 906 indivíduos, classificados em 49 famílias botânicas e 193 espécies, dentre estes indivíduos, 885 individuos foram identificados e 21 não identificados.

As famílias de maior riqueza florística foram: Moraceae (23), Fabaceae (17), Sapotaceae (15), Burseraceae (13), Meliaceae (10) e Lauraceae (10), como mostra a (Figura 5). Em estudos realizados por Moser (2013), nas margens do rio Madeira, no noroeste de Rondônia, onde a formação florestal é constituida de floresta ombrófila aberta, florestas de terra firme, campinaranas e florestas de várzea, foi observado que as famílias Fabaceae, Moraceae, Burseraceae e Sapotaceae destacaram-se entre as 10 principais famílias mais abundantes, considerando as classes de diâmetro $1 \mathrm{~cm} \leq \mathrm{DAP}<10 \mathrm{~cm}$, Classe 2: $10 \mathrm{~cm} \leq \mathrm{DAP}<30 \mathrm{~cm}$ e Classe 3: DAP $\geq 30 \mathrm{~cm}$. Em estudo realizado por Rocha Filho(2019), em uma Floresta Ombrófila Densa próximo ao Reservatório da UHE Teles Pires, no municípios de Paranaíta em Mato Grosso, também identificou que as familías Fabaceae e Moraceae foram mais abundantes, por apresentarem a maior riqueza nos inventários florestais.

Segundo Cabral (2010) as famílias botânica mais abundantes em relação a espécies e indivíduos presentes em florestas tropicais são: Sapotaceae, Fabaceae, Lecythidaceae, Moraceae, Burseraceae, Lauraceae e todas essas famílias foram encontradas no presente trabalho e teveram destaque no número de espécies.

Em um estudo realizado por Spletozer (2015) em dois fragmentos florestais próximo ao perímetro urbano do município de Alta Floresta, Mato Grosso, as famílias que se destacaram em número de espécies foram Fabaceae (13 espécies) e Moraceae (12 espécies). 
Figura 5 - Famílias com maior riqueza florística em número de espécies.

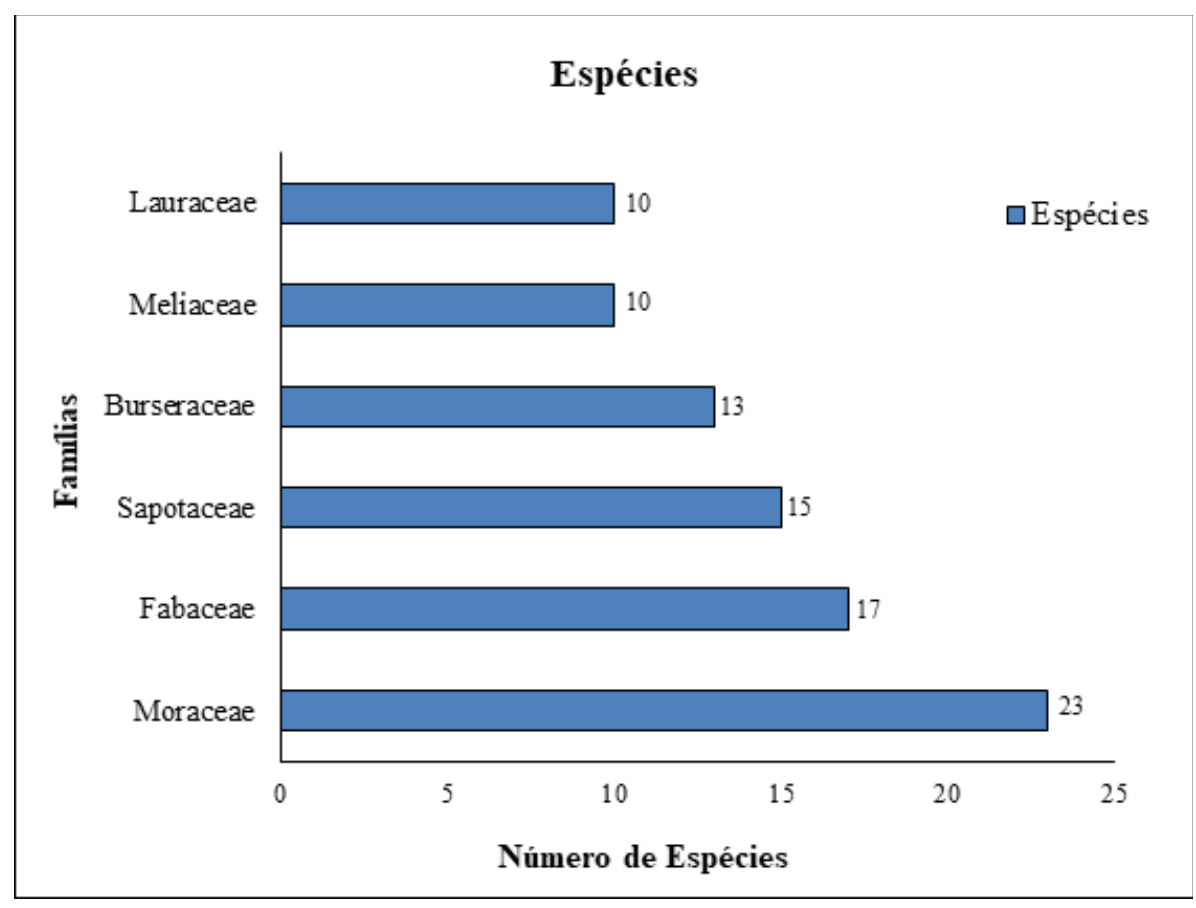

Fonte: o autor.

O índice de diversidade Shannon foi de 4,60 nats, destacando que a área tem uma grande diversidade florística e segundo Knight (1975), este valor pode ser considerado alto e dentro dos limites consideráveis para Florestas Amazônicas, que normalmente variam de 3,83 a 5,85. Em estudo realizado por Claudino et al. (2015) em uma floresta ombrófila densa, onde está localizado o Parque Nacional do Juruena, Mato Grosso, o indice de diversidade encontrad o foi próximo ao encontrado nesse estudo, sendo o índice de diversidade $\mathrm{H}^{\prime}$ igual a 4,21 nats e segundo o autor o alto índice de diversidade encontrado nessa área é devido o índice apresentar sensibilidade a espécies com apenas um indivíduo por hectare.

O índice de Shannon ( $\mathrm{H}^{\prime}$ ) desse estudo foi próximo ao encontrado por Francez et al. (2007) em uma floresta ombrófila densa submontana manejada no município de Paragominas, Pará, que foi de 4,27 nats e superior aos dados entrontrado por Bambolim et al. (2018) em uma floresta estacional decidual localizada no município de Santa Tereza no estado do Rio Grande do Sul que foi 3,34 nats e por Silva et al. (2011) em uma floresta ombrófila mista na Floresta Nacional de São Francisco de Paula, Rio Grande do Sul que foi de 1,34 nats, um valor muito baixo comparado ao índice de diversidade Shannon encontrado por esse estudo. A área em estudo apresentou um valor de 3,35 de índice de diversidade.

Em estudos realizados por Araujo et al. (2009) em um fragmento florestal na região norte do Mato Grosso, obteve um índice de diversidade de Shannon ( $\left.\mathrm{H}^{\prime}\right)$ de 3,55 nats. Em um levantamento florestal realizado no estado de Rondônia em área de floresta ombrófila aberta o índice de diversidade $\left(\mathrm{H}^{\prime}\right)$ foi de 3,41 nats (SILVA; GAMA 2008). Em estudo realizado por Ferreira Júnior et al (2008) em uma área de floresta estacional semidecidual localizada no município de Marcelândia-MT, encontrou um índice igual a de 3,35 nats. 
Para Lima (2012) os índices de Shannon são considerados altos, devido à utilização de um menor nível de inclusão diamétrica, o mesmo autor cita que a inclusão de lianas e palmeiras na amostragem, pode aumentar oíndice de diversidade na comunidade.

O índice de Pielou encontrado foi de 0,88 , isso indica uma alta uniformidade, ou seja, o componente arbóreo apresenta uma heterogeneidade florística elevada, sendo $88 \%$ da máxima possível. Este resultado mostrou que a aréa possui muitos indivíduos diferentes e apresenta pouca dominância ecológica (OLIVEIRA; AMARAL, 2004).

Em estudos realizados por Bambolim et al. (2018) em uma floresta estacional decidual localizada no município de Santa Tereza no Estado do Rio Grande do Sul, o índice de equitabilidade de Pielou (J) foi de 0,83 próximo ao índice da presente nessa pesquisa.

Em estudos realizados por Araujo et al. (2009) em um fragmento florestal na região norte do Mato Grosso, obteve um índice de equitabilidade (J') de 0,75. Em um levantamento florestal realizado no estado de Rondônia em área de floresta ombrófila aberta o índice de equitabilidade (J') encontrado foi 0,80 (SILVA; GAMA, 2008). A elevada heterogeneidade de uma floresta é refletida em uma alta equitabilidade (uniformidade) e isso evidência que não ocorre dominância de uma ou poucas espécies na floresta (OLIVEIRA; AMARAL, 2004)

As famílias botânicas que apresentaram maior número de indivíduos foram: Moraceae (140), Violanaceae (72), Fabaceae (69), Sapindaceae (61), Malvaceae (54), Meliaceae e Burseraceae (51), representando cerca de $54,97 \%$ do total de indivíduos identificados (Figura 6). As demais famílias foram inferior a 40 indivíduos.

Figura 6 - Representatividade das famílias com maior número de indivíduos.

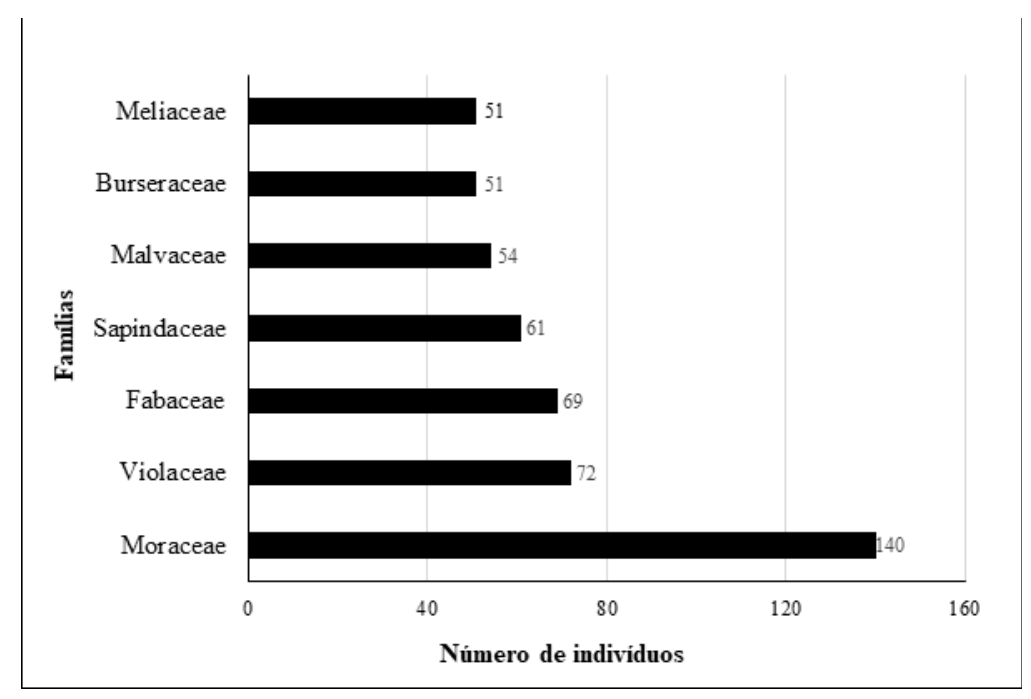

Fonte: 0 autor.

Neste estudo 10 famílias apresentaram apenas um indivíduo, sendo elas: Anacardiaceae, Cannabaceae, Celastraceae, Clusiaceae, Combretaceae, Humiriaceae, Lamiaceae, Melastomataceae, 
Polygonaceae e Rubiaceae. Com base nesses dados, os estudos fitossociológicos foram realizados com as três famílias que apresentaram os maiores números de indivíduos (Tabela 1).

Tabela 1 - Família botânica com maior número de indivíduos na aréa de estudo.

\begin{tabular}{ccc}
\hline Família & N $^{\circ}$ de indivíduos & $\mathbf{N}^{\circ}$ de espécie \\
\hline Moraceae & 140 & 23 \\
Violanaceae & 72 & 3 \\
Fabaceae & 69 & 17 \\
\hline Total & 281 & 43 \\
\hline
\end{tabular}

Fonte: o autor

\subsection{PARÂMETROS FITOSSOCIOLÓGICOS}

Devido à dimensão da Floresta Amazônica os estudos que buscam entender a composição florística geralmente têm sido realizados em nível de família (TERBORGH; ANDRESEN, 1998). As três espécies que apresentaram maior número de indivíduos e seus respectivos valores referentes aos parâmetros fitossociológicos da estrutura horizontal, estão apresentadas na (Tabela 1).

Os parâmetros fitossociológicos foram cálculados com os indivíduos das três famílias botânicas: Moraceae, Violanaceae e Fabaceae. O número de indivíduos totais foi 285 individuos, pertencentes a 43 espécies florestais. Dentre estes indivíduos pentencente as três famílias botânicas, quatro não foram identificados a nível de gênero e espécie.

Os indivíduos não intentificados pertencentes as três famílias botânicas apresentaram densidade absoluta igual 4 ind e densidade relativa de 1,40\%, índice de valor de importância igual a 2,19 \%, 0 indivíduos identificados apresentaram altura média de $10,8 \mathrm{~m}$, diâmetro médio de $14,36 \mathrm{~m}^{2}$ e área basal de 7,42057 $\mathrm{m}^{2}$

A espécie Rinoreocarpus ulei (Melch.) Ducke, conhecida popularmente como (Pau estalado) apresentou maior densidade absoluta no componente arbóreo com valor igual a 53 ind.ha- ${ }^{1}$ e densidade relativa de $18,60 \%$, seguida pela espécie Sorocea guilleminiana Gaudich. conhecida com o nome vulgar de bainhade-espada, com 35 ind.ha- ${ }^{1}$, densidade relativa de 12,28 \%, e em sequência as espécies, Brosimum guianensis (Aubl.) Huber ex Ducke (Pau-cobra) 17 ind.ha- ${ }^{1}$, densidade relativa de 5,96 \% e Bauhinia ungulata L. (Mororó vermelho) com densidade absoluta de 24 ind.ha-1 , 8,42 \% (Figura 7). Essas espécies foram destaques na comunidade devido ter número de indivíduos superior às demais espécies.

Em um estudo realizado por Spletozer (2015) em um fragmento florestal do município de Alta Floresta, Mato Grosso, a espécies Rinoreocarpus ulei (Melch.) Ducke apresentou parâmetros fitossociológico de densidade relativa igual a 26 \%, frequência igual a 90, dominância igua a 0,31. 
Figura 7 - Densidade relativa das 5 principais espéceis.

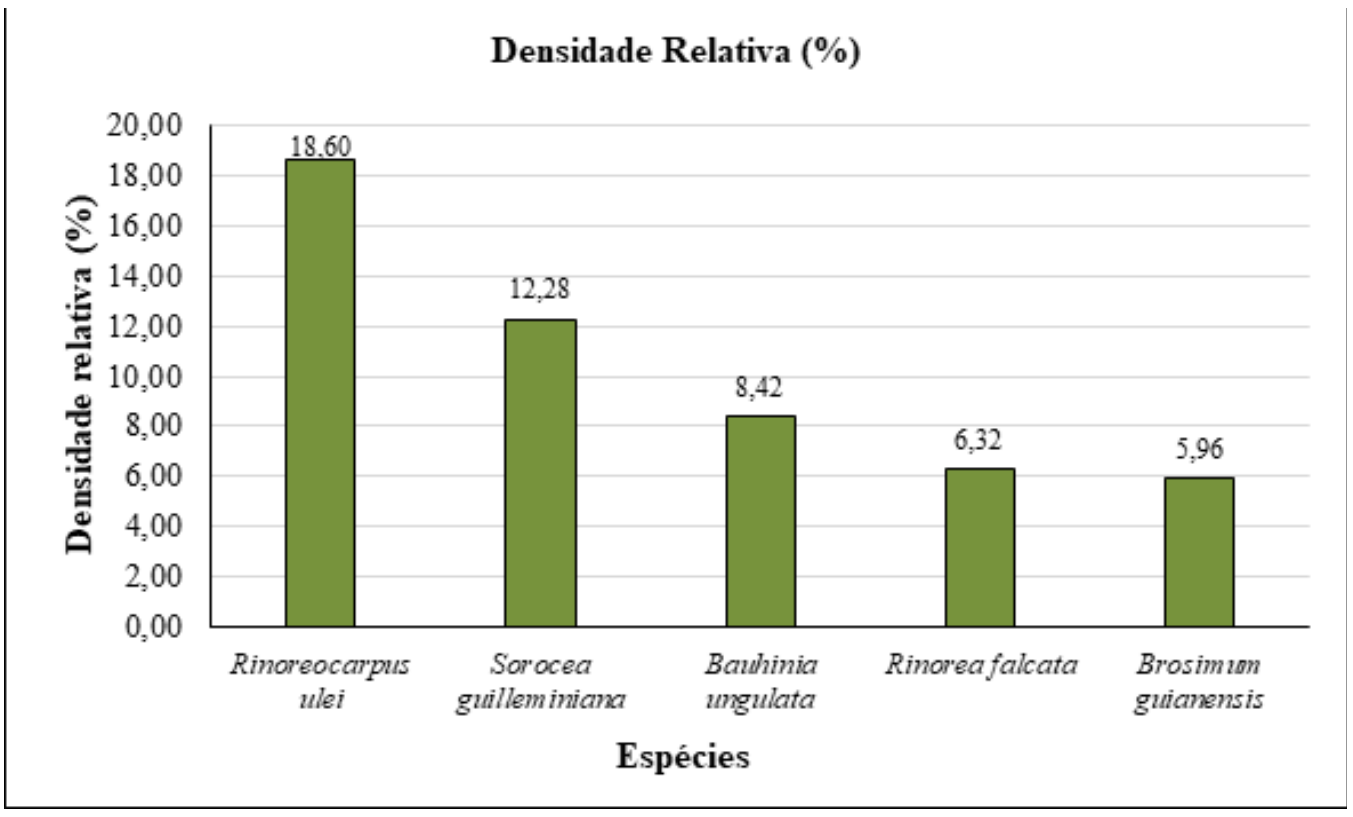

Fonte: o autor.

Em relação as frequências, a espécie Rinoreocarpus ulei (Melch.) Ducke, (Pau estalado) apresentou a maior frequência absoluta (76), e frequência relativa igual a 10,22 \%, seguida da espécie Sorocea guilleminiana Gaudich, com (68) de frequência absoluta, e 9,14\% de frequência relativa e as espécies Brosimum guianensis (Aubl.) Huber ex Ducke (Pau-cobra) e Bauhinia ungulata L. (Mororó vermelho), apresentaram frequência absoluta de (48) e frequência relativa $6,45 \%$.

Dentre as 43 espécies, foi possível observar que a maior frequência relativa foi 10,22 \% representado por uma uníca espécie Rinoreocarpus ulei Melch. Ducke. pertencente a família Violanaceae e a menor frequência relativa foi 0,54\% representado por 17 espécies. As espécies que apresentaram as menores frequências relativas foram: Maquira guianensis Aubl (Muiratinga-da-folha-miúda), Ficus gomelleira Kunth. (Apuí preto), Schizolobium parahyba var, Amazonicum Huber e Ducke (Barneby). (Paricá), Leonia glycycarpa Ruiz e Pav. (Coração de negro), Tachigali chrysophylla Poepp. Zarucchi e Herend. (Taxi-vermelho), Pseudolmedia macrophylla Trécul. (Pama), Ficus clusifolia (Figueiravermelha), Tachigali prancei (H.S.Irwin e Arroyo) L.G.Silva e H.C.Lima , Andira indet, Brosimum potabile Ducke. (Guariúba-da-folha-miúda), Deguelia angulata (Ducke) A.M.G.Azevedo e R.A.Camargo (Timbó-do-mato), Helicostylis pedunculata Benoist. Inga alba (Sw.) Willd. (Ingá ferro), Inga gracilifolia Ducke. (ingá chichica), Sorocea briquetii J.F.Macbr. (Capeba) , Clarisia ilicifolia (Spreng.) Lanj. e Rossberg (folha-de-serra) e Inga laurina (Sw.) Willd. (Ingá feijão)

As espécies que apresentaram os maiores valores de dominância relativa estão representados na (Figura 8). Nesse estudo a espécie que apresentou a maior dominância relativa foi a Rinoreocarpus ulei (Melch.) Ducke, (Pau estalado) com valor igual a 11,15\%, seguida da espécie Pseudolmedia laevis com 7,27\%. 
Figura 8 - Dominância relativa das 6 principais espécies.

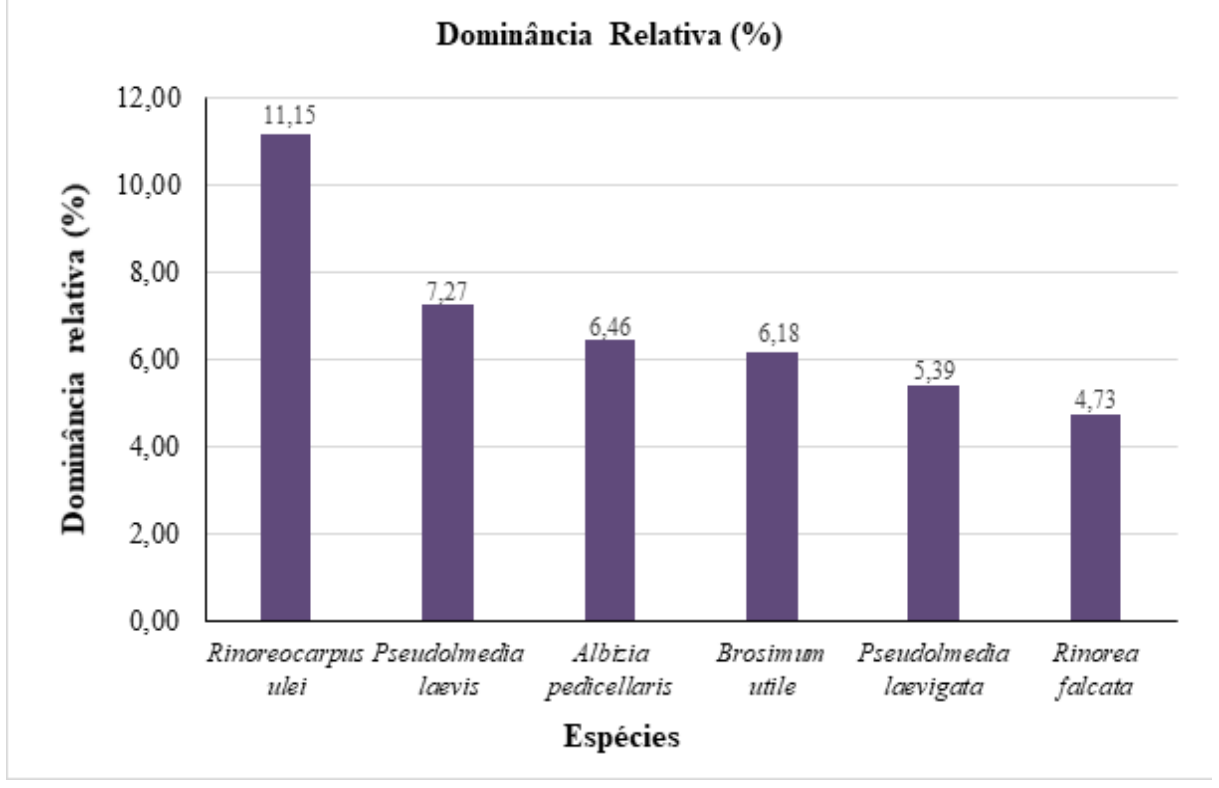

Fonte: o autor.

A espécie que teve a maior representatividade referente ao índice de valor de importância (IVI \%), foi a Rinoreocarpus ulei (Melch.) Ducke, (Pau estalado) com 13,32 \%, essa espécie pertencente a família botânica violanaceae que apresentou apenas três espécies e 71 indivíduos em toda a aréa amostral, destacando-se a sua importância e seu valor de cobertura nessa comunidade (Figura 9).

A segunda e a terceira espécie com maior índice de valor de importância (IVI \%) foi a Sorocea guilleminiana Gaudich. com 8,05 \% e Brosimum guianensis (Aubl.) Huber ex Ducke (Pau-cobra) com $6,09 \%$, ambas pertencente a familía moraceae, nessa família foi encontrada 23 espécies e 140 indivíduos identificados na aréa amostral.

Figura 9 - Espécies com maiores índices de valor de importância IVI (\%).

IVI (\%)

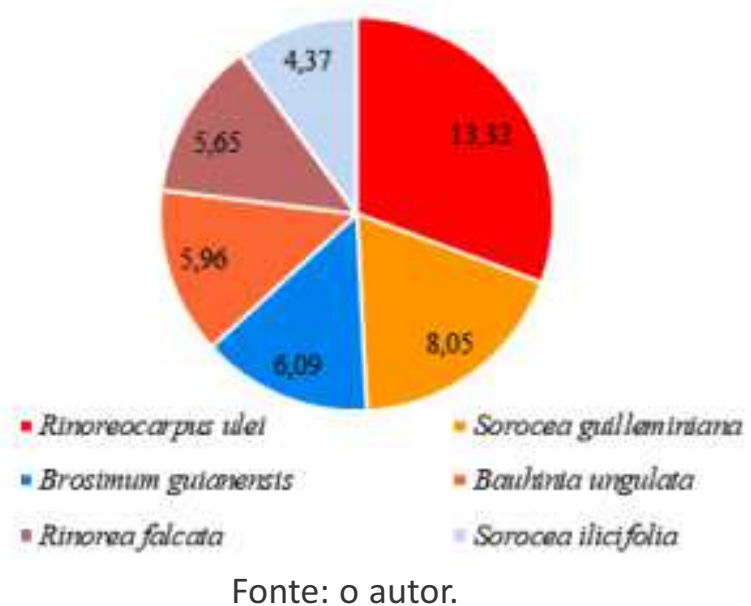


O índice de valor de cobertura representado na (Figura 10) estão em ordem decrescentes, representando as cinco espécies com os maiores IVC (\%) desse estudo, as cinco espécies ocupa cerca de 39,51\% do (IVC \%) total. A espécie que teve a maior representatividade referente ao índice de valor de cobertura IVC (\%) foi a Rinoreocarpus ulei (Melch.) Ducke, (Pau estalado) com 14,87\%, pertencente a família violanaceae. $O$ índice de valor de cobertura está relacionado com a soma das densidades e as dominâncias relativas de cada espécie.

Figura 10 - Espécies com maiores índice de valor de cobertura (IVC \%).

\section{IVC $(\%)$}

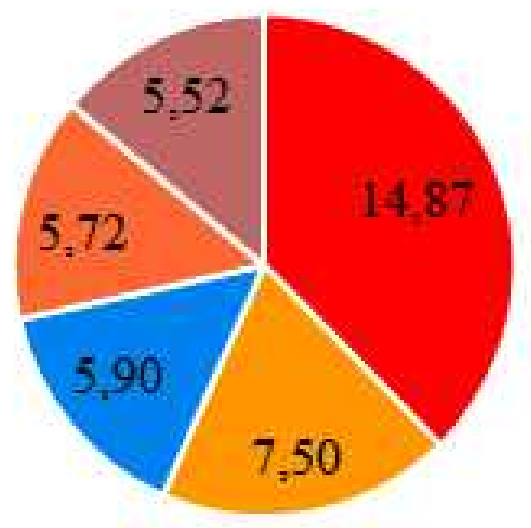

- Rinoreocarpus ulei

- Sorocea guilleminiana

- Brosimum guianensis

- Bauhinia ungulata

- Rinore a falc ata

Fonte: o autor.

Diante dos dados ilustrados, observou-se que a família moraceae teve a maior riqueza florística e observando a (figura 10) duas espécies dessa família apresentaram índice de valor de cobertura (IVC \%) relativamente alto, as espécies são Sorocea guilleminiana Gaudich. (bainha-de-espada) 7,50\% e Brosimum guianensis (Aubl.) Huber ex Ducke (Pau-cobra) 5,90\%. A quantidade de aréa que os indivíduos dessa duas espécies ocupa é equivalente á $13,4 \%$ da aréa amostral. A espécies Rinoreocarpus ulei (Melch.) Ducke, (pau estalado) e Rinorea falcata (Mart. ex Eichler) Kuntze pertence a família violanaceae, juntas apresentaram índice de valor de cobertura (IVC \%) igual a $20,39 \%$.

A (Figura 11) ilustra a contribuição dos parâmetros densidade relativa (DR), frequência relativa (FR), dominância relativa (DoR) para o cálculo dos índices de valor de importância (IVI \%) das espécies mais importantes nesse estudo. 
Figura 11 - Estrutura horizontal das sete espécie com maiores valores de importância. Densidade relativa (DR\%), Frequência relativa (FR\%), Dominância relativa (DoR\%), Índice de valor de cobertura (IVC\%) e Índice de valor de importância (IVI\%).

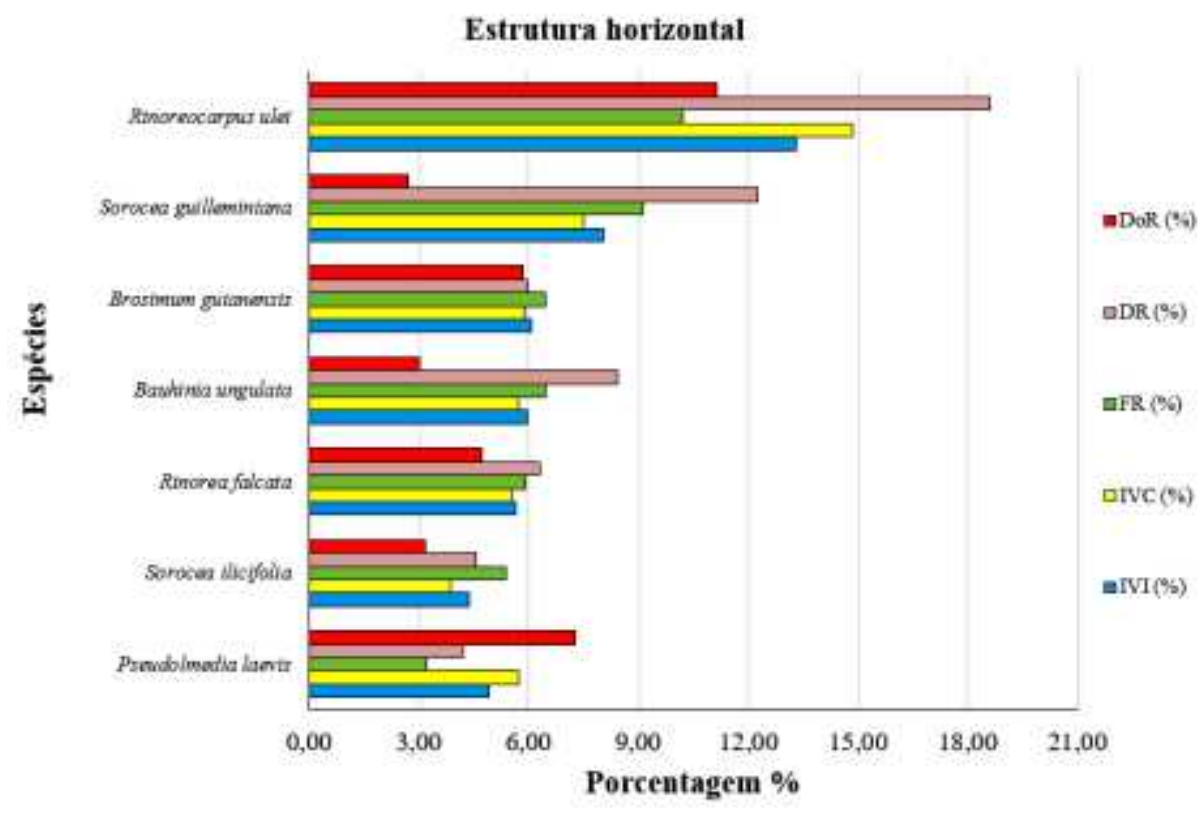

Fonte: o autor.

A espécie Rinoreocarpus ulei (Melch.) Ducke. (Pau estalado) apresentou os maiores percentuais em relação aos parâmetros fitossociológicos analisados, essa espécie apresentou 53 indivíduos em toda a aréa amostral, destacando-se a sua importância e seu valor de cobertura nessa comunidade. A dinâmica dos indivíduos por parcelas estão representados na (Figura 12).

Figura 12 - Dinâmica dos indivíduos por subparcela.

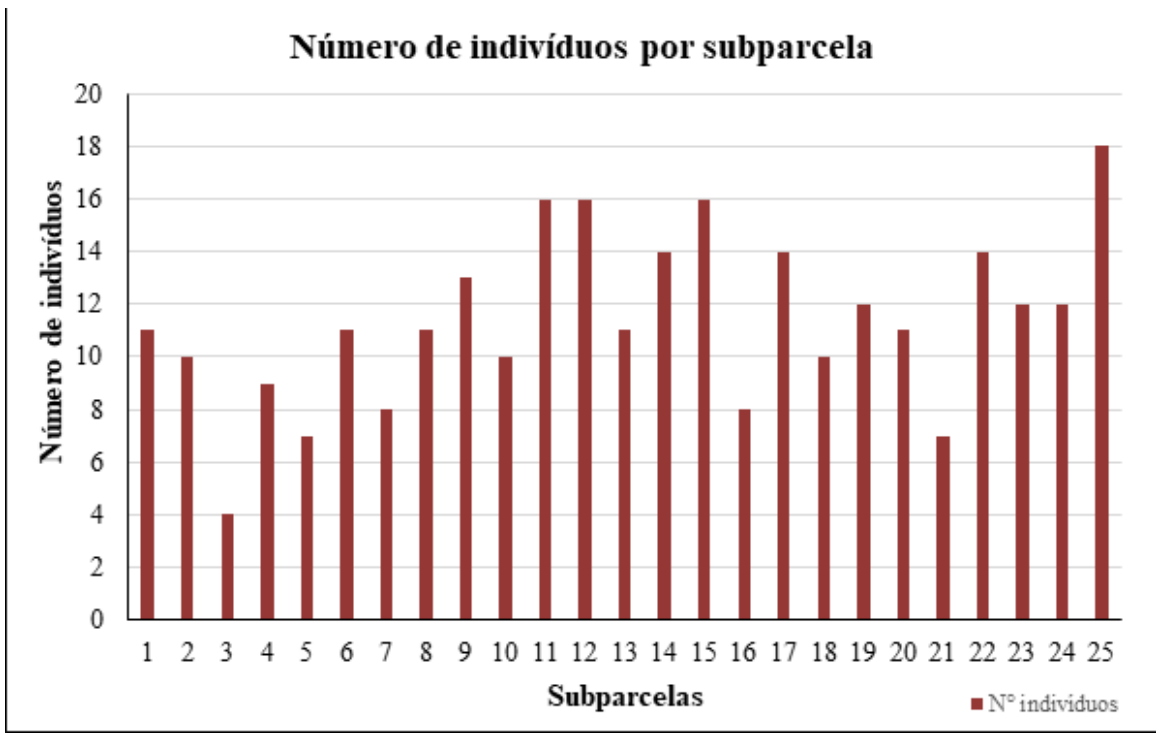

Fonte: o autor. 
Análisando a (Figura 12) é possivel observar que a subparcela 25 teve a maior incidência de indivíduos, estes pertencentes as três famílias com maior número de indivíduos: Moraceae, Violanaceae e Fabaceae. A espécie que teve o maior número de indivíduos foi a Rinoreocarpus ulei (Melch.) Ducke. (Pau estalado), pertencente a família botânica Violanaceae, com um total de 53 indivíduos por hectare e presente em 19 subparcelas, seguida da Sorocea guilleminiana Gaudich. (Bainha-deespada), pertencente a familía Moraceae, com um total de 35 indivíduos por hectare e presente em 17 subparcelas. Já a subparcela 3 apresentou apenas quatro indivíduos sendo o Ficus gomelleira, Sorocea bonplandii, Sorocea briquetii e Sorocea klotzschiana, todas pertencentes a família Moraceae.

Figura 13 - Distribuição das espécies por subparcela.

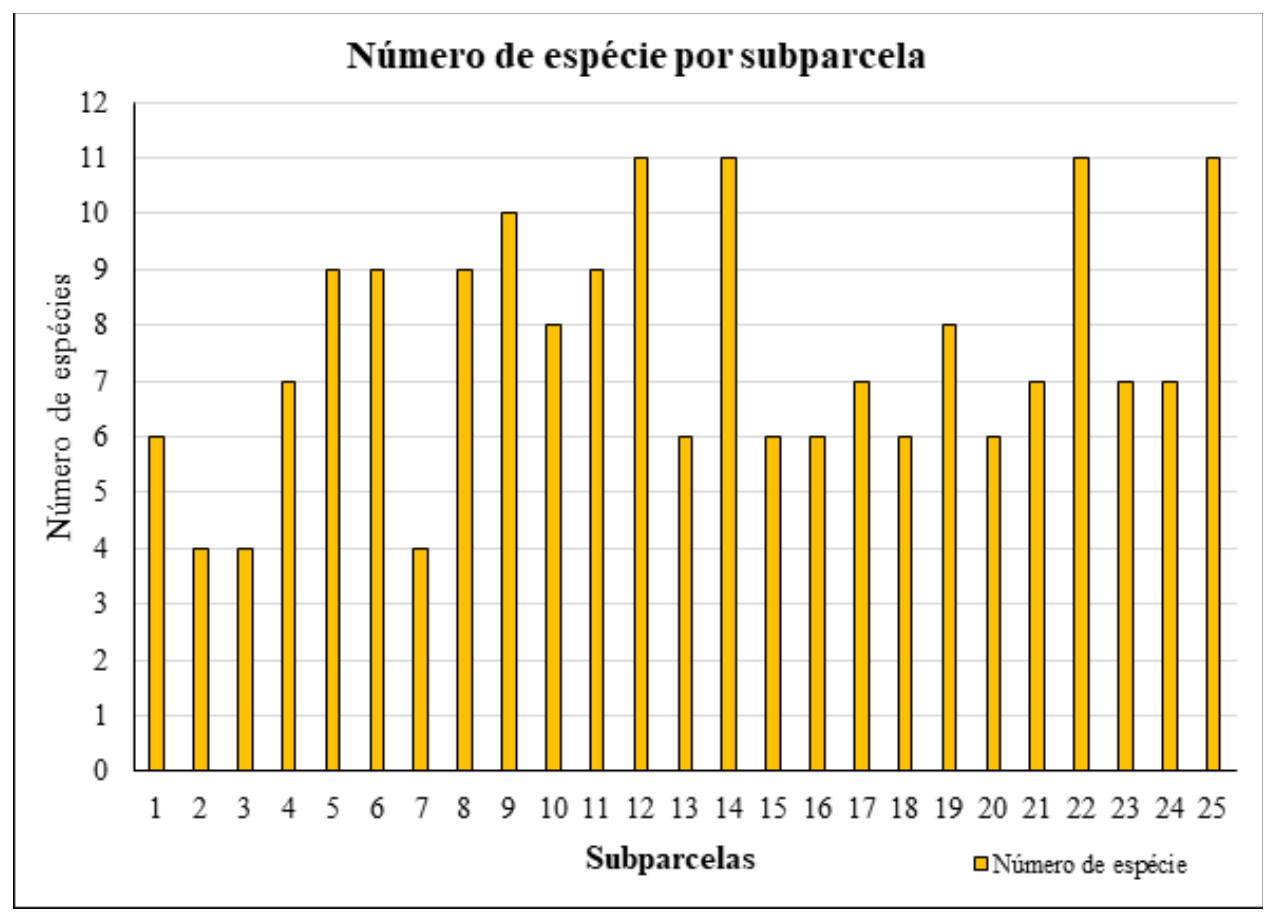

Fonte: o autor.

As subparcelas 12, 14, 22 e 25 apresentaram os maiores número de espécies sendo 11 espécies diferentes em cada subparcela (Figura 13). O número de espécies totais analisadas nesse estudo foi de 43 espécies distribuidas nas famílias botânica com maior número de indivíduos: Moraceae, Violanaceae e Fabaceae. A subparcela 25 foi a que apresentou maior número de indivíduos representando $6,31 \%$ dos indivíduos totais e foi uma das subparcelas que apresentou os maiores números de espécies, representando $25,58 \%$ das espécies totais desse estudo. A presença ou ausência das três famílias botânica nas 25 subparcelas estão representadas na (Figura 14). 
Figura 14 - Distribuição das famílias dentro das subparcelas amostrais.

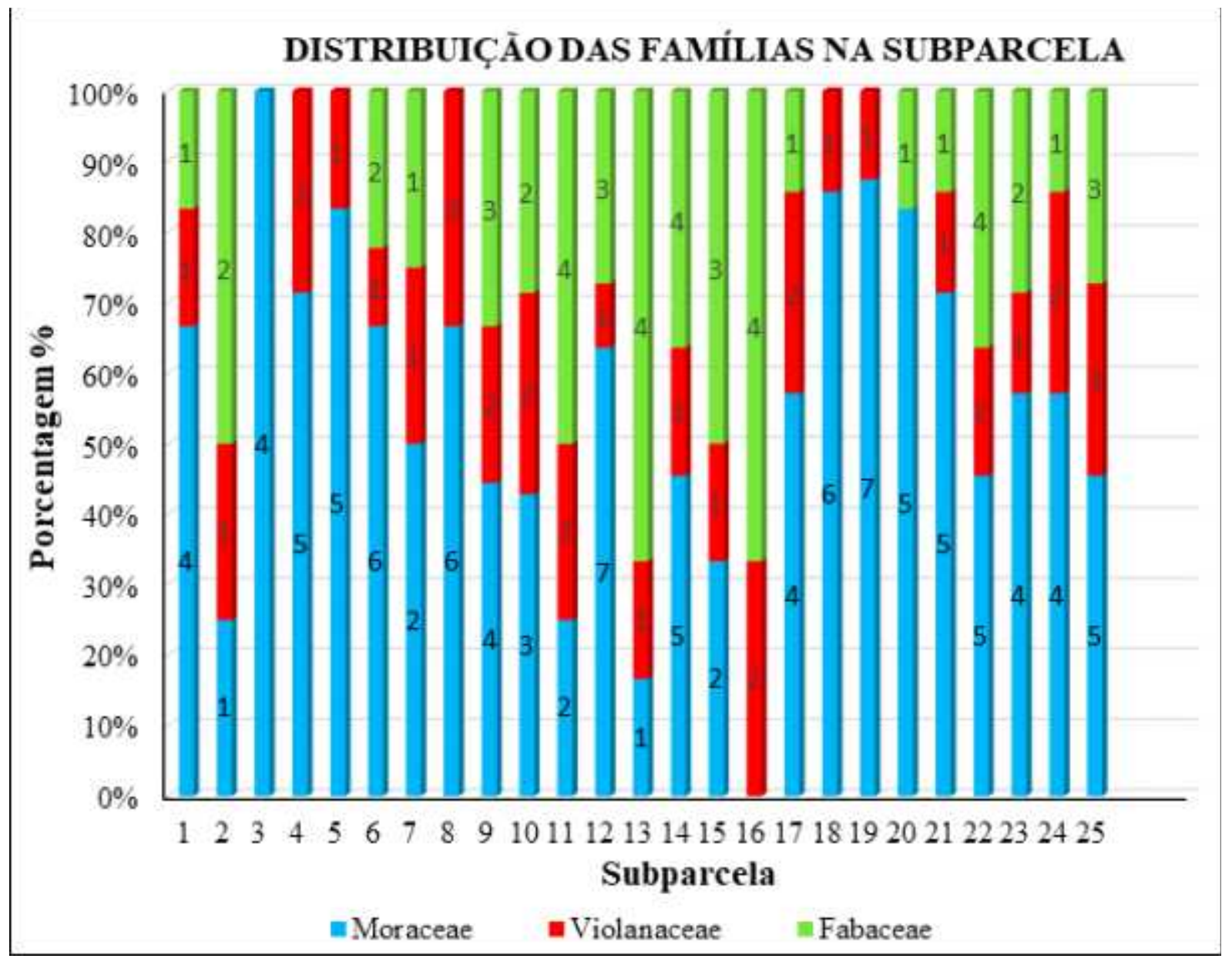

Fonte: o autor.

$\mathrm{Na}$ (Figura 14) é possivel observar que a família Moraceae esteve presente em 24 subparcelas, a família Violanacea em 23 e a Fabaceae em 19 subparcelas. Os indivíduos não identificados estão presentes na subparcela 8, 9, 10 e 11 . Na subparcela 3, identificou-se a ocorrência apenas de indivíduos da família Moraceae e ausência de indivíduos das famílias Violanaceae e Fabaceae. Os indivíduos não identificados a nivel de gênero e espécie presente na parecala 8, 10 e 11 pertence a família botânica Fabaceae e o indivíduo presente na subparcela 9 pertence a família botânica Moraceae. De modo geral 15 indivíduos não foram identificados a nivel de gênero, espécie e família. Dentre os indivíduos identificados apenas a nivel de família foi identificado um pertencente a família Sapindaceae, um pertencente a família Sapotaceae, um pertencente a família Moraceae e três pertencente a família Fabaceae.

A distribuição diamétrica estão representadas no intervalo de classe de 10 centímetros, onde os 285 indivíduos foram divididos em 9 classes diamétricas (Figura 15). Analisando a ilustração abaixo, é possível observar que a maioria dos indivíduos estão na classe de $0-9,99$ centímetros, o que supõe que a vegetação seja composta de muitos indivíduos jovem e essa floresta pode estar em fase de regeneração. Em relação as (285) árvores medidas, (147) árvores encontra-se na menor classe de 
diâmetro, sendo assim 51,58 \% dos indivíduos estão entre a classe de diametro de 0-9,99 centímetro. Os indivíduos que apresentaram os maiores diâmetros foram, Albizia pedicellaris (DC.) L.Rico. (Mapuxique vermelho), com $77 \mathrm{~cm}$, Andira indet 64,5 cm ambos pertencentes a família Fabaceae e Maquira guianensis Aubl. (Muiratinga-da-folha-miúda), com $61,3 \mathrm{~cm}$ pertencente a família Moraceae. Os indivíduos com os menores diâmetros foram Dialium guianensis (Aubl.) Sandwith (Pauferro ) com 5,2 cm, Clarisia racemosa Ruiz e Pav. (Guariúba) com 5,2 cm, Tachigali glauca Tul. com $5,2 \mathrm{~cm}$, Bauhinia ungulata L. (Mororó vermelho), com 5,2 cm e Tachigali glauca Tul. com $5 \mathrm{~cm}$.

Figura 15 - Distribuição diamétrica dos indivíduos das famílias botânica:

Moraceae, Violanaceae e Fabaceae

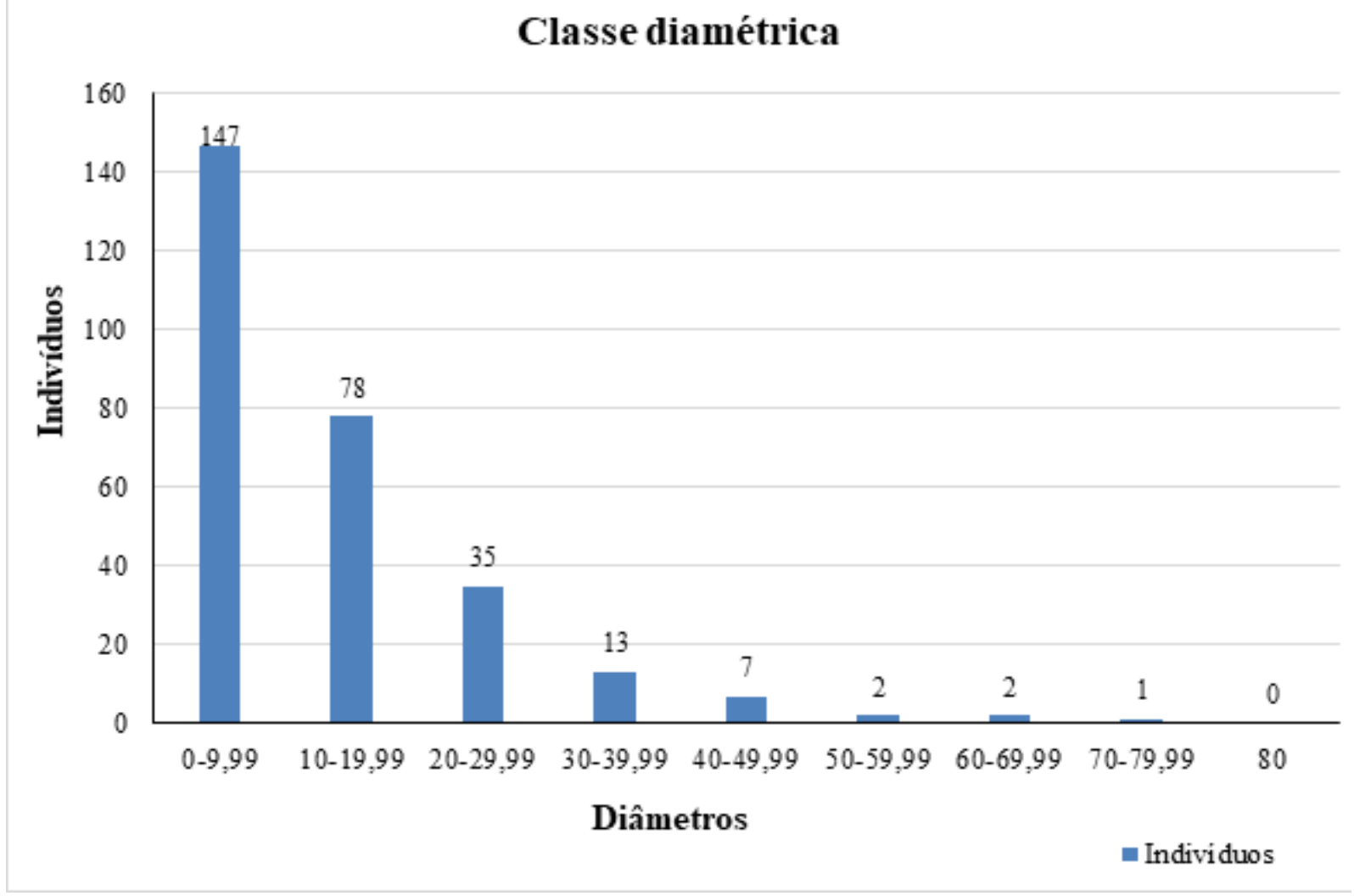

Fonte : autor

Em estudos realizadaos por Almeida et al. (2014) em uma Floresta Ombrófila Aberta Submontana localizada na Fazenda Viviane, município de Alta Floresta, Mato Grosso, o diâmetro de classe que mais se destacou foi entre 3,18 e $10 \mathrm{~cm}$, com um total de 604 indivíduos e 243 com diâmetro entre 10,1 a $20 \mathrm{~cm}$. Bombolim et al. (2014) salientou que a distribuição das classes de diâmetro que fica semelhante a do "J" invertido ou exponencial negativa, esse formato exponencial está relacionado com a idade desses indivíduos, onde é notavél a predominância dos indivíduos jovens nas primeiras classes diamétricas, observando decréscimo à medida que se avança para as últimas classes, demonstrando que a floresta está em processo de regeneração. 
Em um estudo realizado por Spletozer (2015) em um fragmento florestal do município de Alta Floresta, Mato Grosso, foi encontrado aproximadamente 500 indivíduos nas menores classes de diâmetro (9,54 - 18,46 cm), ou seja, existe uma maior concentração de indivíduos nas classes menores e uma baixa concentração de indivíduos distribuídos nas classes maiores, formando o padrão J invertido.

A distribuição espacial das três famílias botânica com maior número de indivíduos esta representado na (TABELA 2). Utilizando o índice de Payandeh ( $\mathrm{Pi}$ ) foi possível perceber que na área amostral pertencente a um fragmento de floresta ombrófila aberta, 49,5\% das espécies apresentaram padrão de tendência à agrupamento, 29,4\% aleatório e 21,1\% padrão agrupado.

Em trabalhos realizados por Gama et al. (2007) em uma floresta ombrófila aberta de cipó (FOAcipó) localizada no Município de Codó, estado do Maranhão, 64,5\% das espécies apresentaram padrão aleatório, 4,3\% tendência à agregação e 31,2\% padrão agregado.

Foi observado que as espécies pertencente as três famílias botânicas de maior relevância desse estudo e seus respectivos valores de índice de agregação. Dentre as 43 espécies, apenas 9 espécies encontra-se com distribuição de agrupamento que sugere que esse padrão ocorre devido a dispersão das sementes (CHRISTIANINI, 2004), 13 espécies apresentaram distribuição aleatória, 21 espécies encontra-se com tendência de agrupamento e os 21 indivíduos não identificados na área apresentaram distribuição espacial de agrupamento.

Para a obtenção do grau de agregação das espécies, utilizou-se o índice de Payandeh (Pi), e calculado para as 193 espécies encontradas na área amostral. A distribuição espacial que apresenta um alto nível de agregação, esta relacionado aos indivíduos que estão presentes em uma única parcela, como por exempo as espécies encontradas no trabalho de (WATZLAWICK et al., 2011), em uma Floresta Ombrófila Mista, onde a espécie Curitiba prismatica (Murta) teve um Pi igual a 4,01 e Eugenia pyriformis (Uvaia) igual a 4,00.

Segundo Bleher e Böhning-Gaese (2001), a distribuição classificada como agrupada pode estar relacionado a uma distribuição mais localizada de micro-sítios favoráveis ao estabelecimento desses indivíduos. Em relação a classificação de não agrupamento, onde as espécies ocorrem mais espalhadas na área e apresenta os menores valores das médias no número de indivíduos e baixos valores da razão variância/média (valores menores que um) e esses indivíduos em algum momento podem, apresentarem problemas em relação a regeneração natural (NASCIMENTO et al., 2001).

Segundo Lima et al. (2018), os estudos sobre a distribuição espacial são importantes para conhecer a dinâmica ecológica das espécies, uma vez que os padrões de distribuição espacial podem influenciar na ecologia da comunidade e conhecendo a dinâmica das espécies é possivel tornar os recursos naturais das espécie mais sustentável. O comportamento do padrão espacial em diferentes escalas (agrupamento, tendência ao agrupamento e aleatório), pode contribuir positivamente na elaboração dos planejamentos de inventários florestais e manejo florestal, assim como reduzir impactos ambientais (CONDÉ et al., 2016). 


\section{CONCLUSÃO}

As três famílias com maior abundância em número de índivíduos foi a Moraceae Violanaceae, Fabaceae, sendo elas o maior objetivo do estudo. A espécie Rinoreocarpus ulei apresentou os maiores percentuais em relação aos parâmetros fitossociológicos analisados: densidade relativa (18,60\%), frequência relativa $(10,22 \%)$, dominãncia relativa $(11,15 \%)$, índice de valor de cobertura $(14,87 \%)$, índice de valor de importância (13,32 \%), índice de Payandeh (Pi) 2,02 inferindo assim distribuição espacial agregada desses indivíduos, essa espécie tem 53 indivíduos em toda a aréa amostral, destacando-se a sua importância e seu valor de cobertura nessa comunidade.

A área de estudo é classificada como uma Floresta Ombrófila Aberta e devido ter passado por um processo de exploração seletiva com baixa intensidade a alguns anos atrás, apresenta muitos indivíduos jovens, o que supõe que a floresta pode estar em fase de regeneração. Atualmente a área possui muitas espécies florestais distintas, sendo assim considerada uma área com elevada diversidade florística, pouca dominância e os indivíduos estão distribuidos espacialmente com tendência ao agrupamento 


\section{REFERÊNCIAS}

ALMEIDA, E.; LOPES, C. R.; RODRIGUES, L., SIMÃO, S.; FERNANDES, J. (2014). Estrutura fitossociológica de floresta estacional decidual submontana e floresta ombrófila aberta submontana em Alta Floresta, Mato Grosso. 2014. Enciclopédia Biosfera, v. 10, n. 19, 2014

ALVARES, C. A, et al. Köppen's climate classification map for Brazil. (2013). Meteorologische Zeitschrift, , v. 22, n.6, p.711-728, 2013.

ARAÚJO, F. S.; MARTINS, S. V.; NETO, J.A. A. M.; LANI, J. L.L.; PIRES, I. E. Estrutura da Vegetação Arbustivo-Arbórea Colonizadora de uma Área Degradada por Mineração de Caulim, Brás Pires, MG. Revista Árvore, v.30, n.1, p.107116, 2006.

BAMBOLIM, A.; DONDE, A. R.; WOJCIECHOWSK, J. C. Análise fitossociológica e estrutura florística de uma floresta estacional decidual. Revista de Agricultura Neotropical, Cassilândia-MS, v. 5, n. 2, p. 62-68, 2018.

BAMBOLIM, A.; DONDE, A. R.; WOJCIECHOWSK, J.C. Análise fitossociológica e estrutura florística de uma floresta estacional decidual. JOURNAL OF NEOTROPICAL AGRICULTURE, v. 5, n. 2, p. 62-68, 2018.

BLEHER, B.; BÖHNING-GAESE, K. Consequences of frugivore diversity for seed dispersal, seedling establishment and the spatial pattern of seedlings and trees. Oecologia, Berlin, v. 129, p.385-394. 2001.

BRUZINGA, J. S.; OLIVEIRA, M. L. R. DE; MACHADO, E. L. M.; LEITE, H. G.;PEREIRA, I. M.; NOGUEIRA, G. S. Distribuição espacial de indivíduos adultos de pequi. Scientia Forestalis/Forest Sciences, v. 41, n. 98, p. 249-256, 2013.

CABRAL, F. F. Levantamento Florístico e Fitossociológico do "Parque Ecológico Municipal Leopoldo Linhares Fernandes", Alta Floresta, Mato Grosso, Amazônia Meridional, Brasil. 2010. 121 f. Trabalho de Conclusão de Curso (Licenciatura em ciências biológicas) - Universidade do Estado de Mato Grosso, Alta Floresta, 2010.

CHAVES, A. D. C. G., SANTOS, R. M. S.;SANTOS, J. O.; FERNANDES, A. A.; MARACAJÁ, P. B. A importância dos levantamentos florístico e fitossociológico para a conservação e preservação das florestas. Agropecuária Científica no Semiárido, v. 9, n. 2, p. 43-48, 2013.

CHRISTIANINI, A. V., ANTONELLI, A., RODRIGUES, G. B., \& VIANI, R. A. Síndromes de dispersão e distribuição espacial de indivíduos de sete espécies lenhosas do cerrado. (2004). Relatórios da disciplina NE211-PPGEcologia.(FAM Santos, FR Martins, JY Tamashiro, coords.). Universidade Estadual de Campinas, Campinas, 2004.

CLAUDINO, W.V.; GARCIA, M.L.; LOPES, C.R.A.S.L.; RODRIGUES, L., CABRAL, F. F, PIVA, J. H.; DA SILVA, A. C. S. (2015). Análise fitossociológica da vegetação na região do arco do desmatamento. Ciências Agroambientais, Alta Floresta, v. 13, n. 1, p. 43-52, 2015.

CONDÉ, T. M.; TONINI, H.; SILVA, F. DA; BARNI, P. E.; SOUZA CELES, C. H.; ARAUJO, R. F. DE; ASSIS CAMPOS, M. A.; CARNEIRO DE MIRANDA, D. L. Padrão espacial de espécies madeireiras da Amazônia pelo método de coordenadas cartesianas e espaciais. Pesquisa Florestal Brasileira, v. 36, n. 86, p. 115, 2016.

CORSINI, C. R.; SCOLFORO, J. R. S.; OLIVEIRA, A. D.; MELLO, J. M.; MACHADO, E. L. M. Diversidade e similaridade de fragmentos florestais nativos situados na região nordeste de Minas Gerais. Cerne, Lavras-MG, v. 20, n. 1, p. 1-10, 2014 
DAS NEVES, E.; DA SILVA, F. C. O. PANORAMA ATUAL DO POLO CACAUEIRO NO MUNICIPIO DE ALTA FLORESTA E PERFIL DO PRODUTOR FAMILIAR. 2013. Agrotrópica 25 (1): 17 - 32. Centro de Pesquisas do Cacau, Ilhéus, Bahia, Brasil. 2013.

DE SOUZA, R. L. F. Padrão espacial da castanheira em floresta no sul do Amapá, Amazônia Oriental.(2020). Revista Arquivos Científicos (IMMES), v. 3, n. 1, p. 67-72, 2020.

DIAS, A. C. Composição florística, fitossociologia, diversidade de espécies arbóreas e comparação de métodos de amostragem na floresta ombrófila densa do Parque Estadual Carlos Botelho/SP-Brasil. 2005. Tese de Doutorado. Universidade de São Paulo, p.184, Piracicaba-SP, 2005.

FEARNSIDE, P.M. Desmatamento na Amazônia brasileira: história, índices e consequências. 2005. Megadiversidade, Belo Horizonte, v.1, n.1, p.113-123, 2005.

FERREIRA JÚNIOR, E. V., Soares, T. S., Costa, M. F. F. D., \& Moraes e Silva, V. S. (2008). Composição, diversidade e similaridade florística de uma floresta tropical semidecídua submontana em Marcelândia-MT. Acta amazônica, v. 38, n. 4, p. 673-679, 2008.

FERREIRA, C. A.; da SILVA, H. D.; REISSMANN, C. B.; BELLOTE, A. F. J.; MARQUES, R. Nutrição de pinus no Sul do Brasil: diagnóstico e prioridades de pesquisa. 2001. Embrapa Florestas-Documentos (INFOTECA-E), 2001.

FERREIRA, L.V.; VENTICINQUE, E.; ALMEIDA, S. O desmatamento na Amazônia e a importância das áreas protegidas. Estudos Avançados, São Paulo, v.19, n.53, p.157-166, 2005.

FRANCEZ, L.M. B.; CARVALHO, J.O.P.; JARDIM, F.C.S. 2007. Mudanças ocorridas na composição florística em decorrência da exploração florestal em uma área de floresta de terra firme na região de Paragominas, PA. Acta Amazonica, v.37, p.211-228.2007.

GAMA, J. R. V.; SOUZA, A. L. D.. CALEGÁRIO, N.;LANA, G. C. Fitossociologia de duas fitocenoses de floresta ombrófila aberta no município de Codó, Estado do Maranhão. (2007). Revista Árvore, v. 31, n. 3, p. 465-477, 2007.

IBGE. Instituto Brasileiro de Geografia e Estatística. Manual técnico da vegetação brasileira. 2a ed. Rio de Janeiro: Departamento de Recursos Naturais e Estudos Ambientais/IBGE, p.271, 2012.

IBGE. Instituto Brasileiro de Geografia e Estatística. Manual técnico da vegetação brasileira. 2ạ ed. Rio de Janeiro: Séries Manuais técnicos em geociências/IBGE p. 271, 2012.

IVANAUSKAS, N. M., MONTEIRO, R., RODRIGUES, R. R. Composição florística de trechos florestais na borda sulamazônica. 2004. Acta Amazonica, v. 34, n. 3, p. 399-413, 2004.

KNIGHT, D,H. A phytosociological analysis of species-rich tropical forest on Barro Colorado Island, Panamá, Ecological Monographs, v.45, p. 259-284, 1975.

LIMA, D.; MISAEL, C.; GODINHO, S. T.; BEZERRA, B. R.; VASCONCELLOS, R.; OLIVEIRA, G. L.; CUNHA, M. L.; ALVES, X. A. Estrutura e distribuição espacial de Symphonia globulifera L . f . em floresta de várzea baixa , Afuá-PA. Advances in Forestry Science, v. 5, n. 1, p. 275-281, 2018.

LIMA, R. B. A.;SILVA, J. A. A.; MARANGON, L. C.; FERREIRA, R. L. C.;SILVA, R. K. S.(2012), Fitossociologia de um trecho de floresta ombrófila densa na Reserva de Desenvolvimento Sustentável Uacari, Carauari, Amazonas, Scientia Plena, v. 8, n. 1, 2012.

LUDW IG, J. A.; REYNOLDS, J. F. Statistical ecology: a primer on methods and computing. (1988). New York, John Wiley e Sons. p.337 (1988). 
MALHEIROS, A. F.; HIGUCHI, N.; SANTOS, J. D. Análise estrutural da floresta tropical úmida do município de Alta Floresta, Mato Grosso, Brasil. (2009). Acta Amazônica, v. 39, n. 3, p. 539-548, 2009.

MARTINS, F. R. Fitossociologia de florestas no Brasil: um histórico bibliográfico.1989. Pesquisas - Série Botânica, São Leopoldo, n. 40, p. 103-164, 1989.

MAGURRAN, A.E. Ecological diversity and its measurements. Princeton: Princeton University Press. 1988.

MIRANDA, L. Atlas geográfico de Mato Grosso. 2a Ed. Cuiabá: Entrelinhas, p. 64. 2016.

MOSER, P. Vegetação arbórea e sua relação com fatores ambientais e espaciais em florestas de terra firme no noroeste de Rondônia, Brasil. 2013 Dissertação (Mestrado em Ecologia) UNB, 2013.

MOTA, C. M.; MOURÃO, A.E. B.; ALVES, M. M. A.; MOTA, H. R.; CAVALCANTE, A. C. R.;Parâmetros fitossociológicos do estrato arbóreo de áreas de Caatinga em sistema agrossilvipastoril, In:Embrapa Caprinos e Ovinos-Artigo em anais de congresso (ALICE), In: CONGRESSO NORDESTINO DE PRODUÇÃO ANIMAL, f.8 2013, Fortaleza,[Anais...Sobral: Universidade Estadual Vale do Acaraú; Embrapa Caprinos e Ovinos, f.5. 2013.

NASCIMENTO, A. R. T.; LONGHI, S. J.; BRENA, D. A. Estrutura e padrões de distribuição espacial de espécies arbóreas em uma amostra de Floresta Ombrófila Mista em Nova Prata, RS. Ciência Florestal, Santa Maria, v. 11, n.1, p. 105-119, 2001.

NOUKEU, N. A.; PRISO, R. J.; DIBONG, S. D.; NDONGO, D.; KONO, L.; ESSONO, D.Floristic diversity of receiving environments polluted by effluent from agri-food industries. 2019. Heliyon, v. 5, n. 11, p. e02747, 2019.

OLIVEIRA, A. A. de. Inventários quantitativos de árvores em matas de terra firme: histórico com enfoque na Amazônia brasileira. (2000). Acta Amazonica, v. 30, n. 4, p. 543-543, 2000.

OLIVEIRA, A. N. D., AMARAL, I. L. D., RAMOS, M. B. P., NOBRE, A. D., COUTO, L. B., \& SAHDO, R. M Composição e diversidade florístico-estrutural de um hectare de floresta densa de terra firme na Amazônia Central, Amazonas, Brasil. 2008. Acta amazônica, v. 38, n. 4, p. 627-641, 2008.

OLIVEIRA, A.N.D.; AMARAL, I. L. Florística e fitossociologia de uma floresta de vertente na Amazônia Central, Amazonas, Brasil. Acta Amazônica, v.34, p.21-34. 2004.

OLIVEIRA, W. P. S. Serapilheira acumulada a astoque de nutrientes em uma floresta ombrófila aberta na região de Alta Floresta-MT. 2019. Trabalho de conclusão de curso (Graduação em Engenharia Florestal). Universidade do Estado de Mato Grosso Carlos Alberto Reys Maldonado, Campus de Alta Floresta, 37 p. 2019.

PAYANDEH, B. Comparison of method for assessing spatial distribution of trees. Forest Science, Bethesda, v. 16, p. 312-317, 1970.

PHILLIPS, O.; BAKER, T.; FELDPAUSCH, T.; BRIENEN, R. (2016). Manual de Campo para o Estabelecimento e Remedição de Parcelas da RAINFOR. The Royal Society, 2016.

PIELOU, E, C, Species diversity and pattern diversity in the study of ecological succession, Journal of Theo-retical Biology , v,10, n,2, p.370-383, 1966.

PIELOU, E,C, Ecological Diversity, New York: Wiley InterScience, p.165, 1975.

POLLOCK, M. Biodiversity, In: BILBY, R,E,; NAIMAN, R,J, Ecology and Management of streams and rivers in the Pacific Northwest Coastal Ecoregion, New York: SpringerVerlag, p, 430-452, 1998. 
ROCHA FILHO, J, A. Estrutura e dinâmica de florestas: respostas dessas à formação do reservatório de uma hidrelétrica na amazônia, bacia do rio teles pires. 2019. Dissertação de Mestrado, Universidade do Estado de Mato Grosso, Faculdade de Ciências Biológicas e Agrárias, Alta Floresta, MT, f. 109, 2019.

SCOLFORO, J. R.; OLIVEIRA, A. D.; FILHO, A. C. F.; MELLO, J. M. (2008). Diversidade, equabilidade e similaridade no domínio da caatinga. Inventário Florestal de Minas Gerais: Floresta Estacional Decidual-Florística, Estrutura, Similaridade, Distribuição Diamétrica e de Altura, Volumetria, Tendências de Crescimento e Manejo Florestal. Lavras: UFLA, p. 118-133, 2008.

SFB - SISTEMA FLORESTAL BRASILEIRO. Área de floresta nativa no Brasil.2016. Disponível em: <http://snif.florestal.gov.br/pt-br/conhecendo-sobre-florestas> Acesso em: 08 de janeiro 2021.

SPLETOZER, A. G. SANTOS, L. G.; RODRIGUES, L.; SANTOS, C. R. D. Análise da Estrutura de Espécies Arbóreas em Fragmentos Florestais do Município de Ata Floresta,MT. In: 6a Jornada Científica da Unemat, 6a . (JC), 2015, Cáceres/MT. Anais...Cáceres/MT: Universidade do Estado de Mato Grosso - UNEMAT, Vol. (6). ISSN 2178-7492. 2015

SILVA, M. M.; GANADE, G. M. S.; BACKES, A. Fitossociologia do estrato arbóreo de um remanescente de floresta ombrófila mista, na Floresta Nacional de São Francisco de Paula, Rio Grande do Sul, Brasil. Pesquisas, Série Botânica, São Leopoldo-RS, v. 62, n. 1, p. 199-210, 2011.

SILVA, A. P. F. F.; GAMA, M. M. B. Fitossociologia de uma Floresta Ombrófi la Aberta em Área de Assentamento Rural no Distrito de Jaci Paraná, 119 Porto Velho, Rondônia. Ambiência - Revista do Setor de Ciências Agrárias e Ambientais v. 4 N. 3, p. 437, 2008

TERBORGH, J.; ANDRESEN, E. The composition of Amazonian forests: patterns at local and regional scales, Journal of Tropical Ecology, v, 14, p, 645-664, 1998.

WATZLAWICK, L. F.; de ALBUQUERQUE, J. M.; REDIN, C. G.; LONGHI, R. V.; LONGHI, S.J. Estrutura, diversidade e distribuição espacial da vegetação arbórea na Floresta Ombrófila Mista em Sistema Faxinal, Rebouças (PR). Ambiência, v.7, n.3, p.415-427, 2011. 


\section{ASPECTOS RELACIONADOS À PRODUÇÃO DE SOJA NO BRASIL - UMA REVISÃO DA LITERATURA}

Juliana Amaral Vinhote

Centro Universitário Luterano de Santarém - CEULS/ULBRA Santarém - PA

\section{Gabriel Coradini}

Centro Universitário Luterano de Santarém - CEULS/ULBRA Santarém - PA

Éder Bruno Rebelo da Silva

Universidade Federal Rural da Amazônia - UFRA

Capanema - PA

\author{
Welligton Conceição da Silva \\ Universidade Federal Rural da Amazônia - UFRA \\ Belém - PA \\ Gilbson Santos Soares \\ Centro Universitário Luterano de Santarém - CEULS/ULBRA \\ Santarém - PA
}

\section{RESUMO}

O objetivo neste estudo foi realizar uma revisão de literatura dos aspectos relacionados à produção de soja no Brasil, com ênfase na colheita e pós-colheita, bem como na qualidade e classificação dos grãos. Dito isto, após a análise dos dados científicos, foi possível compreender acerca da cultura da soja, bem como, a importância da qualidade dos grãos, fazendo-se necessária a adoção de práticas que minimizem as perdas, sinalizando os principais problemas no momento da colheita e pós-colheita. Além disso, na pós-colheita a classificação dos grãos é importante, pois apresentará respostas mais consistentes, podendo ser física, fisiológica ou mecânica, instigando a comunidade científica para a utilização dessa ferramenta objetivando tratar de forma pontual a origem dos prejuízos da produção de soja no Brasil.

\section{Palavras-chave:}

Cultura de soja; Colheita. Pós-colheita; Qualidade; Classificação.

\section{ABSTRACT}

The aim of this study was to conduct a literature review of aspects related to soy production in Brazil, with an emphasis on harvest and post-harvest, as well as on the quality and classification of grains. That said, after analyzing the scientific data, it was possible to understand about soybean culture, as well as, the importance of grain quality, making it necessary to adopt practices that minimize losses, signaling the main problems at the time of harvest and post-harvest. In addition, in the post-harvest the classification of grains is important, as it will present more consistent responses, which may be physical, physiological or mechanical, instigating the scientific community to use this tool aiming to deal in a timely manner the origin of the losses of soy production in Brazil.

\section{Keywords:}

Soy culture; Harvest; Post-harvest; Quality; Classification. 
INTRODUÇÃO

O comércio da soja passou por grande expansão na década de 70, com o aumento da comercialização e da demanda internacional pelos grãos, resultando na ampliação e difusão de indústrias de óleo de soja no Brasil, em seguida o cultivo de soja no Brasil cresceu, devido ao desenvolvimento acelerado de tecnologias e pesquisas específicas na área da soja (CONAB, 2018). Assim, o setor está em constante busca por melhorias no manejo do grão, uma vez que o país perde em quantidade e qualidade, tanto pela falta de unidades armazenadoras como pela precariedade de infraestrutura (BUSS et al., 2019).

As diversas perdas produtivas desse grão relacionam-se principalmente com as operações de distribuição, sendo as principais fontes de estragos desse commodity o armazenamento incorreto, visto que estão interligados durante todo o ciclo pós-colheita, que inicia na lavoura e se estende até a disponibilização no mercado consumidor, necessitando de operações de colheita corretas, que visem não causar injúrias no grão, assim como um escoamento que atenda a todas as exigências (MACHADO et al., 2013).

Um dos problemas logísticos existentes é a armazenagem dos grãos de soja, onde faltam espaços suficientes, ocasionando o armazenamento inadequado e em locais impróprios e sob condições não apropriadas, resultando em grãos com diversas avarias e de baixa qualidade, gerando prejuízos ao produtor e perdas significativas ao longo das demais etapas da cadeia de escoamento (CONAB, 2015).

A comercialização e processamento da soja tem como principal parâmetro a qualidade dos grãos, que quando ocorrem de maneira inadequada afetam o valor do produto, demonstrando que a agricultura brasileira ainda não controla totalmente as perdas durante o pós-colheita, sofrendo interferência por fatores externos, sendo eles físicos, como temperatura e umidade; químicos, como fornecimento de oxigênio, e biológicos, como bactérias, fungos, insetos e roedores (SAATH, 2017).

Os grãos de soja são classificados de acordo com a Instrução Normativa № 11, de 15 de maio de 2007 e Instrução Normativa № 37 de 27 de julho de 2007, do Ministério da Agricultura, Pecuária e Abastecimento (Brasil, 2007a; 2007b), que padroniza defeitos, regras e limites de grãos de soja para a comercialização. Os principais defeitos padronizados são: grãos queimados, grãos ardidos, grãos mofados, grãos fermentados, grãos germinados, grãos imaturos, grãos danificados, grãos chochos.

Sendo classificado em esverdeados, os grãos ou pedaços de grãos com desenvolvimento fisiológico completo. Os grãos avariados representam a soma dos queimados, ardidos, mofados, fermentados, germinados, imaturos, danificados por pragas e chochos, sendo a tolerância de 8\% (BRASIL, 2007a). Com base nessas informações, o objetivo neste estudo foi realizar uma revisão de literatura dos aspectos relacionados à produção de soja no Brasil, com ênfase na colheita e pós-colheita, bem como na qualidade e classificação de grãos. 


\section{CULTURA DA SOJA}

Para Farias et al. (2007) e Tejo (2019) a soja (Glycine max) é considerada uma das culturas mais antigas do mundo, estima-se que sua utilização como fonte de proteína existe a pelo menos cinco mil anos. Difundiu-se pelo mundo por intermediação dos viajantes ingleses e imigrantes. Conforme Embrapa (2019), no Brasil, a soja é a cultura de maior expressão, sendo considerado o segundo maior produtor, ocupando na safra de 2018/19 uma área total de 36,945 milhões de hectares, resultando em uma produção de 120,883 milhões de toneladas.

Segundo Conab (2017), nesse sentido em âmbito mundial a soja é classificada economicamente como um dos mais importantes produtos agrícolas, representando um grande papel para a economia brasileira, devido suas diversas maneiras de utilização em diferentes segmentos. Sob o mesmo ponto de vista Lemos et al. (2017) diz que o grão de soja é utilizado para a fabricação de proteína animal, sendo que seu uso vem conquistando o cenário para a utilização na alimentação humana, através das cadeias agroindustriais, podendo inclusive ser utilizada na fabricação de biocombustível.

Assim, Lemos et al. (2017) menciona em sua pesquisa que as américas detêm os três maiores produtores de soja, representando $82,4 \%$ de toda a produção mundial, os Estados Unidos da América (EUA) respondem por 34,4\%, posteriormente o Brasil, com 31,7\% e a Argentina, com 16,3\%. Devido os dois grandes produtores estarem em hemisférios diferentes, as safras não coincidem, o que favorece a estabilidade mundial de ofertas durante o ano todo. De acordo com Pereira e Nascimento (2017) a China embora ocupe o quarto lugar em produtividade, é o maior consumidor mundial da oleaginosa.

Para Rigo (2015) e Organização Mundial da Saúde (OMS) a proteína vegetal presente no grão de soja contém todos os aminoácidos essenciais à saúde e manutenção do organismo, além de auxiliar a otimizar os níveis sanguíneos de colesterol, sendo uma alternativa para pessoas com intolerância à lactose.

\section{COLHEITA DA SOJA}

Conforme França Neto et al. (2016), a colheita da semente deve ocorrer no período adequado, deve-se evitar o retardamento da colheita, em via de regra o grão deve ser colhido quando o teor de água atingir valores igual ou menor que $15 \%$, durante o processo de secagem a campo. Entretanto, caso ocorra o retardamento da colheita, a semente sofre reduções de germinação e vigor, além de um elevado índice de infecção por fungos, segundo Costa et al. (1983), em trabalho pioneiro realizado no Brasil.

Para Garcia et al. (2007), para evitar a sobrecarga na colheita da lavoura de soja, a semeadura deve ocorrer de maneira escalonada, evitando que a maioria dos campos amadureçam e seja necessário colher ao mesmo tempo, devendo preferencialmente semear em épocas apropriadas para a produção de grãos de qualidade.

De acordo com Aguila et al. (2011), o isolamento entre campos de produção é indispensável, além da limpeza das máquinas colhedoras e carretas de transporte. Quando houver a troca de cultivares, é necessário realizar uma limpeza completa em todos os componentes da colhedora. Para a obtenção 
de menores índices de danos mecânicos, o mecanismo de trilha deve estar bem ajustado, pois é na operação de trilha das vagens que ocorre a quebra da semente de soja, devido à baixa umidade.

Da mesma forma, segundo França Neto et al. (2016), o conteúdo de água na semente é outro fator que deve ser colocado em evidência, pois a semente seca, sendo que aquela com baixo conteúdo de água, $12 \%$, tende a apresentar dados mecânicos instantâneos, caracterizados por fissuras, rachaduras e quebras, e a semente com conteúdo acima de 14\% fica vulnerável aos danos mecânicos latentes, caracterizados por amassamentos e abrasões.

\section{PÓS-COLHEITA DA SOJA}

Para França Neto et al. (2007), a UBS (Unidade de Beneficiamento de Sementes de Soja) é utilizada logo após a colheita, onde as moegas não devem ser fundas, evitando a ocorrência de danos mecânicos. Em seguida a semente passa pela máquina de pré-limpeza, com a remoção de impurezas grosseiras e de grãos menores. Se a umidade da semente estiver em $12,5 \%$ na UBS, recomenda-se a secagem até a porcentagem de $12 \%$, sendo que em períodos de chuva é frequente que a soja seja colhida com $18 \%$ a $19 \%$ de umidade, tornando-se imprescindível que a secagem seja realizada imediatamente.

De acordo com Kolling (2007), o beneficiamento do grão remove contaminantes, sejam eles, materiais estranhos (vagens, ramos, torrões e insetos), sementes de outras culturas e de ervas daninhas. Além do mais, essa etapa tem a finalidade de classificar a semente por tamanho, melhorando a qualidade do lote com a separação de sementes danificadas e deterioradas, aplicar agroquímicos à semente, fungicidas e inseticidas, quando necessário e também embalar a semente para a comercialização.

Para Cardoso et al. (2004), após o beneficiamento os grãos são ensacados ou colocado em sacolões para serem armazenados em armazéns convencionais (construídos com pisos tratados para barreira de umidade e com isolamento térmico na parte superior, abaixo das tesouras, com uma grande camada de ar na parte superior para auxiliar no isolamento térmico) ou climatizados, permanecendo até serem retirados. O ideal para as condições de temperatura e umidade do ar são de 25 ㄷ $\mathrm{e} 70 \%$ de umidade, dessa forma permitindo a preservação da viabilidade e do vigor da semente.

\section{QUALIDADES DE GRÃOS}

Segundo França Neto et al. (2016) a semente da soja sofre diversas interferências na sua qualidade, que podem ocorrer no campo, na colheita e secagem, durante seu beneficiamento e armazenamento, no transporte e semeadura. Esses fatores abrangem extremos de temperatura na maturação, flutuações de umidade do ambiente, seca, déficit nutricional, ocorrência de pragas e moléstias, além da forma inadequada de técnicas inadequadas de colheita, secagem e armazenamento. 
Conforme Tsukahara et al. (2016), em campo, os fatores climáticos e nutricionais, além de ataques de insetos e microrganismo, são as principais causas da deterioração dos grãos. Ademais a umidade nessa fase causa deterioração logo após a maturação fisiológica, antes da colheita, resultando em um índice elevado de danos mecânicos, uma vez que a semente deteriorada por umidade fica suscetível aos danos mecânicos.

Alencar et al. (2009) argumentam que para a comercialização e processamento, a qualidade dos grãos de soja são um parâmetro relevante, sendo um fator que afeta o valor do produto. Entretanto com o advento de toda a tecnologia na agricultura nacional, as perdas recorrentes do processo de póscolheita ainda não são totalmente controladas e, durante o armazenamento, os grãos são submetidos a fatores físicos, químicos e biológicos.

\section{CLASSIFICAÇÃO DOS GRÃOS}

De acordo com Brasil (2007), a classificação dos grãos é instituída pela lei no 9.972, de 25 de maio de 2000 e regulamentada pelo Decreto no 3.664, de 17 de novembro de 2000. O Ministério da Agricultura, Pecuária e Abastecimento através da normativa 11/2017 estabelece o padrão oficial de classificação, com os fatores identidade e qualidade intrínseca e extrínseca.

No mesmo sentido, a normativa 11/2007 classifica os principais defeitos dos grãos, em: ardidos (grãos que se apresentam visualmente fermentados, ou com sua coloração marrom escura, prejudicando o cotilédone), mofados (grãos com a presença de fungos visíveis a olho nu), fermentados (grãos que devido a fermentação sofreram alteração visível na cor do cotilédone), danificados (grãos com manchas na polpa e deformados, perfurados ou atacados por patologias ou insetos), imaturos (grãos oblongo, verdes), chochos (grãos com formato irregular, enrugados, atrofiados e desprovidos de massa interna) e esverdeados (grãos com desenvolvimento fisiológico completo com coloração esverdeada no cotilédone). Sendo o resultado da classificação a soma dos ardidos, mofados, fermentados, danificados, imaturos, chochos, germinados e queimados, com tolerância de $8 \%$ na comercialização dos grãos (BRASIL, 2007).

\section{CONSIDERAÇÕES FINAIS}

Com base nas informações extraídas da literatura, foi possível compreender acerca da cultura da soja, bem como, a importância da qualidade dos grãos, fazendo-se necessária a adoção de práticas que minimizem as perdas, sinalizando os principais problemas no momento da colheita e pós-colheita. Além disso, na pós-colheita a classificação dos grãos é imprescindível, pois apresentará respostas mais consistentes, podendo ser física, fisiológica ou mecânica, instigando a comunidade científica para a utilização dessa ferramenta e objetivando tratar de forma pontual a origem dos prejuízos da produção de soja no Brasil. 


\section{REFERÊNCIAS}

AGUILA, L. S. H.; AGUILA, J. S.; THEISEN, G. Perdas na Colheita na Cultura da Soja. ISSN 1806-9185. 9185 Pelotas, RS, 2011. 12 p (Comunicado Técnico 271).

ALENCAR, E. R.; FARONI, L. R. D.; LACERDA FILHO, A. F.; PETERNELLI, L. A.; COSTA, A. R. Qualidade dos grãos de soja armazenados em diferentes condições. Revista Brasileira de Engenharia Agrícola e Ambiental, v.13, p.606-613, 2009.

BRASIL - Ministério da Agricultura, Pecuária e Abastecimento. Instrução normativa n. 11, de 15 de maio de 2007a. Estabelece o Regulamento Técnico da Soja, definindo o seu padrão oficial de classificação, com os requisitos de identidade e qualidade intrínseca e extrínseca, a amostragem e a marcação ou rotulagem. Diário Oficial [da] República Federativa do Brasil, Brasília, DF, n. 93, p. 13-15, 16 maio 2007a. Seção 1.

BRASIL - Ministério da Agricultura, Pecuária e Abastecimento. Instrução normativa n. 37, de 27 de julho de 2007b. Altera o inciso IV, do art. 2ㅇ, do Capítulo I, do anexo da Instrução Normativa n. 11, de 15 de maio de 2007, que passa a vigorar com alterações, dando-se nova redação às alíneas " $b$ " e "g" e acrescentando-se a alínea " $h$ ". Diário Oficial [da] República Federativa do Brasil, Brasília, DF, n. 145, p. 9, 30 jul. 2007b. Seção 1.

BUSS, R. N.; MENDANHA, J. F.; SILVA, D. M.; SIQUEIRA, G. M. Infraestrutura logística de transporte e armazenagem da soja no estado do Maranhão - Brasil. Brazilian Journal of Development. Curitiba, v. 5, n. 12, p. 31564-31580, 2019.

CARDOSO, P.C.; BAUDET, L.; PESKE, S. T.; LUCCA FILHO, O. A. Armazenamento em sistema a frio de sementes de soja tratadas com fungicida. Revista Brasileira de Sementes, v.26, n.1, p.15-23, 2004.

CONAB - Companhia Nacional de Abastecimento. Acompanhamento da safra brasileira de grãos, v.10, safra 2017/18 - Décimo levantamento, Brasília, p. 1-178, julho 2018.

CONAB - Companhia Nacional de Abastecimento. Acompanhamento de Safra Brasileira de Grãos. Brasília, v.4, Safra 2016/2017, n.6, Sexto levantamento, mar. 2017.

CONAB - COMPANHIA NACIONAL DE ABASTECIMENTO. Série histórica: Produção vs Capacidade de Armazenamento. 2015.

COSTA, N.P. da; FRANCA NETO, J.B.; HENNING, A.A.; KRZYZANOWSKI, F.C.; PEREIRA, L.A.G.; BARRETO, J.N. Efeito de retardamento de colheita de cultivares de soja sobre a qualidade da semente produzida. In: EMBRAPA. Centro Nacional de Pesquisa de Soja (Londrina, PR). Resultados de pesquisa de soja 1982/83. Londrina. 1983. p.61-64.

EMBRAPA - Empresa Brasileira de Pesquisa Agropecuária; Soja em números (safra 2018/19). Embrapa Soja. Disponível em: <https://www.embrapa.br/soja/cultivos/soja1/dados-economicos>. Acesso em: 09 de setembro de 2020.

FARIAS, J.R.B.; NEPOMUCENO, A.L.; NEUMAIER. Circular Técnica 48 - Ecofisiologia da Soja. ISSN 1516-7860. Londrina, PR. Setembro, 2007.

FRANÇA NETO, J. B.; KRZYZANOWSKI, F. C.; HENNING, A. A.; PÁDUA, G. P.; LORINI, I.; HENNING, F. A. Tecnologia da produção de semente de soja de alta qualidade. ISSN 2176-2937. Circular Técnico. Londrina: Embrapa Soja, 2016. $84 p$ (Documento 380). 
FRANÇA NETO, J. B.; KRZYZANOWSKI F. C.; PÁDUA G. P. DE; COSTA; N. P. DA, HENNING, A. A. Tecnologia da produção de semente de soja de alta qualidade. Londrina: Embrapa Soja, 2007. p.12. (Circular Técnica n. 40 - Série Sementes).

GARCIA, A. PÍPOLO, A.E.; LOPES, I.O.N.; PORTUGAL, F.A.F. (2007) - Instalação da lavoura de soja: época, cultivares, espaçamento e população de plantas. Londrina, PR. Embrapa Soja. 12 p. (Circular Técnica, 51).

KOLLING, E. M. Análise técnica de unidade beneficiadora e armazenadora de produtos agrícolas, Maringá, PR, p. 2-9, 2007.

LEMOS, M. L. F.; GUIMARÃES, D. D.; MAIA, G. B. S.; G, F. A. Agregação de Valor na Cadeia da Soja. Agroindústria BNDES Setorial, v. 46, p. 167-217, 2017.

MACHADO, S. T.; REIS, J.G.M.; SANTOS, R.C.; OLIVEIRA, R.V.; DELIBERADOR, L.R. Perdas na Cadeia Produtiva da Soja: Uma Análise sob a Ótica das Redes de Suprimentos. In: XXXIII Encontro Nacional de Engenharia de Produção. Salvador, BA. Anais... Salvador, 8 a 11 de outubro. 2013.

PEREIRA, G.; NASCIMENTO, N. Cenário das Exportações Brasileiras de Soja: uma análise do mercado chinês. Caderno Científico Ceciesa-Gestão, v.3, 2017.

RIGO, A. A. Obtenção e caracterização de farinhas de soja das cultivares BRS 267, BRS 257 e VMAX. Erechim: Universidade Regional Integrada do Alto Uruguai e das Missões, 2015. 89 p. Dissertação Mestrado.

SAATH, R.; SILVA, T. J. H.; TERENCIANO, R. M.; THIAGO EVARISTO, T.; DEL ROSSO, B. C. Desempenho fisiológico e qualidade físico-química de grãos de soja secados sob diferentes temperaturas. Colloquium Agrarie, v. 13, n.2, p. 19-33, 2017.

TEJO, D. P.; FERNANDES, C. H. S.; BURATTO, J. S. Soja: fenologia, morfologia e fatores que interferem na produtividade. Revista Científica Eletrônica de XIX da FAEF, v.35, n.1, junho, 2019

TSUKAHARA, R. Y.; FONSECA, I. C. B.; SILVA, M. A. A.; KOCHINSKI, E.G.; PRESTES NETO, J. E.; SUYAMA, J. T. Produtividade de soja em consequência do atraso da colheita e de condições ambientais. Pesquisa Agropecuária Brasileira, Brasília, v. 51, n. 8, p.905-915, 2016. 


\section{ASPECTOS LIGADOS À UTILIZAÇÃO E DESCARTE DE EMBALAGENS VAZIAS DE AGROQUÍMICOS: REVISÃO DE LITERATURA}

Éder Bruno Rebelo da Silva

Universidade Federal Rural da Amazônia - UFRA

Capanema - PA

\author{
Welligton Conceição da Silva \\ Universidade Federal Rural da Amazônia - UFRA \\ Belém - PA
}

\section{Eudilene Dalet Vitor de Sousa \\ Faculdade Venda Nova do Imigrante - FAVENI} Santarém - PA

\author{
Juliana Amaral Vinhote \\ Centro Universitário Luterano de Santarém - CEULS/ULBRA \\ Santarém - PA \\ Maria Roseane Pereira dos Santos \\ Universidade Federal do Oeste do Pará - UFOPA \\ Santarém - PA
Gilbson Santos Soares
Centro Universitário Luterano de Santarém - CEULS/ULBRA Santarém - PA

\begin{abstract}
RESUMO
O objetivo neste estudo foi realizar uma revisão de literatura sobre os aspectos ligados a utilização e descarte de embalagens vazias de agroquímicos. Diante disto, após pesquisa na literatura, verificou-se que o manejo incorreto e a falta de conhecimento no uso de agroquímicos pode ocasionar contaminação ao meio ambiente e prejudicar a saúde do ser humano e dos animais, fato que é agravado pela falta de utilização do Equipamento de Proteção Individual (EPI) e descarte incorreto de embalagens vazias. Além do mais, observou-se as utilidades dos defensivos agrícolas, assim como sua classificação quanto ao
\end{abstract}

grupo químico. Dessa maneira, é necessário que todos os envolvidos na cadeia de distribuição dos agroquímicos zelem pela segurança em todas as etapas, cabe ao engenheiro agrônomo receitar os produtos químicos, o produtor deve ser ciente da validade dos produtos, manejo e local de devolução, além de exigir a nota fiscal e o aplicador deve utilizar o EPI visando garantir a sua integridade.

\section{Palavras-chave:}

Agrotóxicos; Contaminação; Aplicação; Toxidade; Ambiente.

\section{ABSTRACT}

The aim of this study was to carry out a literature review on aspects related to the use and disposal of empty agrochemical packaging. Therefore, after researching the literature, it was found that incorrect handling and lack of knowledge in the use of agrochemicals can cause contamination of the environment and harm the health of humans and animals, a fact that is aggravated by the lack of use of Personal Protective Equipment (PPE) and incorrect disposal of empty packaging. In addition, the utility of pesticides was observed, as well as their classification in terms of the chemical group. Thus, it is necessary that everyone involved in the agrochemicals distribution chain must ensure safety at all stages, it is up to the agronomist to prescribe the chemical products, the producer must be aware of the validity of the products, handling and place of return, in addition to require the invoice, the investor must use the PPE in order to guarantee its integrity.

\section{Keywords:}

Pesticides; Contamination; Application; Toxicity; Pesticides; Environmen. 


\section{INTRODUÇÃO}

Os agroquímicos são substâncias químicas artificiais utilizadas na agricultura e pecuária, sendo tóxicos em graus variados ao homem, animais e ao meio ambiente. Sua principal função é a proteção vegetal contra-ataques de pragas e moléstias, tais como bactérias, fungos, insetos e no controle das chamadas ervas daninhas ou plantas invasoras (LOPES; ALBUQUERQUE, 2018)

O Brasil por ser um grande produtor agrícola apresenta altas taxas de intoxicação por agroquímicos, seja no meio rural ou urbano, devido principalmente à falta de conhecimentos de manejo e na estrutura social (TRAPÉ, 2003; LEÃO et al., 2018). Os agroquímicos podem trazer riscos à saúde, principalmente pelo tempo de exposição, quantidade utilizada e falta de conhecimento, que resultam em superdosagens, além disso, a falta de uso ou utilização parcial dos Equipamentos de Proteção Individual (EPI) agravam ainda mais os riscos de contaminação (SILVA et al., 2020).

O uso do EPI torna seguro a aplicação de agroquímicos, entretanto há grandes evidências que um elevado número de agricultores não faz o uso desses equipamentos de proteção (SOUSA et al., 2016). Em estudo realizado por Silva et al. (2020) em Santarém no estado do Pará, foi perceptível o uso de equipamentos de forma parcial ou nula pelos aplicadores de agroquímicos. Segundo Alves (2013) os EPIs existem para proteger a saúde do trabalhador e devem ser testados e aprovados pelas autoridades competentes objetivando comprovar sua eficácia, desse modo, devem ser utilizados para garantir a integridade do aplicador e proteger contra contaminações ao meio externo.

$\mathrm{Na}$ aplicação de agroquímicos a preocupação extra é quanto ao descarte das embalagens vazias, sendo que o principal motivo da destinação correta das embalagens é diminuir o risco à saúde e a contaminação do meio ambiente (TERRA, 2008). A grande demanda na produção faz com que o produtor busque otimizar sua produção utilizando agroquímicos, o que favorece o aumento de recipientes para descarte. Estima-se que o Brasil produz para acompanhar essa demanda 115 milhões de embalagens para armazenar 250 toneladas de agroquímicos (BERNARDI et al., 2018).

A utilização e o manejo inadequado de defensivos agrícolas podem ocasionar impactos ambientais e prejuízos à saúde dos seres humanos e dos animais (LOPES; ALBUQUERQUE, 2018). Com base nessas informações, o objetivo neste estudo foi realizar uma revisão de literatura sobre os aspectos ligados a utilização e descarte de embalagens vazias de agroquímicos.

\section{DEFENSIVOS AGRÍCOLAS}

Os produtos fitossanitários, conhecidos como agrotóxicos, agroquímicos, pesticidas ou defensivos agrícolas, são substâncias químicas ou misturas utilizadas para prevenir, repelir ou inibir a ocorrência ou efeito de organismos vivos capazes de prejudicar lavouras e trazer prejuízos ao produtor (OLIVEIRA, 2018). 
Em meados da segunda Revolução Industrial, a produção de defensivos agrícolas avançou significativamente, devido à descoberta de novos compostos químicos e a criação de grandes indústrias para a produção desses compostos. Apesar da eficácia, muitos produtos tornaram-se problema no meio agrícola e na saúde mundial, devido a sua toxicidade (SENA, 2017).

Nesse contexto, um movimento conhecido como Revolução Verde teve início nos Estados Unidos da América (EUA) em 1960, e objetivou a disseminar práticas agrícolas que permitissem um vasto aumento na produção. O movimento ganhou grande repercussão no Brasil com a criação do Programa Nacional de Defensivos Agrícolas (PNDA), oferecendo crédito aos agricultores para o uso de agroquímicos, obtendo a maioria dos incentivos do governo Federal (SIQUEIRA et al., 2013).

Dados da Agência Nacional de Vigilância Sanitária (ANVISA), divulgados durante o segundo seminário sobre Mercado de Agroquímicos e Regulação, realizado em Brasília, Distrito Federal, em abril de 2012, colocam em evidência que em dez anos o mercado mundial de agrotóxicos cresceu $93 \%$ e o mercado brasileiro disparou com 190\%, fator que demonstra a preocupação com a utilização de agroquímicose aos males que eles podem trazer (CASSAL et al., 2014).

Para Spadotto (2006, p. 2):

O uso frequente, e muitas vezes incorreto, de agrotóxico pode causar a contaminação dos solos, da atmosfera, das águas superficiais e subterrâneas, dos alimentos, apresentando, consequentemente, efeitos negativos em organismos terrestres e aquáticos e intoxicação humana pelo consumo de água e alimentos contaminados, assim como o risco de intoxicação ocupacional de trabalhadores e produtores rurais.

Apesar da ampla tecnologia para a produção de agroquímicos, o seu uso inadequado ainda representa a principal barreira, principalmente pela alta chance de intoxicações, devido à falta de treinamentos, a ausência de Equipamentos de Proteção Individual (EPI) e equipamentos adequados para manuseio e aplicação, além disso, a carência de vigilância em saúde podem levar a graves casos de intoxicação, agudas ou crônicas, podendo até serem fatais (MELLO; SILVA, 2013).

\section{CLASSIFICAÇÕES QUANTO AO GRUPO QUÍMICO}

Os agroquímicos podem ser classificados em: inseticidas: os que possuem ação de combate a insetos, larvas e formigas; fungicidas: auxiliam no combate de fungos e herbicidas: combatem ervas daninhas. Essa forma de classificar os agrotóxicos é bastante relevante, pois pode ser útil para o diagnóstico das intoxicações e para a adoção de tratamento específico (RUPPENTHAL, 2013). 
Os organoclorados são altamente perigosos, e devido a isso estão proibidos desde 1985, visto que seus resíduos se acumulam nos tecidos gordurosos de mamíferos, aves e peixes, podendo contaminar a sociedade pela alimentação, sendo capaz de persistir até cem anos no meio ambiente. Se tratando de Carbamatos, este inseticida é considerado menos perigoso, apesar de possuir os mesmos efeitos inibidores do organofosforados, seus sintomas e efeitos duram aproximadamente uma semana (FILHO et al., 2017).

Quanto a classe dos fungicidas, Grisolia (2005) ressalta que, o mancozebe é um fungicida etilenobisditiocarbamato (EBDC), que é amplamente utilizado na agricultura auxiliando no controle de pragas, em hortaliças e até em cereais, além disso, seus efeitos tóxicos já foram estudados em diversas espécies. Com relação a isso, Goldoni e Silva (2012) afirmam que exposição crônica de humanos ao mancozebe é capaz de gerar danos ao DNA (Ácido desoxirribonucleico), a qual pode desencadear processos carcinogêneos e anormalidades morfológicas, ou alterações nos gametas, influenciando na sobrevivência.

Com relação aos herbicidas, Moreira (2002) discorre que são agroquímicos utilizados para o combate a ervas daninhas. Dentre os mais comuns estão o Paraquat, altamente tóxico, pois ataca severamente todos os tecidos do organismo, sendo que sua contaminação ocorre por ingestão ou inalação, bastando apenas $10 \mathrm{ml}$ para causar óbito. Já o glifosato apresenta um nível de toxicidade relativamente baixo para o ser humano, causando vômitos, náuseas e outros tipos de distúrbios gastrointestinais, e os Clorofenóxicos, que possuem baixo nível de toxicidade para os seres humanos quando sua fabricação e manipulação ocorrer de forma correta, caso contrário, torna-se um produto cancerígeno.

\section{USO CORRETO E SEGURO DE DEFENSIVOS AGRÍCOLAS}

Assim como qualquer produto químico, os produtos fitossanitários devem ser manuseados com cautela e cuidado, a fim de preservar a saúde e evitar danos à Flora e à Fauna. O seu uso de maneira correta, segura e eficiente deve ser garantido em todas as etapas de utilização do defensivo agrícola, que começa na aquisição, com a receita agronômica prescrita por um profissional credenciado, transporte, armazenamento, aplicação e descarte de embalagens vazias (ZAMBOLIM et al., 2003).

Para a aquisição de defensivos agrícolas, somente o Engenheiro Agrônomo, profissional legalmente habilitado, pode receitar com segurança o produto correto a ser administrado, levando em consideração os problemas na lavoura, ataque de pragas, doenças e plantas daninhas. O produtor deve ser ciente sobre a data de validade dos produtos fitossanitários, deve seguir com atenção as recomendações do profissional e ler com cautela rótulos e bulas, além de exigir a nota fiscal do estabelecimento de compra para evitar falsificações (ANDEF, 2016).

A legislação deve ser respeitada no momento do transporte até o local de armazenamento, sendo que o desrespeito às normas pode levar a multas para o vendedor e comprador do produto. 0 transportador receberá do expedidor informações sobre classificações dos produtos. Produtos 
considerados cargas perigosas requerem cuidados ainda maiores garantidos por lei. $\mathrm{O}$ armazenamento dos produtos deve ser em construção de alvenaria, bem ventilada e iluminada, sem goteiras, com a parte elétrica em bom estado de conservação, sem umidade, muito bem sinalizado e de preferência trancado para evitar entrada de crianças, pessoas não autorizadas e animais, além disso, após o uso, as embalagens devem ter fim adequado como lavagem e descarte adequado (ZAMBOLIM et al., 2003).

\section{DESCARTE DE EMBALAGENS}

No Brasil, foi criado um decreto que estabelece o destino correto para o descarte das embalagens de agroquímicos, regulamentado pelo n 98.816, de 11 de janeiro de 1990, Capítulo IV, Seção III, Artigos 45 a 48. No mesmo fica estabelecido a proibição do reaproveitamento das embalagens de agroquímicos e afins, sendo que essas embalagens só poderão ser reutilizadas com autorização do órgão federal registrante. Ainda, a legislação ressalta que o descarte de cada recipiente deverá atender as recomendações que estão no rótulo de cada produto (BRASIL, 1990). O Art. 12ㅇ da mesma lei regulamenta que compete ao poder público fiscalizar a devolução e destinação dessas embalagens vazias de agroquímicos.

O InpEV (Instituto Nacional de Processamento de Embalagens Vazias), criado em 2001, trata-se do órgão nacional responsável pela representação da indústria de fabricantes de agrotóxicos e afins, cujo objetivo é o gerenciamento do processo de destinação de embalagens vazias de produtos de agrotóxicos no país. Atualmente, o instituto gerencia mais de 400 centrais e postos de recebimento de embalagens distribuídas em todo o Brasil e somente no ano de 2017, atingiu a marca de destinação adequada de $94 \%$ do total das embalagens de agrotóxicos, volume correspondente a aproximadamente 44.528 mil toneladas de embalagens vazias de agroquímicos (FRANÇA et al., 2018).

\section{EQUIPAMENTO DE PROTEÇÃO INDIVIDUAL}

A aplicação segura dos agroquímicos exige o uso correto dos Equipamentos de Proteção Individual (EPIs) que são definidos como todo dispositivo de uso individual destinado a proteger a integridade física do trabalhador. A falta da utilização ou a utilização incompleta do EPI representa grande perigo à saúde do aplicador, aumentando os riscos de intoxicações (NUNES, 2010; OLIVEIRA et al., 2017). Sendo que a principal queixa no uso parcial dos EPIs é o desconforto térmico ocasionado pelo uso de todos os acessórios de proteção, fator que se agrava em regiões de clima quente (SILVA et al., 2020).

A Norma Regulamentadora 6 - NR 6, considerada Equipamento de Proteção Individual (EPI), todo produto ou dispositivo de uso individual utilizado pelo trabalhador, com a finalidade de protegê-lo de riscos que ameacem a sua segurança e a sua saúde (BRASIL, 2010). 
Segundo Borges (2012), os Equipamentos de Proteção Individual (Figura 1) do aplicador são:

- Luvas: protegem as partes do corpo com maior possibilidade de exposição, as mãos;

- Respiradores: chamados de máscaras, os respiradores têm o objetivo de evitar a absorção dos vapores e partículas tóxicas através dos pulmões;

- Viseira Facial: material transparente, para proteger os olhos e o rosto contra respingos, no preparo de caldas e durante a pulverização;

- Jaleco e Calça: proteção do tronco, membros inferiores e repelentes;

- Camisa de manga comprida: proteção do tórax e braços;

- Boné árabe (touca árabe) - é hidro-repelente, protege a cabeça e pescoço;

- Avental - de material impermeável, deve ser utilizado adaptado na parte frontal do jaleco durante o preparo da calda e na parte costal do jaleco durante as aplicações com equipamento costal; e

- Botas impermeáveis - devem ser preferencialmente de cano alto e impermeáveis. Não devem ser de couro.

Figura 1 - Equipamento de Proteção Individual (EPI).

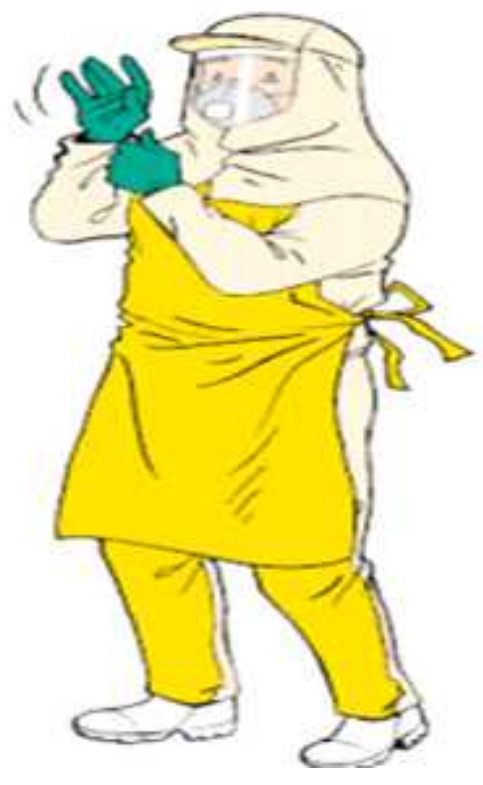

Fonte: ANDEF, 2003.

O Equipamento de Proteção Individual não é utilizado corretamente por muitos agricultores e aplicadores, e isso influencia as altas taxas de contaminação, deixando-os mais vulneráveis frente aos efeitos nocivos desses produtos (SILVEIRA, 2011). 


\section{CONSIDERAÇÕES FINAIS}

Com base nessas informações, foi possível averiguar que o manejo correto de agroquímicos inicia-se nos pontos de venda e devem seguir até o momento da devolução segura das embalagens vazias, em postos autorizados, sendo que todos os envolvidos no manejo devem ser responsáveis por garantir a segurança durante a compra, manejo e devolução das embalagens vazias. Ademais, notou-se a importância de se utilizar de maneira correta defensivos agrícolas, pois a falta de conhecimento associado à alta toxicidade compromete a saúde humana e dos animais, além de causar contaminações ao meio ambiente. Por fim, o uso do EPI, com todos os acessórios exigidos, é responsável por garantir a integridade do aplicador, que deve utilizá-lo durante o manejo e aplicação.

Após a análise da literatura, recomenda-se um trabalho de conscientização capaz de atingir o vendedor até o consumidor de produtos agrícolas, com o objetivo de informar a sociedade sobre os impactos negativos do uso indiscriminado de agroquímicos para o meio ambiente e para o homem. 


\section{REFERÊNCIAS}

ALVES, T. C. Manual de equipamento de proteção individual. Circular técnica. São Carlos, SP: Embrapa Pecuária Sudeste, 2013.

ASSOCIAÇÃO NACIONAL DE DEFESA VEGETAL- ANDEF. Manual de tecnologia de aplicação. São Paulo: Linea Creativa, 52 p. 2016.

ASSOCIAÇÃO NACIONAL DE DEFESA VEGETAL - ANDEF. Manual de uso correto de equipamentos de proteção individual. Campinas, São Paulo: Linea Creativa, 28 p.2003.

BERNARDI, A. C. A.; HERMES, R.; BOFF, V. A. Manejo e Destino das embalagens de agrotóxicos. Perspectiva, Erechim, v. 42, n. 159, p.15-28, 2018.

BORGES, A. D. Uso de EPIs na agricultura: os equipamentos de proteção individual são de extrema importância para os agricultores, 2012. Disponível em: http://www.catalaonoticias.com.br/noticiasphp? =NoticiasVer\&id =MTE30Tk.

BRASIL. Decreto No 98.816, de 11 de janeiro de 1990. Disponível em: <www.planalto.gov.br.>

BRASIL. Norma Regulamentadora № 06, de 08 de dezembro de 2010. Equipamento de Proteção Individual EPI. BR, 2011.

CASSAL, V. B.; AZEVEDO, L. F.; FERREIRA, R. P.; SILVA, D. G.; SIMÃO, R. S.; Agrotóxicos: uma revisão de suas consequências para a saúde pública. Centro do Ciências Naturais e Exatas - UFSM, Santa Maria, Revista Eletrônica em Gestão, Educação e Tecnologia Ambiental -REGETe, v. 18, n. 1, p.437-445, 2014.

FILHO, A. P. S.; AGUIAR, M. M.; BARBOSA, N. O Agrotóxicos: dos impactos a saúde individual e coletiva. Anais Colóquio Estadual de Pesquisa Multidisciplinar, v. 1, n. 1, p. 1-7, 2017.

FRANÇA, I.; SÁ L.; DALPIAN P. Logística reversa de embalagens vazias de agrotóxicos: o caso de sucesso da central de recebimento de embalagens vazias de Aurora/SC. VI Simpósio da Ciência do Agronegócio, Faculdade de Agronomia, UFRGS. Porto Alegre, 2018.

GOLDONI, A.; SILVA L. B. Potencial mutagênico do fungicida mancozebe em Astyanaxjacuhiensis - Uberlândia, 2012.

GRISOLIA, Cesar Koppe. Agrotóxicos: mutações, câncer e reprodução. Brasília: Editora Universidade de Brasília, 392 p. 2005.

LEÃO, R. S.; MARQUES, R. C.; BURALLI, R. J.; SILVA, D. S.; J. R. D. Avaliação de saúde pública por exposição a agroquímicos uma experiência com a agricultura familiar no noroeste do Rio de Janeiro. Sustentabilidade em debate, v. 9, p 81-94, 2018.

LOPES, C. V. A.; ALBUQUERQUE, G. S. C. Agrotóxicos e seus impactos na saúde humana e ambiental: uma revisão sistemática. Saúde em Debate, v. 42, p. 518-534, 2018.

MELLO, C. M; SILVA, L. F. Fatores associados à intoxicação por agrotóxicos: estudo transversal com trabalhadores da cafeicultura no sul de Minas Gerais. Epidemiologia e Serviços de Saúde, v. 22, n. 4, p. 609-620, 2013. 
MOREIRA, Josino C. et al. Avaliação integrada do impacto do uso de agrotóxicos sobre a saúde humana em uma comunidade agrícola de Nova Friburgo, RJ. Ciência e Saúde Coletiva, v. 7, n. 2, p. 299-311, 2002.

NUNES, G. C. Uso do EPI - Equipamentos de Proteção Individual nas pequenas propriedades rurais produtoras de fumo no município de Jacinto Machado-SC. [Dissertação]. Criciúma (SC): Universidade do Extremo Sul Catarinense, 2010.

OLIVEIRA, A. C. Produtos fitossanitários aplicados em diferentes espectros de gotas, e suas consequências sobre a diversidade de polinizadores no girassol. 2018. 20 f. Trabalho de Conclusão de Curso (Graduação em Agronomia) Universidade Federal de Uberlândia, Uberlândia, 2018.

OLIVEIRA, S. A; BORGES-PALUCH, L. R; CERQUEIRA, T. P. S.; TELES, A. L. B. Utilização de equipamentos de proteção individual e agrotóxicos por agricultores de município do recôncavo Baiano. Revista da Universidade Vale do Rio Verde, v. 15, n. 1, p. 738-754, 2017.

RUPPENTHAL, J. E. Toxicologia. Santa Maria-RS. Rede E-tec Brasil, 128 p. 2013.

SENA, T. R. R. Detecção precoce de perda auditiva em trabalhadores expostos a agrotóxicos com uso de audiometria de altas frequências. 2017. 93 f. Tese (Doutorado) - Curso de Programa de Pós-graduação em Ciências da Saúde, Universidade Federal de Sergipe, Aracaju, 2017.

SILVA, E. B. R.; SOARES, G. S..; SILVA, W. C.; SANTOS, M. R. P. Percepção de risco da utilização e descarte de embalagens de agroquímicos em hortas, Santarém, Pará. Caderno de Ciências Agrárias, [S. I.], v. 12, p. 1-7, 2020.

SILVEIRA, M. A. S. Importância do uso de equipamento de proteção individual por agricultores no município de São Sepé/RS. 2011. 34 f. Monografia (Especialização) - Curso de Educação Ambiental, Universidade Federal de Santa Maria, Santa Maria, 2011.

SIQUEIRA, D. F.; MOURA, R. M.; LAURENTINO, G. E. C.; ARAUJO, A. J.; CRUZ, S. L. Análise da Exposição de Trabalhadores Rurais a Agrotóxicos. 190. Revista Brasileira em Promoção a Saúde, Fortaleza, v. 26, n. 2, p. 182191, 2013.

SOUSA, J. A.; FEITOSA, H. D. O.; CARVALHO; C. M. de; PEREIRA, C. F.; FEITOSA, S. D. O; SILVA,S. L. Percepção dos produtores rurais quanto ao uso de agrotóxicos. Revista Brasileira de Agricultura Irrigada v, v. 10, p. 976-989, 2016.

SPADOTTO, C. A. Abordagem interdisciplinar na avaliação ambiental de agrotóxicos. Revista Núcleo de Pesquisa Interdisciplinar, São Manuel, 2006. Acesso em: 13 bri. 2019.

TERRA, F. H. B. Alndústria de Agrotóxicos no Brasil. 156f. Dissertação de Mestrado. Programa de Pós-Graduação em Desenvolvimento Econômico da Universidade Federal doParaná. Curitiba, 2008.

TRAPÉ, A. Z. Uso de agrotóxicos e a saúde humana. In: WORKSHOP TOMATE NA UNICAMP: PERSPECTIVAS E PESQUISAS, 2003, Campinas-SP. Anais do Workshop: Tomate na UNICAMP: Perspectivas e Pesquisas. FEAGRI/UNICAMP. 2003-2004.

ZAMBOLIM, L.; CONCEIÇÃO, M.Z.; SANTIAGO, T. O que engenheiros agrônomos devem saber para orientar o uso de produtos fitossanitários. UFV, Viçosa, 2003. 


\section{PERFIL DOS TRABALHADORES FLORESTAIS E CONDIÇÕES ERGONÔMICAS DO TRABALHO EM ATIVIDADES DE PRODUÇÃO DE EUCALIPTO}

\author{
Rômulo Maziero \\ Universidade Federal do Espírito Santo - UFES \\ maziero.ufes@gmail.com
}

Elizabeth Neire da Silva Oliveira de Paula

\author{
Filipe de Moraes \\ Universidade Federal do Espírito Santo - UFES
}

\begin{abstract}
RESUMO
O objetivo deste trabalho foi realizar o diagnóstico do perfil de trabalhadores florestais e de condições ergonômicas do trabalho nas atividades de implantação, manutenção e colheita florestal, no sul do Espírito Santo. Especificamente, avaliou-se os fatores humanos, as condições de trabalho, o ambiente de trabalho e a carga física de trabalho. A pesquisa foi realizada em áreas de implantação, manutenção e colheita de florestas de produção de eucalipto. Foi aplicado um check-list semiestruturado em forma de entrevista individual aos trabalhadores para análise dos fatores humanos e das condições de trabalho. O ambiente de trabalho foi analisado conforme as normas regulamentadoras (NR) no 15 e 17. A carga física de trabalho foi avaliada com um monitor de frequência cardíaca. Os colaboradores avaliados que atuam na implantação, manutenção e colheita florestal na região sul do estado do Espírito Santo caracterizam-se por baixo nível de escolaridade, pouca permanência na atividade florestal e de origem predominantemente rural. As atividades florestais de
\end{abstract}

roçada semimecanizada, desrama semimecanizada e corte semimecanizado ultrapassaram os níveis de ruído (média) estabelecidos pela NR no 15. Os níveis de iluminância (média) encontrados nas atividades de implantação, manutenção e colheita florestal estavam dentro dos padrões mínimos da ABNT NBR ISO/CIE 8995-1:2013. As operações florestais de roçada semimecanizada, capina química manual e marcação de covas apresentaram maiores índices de estresse térmico. Quanto à maior exigência física no trabalho, foi verificada nos colaboradores que desempenhavam as atividades de roçada manual, capina química manual, coveamento manual, desrama manual e corte semimecanizado, com carga cardiovascular superior a 40\% (limite), classificadas como atividades moderadamente pesada e pesada.

\section{Palavras-chave:}

Ergonomia florestal; Fatores humanos; Segurança no trabalho florestal.

\begin{abstract}
The objective of this work was to diagnose the profile of forest workers and the ergonomic conditions of the work in the implantation, maintenance and harvesting activities in the south of Espirito Santo. Specifically, the human factors, the working conditions, the work environment and the physical workload were evaluated. The research was carried out in areas of implantation, maintenance and harvesting of forests of eucalyptus production. A semistructured checklist was applied in the form of an individual interview to the workers to analyze human factors and working conditions. The work environment was analyzed according to regulatory standards (NR) n. 15 and 17. The physical workload was evaluated with a heart rate monitor. The employees who work in the implantation, maintenance and forest harvesting in the southern region of the state of Espirito Santo, are characterized by low level of schooling, little permanence in the forestry activity and being of predominantly rural origin. Semi-mechanized mowing,
\end{abstract}

semi-mechanized stripping and semi-mechanized cutting activities exceeded the average (noise) levels established by NR n. 15. The levels of (average) illuminance found in the implantation, maintenance and harvesting activities were within the minimum standards of ABNT NBR ISO/IEC 89951:2013. Forest operations of semi-mechanized mowing, manual chemical weeding and pit marking showed higher rates of thermal stress. As for the higher physical requirement in the work, it was verified in the employees who performed the activities of manual scrubbing, manual chemical weeding, manual cobraing, manual debris and semi-mechanized cutting, with a cardiovascular load higher than 40\% (limit); classified as moderately heavy and heavy activities.

\section{Keywords:}

Forest ergonomics; human factors; forest work safety. 


\section{INTRODUÇÃO}

Com o aumento da área de florestas plantadas no Brasil após a década de 1960, houve a necessidade de se adaptar as operações florestais ao trabalhador e de buscar sistemas de execução das atividades que proporcionassem maior rendimento, menor custo e melhor aproveitamento (MINETTE et al., 2007). Algumas atividades florestais de implantação, manutenção e colheita, dependendo da forma como são executadas, podem ser classificadas como extremamente pesadas, principalmente se realizadas de forma manual ou semimecanizada (FIEDLER et al., 2012).

As operações florestais de implantação, manutenção e colheita podem expor os trabalhadores a movimentos repetitivos e ambientes de trabalho insalubres. Segundo Alvarez (1996), as características de um ambiente de trabalho refletem, de maneira expressiva, as qualidades do colaborador. Segundo Minette (1996), conhecer o perfil do trabalhador é importante para que o posto de trabalho, as máquinas e ferramentas sejam adaptados às capacidades psicofisiológicas, antropométricas e biomecânicas do indivíduo. A preocupação com o bem-estar, a saúde e segurança do indivíduo no trabalho, seja este pesado ou leve, vem se acentuando no decorrer dos últimos anos (SILVA, 1999). A ergonomia procura adequar o trabalho ao homem (IIDA, 2005), propiciando a melhor satisfação e o bem-estar do colaborador, para que possa produzir com qualidade e produtividade.

O homem possui grande capacidade para ajustar-se às condições de exposição que Ihes são impostas, adaptando-se rapidamente às situações (COUTO, 1995). Assim, apresenta capacidade para manusear máquinas, ferramentas e equipamentos ergonomicamente mal projetados, suportando posições incômodas e inadequadas a tarefa. No entanto, para Minette (1996), ao realizar um trabalho em condições inóspitas, há perdas na produtividade e a saúde pode ser severamente prejudicada. Segundo Fiedler, Rodrigues e Medeiros (2006), isso causa desconforto, aumenta o risco de acidentes e pode provocar danos consideráveis à saúde, sendo que grande parte das lesões decorrentes do risco ergonômico é do tipo trauma cumulativo, ou seja, o trabalhador somente irá perceber os efeitos depois de alguns anos numa situação de trabalho que a princípio considerava cômoda.

Nas avaliações de trabalhos que exigem elevado esforço físico, deve ser observado o tipo de atividade, com relação ao desgaste físico requerido, considerando o metabolismo, o consumo energético, as pausas (descanso), a alimentação, a postura escolhida e o ambiente físico de trabalho. Quando a atividade exigir manuseio de materiais, os principais fatores que interferem são o desgaste energético e as posturas (quando impostas e não variando ao longo do tempo), sendo importante avaliar se a carga é admissível (WATERS et al., 1993).

Diante do exposto, esta pesquisa teve por objetivo realizar o diagnóstico do perfil de trabalhadores florestais e de condições ergonômicas do trabalho em operações de implantação, manutenção e colheita de eucalipto no sul do Espírito Santo, Brasil, para uma reorganização ergonômica do trabalho, tendo como fatores principais o bem-estar e a produtividade dos colaboradores. 


\section{Materiais e métodos}

O trabalho foi realizado em propriedades florestais (vocação para florestas de produção de eucalipto) localizadas no sul do estado do Espírito Santo, compreendidos entre setembro de 2012 a julho de 2013. Foram avaliadas as operações florestais de roçada manual, roçada semimecanizada, capina química manual, marcação de covas, coroamento, coveamento manual, enchimento de covas, adubação préplantio, plantio, desrama manual, desrama semimecanizada e corte semimecanizado.

A pesquisa foi realizada a partir de um levantamento de todas as operações florestais, em que foi determinado o número mínimo de colaboradores necessários para um erro de $5 \%$, conforme metodologia de Conaw (1977), $n \geq t^{2} s^{2} / e^{2}$, onde, $n$ é o número mínimo de colaboradores (por atividade); $t$, o coeficiente a $5 \%$ (distribuição de Student); s; o desvio padrão; $e$ é o erro admissível a 5\%.

Por meio de entrevistas in loco foram aplicados check-list estruturados (adaptados de Fleming (2003) e Leite (2002)) individuais aos trabalhadores florestais convidados em participar do estudo, para avaliação dos fatores humanos e das condições de trabalho. Nesse check-list, procurou-se caracterizar os colaboradores quanto aos aspectos de origem, idade, estado civil, escolaridade, experiência na função, saúde, alimentação, treinamento e segurança no trabalho. Ao final, foi preparada uma planilha para cada operação florestal analisada, sendo composta de conforto térmico, níveis de ruído, níveis de iluminância e carga física de trabalho.

O clima foi avaliado com um termômetro digital de Índice de Bulbo Úmido Termômetro de Globo (IBUTG), da marca METROSONICS, modelo HS-3600, instalado no campo (próximo aos trabalhadores florestais). $\mathrm{O}$ armazenamento das leituras foi realizado de hora em hora durante a jornada de trabalho, começando às 08 horas e finalizando às 17 horas. Quanto às medições, foi utilizada a equação do IBUTG para ambientes externos com carga solar: IBUTG $=0,7 t b n+0,1 t b s+0,2 t g$, onde, tbn é a temperatura de bulbo úmido natural (으); $t g$, a temperatura de globo (으); tbs, a temperatura de bulbo seco (으).

Os níveis de ruído foram avaliados com um dosímetro de ruído digital portátil da marca INSTRUTHERM, modelo DOS-500. Durante a jornada de trabalho, o aparelho ficou fixado à calça do colaborador e o sensor, próximo ao canal auditivo, conforme recomenda a norma regulamentadora (NR) n 15 (atividades e operações insalubres). No final do expediente, os dados armazenados eram descarregados em um computador para posterior análise. O nível equivalente de ruído (Leq) foi calculado e, em seguida, procedeu-se a soma de níveis equivalentes a partir de várias dosimetrias (LeqFinal), para melhor amostragem dos dados, de acordo com Diniz (2007): LeqFinal $=100+16,61$ Log ( $\Sigma \%$ Dose / $\Sigma T)$, onde, $\Sigma \%$ Dose é o somatório da porcentagem de dose; $\Sigma T$, o somatório do tempo de exposição (horas).

Os níveis de iluminância foram medidos com um luxímetro digital portátil da marca TES, modelo TES1332A. A primeira leitura foi às 08 horas e a última, às 17 horas, em intervalos de uma hora durante a jornada de trabalho. O instrumento (luxímetro) foi direcionado com a fotocélula no plano X (horizontal) a uma distância de 0,75 m do solo, conforme ABNT NBR ISO/CIE 8995-1:2013.

A carga física de trabalho foi avaliada com um monitor de frequência cardíaca da marca POLAR, modelo RS300X, fixado ao trabalhador florestal. O aparelho é composto por um receptor digital de pulso, uma correia elástica e um transmissor com eletrodos fixados na altura do tórax do colaborador, por meio da correia elástica. O equipamento foi programado para armazenar os batimentos cardíacos 
a cada 15 segundos e, após a coleta, os dados armazenados foram compilados com a utilização da interface que acompanha o aparelho. Com esses dados, foi possível determinar a carga física de trabalho imposta em cada operação florestal e estabelecer os limites aceitáveis pela legislação vigente para um desempenho contínuo no trabalho, bem como ajustar a carga física de trabalho à capacidade dos colaboradores. Essa classificação laboral foi proposta por Apud (1997), dependente da frequência cardíaca média por atividade durante a implantação, manutenção e colheita florestal. Por meio dessas análises, foi possível calcular a carga cardiovascular (CCV) no trabalho (APUD, 1997), que corresponde à frequência cardíaca máxima $(F C M): C C V=(F C T-F C R) /(F C M-F C R) 100$, onde, CCV é a carga cardiovascular (\%); $F C T$, a frequência cardíaca de trabalho (bpm); $F C R$, a frequência cardíaca de repouso (bpm); FCM, a frequência cardíaca máxima (220 bpm -idade em anos).

Em um trabalho contínuo sem riscos para o trabalhador que goza de boas condições de saúde, a carga cardiovascular; conforme Apud (1997), não deve ultrapassar a 40\% (limite) em uma jornada de trabalho (8 horas). Em seguida, procedeu-se o cálculo da $F C L: F C L=0,40(F C M-F C R)+F C R$. Nas avaliações em que os valores ultrapassaram os $40 \%$ (CCV), para reorganização do trabalho, foi determinado o tempo de repouso (descanso) necessário: $\operatorname{Tr}=H t(F C T-F C L) / F C T-F C R$, onde, $\operatorname{Tr}$ é o tempo de repouso, descanso (minutos); $H t$, a duração do trabalho (minutos).

\section{Resultados e discussão}

O número mínimo de trabalhadores foi atendido em todas as operações florestais analisadas, conforme Tabela 1.

Tabela 1 - Número mínimo de colaboradores para um erro admissível de 5\%.

\begin{tabular}{lc}
\hline Operações florestais & Número mínimo \\
\hline Roçada manual & 11 \\
Roçada semimecanizada & 8 \\
Capina química manual & 8 \\
Marcação de covas & 8 \\
Coroamento & 9 \\
Coveamento manual & 8 \\
Enchimento de covas & 7 \\
Adubação pré-plantio & 6 \\
Plantio & 7 \\
Desrama manual & 3 \\
Desrama semimecanizada & 8 \\
Corte semimecanizado & 3 \\
\hline
\end{tabular}


Os valores relativos aos fatores humanos dos 86 trabalhadores florestais avaliados são apresentados na Tabela 2.

Tabela 2 - Fatores humanos relacionados ao trabalho.

\begin{tabular}{lc}
\hline Variáveis avaliadas & Média \\
\hline Estatura (m) & 1,71 \\
Peso corporal (kg) & 69,2 \\
Idade (anos) & 32,2 \\
Filhos (n) & 4,0 \\
Tempo na empresa atual (meses) & 27,3 \\
Salário mensal (R\$) & 537,5 \\
Estado civil (\% casados) & 73,3 \\
Analfabetismo (\%) & 3,6 \\
Analfabetismo funcional (\%) & 37,3 \\
Destros (\%) & 77,5 \\
Origem (\% ambiente rural) & 93,1 \\
Possuem casa própria (\%) & 54,2 \\
Treinamento na operação (\% colaboradores formalmente treinados) & 72,2 \\
Vícios (\% consumidores de bebidas alcoólicas) & 34,1 \\
\multicolumn{1}{c}{$(\%$ fumantes) } & 65,9 \\
\hline
\end{tabular}

De acordo com a Tabela 2, a média de idade foi de 32,2 anos, valor superior ao encontrado por Fiedler (1998), com 29,0 anos para colaboradores que trabalhavam na colheita de madeira em empresas florestais no litoral norte do estado da Bahia, Brasil. Quanto ao tempo de serviço nas propriedades rurais, foi consideravelmente baixo e, desse modo, pode-se supor que existe elevada rotatividade nesse tipo de segmento. Grande maioria dos trabalhadores $(93,1 \%)$ era de origem rural, vindos de São José do Calçado, Castelo, Alegre, Muqui, Jerônimo Monteiro, Cachoeiro de Itapemirim, Alfredo Chaves, Domingos Martins, lúna e Guaçui, municípios onde estavam instaladas as empresas florestais responsáveis pela implantação, manutenção e colheita das florestas de produção. Esse resultado indica que nas regiões citadas existe mão de obra favorável para as operações florestais levantadas nas visitas.

Em relação aos vícios, verificou-se que $34,1 \%$ dos trabalhadores são consumidores de bebidas alcoólicas; fazendo uso dela semanalmente e fora do expediente de trabalho e, 65,9\% são adeptos do fumo. Esses vícios tendem a diminuir a atenção e produtividade dos trabalhadores, devido aos malefícios dessas drogas no organismo. Esses resultados são superiores ao encontrado por Fiedler (2000) para trabalhadores da colheita florestal, cujo percentual foi de $37,8 \%$ (fumantes + consumidores de bebidas alcoólicas). 
Para a seleção de trabalhadores (carteira assinada), 77,7\% dos colaboradores disseram ter participado de um teste de seleção, realizados por empresas terceirizadas ou pelas próprias empresas florestais contratantes. Esse índice é superior ao encontrado por Souza et al. (2004) para trabalhadores da colheita florestal terceirizada, no qual $66,3 \%$ dos indivíduos foram admitidos na empresa, após passar por uma seleção. Quanto à lateralidade, 77,5\% dos colaboradores avaliados eram destros; 15,6\%, canhotos; e 6,9\%, ambidestros. A jornada de trabalho era das 08 horas às 17 horas, de segunda a sexta, com intervalo de uma hora de almoço, das 11 horas às 12 horas, ou seja, a jornada de trabalho semanal era de 40 horas, incluindo-se o tempo de transporte. Esse valor está de acordo com a jornada de trabalho máxima permitida pela Constituição Brasileira (BRASIL, 1988).

O transporte dos trabalhadores até as áreas de implantação, manutenção e colheita eram feitos em microônibus e/ou ônibus das empresas florestais contratantes, assim como os equipamentos de segurança (Equipamentos de Proteção Individual (EPIs), Equipamentos de Proteção Coletiva (EPCs)), combustíveis, lubrificantes e ferramentas eram transportados nos próprios veículos (sem nenhum tipo de armazenamento desses materiais).

Todos os trabalhadores disseram receber café da manhã e almoço nas propriedades florestais. Para $89,4 \%$, a alimentação fornecida era satisfatória, ou seja, não necessitava de complementação. Os lanches e almoço eram fornecidos por restaurantes contratados pelas empresas florestais, localizados nas proximidades dos municípios citados anteriormente. No café da manhã, eram servidos pães com ou sem manteiga, café e/ou suco e, no almoço; verduras, arroz, feijão, farinha, carne de boi, de frango e/ou porco). O consumo de água durante a jornada de trabalho foi de 3,1 litros/dia (média), o que precede a NR n²4, que é de 2,0 litros/dia (média) mínimo. A água era consumida de garrafas térmicas, disponibilizadas pelas próprias empresas florestais.

Para um número elevado de colaboradores entrevistados, 92,9\% afirmaram não ter nenhum tipo de doença e, quando questionados sobre o recente estado de saúde, 91,5\% disseram gozar de boa saúde; $76,6 \%$ consideraram a saúde perfeita e $8,1 \%$ regular. Entretanto, dentre os entrevistados, $68,5 \%$ revelaram ter tido problemas de lombalgias, ocorridas na maioria $(27,6 \%)$ em suas residências após o expediente. Esse fato pode ser explicado pelas posturas adotadas pelos trabalhadores nas atividades rotineiras, principalmente nas funções de roçada manual, roçada semimecanizada, marcação de covas, coroamento, coveamento manual, enchimento de covas e corte semimecanizado, as quais exigem o encurvamento das regiões lombar e cervical e, levantamento de peso nas atividades de roçada semimecanizada, capina química manual, adubação pré-plantio, desrama semimecanizada e corte semimecanizado.

Quanto às dores nas áreas do corpo surgidas pelas funções diárias desempenhadas, os colaboradores afirmaram que as costas (lombar e cervical) é a parte mais afetada, seguida pelos braços e ombros, conforme apresentada na Figura 1. 
Figura 1 - Opinião dos trabalhadores quanto as queixas e/ou dores pelo corpo.

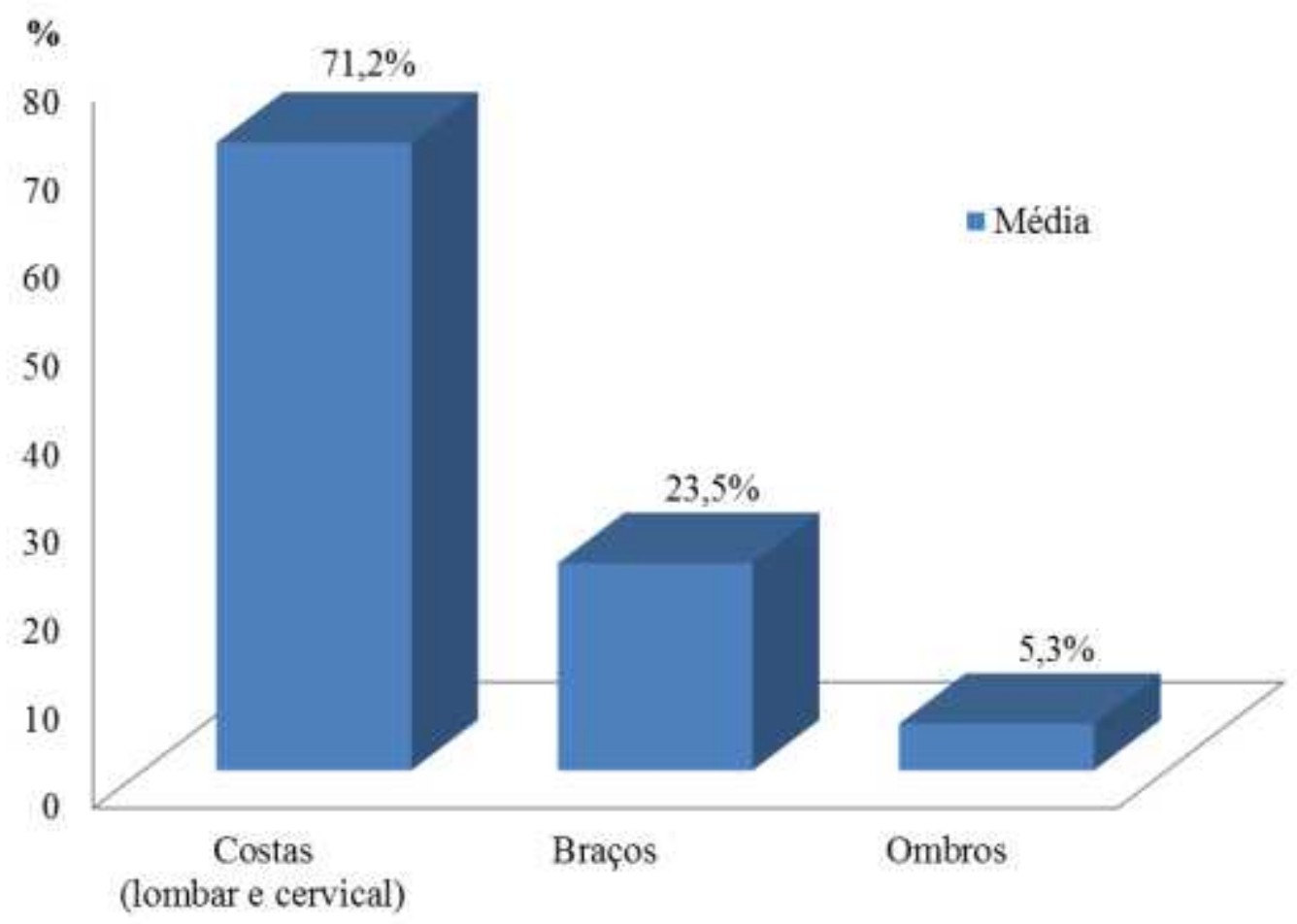

Áreas afetadas

A necessidade de uma intervenção ergonômica no ambiente de trabalho de acordo com esse resultado é imprescindível, adotando-se um maior número de pausas (descanso) no decorrer da jornada de trabalho, ou seja, de forma a contribuir para o bem-estar e produtividade do indivíduo. 0 uso de EPI foi unânime como resposta pelos colaboradores florestais, sendo o uso obrigatório. Ainda, grande parte dos trabalhadores entrevistados $(75,8 \%)$ afirmaram que os EPIs utilizados causavam incômodos, principalmente as perneiras, as botinas e a camisa manga longa, sendo que esta última significou $61,1 \%$ de insatisfação, pois mencionaram esquentar muito.

Verificou-se que um número consideravelmente elevado (8,5\%) de trabalhadores já sofreu com algum tipo de acidente de trabalho, sendo as regiões das mãos e dos pés as partes do corpo mais afetadas para $93,6 \%$ dos casos. Esse resultado demonstrou que as atividades florestais de roçada manual, roçada semimecanizada, marcação de covas, coveamento manual, desrama semimecanizada e o corte semimecanizado são as funções com maiores chances de acidentes, decorrentes das lâminas afiadas dessas ferramentas citadas.

Além disso, esse resultado reforça a importância dos trabalhadores que atuam nas atividades florestais usarem sempre os EPIs, principalmente as perneiras e botinas, de forma a evitar ou reduzir a ocorrência de acidentes, perda de trabalho e queda na produtividade. Dentre os colaboradores entrevistados, 92,3\% consideraram a roçada manual, o coveamento manual, a capina química manual e o corte semimecanizado as operações florestais com maior desgaste físico, enquanto $44,7 \%$ consideraram as operações florestais de marcação de covas, enchimento de covas, adubação préplantio e plantio como sendo as de menor esforço físico. 
Os trabalhadores foram questionados sobre a necessidade de treinamentos,. Dos entrevistados, $72,2 \%$ disseram ter recebido treinamento sobre Segurança e Saúde Ocupacional (SSO), para exercer a tarefa que desempenham atualmente, sendo que o processo de pleno aprendizado ocorreu no decorrer do exercício. Ainda assim, 5,8\% dos entrevistados não consideraram necessário o treinamento para executar as respectivas atividades, explicado pelo fato de considerarem as funções diárias de fácil assimilação. Dentre os colaboradores entrevistados, 12,9\% tiveram dificuldades com o conteúdo exposto em treinamento. $O$ treinamento teve duração de um dia a duas semanas, conforme a função. Todos os entrevistados afirmaram ser orientados pelo chefe ou coordenador de área com relação às atividades, sendo que, 55,2\% estavam satisfeitos; 41,8\%, muito satisfeitos; e 3,0\%, insatisfeitos com o tipo de orientação transmitida.

Para o conforto térmico, conforme as normas do Ministério do Trabalho e Emprego (MTE) (NR n 15, anexo 3), o limite de tolerância para exposição ao calor não pode ultrapassar a 30,0 ㄷ; 26,7 ㄷ e 25,0 C para trabalhos leves, moderados e pesados, respectivamente. Acima de $30 \stackrel{\circ}{ }$, aumentam-se os riscos de efeitos danosos à saúde do trabalhador, o foco reduz e os acidentes elevam significativamente, sendo as pausas necessárias. Na Figura 2 são apresentados os resultados do conforto térmico durante a coleta de dados em campo (próximo às atividades florestais).

Figura 2 - Dados de conforto térmico (IBUTG) das operações estudadas.

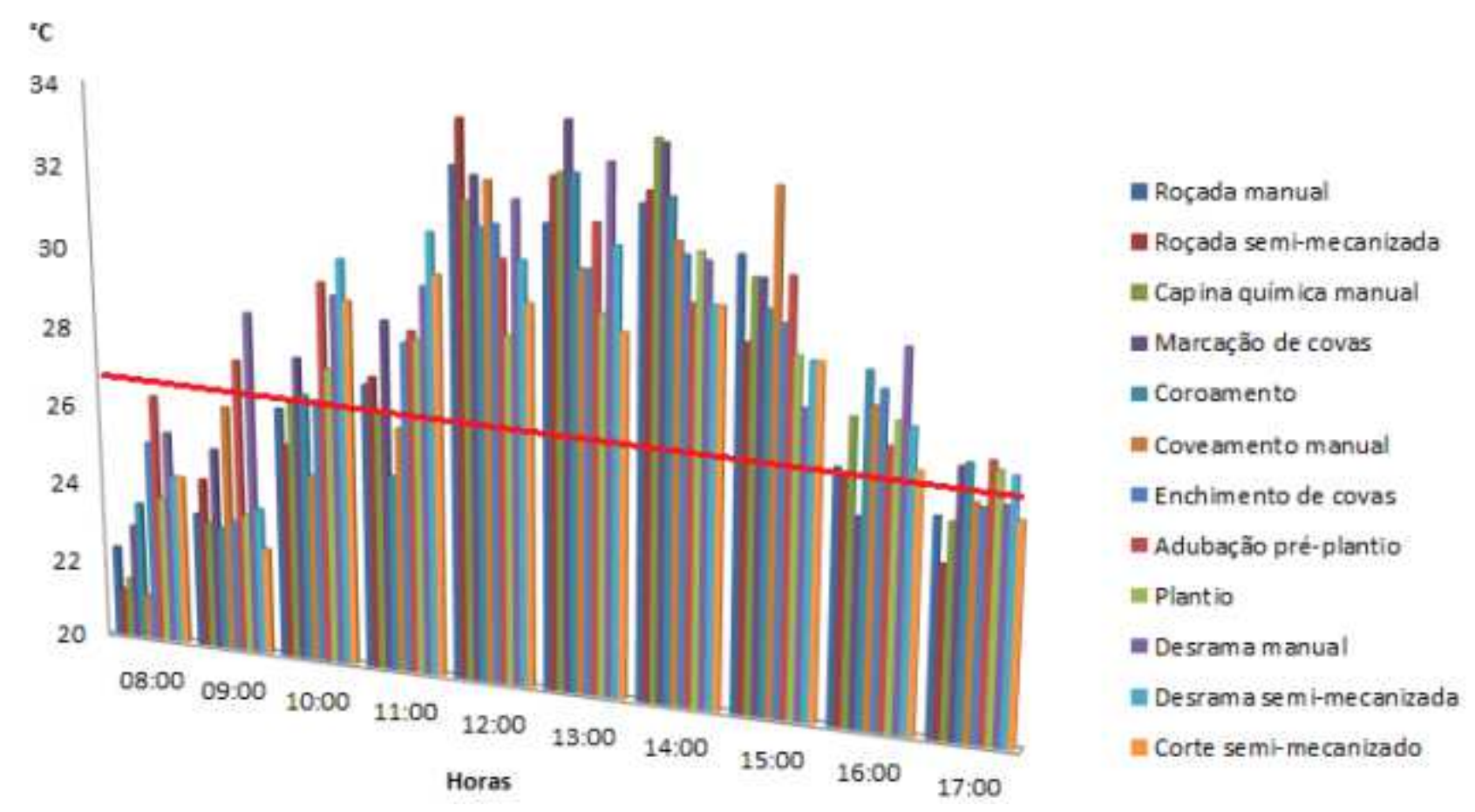

Segundo a NR no 15 e analisando os resultados apresentados na Figura 2 tomados pela média das atividades florestais, evidenciou-se que, nas atividades de roçada semimecanizada, capina química manual e marcação de covas, é necessário, a cada hora de trabalho, uma pausa de 15 minutos. Para as operações de roçada manual, coveamento manual e corte semimecanizado, esse tempo de repouso deverá representar 30 minutos de descanso. A Figura 3 indica as porcentagens de doses ( 8 horas) por jornada de trabalho de cada atividade florestal avaliada. 
Figura 3 - Porcentagem (dose) em cada atividade florestal.

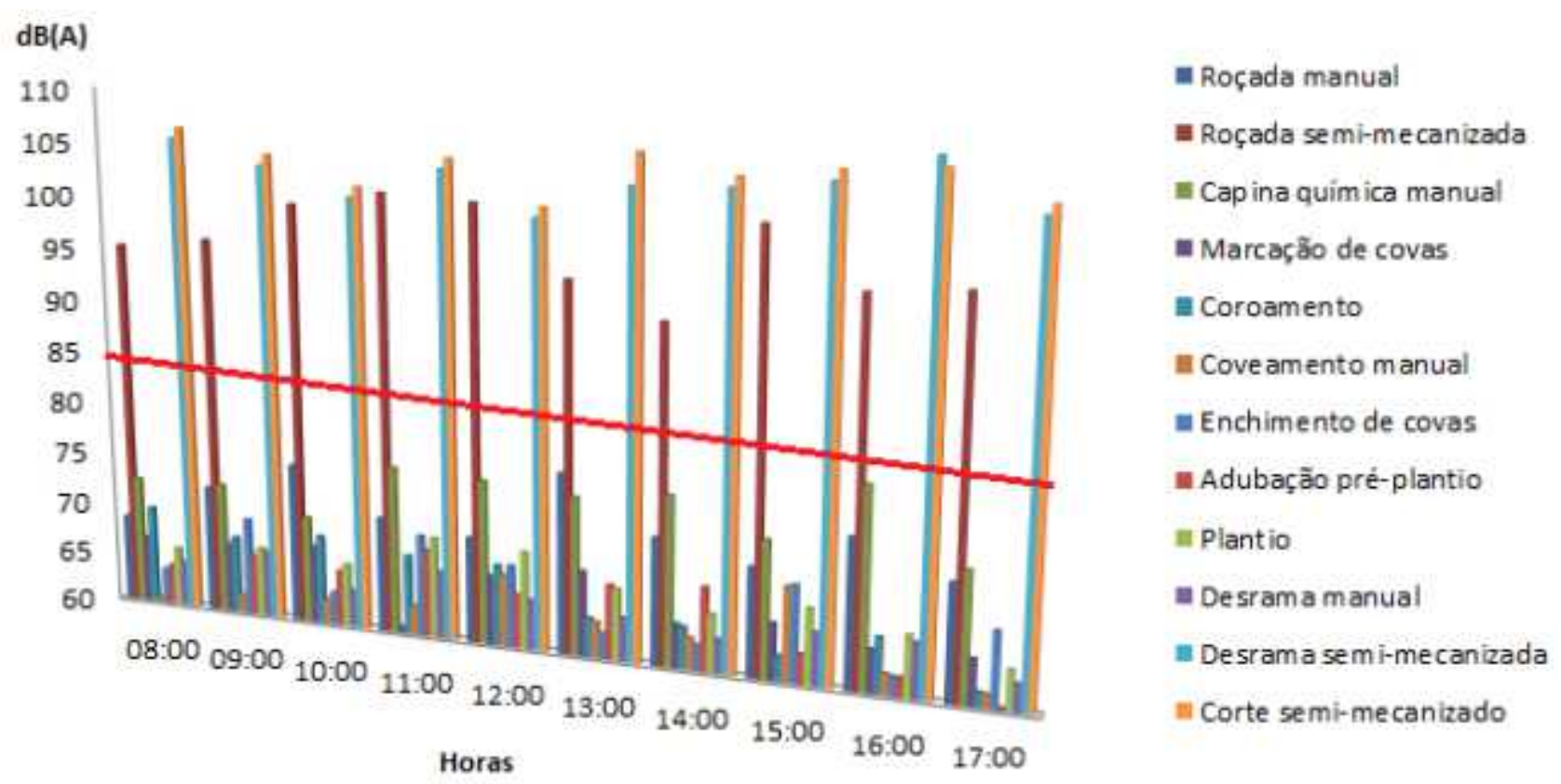

Com os dados da Figura 3, verificou-se que as operações florestais de roçada semimecanizada, desrama semimecanizada e o corte semimecanizado ultrapassaram o nível tolerado pela NR no 15 $(85,0 \mathrm{~dB}(\mathrm{~A}))$, sendo necessário o uso de protetores auriculares (tipo plug ou concha).

As atividades de implantação, manutenção e colheita florestal são executadas em ambientes externos, o que é influenciado diretamente pela variação de iluminação ao longo da jornada de trabalho. Desse modo, as operações florestais de roçada manual, roçada semimecanizada, plantio, desrama manual e desrama semimecanizada apresentaram valores de lux (média) menor em relação às outras atividades estudadas, verificadas na Figura 4.

Figura 4 - Níveis de iluminância (lux) médios nas atividades florestais.

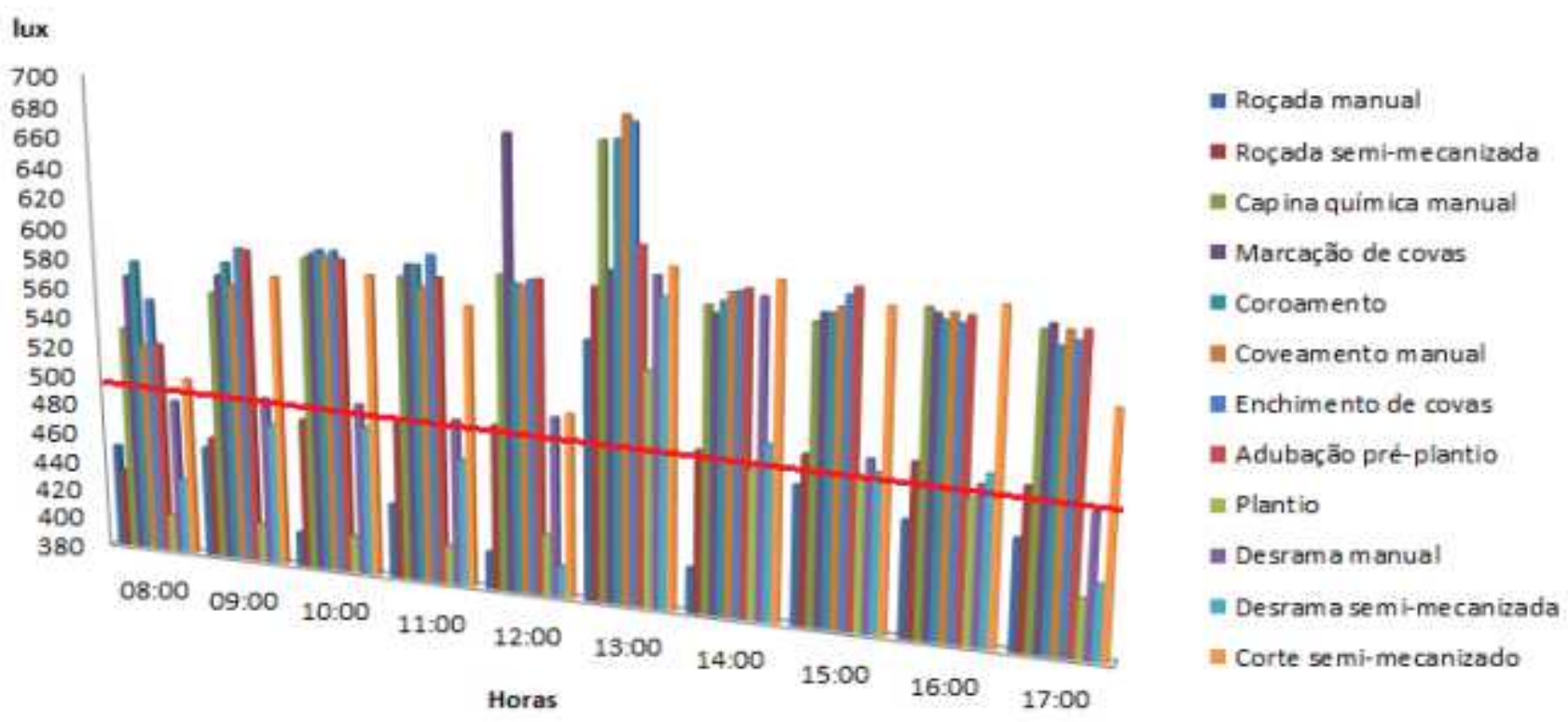


Segundo ABNT NBR ISO/CIE 8995-1:2013, nenhuma das atividades estavam com os valores de iluminância abaixo do mínimo necessário (200-500 lux). Nessas circunstâncias, o excesso de luz deve ser o fator preocupante, em que operações florestais realizadas sob incidência direta dos raios solares podem comprometer a saúde do trabalhador (tempo de exposição) e, o colaborador deve-se resguardar (proteção) com o uso de óculos de sol, camisa manga longa, chapéu, boné com protetor de pescoço e filtro solar.

Os valores por operação florestal avaliados referente à idade média dos trabalhadores (anos), frequência cardíaca média em repouso (bpm), frequência cardíaca média no trabalho (bpm), frequência cardíaca média máxima (bpm), frequência cardíaca limite (bpm), carga cardiovascular (\%), tempo de repouso ( $\mathrm{min} / \mathrm{h}$ ) e classificação do trabalho são indicados na Tabela 3.

Tabela 3 - Carga física de trabalho decorrente das operações florestais.

\begin{tabular}{l|c|c|c|c|c|c|c|c}
\hline Atividades & $\begin{array}{c}\text { Idade } \\
\text { média } \\
\text { (anos) }\end{array}$ & $\begin{array}{c}\text { FCR } \\
\mathbf{( b p m )}\end{array}$ & $\begin{array}{c}\text { FCT } \\
\mathbf{( b p m )}\end{array}$ & $\begin{array}{c}\text { FCM } \\
\mathbf{( b p m )}\end{array}$ & $\begin{array}{c}\text { FCL } \\
\mathbf{( b p m )}\end{array}$ & $\begin{array}{c}\mathbf{C C V} \\
\mathbf{( \% )}\end{array}$ & $\begin{array}{c}\mathbf{T r} \\
\mathbf{( m i n / h )}\end{array}$ & Classificação \\
\hline Roçada manual & 32 & 71 & 125 & 188 & 118 & 46 & 8,00 & Pesado \\
\hline $\begin{array}{l}\text { Roçada semi - } \\
\text { mecanizada }\end{array}$ & 35 & 68 & 115 & 185 & 115 & 40 & - & Leve \\
\hline $\begin{array}{l}\text { Capina química } \\
\text { manual }\end{array}$ & 28 & 72 & 121 & 192 & 120 & 41 & 1,17 & $\begin{array}{c}\text { Moderadamente } \\
\text { pesado }\end{array}$ \\
\hline $\begin{array}{l}\text { Marcação de } \\
\text { covas }\end{array}$ & 37 & 69 & 106 & 183 & 115 & 32 & - & Leve \\
\hline Coroamento & 30 & 70 & 118 & 190 & 118 & 40 & - & Leve \\
\hline $\begin{array}{l}\text { Coveamento } \\
\text { manual }\end{array}$ & 27 & 73 & 124 & 193 & 121 & 42 & 3,52 & $\begin{array}{c}\text { Moderadamente } \\
\text { pesado }\end{array}$ \\
\hline $\begin{array}{l}\text { Enchimento de } \\
\text { covas }\end{array}$ & 33 & 71 & 116 & 187 & 117 & 39 & - & Leve \\
\hline $\begin{array}{l}\text { Adubação pré - } \\
\text { plantio }\end{array}$ & 29 & 67 & 91 & 191 & 117 & 19 & - & Leve \\
\hline Plantio & 31 & 72 & 88 & 189 & 119 & 14 & - & Leve \\
\hline $\begin{array}{l}\text { Desrama manual } \\
\text { Desrama semi - }\end{array}$ & 34 & 70 & 118 & 186 & 116 & 41 & 2,50 & $\begin{array}{c}\text { Moderadamente } \\
\text { pesado }\end{array}$ \\
\hline $\begin{array}{l}\text { mecanizada } \\
\text { Corte semi - } \\
\text { mecanizado }\end{array}$ & 35 & 69 & 123 & 185 & 115 & 47 & 9,00 & Leve \\
\hline
\end{tabular}

As atividades florestais de maior carga física de trabalho foram a roçada manual, a capina química manual (pulverizador costal), o coveamento manual, a desrama manual e o corte semimecanizado, enquanto que as outras operações florestais avaliadas foram as de menor carga física exigida, ou seja, atingiram valores iguais ou abaixo de $40 \%$ (CCV), não sendo necessário uma reorganização do ambiente de trabalho para essas atividades de menor esforço físico, mas o controle de qualidade do ambiente de trabalho deve ser realizado periodicamente, para a quantificação (controle) da perda de rendimento por sobrecarga física. 


\section{CONCLUSÃO}

O grupo de colaboradores avaliados neste estudo que atuam na implantação, manutenção e colheita florestal na região sul do estado do Espírito Santo caracterizam-se socioeconomicamente como indivíduos com baixo grau de instrução, e, desse modo, se submetem a trabalhos muitas vezes penosos, com medo do desemprego. Foi constatado um elevado índice de trabalhadores com perspectivas de novos segmentos, em que o principal motivo está o alto desgaste físico proposto pelas atividades florestais.

Quanto à saúde e segurança (EPIs, EPCs) dos colaboradores, foi notado em maioria satisfatória (opinião das pessoas envolvidas na pesquisa, observação e anotação em campo), sendo que grande parte das atividades eram acompanhadas pelos responsáveis das áreas (implantação, manutenção, colheita) e tanto os encarregados quanto os trabalhadores receberam treinamentos específicos para cada função. Para os colaboradores, a roçada manual, a roçada semimecanizada, o coveamento manual, a desrama semimecanizada e o corte semimecanizado foram consideradas as operações florestais de maior periculosidade.

Por meio das análises do ambiente de trabalho, para o conforto térmico, apresentou-se maior rendimento no início e final das atividades florestais. Para os níveis de ruído, as operações florestais semimecanizadas ultrapassaram os níveis aceitáveis pela legislação vigente, sendo de obrigação do empregador a manutenção do equipamento, conforme recomenda o fabricante e o dever do trabalhador a guarda, limpeza e uso adequado do equipamento. Quanto aos níveis de iluminância, todas as atividades estavam dentro do padrão regido pela ABNT NBR ISO/CIE 8995-1:2013, o que não dispensa o uso de barreiras físicas contra os raios solares.

A operação de maior carga física foi a roçada manual, a capina química manual, o coveamento manual, a desrama manual e o corte semimecanizado, atividades que exigem elevados desgastes físicos na execução, pois são tarefas que influenciam diretamente na postura e proporcionam alto esforço para movimentação de cargas e, desse modo, deve-se reorganizar o ambiente de trabalho, como, por exemplo, constantes pausas durante a jornada laboral.

\section{AGRADECIMENTOS}

À Universidade Federal do Espírito Santo (UFES), pela estrutura física e, à Fundação de Amparo à Pesquisa do Espírito Santo (FAPES), pelo suporte financeiro. 


\section{REFERÊNCIAS}

ALVAREZ, B. R. Qualidade de vida relacionada à saúde de trabalhadores: um estudo de caso. 1996. Dissertação (Mestrado em Engenharia de Produção) - UFSC, Universidade Federal de Santa Catarina, Florianópolis, 1996.

APUD, E. Temas de ergonomia aplicados al aumento de la productividad de la mano de obra en cosecha florestal. In: SIMPÓSIO BRASILEIRO SOBRE COLHEITA E TRANSPORTE FLORESTAL, 3, 1997, Vitória. Anais... SIF; DEF, 1997.

ASSOCIAÇÃO BRASILEIRA DE NORMAS TÉCNICAS. ABNT NBR ISO/CIE 8995-1: Iluminação de ambientes de trabalho-Parte 1: Interior, 2013.46p.

BRASIL. Constituição da República Federativa do Brasil. Brasília, DF: Senado Federal, 1988. 193 p.

CONAW, P. L. Estatística. São Paulo: Edgard Blucher Ltda, 1977.

COUTO, H. A. Ergonomia aplicada ao trabalho - o manual técnico da máquina humana. 1. ed. Belo Horizonte: Ergo, 1995.

DINIZ, E. P. H. Os fatores ambientais no trabalho Florestal e Agrícola: ruído. $3^{\circ}$ ErgoFlor-Simpósio Brasileiro sobre Ergonomia e Segurança no Trabalho Florestal e Agrícola. Viçosa, UFV, 2007.

FIEDLER, N. C. Análise de fatores humanos e condições de trabalho em operações de colheita florestal. Revista Árvore, v. 24, n. 2, p. 135-142, 2000.

FIEDLER, N. C. Análise de posturas e esforços despendidos em operações de colheita florestal no litoral norte do Estado da Bahia. 1998. Tese (Doutorado em Ciência Florestal) - UFV, Universidade Federal de Viçosa, Viçosa, 1998.

FIEDLER, N. C.; RODRIGUES, T. O.; MEDEIROS, M. B. Avaliação das condições de trabalho, treinamento, saúde e segurança de brigadistas de combate a incêndios florestais em unidades de conservação do Distrito Federal. Revista Árvore, v. 30, n. 1, p. 55-63, 2006.

FIEDLER, N. C.; JUVANHOL, R. S.; PAULA, E. N. S. O.; GONÇALVES, S. B.; CARMO, F. C. A.; MAZIERO, R. Análise da carga de trabalho físico em atividades de implantação florestal em áreas declivosas. Revista Floresta, v. 42, n. 2, p. 241-248, 2012.

FLEMING, I. Diagnóstico ergonômico preliminar em comunidade agrícola com produção diversificada. 2003. Dissertação (Mestrado em Engenharia de Produção) - UFSC, Universidade Federal de Santa Catarina, Florianópolis, 2003.

IIDA, I. Ergonomia: Projeto e Produção. 2. ed. São Paulo: Edgard Blucher Ltda, 2005.

LEITE, A. M. P. Terceirização na Colheita Florestal no Brasil. 2002. Tese (Doutorado em Ciência Florestal) - UFV, Universidade Federal de Viçosa, Viçosa, 2002.

MINETTE, L. J. Análise de fatores operacionais e ergonômicos na operação de corte florestal com motosserra. 1996. Tese (Doutorado em Ciência Florestal) - UFV, Universidade Federal de Viçosa, Viçosa, 1996. 
MINETTE, L. J.; SILVA, E. P.; SOUZA, A. P.; SILVA, K. R. Avaliação dos níveis de ruído, luz e calor em máquinas de colheita florestal. Revista Brasileira de Engenharia Agrícola e Ambiental, v. 11, n. 6, p. 664-667, 2007.

SILVA, K. R. Análise de fatores ergonômicos em marcenarias no município de Viçosa, MG. 1999. Dissertação (Mestrado em Ciência Florestal) - UFV, Universidade Federal de Viçosa, Viçosa, 1999.

SOUZA, A. P.; MINETTE, L. J.; LEITE, A. P. M.; SILVA, S. O. Análise de fatores ergonômicos na colheita florestal terceirizada. In: CONGRESSO BRASILEIRO DE ERGONOMIA, 2004, Viçosa. Anais... UFV, 2004.

WATERS, T. R.; ANDERSON, V. P.; GARG, A.; FINE, L. J. Revised NIOSH equation for the design and evaluation of manual lifting tasks. Ergonomics, v. 36, n. 7, p. 749-776. 1993. 

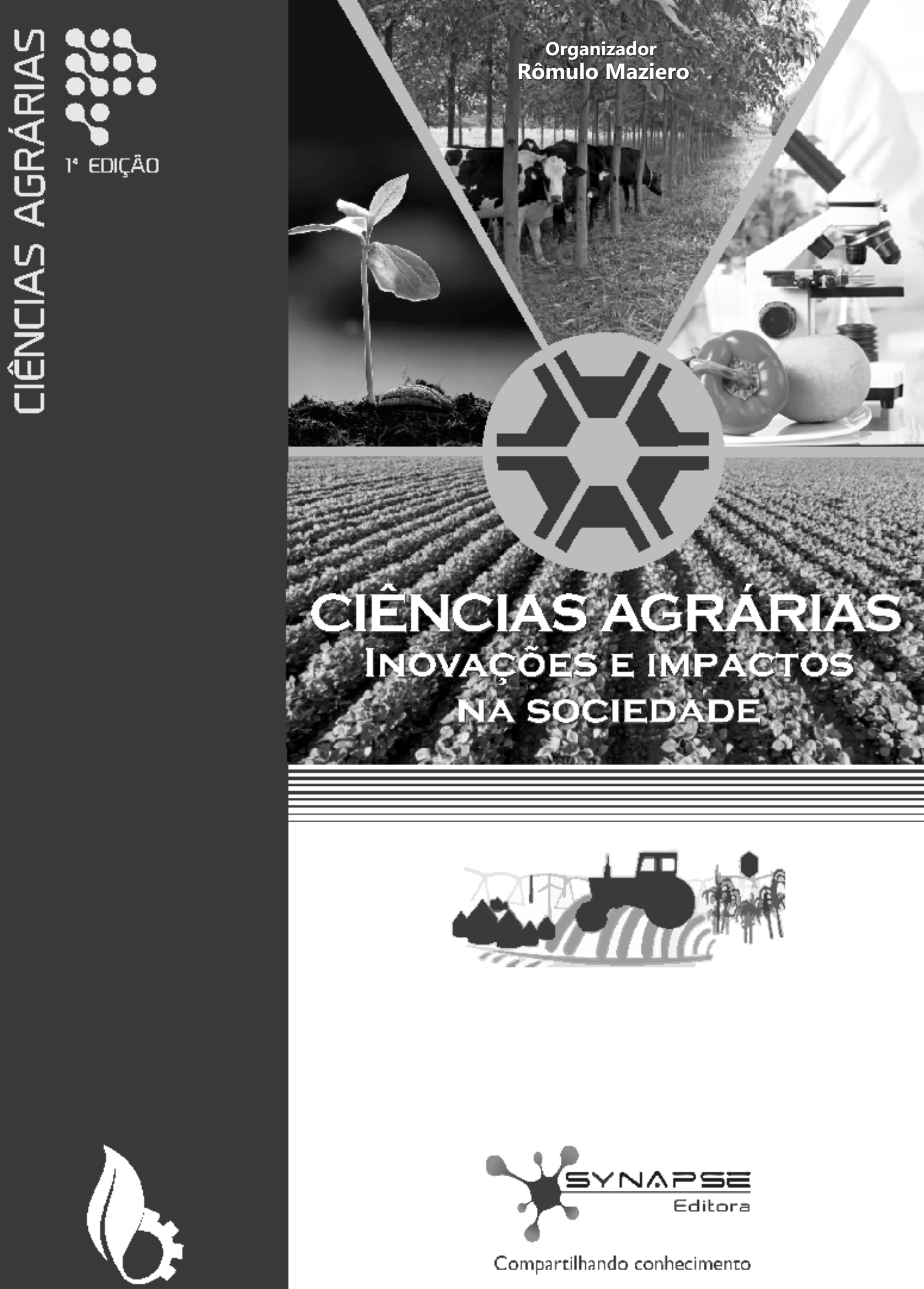

Compartilhando conhecimento 


\section{Sobre o Organizador}

\section{Prof. Rômulo Maziero}

Doutorando em Engenharia Mecânica (UFMG), pesquisador do Grupo de Inovação e Tecnologia em Materiais (GiTeM/UFMG), Mestre em Engenharia Metalúrgica e de Materiais (IFES), Especialização no Ensino de Ciências, Saúde e Ambiente (IFES), Aperfeiçoamento em Tecnologia Educacional (IFES) e Engenheiro Industrial Madeireiro (UFES). Atuou como professor no Instituto Federal de Educação, Ciência e Tecnologia do Espírito Santo e no Centro Universitário de Maringá (Polo EAD Aracruz - ES). Revisor e membro do corpo editorial de diversos periódicos nacionais e internacionais. Experiência na área de Engenharia de Materiais e Mecânica, com ênfase em materiais conjugados não-metálicos e aproveitamento de resíduos sólidos.

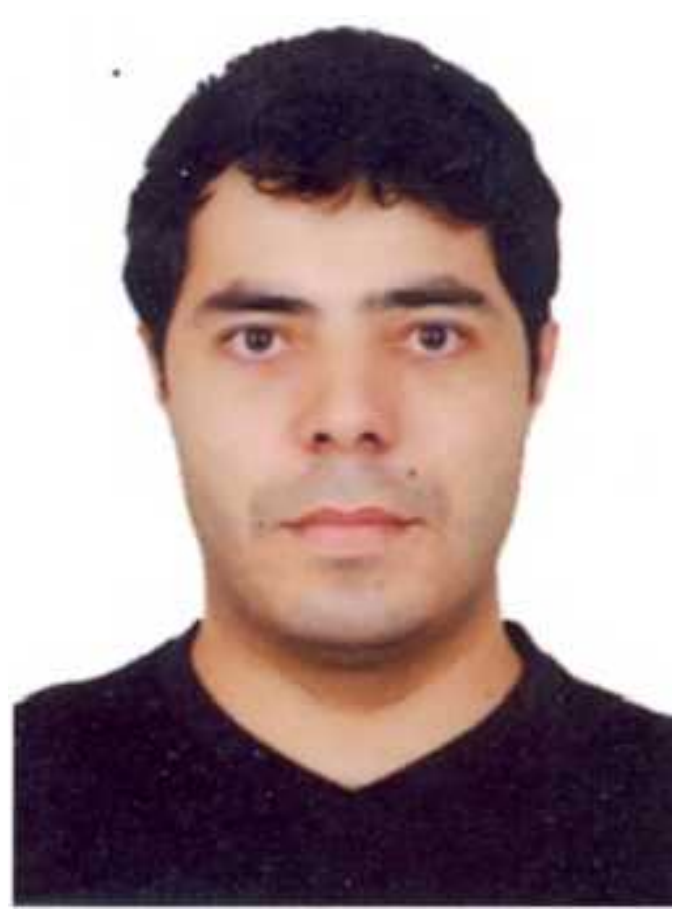




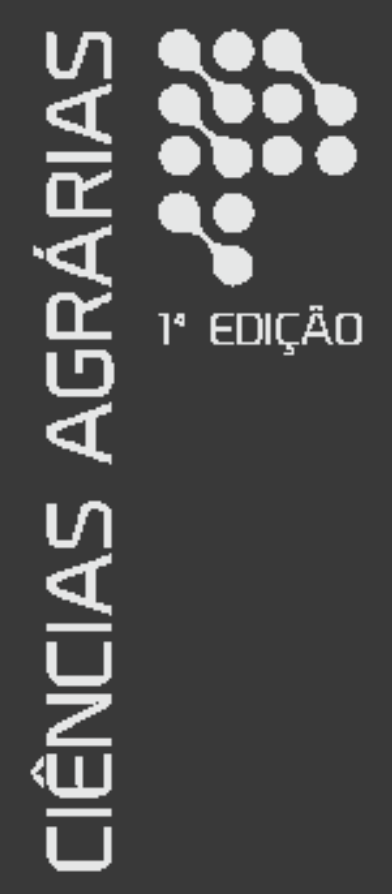

https://www.facebook.com/Synapse-Editora-111777697257115

(O) https://www.instagram.com/synapseeditora

in https://www.linkedin.com/in/synapse-editora-compartilhando-conhecimento/

(C) $3198264-1586$

editorasynapse@gmail.com
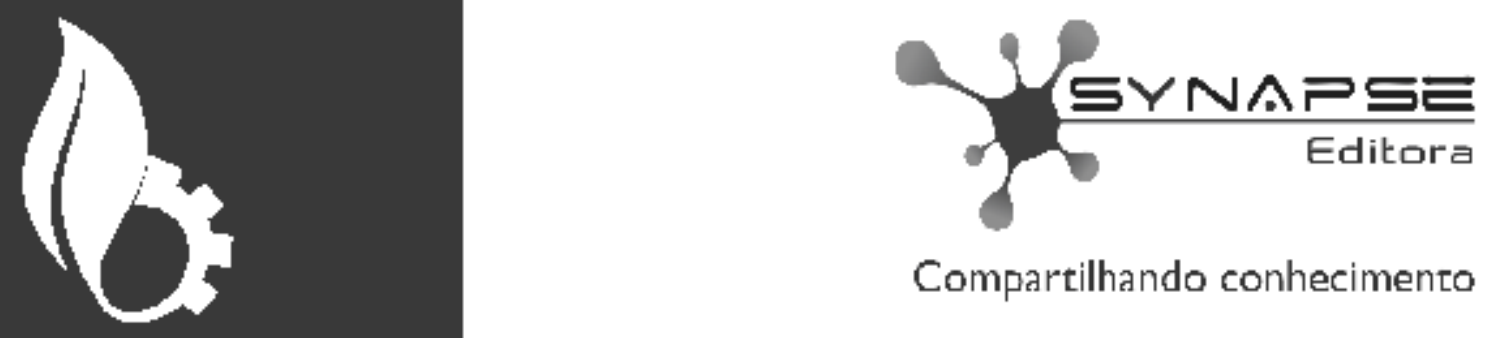

Compartilhando conhecimento 